\title{
IntechOpen
}

\section{Cognitive and Intermedial Semiotics}

\author{
Edited by Marta Silvera-Roig \\ and Asunción López-Varela Azcárate
}





\title{
Cognitive and Intermedial Semiotics
}

\author{
Edited by Marta Silvera-Roig \\ and Asunción López-Varela Azcárate
}



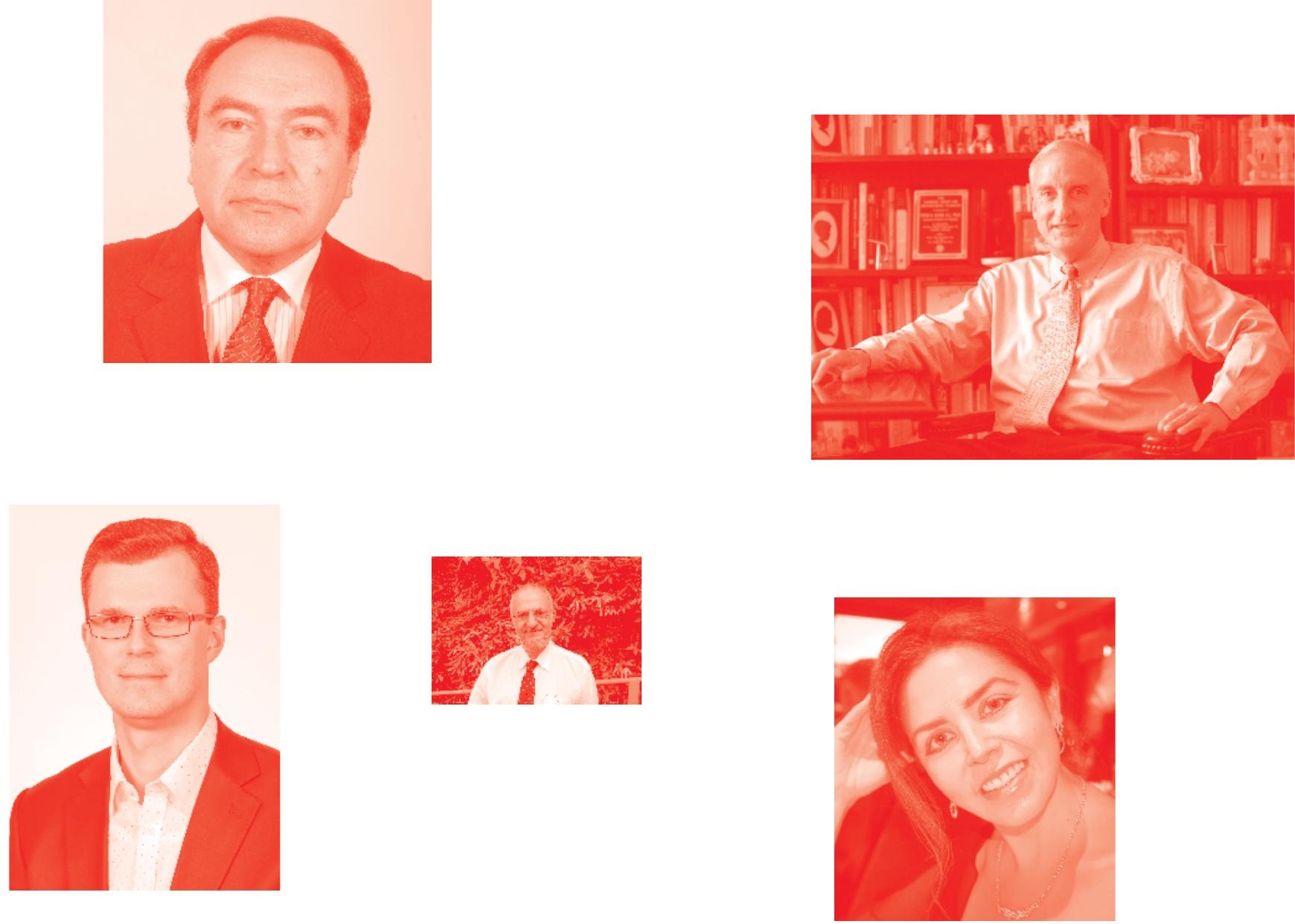

Supporting open minds since 2005
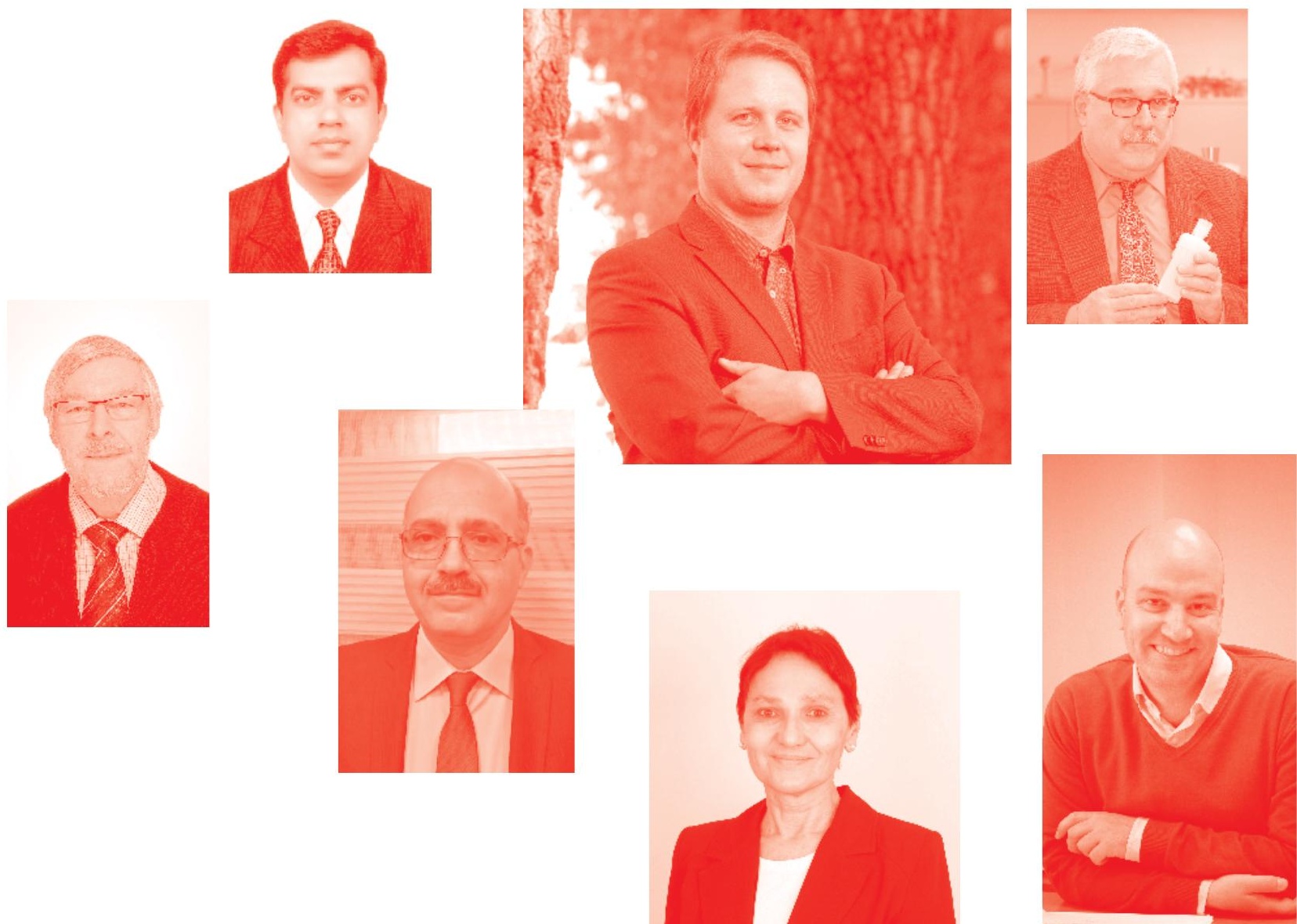
Cognitive and Intermedial Semiotics

http : //dx . doi . org/10.5772/intechopen. 74897

Edited by Marta Silvera-Roig and Asunción López-Varela Azcárate

\section{Contributors}

Larisa Yusifovna Ismailova, Viacheslav Wolfengagen, Sergey V. Kosikov, Berna Valle, Cesar Chavarria, Noury Bakrim, Gabriel Francescoli, Vladimir Averbukh, Edna Andrews, Ted Gemberling, Orkun Alptekin, Hasan Unver, Marta Silvera-Roig

(-) The Editor(s) and the Author(s) 2020

The rights of the editor(s) and the author(s) have been asserted in accordance with the Copyright, Designs and Patents Act 1988. All rights to the book as a whole are reserved by INTECHOPEN LIMITED . The book as a whole (compilation) cannot be reproduced, distributed or used for commercial or non-commercial purposes without INTECHOPEN LIMITED's written permission. Enquiries concerning the use of the book should be directed to INTECHOPEN LIMITED rights and permissions department (permissions@intechopen.com).

Violations are liable to prosecution under the governing Copyright Law .

\section{(cc) BY}

Individual chapters of this publication are distributed under the terms of the Creative Commons Attribution 3.0 Unported License which permits commercial use, distribution and reproduction of the individual chapters, provided the original author(s) and source publication are appropriately acknowledged. If so indicated, certain images may not be included under the Creative Commons license. In such cases users will need to obtain permission from the license holder to reproduce the material. More details and guidelines concerning content reuse and adaptation can be found at http : //www . intechopen . com/copyright-policy . html.

\section{Notice}

Statements and opinions expressed in the chapters are these of the individual contributors and not necessarily those of the editors or publisher. No responsibility is accepted for the accuracy of information contained in the published chapters. The publisher assumes no responsibility for any damage or injury to persons or property arising out of the use of any materials, instructions, methods or ideas contained in the book.

First published in London, United Kingdom, 2020 by IntechOpen IntechOpen is the global imprint of INTECHOPEN LIMITED, registered in England and Wales, registration number: 11086078 , 7th floor, 10 Lower Thames Street, London, EC3R 6AF, United Kingdom

Printed in Croatia

British Library Cataloguing-in-Publication Data

A catalogue record for this book is available from the British Library

Additional hard and PDF copies can be obtained from orders@intechopen.com

Cognitive and Intermedial Semiotics

Edited by Marta Silvera-Roig and Asunción López-Varela Azcárate

p. $\mathrm{cm}$.

Print ISBN 978-1-83880-552-4

Online ISBN 978-1-83880-553-1

eBook (PDF) ISBN 978-1-83880-905-8 


\section{We are IntechOpen, \\ the world's leading publisher of Open Access books}

\section{Built by scientists, for scientists}

\section{$4,900+$ \\ Open access books available \\ $123,000+$ \\ International authors and editors \\ $140 \mathrm{M}+$ \\ Downloads}

151

Countries delivered to

Our authors are among the

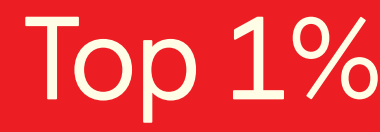

most cited scientists

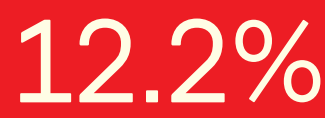

Contributors from top 500 universities

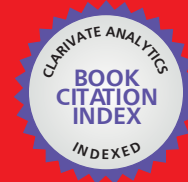

WEB OF SCIENCE ${ }^{\mathrm{M}}$

Selection of our books indexed in the Book Citation Index in Web of Science ${ }^{\mathrm{TM}}$ Core Collection (BKCI)

Interested in publishing with us?

Contact book.department@intechopen.com

Numbers displayed above are based on latest data collected.

For more information visit www.intechopen.com

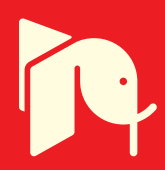





\section{Meet the editors}

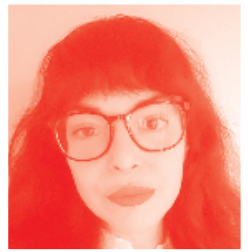

Marta Silvera-Roig holds a PhD with European Honours in Cognitive Sciences from the University of Las Palmas de Gran Canaria. She is currently an assistant professor in the Department of English Studies at Complutense University of Madrid, and a member of the research groups Studies on Intermediality and Intercultural Mediation (SIIM-UCM) and Biopoetics, Cognitive Semiotics and Neuroesthetics (IUIBS-ULPGC). Her academic interests revolve around the new cognitive studies in neuroesthetics, semiotics, and narratology. In particular, her research is based on investigating the importance of affective neuroscience in the invisible and visible mechanisms of human creativity. For information on her activities and publications, please visit https://www.ucm.es/ siim/marta-silvera-roig.

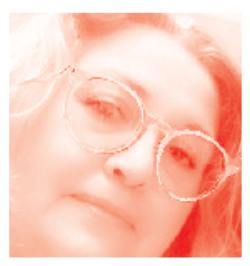

Asunción López-Varela Azcárate is Professor at Universidad Complutense de Madrid. Her research interests are comparative literature, cultural and education studies, and cognitive and intermedial semiotics. In 2007 she established the Research Program Studies on Intermediality and Intercultural Mediation (SIIM), which has received funding from various sources for several projects. She is an external evaluator in various research programs of the European Commission and other national agencies (the Netherlands Organisation for Scientific Research (NWO) and the German Academic Exchange Service (DAAD), etc.). She is also editor in several journals in her research areas. She has served as President of the European Society of Comparative Literature and Deputy Head of the English Department at Complutense. For information on her activities and publications, please visit https://www.ucm.es/siim/asun-lopez-varela. 



\section{Contents}

Preface

Chapter 1

Cognitive Semiotics and Conceptual Blend: A Case Study from

The Crying of Lot 49

by Marta Silvera-Roig

Chapter 2

Semiotic Principles in Cognitive Neuroscience

by Edna Andrews

Chapter 3

Analog, Embodiment, and Freedom

by Ted Gemberling

Chapter 4

'Evolutionary Stories': Narratives as Evolutionary Tools to

Describe and Analyse Animal Behaviour and Animal Signals

by Gabriel Francescoli

Chapter 5

Assessment of Perception of Physical Environment in the Context of Cognitive Maps and Experiences

by Orkun Alptekin and Hasan Unver

Chapter 6

Semiotic Architecture of Viral Data

by Berna Leticia Valle Canales and Julio César Chavarría Hernandez

Chapter 7

Sources of Computer Metaphors for Visualization and

Human-Computer Interaction

by Vladimir L. Averbukh

Chapter 8

The Biolinguistic Instantiation: Form to Meaning in Brain/Syllable Interactions

by Noury Bakrim 
Chapter 9

Computational Model for the Construction of Cognitive Maps

by Larisa Yu. Ismailova, Sergey V. Kosikov and Viacheslav E. Wolfengagen 


\section{Preface}

In Cognitive and Intermedial Semiotics, we offer a window into applied cognitive semiotics with different examples of meaning production studies. Thus, in the following chapters we will find examples of the different approaches, methods, and theories that cognitive semiotics offers as an interdisciplinary field.

Cognitive semiotics is the interdisciplinary study of meaning, and it combines concepts and methods from developmental, evolutionary, and cognitive psychology, cognitive linguistics, semiotics, narratology, and neuroscience with the idea that cognition is embodied, dynamic, and distributed. Cognitive semiotics investigates fundamental notions such as metaphors, blends, and narratives, how we communicate through semiotic systems such as language, representations, and gestures, how these have evolved, how they are learned, and how they are shared socially.

To undertake the challenge of understanding the emergence of meaning we have to appeal to a field of diffuse and permeable limits that allows us to consider other discourses such as biosemiotics or the study of signs and meaning in living organisms and systems. Connected with this is the study of gestural languages, artistic and communicative expressions, and also the narrative discourse in which we situate ourselves in our own story in relation to the stories of the world, acknowledging in turn the stories of others and the social narrative in which we all live. Thus, cognitive semiotics underlines the importance of placing meaning-making into the broader context of cognitive, social, and neurobiological processes.

The mind is embodied and situated, and bodies are not only physiological entities but also social and emotional entities. Emotions are a major factor in the interaction between environmental conditions and decision processes. Thus, the field of cognitive semiotics aims not only to understand culture and communication on a large scale but also to study the most elemental processes of the thinking and feeling mind.

The manifestations of meaning should be studied and analyzed as they occur, either experimentally or historically, and not created ad hoc to illustrate theories. Our book tries to present extensively this goal. Several semiotic multimodal aspects are discussed in the different chapters, where we will find studies on: the important interactions between cognitive neuroscience of language and brain and semiotic principles; digital technology and free will; the use of narrative analysis and biosemiotic techniques in decoding animal behavior; the cognitive maps students create when interacting in their university campuses; digital communication and its effect on politics; fairy tales, science fiction books, and fantasy films as new sources of computer metaphors used to design visualization systems based on virtual reality; the comparison of iconicity and phonesthemes in English and Berber; a computational model to create cognitive maps; and a case study on a cognitive blend within a literary text. 
This book has been possible thanks to the outstanding contributions of Dr. Orkun Alptekin, Dr. Edna Andrews, Prof. Vladimir Averbukh, Dr. Noury Bakrim, Dr. Gabriel Francescoli, Dr. Ted Gemberling, Dr. Larisa Ismailova, and Dr. Berna Valle.

Dr. Marta Silvera-Roig and Dr. Asunción López-Varela Azcárate Universidad Complutense de Madrid and Universidad de Las Palmas de Gran Canaria, Madrid, Spain 


\title{
Cognitive Semiotics and Conceptual Blend: A Case Study from The Crying of Lot 49
}

\author{
Marta Silvera-Roig
}

\begin{abstract}
Cognitive semiotics has been defined by the linguist Jordan Zlatev as "the need to unify or at least to 'defragment' our world-views, the need to come to terms with increasingly higher levels of dynamism and complexity". If we consider, as it is clear from the second cognitive revolution, when embodiment claimed its leading role, that meaning emerges from the constant interaction of body-brain-environment, we need to redefine the field that asks "what is meaning and how does it emerge." New theories about metaphors as neural nodes and image schemas would shed light over the emergence of meaning in human communication, and, to do so, the study of conceptual blends as essential cognitive tools and as an integrative theory should be put in the center of the debate. In words of Brandt and Brandt, "blends occur as signs and are therefore a natural subject of cognitive semiotics". Here, we will represent the emergence of meaning in a blend from the highly dynamic and complex narrative The Crying of Lot 49 by Pynchon and propose a conceptual story (or mental space sequence of the story) of the mentioned blend.
\end{abstract}

Keywords: cognitive semiotics, conceptual metaphor, conceptual blend, biopoetics, Pynchon

\section{Existing models: conceptual metaphor theory and conceptual blending theory}

One of the most influential treatises of cognitive linguistics, and thus cognitive semiotics, is Metaphors We Live By by George Lakoff and Mark Johnson, where the foundations of the conceptual metaphor theory are laid ([1], pp. 18-19). Lakoff, along with other linguists [2-5], extracts evidence of everyday conventional linguistic expressions to argue the existence of metaphorical relationships or mapping between conceptual domains (or idealized cognitive models) in the human mind. One of the objectives of this theory is to point out the metaphorical mappings between domains and how these guide human thinking and behavior, as it is reflected in its application in literature [5], philosophy [6, 7], mathematics [8], and even politics [9].

According to this theory, in a conceptual metaphor, we understand a domain in terms of another: CONCEPTUAL DOMAIN (A) IS CONCEPTUAL DOMAIN (B). These two domains receive the name of source domain and target domain. Examples of source domains are travel, war, food, or plants, and examples of target 
domains are ideas, theories, love, or life. Langacker [10] calls the domains rooted in direct human experiences as basic domains and those considered as abstract non-basic domains. One of the most important characteristics of the conceptual metaphor is that even our most abstract knowledge has a direct hook on our human experience. The central core of the conceptual metaphor theory is based on the fact that the metaphor is not a property of individual linguistic expressions and their meanings but of the conceptual domains. In principle, any concept from a source domain (where the literal meaning of the expression lies) can describe a concept in the target domain [11].

In Lakoff's words, regarding the conceptual metaphor LOVE IS A JOURNEY, what constitutes the metaphor is not a word or an expression, it is the ontological mapping between conceptual domains from the source domain of travel to the target domain of love. Metaphors are not just a characteristic of language but of thought and reason. Language is secondary. The mapping is primary in that the use of language of the source domains is limited and creates patterns for the concepts of the target domain. The mapping is conventional, since it is a fixed part of our conceptual system, one of the conventional ways of conceptualizing love relationships [3]. A conventional metaphor is, therefore, a recurring conceptual mapping between two domains. The mapping is asymmetric: the metaphorical expression outlines a conceptual structure in the target domain, not in the source domain. Cross-domain mapping involves two types of correspondences: epistemic and ontological. The ontological correspondences are maintained between elements of a domain and elements from another domain; epistemic correspondences are correspondences between element relations in one domain and element relations in another domain. As exemplified by Lakoff [2] in the metaphor ANGER IS HEAT ON A FLUID, the correspondence between the source domain "heat of fluid" and the target domain "anger" is ontological, while the correspondence between "when fluid in a container is heated beyond a certain limit, pressure increases to point at which container explodes" and "when anger increases beyond a certain limit, 'pressure' increases to point at which person loses control" is epistemic.

According to the principle of invariance, image schemas (mental patterns of our bodily experience which provide structure to other experiences) that characterize the source domains are mapped into target domains. This metaphorical mapping preserves the cognitive topology (the structure of the image schema) of the source domain in a consistent fashion with the structure of the target domain. According to Lakoff (as cited in [12]), the principle of invariance does not guarantee that, for example, in the scheme CONTAINER, interiors are mapped on interiors, exteriors on exteriors, and edges on edges. Therefore, to correctly understand the principle, it is important not to think of mappings as algorithmic processes that begin with a structure of source domain and end with a target domain structure. Instead of this, we must understand the principle of invariance in terms of limitations in fixed correspondences: the interiors of the source domain correspond to the interiors of the target domain, and the exteriors of the source domain correspond to the exteriors of the target domain, etc. Therefore, according to Lakoff [3], the structure of the image scheme of the target domain cannot be violated: there will be no cases in which, for example, the interior of a source domain is mapped on the exterior of a target domain. In addition, according to the principle of invariance, the inherent structure of the target domain limits the possibilities of mapping. For example, in the metaphor ACTIONS ARE TRANSFERS, our inherent knowledge tells us that actions do not continue to exist after they are made (if, for example, we give someone a kick, that kick exists at the moment it is given). In this metaphor our actions are conceptualized as objects that are transferred from one person to another, but we know (as part of our knowledge about the target domain) that an 
action does not persist after occurring. Thus, in the source domain, there is the action of giving (in which that who receives the object owns it after being given), but this cannot be mapped on the target domain since according to its inherent structure, this object does not exist once the action has finished.

Although many conventional or everyday metaphors are based on the daily human experience, novel metaphors are not (and some conventional metaphors either). Croft and Cruse [13] suggest that even conventional metaphors require a blending of richer structures than the structure of the image schema between source domain and target domain and add that the difference between conventional metaphor and novel metaphor is only a difference of degree. For this reason, the study of novel, more complex, and creative metaphors (such as the ones found in narratives) is of vital importance to understand the depths of conceptual metaphors and conceptual blends. In The Crying of Lot 49, several possible scenarios are activated by the reader. The projection of all of them at the same time creates a juxtaposition of mental spaces (or frames), thus creating a new one where all of them are competing possibilities: if we consider a blend as an essential and unique tool of human cognition, the ability to recognize the mentioned juxtaposition is the recognition of the blend itself.

Considered a fundamental theory of cognitive linguistics, conceptual blending [14] is no match for the conceptual metaphor theory but presupposes it [15]. While conceptual metaphors operate with two domains and correspondences between them and is a permanent structure, blending operates with four mental spaces that are partial and temporal representational structures. Nevertheless, the latter has an element of conventionality, as explained by Fauconnier and Turner that "dynamically, the input spaces and the blends under construction employ structure of more stable, elaborate and conventional conceptual structures" ([14], p. 115).

Blending spaces are like the domains of the conceptual metaphor but more partial. They add to these domains a generic space that represents what the source and target domains have in common and a blended space where selected conceptual materials from the mental spaces combine to form a new structure. As described by Grady et al., "in a metaphorical blend, the prominent equivalents of the input spaces are projected into one element of the blended space - they 'merge'. A single element from the blend corresponds to an element in each of the spaces" ([15], p. 114). However, and as the most important feature, the blended space not only contains a selection of properties from each input domain: it also contains new conceptual material arising from a blend elaboration based on encyclopedic knowledge.

In our case study, a mental space functioning as a generic space is the solution to a mystery: as the narrative is activated, the plot guides us through an expected resolution (a common expectation of conventional stories). Each possibility presented to us is a temporal mental space, and the blended space is where the new meaning emerges: here we are confronted with four inputs that are four different explanations of a "same reality," and the blended space is the interpretation problem itself, the impossibility of a resolution. This awareness of the problem with pondering different interpretations of reality might be at the core of what makes us unique as humans and the evolutionary precursor of language itself.

\section{Embodied semiotic processes are complex processes}

The relationship established by semiotician René Thom between topology, biology, and semiotics penetrated in some branches of structural semiotics and semio-linguistics in the 1980s. The catastrophe topology was interpreted and applied as a model in the semiotic analysis, thus translating constituents of grammar into logical formats. Even if this application caused epistemological 
problems, it also contributed to the "epistemological naturalization" of the semiotic framework:

\begin{abstract}
Meaning was already seen as 'deeper' than its manifested phenomenon; now it was more drastically separated from language and discourse, and conceived as grounded in the biological nature, i.e. the cognitive neurobiology of the human mind. Here, meaning is what happens in the naturally pre-structured mind of persons when they actively or passively perceive or conceive some entity, or when they express something and 'mean' what they express. ([16], p. 220).
\end{abstract}

As Lakoff and Johnson [7] affirm, our conscious processes are built on functions that serve to control our embodied minds and movements in space, hence, the structural characteristic of the metaphor and its biological hook in narratives. On the other hand, also feelings represent both mental and bodily states, and their processes take place through innate provisions. For this reason, an approach that assumes that human experiences are closely linked to certain specifications of the embodied mind is an integrative approach, in contrast to the classical semiotic models that presuppose an approximation of abstract language to interpretation, without specifying how emotion, perception, cognition, and actions are part of a psychophysical totality [17]. Besides, as explained in The Whole Creature by Wheeler [18], emergent complexity is the heart of both natural and cultural systems, which are semiotic processes.

That being said, can blend theory help us to discern how different mental spaces in the conceptual, prelinguistic mind are able to make new meanings emerge, considering not only the dynamically functioning culture and biological constraints but also the emotional states that are now considered by neuroscience a game changer? What is more, if meaning in the pre-structured mind-as Brandt calls it -is at the preconceptual and conceptual levels influenced by emotions as new studies suggest [19], are the existing models enough to explain meaning emergence? Embodied semiotic processes are complex processes, and the models representing their mechanisms should be inclusive to begin with.

\title{
3. Complexity and conceptual blending
}

Chaos theories speak of a deterministic (paradoxically) chaos; since there is order in the disorder, there is a profound-though sometimes inaccurateconnection between all systems at all levels of its dynamic. According to Gregersen [20], there are, however, differences between chaos theories and complexity theories. Complexity studies try to understand the principles that guide complex systems in order to try to explain how structures are self-organized and ordered without a conscious control organizing the process. These structures arise, are maintained, and develop in a process driven by local agents within the system, and the twists and distortions of this agents produce, very often, consequences that affect the entire system. Complexity theories try to understand these rules of order propagation in "real-world" systems, both natural and social.

Both research on complexity and chaos theories deal with nonlinear processes in which small and simple inputs can generate larger and complex outputs. It is easy to think here in the different dynamics produced by the image-schema relations and the most complex blends both in oral everyday language and in narratives as self-organized systems: while the various trajectories of chaotic systems are highly contingent on the exact values from the initial conditions, complex self-organized systems may arise from a wide variation of initial conditions. 
What do we mean by the nonlinearity of a system? Said in a very simple way, particular effects cannot be assigned with particular causal components because all the components interact with each other. Here, we can easily see an example of what we find in conceptual blending: inputs do not only give place to a blended space, they do it dynamically for their interaction, which is continuous and subject to change (different interpretations through time, emotional states of the mind activating the blend, and the type of context which surrounds it are all variables that influence the emergence of meaning). We can differentiate blends in their material expression and even describe how they function-old and new hermeneutic theories about meaning construction cannot be ignored-and the conceptual blending model offers a description of the different parts conforming to them. However, one can only see that we are at the doors of something bigger.

Could this lack of equilibrium explain the poetic vibrance and esthetic experience of the macro-blend we will describe later in this paper? Cognitive semiotics should include this kind of questions in its quest. The highest levels of complex self-organized systems, despite arising from local and simple initial conditions- "never ignoring, of course, the' bottom-up 'effects of parts on wholes which depend for their properties on the parts being what they are” ([21], p. 191) continue to influence the lower levels, and these over others. In this way, the whole is greater than the sum of the parts: the blended space is not just the sum of the different inputs that conform to it.

In The Way We Think, Fauconnier and Turner [22] attribute this characteristic of the blended space to the emergence of meaning in the blend integration model; thus, new meanings are the imaginative products of blending, whether simple or complex, and they are not predictable in the ways that evoke them. The mapping schemes, however, are predictable in the forms of language used to evoke them that are explained in the description of the blend model itself as described by Turner and Fauconnier. The meaning of "the whole" is not predictable from the meaning of the parts, but the mapping scheme of "the whole" is predictable from the mapping schemes of the parties. That is how the blending process is described: this compositional aspect of the forms is an exceptionally ingenious, useful, and efficient characteristic of the forms that guide meaning. This must be proven, however, in studies designed from neuroscience in all kind of forms of human communication, and not just in linguistic constructions made ad hoc.

\section{Meaning in postmodern narratives: the approach to cognitive semiotics from biopoetics}

Living beings are organized as immensely complex dynamic hierarchies where immensity is defined in an infinite number of possibilities too broad to cover and whose complex nature implies that they, as we have mentioned before, cannot be modeled in a reductionist way. Biological hierarchies reach these immense complexities through chaotic emergency processes [23]. The visible characteristics of postmodernism are closely linked to this immeasurable breadth that is living: the nonlinear dimension of existence. The unpredictable nature of dynamic systems and the inability to determine or establish a stable origin mark the postmodernist literature - this paradigmatic shift towards disorder was analogous in literature and science [24].

According to Katherine Hayles [25], dealing with complex self-organized systems, chaos is a precursor to order, and not the opposite: from chaos spontaneous emergency emerges and dissipative structures arise from systems far from equilibrium [26]. In the words of Lotman [27], "self-organization processes in 
far-from-equilibrium conditions correspond to a delicate interplay between chance and necessity, between fluctuations and deterministic laws. We expect that near a bifurcation, fluctuations or random elements would play an important role, while between bifurcations the deterministic aspects would become dominant". We must notice that chaos differs from real arbitrariness in that the first one contains deep coding structures called strange attractors. Where real arbitrariness systems show no discernible patterns when mapped in the phasic space, chaotic systems trace complex patterns on it. For Guerra [28], the poetic text as a complex adaptive system is the richest unit in information and affordances. Therefore, the high order of complexity of the text can be seen as a cognitive biocultural motivation to investigate the complex human poetics as life sciences (dynamic niche that occupies now, after its emergence in the second revolution of cognitive sciences, biopoetic studies). The complex patterns found in The Crying of Lot 49 can be described through the consistent image-schema relations motivated by emotions [29], the pervasive conceptual metaphors [30], and conceptual blends. Once the models from cognitive linguistics meet biopoetic concerns with the necessity of including complex theory ideas, we will be able to describe the patterns found in the blends. The example we refer to in this paper is a representation of the different blends in the narrative sharing blended spaces as spaces of impossibility.

Meaning integration models operate under the idea that language does not contain meaning but that we access the latter through the former. Thus, language is the product, not of a structural system separated from the brain but of general cognitive processes with which the human mind conceptualizes experience, called embodied understanding by cognitive linguistics [6]. This way, the conceptual metaphors and blends offer the basis of a literature theory rooted in cognitive linguistics. Such as Freeman [31] declares, literary texts are the products of the cognitive minds and their interpretations, the products of other cognitive minds in the context of the physical and sociocultural worlds in which they have been created and read, and there is a need to include these dimensions in the existing models.

Fauconnier and Turner [22] explain in The Way We Think that human beings have the most effective abilities for meaning construction and, therefore, for the creation of the most elaborated forms (language, art, music, mathematics, etc.). By themselves, forms are hollow, but they do contain the potential that can be unfolded in dynamic and imaginative ways. Behind the form there is the human power to construct meaning, and the operations found at the heart of meaning are identity, integration, and imagination. Identity has to do with recognizing similarity or equivalence, which is an imaginative and complex unconscious task; identity and opposition and similarity and difference are accessible through consciousness after an elaborated process. Integration consists on finding identities and oppositions; it is part of a much more complex process of conceptual integration, with dynamic and structural properties and operational restrictions. Identity and integration cannot account by themselves the meaning of imagination. Even in the absence of external stimuli, the brain can carry out imaginative simulations: the imaginative processes are always functioning, even in the simplest meaning constructions ([22], pp. 5-6). In fact, when we approach a poetic text, as Burke [32] notices, these processes are active during all the phases of the "literary reading loop," that is, during pre-reading, post-reading, and no-reading of a literary text. According to Burke's oceanic mind theory, the reading process of a literary text highlights the relevance of the unconscious affective cognition and implicit memory (which takes place together with the conscious cognitive emotion and explicit memory).

The integration models proposed in The Way We Think [22] depend on what organizing frames or related elements get projected into the blended space and 
which of them becomes the dominant one. One may distinguish four types of blends or networks of an increasing level of complexity: simplex networks, mirror networks, single-scope networks, and double-scope networks. In my analysis in this paper, I will only refer to the most complex network, the double-scope network. A double-scope network is one in which two or more input spaces have different frames, and a combination of these frames becomes the organizing frame for the blend. Double-scope blending can resolve clashes between inputs that differ fundamentally in content and topology, and this is considered an essential tool for human creativity. In the example of this paper, I will show what Turner calls double-scope story, in the form of a four-scope story. "Running two stories mentally, when we should be absorbed by only one, and blending them when they should be kept apart, is at the root of what makes us human" [33]. Here, we will see how three stories clash together to create uncertainty: the stories function, epistemically, as possibilities.

\section{Biopoetics}

Biopoetics integrates studies of complex semiotic systems, such as the literary system, evolutionary psychology, and cognitive sciences, from the essentially dynamic theoretical framework of the complexity sciences. One of its objectives is to explain how narratives arise from (and reinforce) the adaptive features of being human. As Marshall [34] states, the universality of narratives suggests an important adaptive objective in human evolution. Some of the hypotheses regarding this suggest that narratives prepare us for specific situations and they contribute to our ability to predict or understand thoughts, feelings, motives, and reactions of others (what psychologists call theory of mind) and to understand that others may perceive something differently from us. Understanding that others may not perceive something as we do is a very complex and sophisticated mental operation, and narratives train us in the notion that many misunderstandings and dissonances arise from this fact. Therefore, narratives meet our needs as an ultra-social species, helping us manage the abundant interpersonal interactions of our daily life. Thus, as Guerra [35] affirms, the importance of biopoetics lies in the fact that it is a primary theory of metacognition. Biopoetics aims to investigate the morphodynamics of natural and artistic language, and of any semiotic system, as a complex bio-social adaptive system. Paradoxically, in this biocultural evolution, academics and artists are experientially located in a metacognitive scaffolding; in the words of Guerra "we are what we make as 'us', more properly, I am what I make as 'us'” ([35], p. 849).

In my thesis, Biopoetics, cognition and emotion: conceptual integration and emergence in Thomas Pynchon's "The Crying of Lot 49" [30], I established an approach from biopoetics to the spatial organization of the poetic act. Thus, I proposed that action in space motivates nuclear metaphors and blends that make possible the construction of new meaning. From spatial image schemas, the mental spaces that construct concepts such as entropy and emotion are our basis to observe the cognitive-affective organization of the narrative system. In the thesis I presented a list of 131 conceptual metaphors of the analyzed linguistic metaphorical expressions, a classification according to their target domain and corresponding source domain, the metaphorical focus, and the mappings between source and target domains. This part served as the scaffolding to explain how the conceptual metaphors behave and evolve in the course of the novel and the four-scope story in which several mental spaces projections create a new space of emerging meaning. I will present the mentioned blends in the next section [36]. 


\section{Blend analysis}

In the following, I present the narrative context of the blend together with references to the conceptual metaphors (in capital letters) that guide meaning: In the sixth chapter, the main character Oedipa Maas has lost the ones who could have help her in her search for meaning, her psychiatrist is mad, her husband is under the effects of LSD, her lover Metzger is now with an underage girl, and Driblette, the director of the play, has died. For this reason, Oedipa keeps on feeling she is lost: LOST IS BEING ALONE (235). ${ }^{1}$ Oedipa attends then to Driblette's funeral; Driblette has committed suicide by drowning in the Pacific. Besides his tomb, Oedipa tries to communicate with him: PROTEIN IN AN OBJECT OEDIPA TRIES TO REACH (240), WINGED SHAPE IS AN OBJECT INSIDE QUIESCENCE, QUIESCENCE IS AN OBJECT INSIDE PROTEIN $(239,240,243)$. Oedipa waits for some information to get out from the earth, but nothing happens. In the labyrinth where information dwells (the reason why Driblette added two lines about Trystero in the theater play), also dwells the reason of his suicide: LABYRINTH IS A CONTAINER FOR INFORMATION (248). Again, information's meaning is unreachable.

The possibility of having found something real in Trystero is, for Oedipa, STUMBLE ONTO A DREAM, ONTO A NETWORK OF COMMUNICATION, ONTO ALTERNATIVE TO EXITLESSNESS, ONTO ALTERNATIVE TO THE ABSENCE OF SURPRISE. However, there exist three equally possible alternatives: that it all is a hallucination, a plot, or that she is imagining there is a plot. When these four mental spaces are projected in the blend, as we can see below, we find that Oedipa is, in the blended space, in a void, EMPTY SPACE IS A DIFFICULT SITUATION (262) (Figure 1).

In the blend, the four elements of the inputs have the same potential to be real, but each mental space changes regarding the idea Oedipa has about them: reality, hallucination, plot, or imagining a plot. In the selective projection, these four ideas about the mental spaces projected in the blend create a new one: a void. Oedipa feels lost: ORIENTATION IS AN OBJECT OEDIPA LOSES (266). All around her is flat and vast, without mountains or borders, and the limits of San Narciso have disappeared: SAN NARCISO IS A LOST OBJECT, THE RESIDUE OF SAN NARCISO IS INSIDE OEDIPA $(268,269)$. This way, SAN NARCISO IS A BOUNDLESS CONTAINER (270). Without borders for the land or for Pierce's legacy, the continent is a continuum: AMERICA IS A LEGACY (272). As in the beginning with the tower, the disappearance of borders and frontiers constructs a feeling of disorientation. Trystero is coded information in the legacy: TRYSTERO IS ENCRYPTED INFORMATION (276); a conspiracy, TRYSTERO IS A PARANOIA AGAINST OEDIPA (279): or something Oedipa found by chance, TRYSTERO IS AN OBJECT (398) FOUND BY OEDIPA (280). The waiting of Oedipa becomes now the waiting for the end of symmetry between the possibilities of the inputs in the previous blend. Oedipa is not able yet to decipher information: OEDIPA IS INSIDE A COMPUTER WITH ENDLESS ONES AND ZEROES (296). Behind the city streets, there is concealed meaning, CITY STREETS ARE A HYEROGLYPH (297), either meaning or just the earth: CITY STREETS ARE A HIDING PLACE FOR MEANING $(298,299)$, CITY STREETS ARE A HIDING PLACE FOR EARTH (298, 300). Thus, all that Oedipa has experienced can have a relevant meaning or just what it seems, and she does not understand any of them: REALITY OF EVENTS

\footnotetext{
1 The number of each conceptual metaphor mentioned alludes to the numbers in the original list created in my thesis [28]. Please refer to the document in order to check the linguistic metaphorical expressions of each conceptual metaphor and their conceptual mappings.
} 


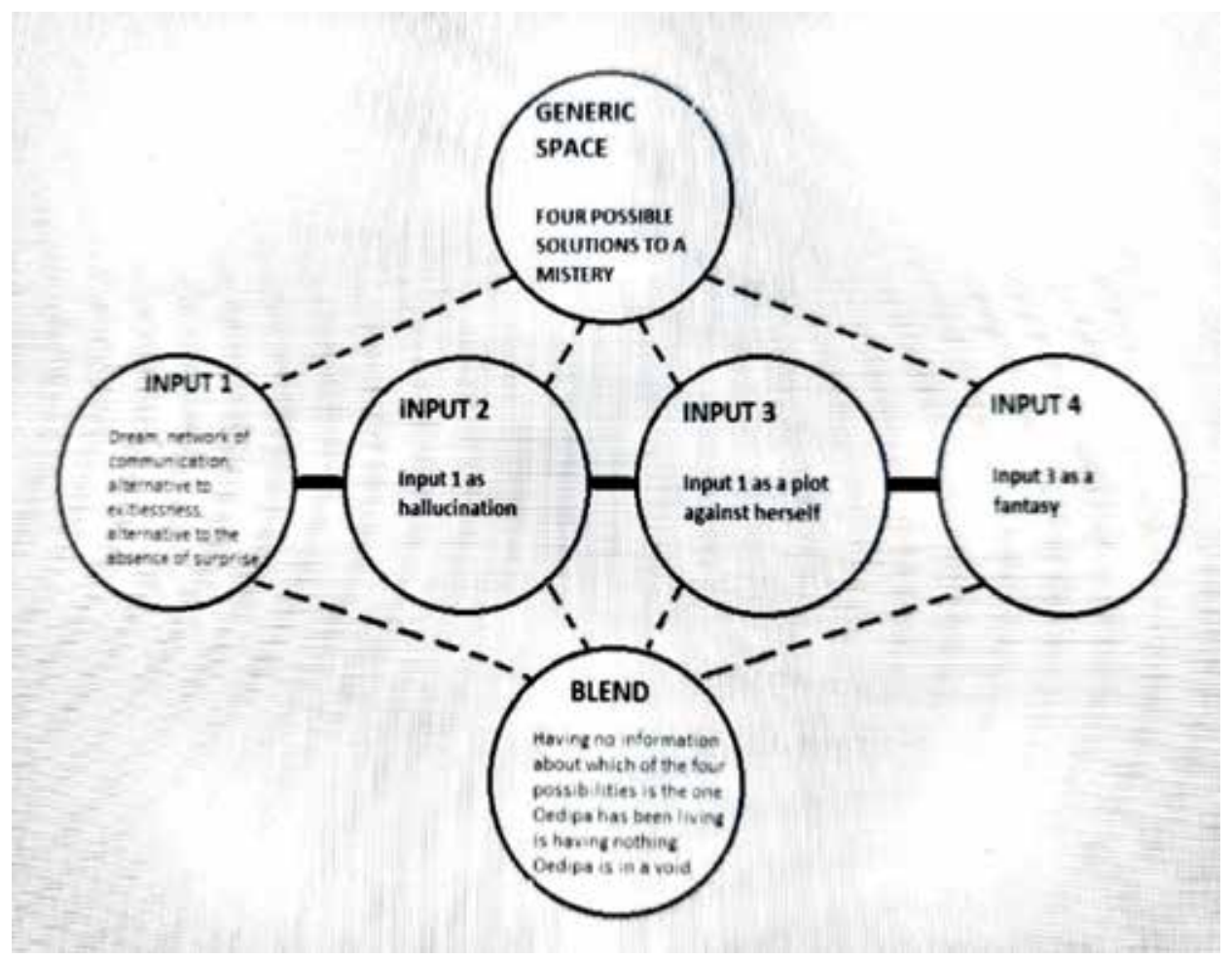

Figure 1.

Double Scope Blend ([30], p.397).

ARE ARRANGED ONES AND ZEROES (304). If Trystero does not exist, Oedipa is then in a state of paranoia: OEDIPA IS AN ENTITY INSIDE ECSTASY, ECSTASY IS A CONTAINER MOVING AROUND PARANOIA $(305,306,307)$. If there is no Trystero in America, BEYOND AMERICA IS TRYSTERO OR AMERICA $(308,309)$, then there is just America. In the case that the last option is the real one, Oedipa can only live in it as someone separated from a world she does not understand. For Oedipa, the possibility of a hidden meaning she cannot reach is better than reality. At the end of the novel, Oedipa goes to the auction of the stamps lot, where she is told that someone very interested in getting them is going. Oedipa sits and waits.

\section{Concluding remarks}

Meaning integration is essential in order to understand human cognition, and narratives are highly complex poetic acts in which new relations and meanings can emerge. If we consider the literary text to be a poetic act, a dynamic open auto-organized system which is dissipative, embodied, situated, distributed, and synergic, the theoretical approaches to it must be inclusive and dynamic. The theories applied, conceptual metaphor and conceptual blend, are valuable models to study poetic acts as a basic feature of what makes us humans. As we can read in the article Making Sense of a Blend (Brandt and Brandt), "the method is to slow down our imagination so we can describe how a meaning is arrived at cognitively, from a phenological perspective" ([11], p. 242).

By integrating in an interactive continuum mind-body-world, we can recognize the biological and evolutionary anchor of our thoughts, creativity, and imagination: the biological anchorage of meaning. Further studies in cognitive semiotics are needed to conform to the theoretical background for this ambitious enterprise. 


\section{Author details}

Marta Silvera-Roig

Universidad Complutense de Madrid and Universidad de Las Palmas de Gran

Canaria, Madrid, Spain

*Address all correspondence to: msilvera@ucm.es

\section{IntechOpen}

(C) 2020 The Author(s). Licensee IntechOpen. This chapter is distributed under the terms of the Creative Commons Attribution License (http://creativecommons.org/licenses/ by/3.0), which permits unrestricted use, distribution, and reproduction in any medium, provided the original work is properly cited. (cc) BY 


\section{References}

[1] Zlatev J. Cognitive semiotics: An emerging field for the transdisciplinary study of meaning. Public Journal of Semiotics. 2012;4(1):2-24

[2] Lakoff G. Women, Fire and Dangerous Things: What Categories Reveal about the Mind. Chicago: The University of Chicago Press; 1987

[3] Lakoff G. The contemporary theory of metaphor. In: Ortony A, editor. Metaphor and Thought. Cambridge: Cambridge University Press; 1993. pp. 202-251

[4] Lakoff G, Johnson M. Metaphors We Live By. Chicago: The University of Chicago Press; 1980

[5] Lakoff G, Turner M. More than Cool Reason: A Field Guide to Poetic Metaphor. Chicago: The University of Chicago Press; 1989

[6] Johnson M. The Body in the Mind: The Bodily Basis of Meaning, Reason and Imagination. Chicago: University of Chicago Press; 1987

[7] Lakoff G, Johnson M. Philosophy in the Flesh: The Embodied Mind and its Challenge to Western Thought. Nueva York: Basic Books; 1999

[8] Lakoff G, Núñez R. Where Mathematics Comes From: How the Embodied Mind Brings Mathematics into Being. Nueva York: Basic Books; 2000

[9] Lakoff G. Moral Politics: What Conservatives Know That Liberals Don't. Chicago: University of Chicago Press; 1996

[10] Langacker RW. Foundations of Cognitive Grammar, Volume 1. Theoretical Prerequisites. Stanford: Stanford University Press; 1987

[11] Brandt L, Brandt PA. Making sense of a blend: A cognitive-semiotic approach to metaphor. Annual Review of Cognitive Linguistics. 2005;3(1):216-249

[12] Geeraerts D, editor. Cognitive Linguistics. Basic Readings. Berlin: Mouton de Gruyter; 2006

[13] Croft W, Cruse DA. Cognitive Linguistics. Cambridge: Cambridge University Press; 2004

[14] Fauconnier G, Turner M. Blending as a central process of grammar. In: Goldberg A, editor. Conceptual Structure, Discourse, and Language. Stanford: Center for the Study of Language and Information; 1996. pp. 113-129

[15] Grady J, Oakley T, Coulson S. Blending and metaphor. In: Gibbs R, Steen G, editors. Metaphor in Cognitive Linguistics. John Benjamins: Ámsterdam; 1999. pp. 101-124

[16] Brandt PA. La Charpente modale du sens. In: Pour une sémio-linguistique morphogénétique et dynamique. Aarhus/Ámsterdam: Aarhus University Press/John Benjamins; 1992

[17] Grodal T. Embodied Visions:

Evolution, Emotion, Culture, and Film. New York: Oxford University Press; 2009

[18] Wheeler W. The Whole Creature: Complexity, Biosemiotics and the Evolution of Culture. London: Lawrence and Wishart; 2006

[19] Jiménez-Ortega L et al. Effects of reader's facial expression on syntactic processing: A brain potential study. Brain Research. 2020:1736

[20] Gregersen NH. From Complexity to Life: On the Emergence of Life and Meaning. Oxford: Oxford University Press; 2003 
[21] Peacocke A. Complexity, emergence, and divine creativity. In: Gregersen NH, editor. Complexity to Life: On the Emergence of Life and Meaning. New York: Oxford University Press; 2003

[22] Fauconnier G, Turner M. The Way We Think. New York: Basic Books; 2002

[23] Scott AC. The Nonlinear Universe: Chaos, Emergence, Life. Berlín, Heidelberg: Springer-Verlag; 2007

[24] Guerra J. La naturaleza creativa del tiempo en el paradigma del caos: una relectura de T. S. Eliot [Tesis doctoral (microficha)]. Madrid: Universidad Complutense de Madrid; 1992

[25] Hayles NK. Chaos Bound: Orderly Disorder in Contemporary Literature and Science. Ithaca: Cornell University Press; 1990

[26] Prigogine I, Stenders I. Order out of Chaos. University of Michigan: Bantam Books; 1984

[27] Lotman YM. Universe of the Mind: A Semiotic Theory of Culture. London \& New York: I. B. Tauris \& Co Ltd.; 1990

[28] Guerra J. What cognitive sciences as an interdisciplinary framework can contribute to the study of literature in general and of Edgar Allan Poe's literary texts in particular. In: Estévez Fuertes N, Llácer Llorca EV, Olivares Pardo MA, editors. Genius and Psicosis in Edgar Allan Poe. New Interdisciplinary Perspectives. Valencia: Servei de Publicacions de la Universitat de València; 2010

[29] Silvera-Roig M. Image schemas as emotional attractors in the crying of lot 49. Journal of Comparative Literature and Aesthetics. 2019;42(3):44-68

[30] Silvera-Roig M. Biopoetics, cognition and emotion: Conceptual integration and emergence. In: Thomas Pynchon's “The crying of Lot 49”. 2016. Available from: http://hdl.handle. net/10553/18017

[31] Barcelona A. Clarifying and applying the notions of metaphor and metonymy within cognitive linguistics: An update. In: Dirven R, Pörings R, editors. Metaphor and Metonymy in Comparison and Contrast. Berlín: Mouton de Gruyter; 2000. pp. 207-277

[32] Burke M. The neuroaesthetics of prose fiction: Pitfalls, parameters and prospects. Frontiers in Human Neuroscience. 2015;9:442

[33] Turner M. Double-scope stories. In: Herman D, editor. Narrative Theory and the Cognitive Sciences. Stanford: Center for the Study of Language and Information; 2003. pp. 117-142

[34] Marshall I. Stalking the gaps:

The biopoetics of haiku. Mosaic (Winnipeg). 2013;46(4):91-107

[35] Guerra J. Cognitive Poetics and Biocultural (con)figurations of life, Cognition and Language towards a theory of socially integrated science. Pensamiento. 2011;254(67):843-850

[36] Pynchon T. The Crying of Lot 49. London: Vintage; 1966 


\title{
Semiotic Principles in Cognitive Neuroscience
}

\author{
Edna Andrews
}

\begin{abstract}
Cognitive neuroscientific approaches to language(s) and brain in the twentyfirst century have made an important contribution to understanding the importance of the relationship of invariance and variation of language mappings across individuals, the dynamic nature of neurological processing of languages throughout the life cycle, and more ecologically valid modeling of cognitive processing that focus on the interactive nature of linguistic perception and production in the cultural context. Beginning with Ojemann's unique contribution to language mappings through cortical stimulation mapping (CSM) and continuing through to fMRI studies, contemporary neuroscience research paradigms have moved toward analyzing neural networks and connectivity, the relevance of embodied cognition, and the complex nature of signification and meaning-generation. This chapter presents important interactions between recent cognitive neuroscience studies of language and brain using proficiency with semiotic principles and semiotic theory as given in Peirce, Eco, Lotman, and Sebeok.
\end{abstract}

Keywords: fMRI, proficiency, embodied cognition, signification, non-arbitrariness, autopoiesis, functional connectivity, default mode network

"For an event to become linguistic...a great many brains must play in unison”- D. Bolinger ([1], p. 233)

"Nevertheless, it deserves more emphasis that functional localization is an intermediate goal, or the 'homework problem' that requires figuring out where things are, before scrutiny turns to the harder and deeper question of how things work." D. Poeppel ([2], p. 4)

\section{Fundamental concepts and principles}

One of the most important principles recognized by the contemporary cognitive neurosciences is the commitment to conducting ecologically valid research and experimentation $[3,4]$. Depending on the particular subfield of cognitive neuroscience, there will be different ways to achieve ecological validity. For example, in the field of cognitive neurolinguistics, a straightforward approach to ensuring ecological validity is by constructing protocols that are designed around dynamic categories that are found in normative speech, including speech acts ([5], p. 196). In addition to this guiding principle, it is imperative to include robust empirical methods at all levels of analysis, whether the object of study is based in experimentation 
with human subjects (healthy and lesion-deficit, behavioral and neuroimaging, laboratory and in situ) or textual studies. The questions discussed here focus on identifying the key areas where semiotic theory has impacted the cognitive neurosciences, which include approaches to understanding sensory-motor mappings in the human brain, multimodality as opposed to modularity, and embodied cognition. The contribution of semiotic principles to reliable scientific research in cognitive neuroscience is discussed in the conclusion.

\section{What is semiotics?}

It is often the case that in research that identifies itself as "semiotic," there is not always a clear explanation of what it is and what it means. In the present work, we will synthesize the epistemological approach to semiotics and semiosis found in Peirce, Sebeok, Lotman, Jakobson, and Eco, where semiotics as an epistemology is articulated originally by Locke as a "doctrine" and evolves into what Sebeok calls "a peculiarly human form of inquiry that is in its essence a theory of perception" ([6], p. 12). For all of these approaches, signification is primary and the basis for communication and text generation. ${ }^{1}$

Umberto Eco points out that semiotics in the United States and France was deeply associated with structuralism in the context of research on cultural and linguistic phenomena in the 1960s ([9], pp. ix-x). It is also at this time that Lotman, working in Estonia, publishes a fundamental work on semiotic methods in the study of literature, in which he calls for the elimination of the opposition between exact science and humanities, it presents semiotic systems as modeling systems that both construct and explain the world in which humans live, all cultural spaces are based on multiple linguo-cultural codes, and it considers semiotics to be a cognitive science. ${ }^{2}$ These modeling systems are not ahistorical and are embedded in complex systems of "non-hereditary collective memory" [11].

Peircean semiotics is a clear departure from the structuralist tradition and has strong ties to the philosophy of science and provides a framework for categorizing triadic sign types in a fundamentally non-binary modeling system. Peirce's most important contribution to semiotics is found in his theory of signs (minimally triadic, never binary) and types of inference (Peirce 2.246, 2.250-2, [12, 13]). For Peirce, the triadic sign always involves (1) its relation to itself (sign-sign relationship), (2) relation

\footnotetext{
${ }^{1}$ Signification is the "initial and primary ability that underlies human language and all of human cognition" and is essential to the creation of non-hereditary collective memory/cultural systems. For an important discussion of the importance of signification and invention of collective symbols, see Donald [7]. Tomasello's characterization of linguistic reference as a "social action" is an important corollary to the phenomenon of signification ([8], p. 97). At the point children begin participating in the signification process as learners of linguistic symbols, they not only can tap into the richness of "preexisting" knowledge but also participate in the uniqueness of linguistic symbols and their inherent polysemic nature. This provides the opportunity to cognitively embrace an event or object at multiple levels simultaneously (cf. "a rose, a flower, and a gift”) ([8], p. 107).

2 As early as the 1970s, one sees a tension between the place of semiotics and the original cognitive sciences (founded on four primary disciplines_computer science, philosophy, psychology, and linguistics). Sebeok at that time, under the influence of Hofstadter's work in artificial intelligence, prefers the term "perception" over "cognition" in order to separate semiotic theory from the cognitive sciences and to emphasize the central role that the generation of meaning plays in understanding sign systems in dynamic interaction ([10], p. 53). By the 1980s semiotics became known in the context of not only human anthropological and linguistic systems but also biological phenomena.
} 
to its object (sign-dynamic object relationship), and (3) its relation to its interpretant (sign-final interpretant) (ibid.).

It was Jakobson who introduced Peirce's icon/index/symbol triad (part of the sign-object relationship) into modern linguistic theory. Through this triad, Peircean semiotic theory became widely known in linguistics and was applied in works that demonstrated the significance of the non-arbitrariness of the linguistic sign [1]. Non-arbitrariness must be understood as a relative phenomenon, not an absolute, and is particularly powerful at the phonological, morphological, and morphophonemic levels in languages. Much later, sociolinguistics and identity studies borrowed the terminology as well but with changes (cf. [14]).

\section{The semiotic approach and semiosis: no more binaries}

The semiotic perspective requires a re-evaluation of research techniques and applications. Such a re-evaluation brings into question the very object of study, as well as the instrumentation used to evaluate the object. Once it is recognized that the focal point of Peircean semiotic theory is not the sign, but semiosis (the sign in action, the prerequisite process of the exchange of information [signification]), the next step is to take a closer look at the interface between functioning signs as they are used $[6,10]$.

Semiotic theory that focuses on signs in action provides an epistemological framework where any linguistic speech act includes the users of the language, and codes and messages are embodied in the users themselves. This idea can be extended to neuroscience and can provide the basis for proposing that the sensory-motor neural image of a given linguistic phenomenon, be it grammatical or lexical, is multisensory and involves cross-modal effects-a notion that is central to all of the current neuroscience research on embodied cognition (including $[15,16]$ ). Another outcome of a theory of dynamic signs requires treating referential meaning as a type of meaning-not the only kind of meaning and not even the most important kind in all instances. In other words, the outcome of this framework is that linguistic meaning is never solely determined or determinable by reference alone. ${ }^{3}$ This outcome has a profound impact on the modeling of multimodality as an organizing principle of human cognition.

\subsection{Defining icon/index/symbol: redefining non-arbitrariness}

Following Peirce (Peirce 8.368, [13] pp. 4-23;[21]), the icon is defined as a qualitative likeness between a sign and its object. The quality upon which the similarity is based belongs to the sign, whether or not its object exists. The index is a real connection between the sign and its object, and the relationship is given via the dynamic object of the sign. The symbol is a general rule between the sign and object, and the object is related to the sign via the interpretant. [Jakobson's rendering of these terms is reanalyzed back into the dyadic terms signifier/signans and signified/signatum, similarity/contiguity (i.e., paradigmatic/syntagmatic axes), and the notions of factual (effectual) and habitual [22, 23]] Each of these 3 sign-object relationships are embedded in each other such that none of these categories may

\footnotetext{
${ }^{3}$ For a full discussion of the Jakobsonian speech act model, which is applicable to explicating the generation of linguistic meanings, as well as language usage both in healthy subjects and in pathology, see ([17], pp. 66-71; [5], pp. 51-58; [18-20]).
} 


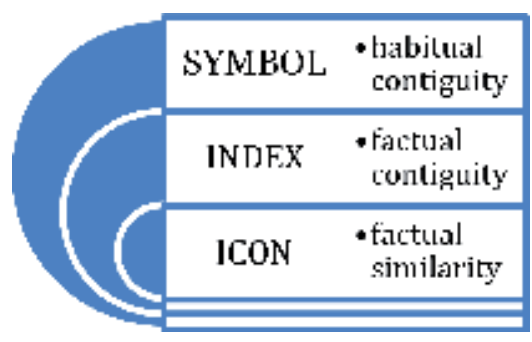

Figure 1.

Peirce's sign-object triadic relation.

ever occur alone, the icon is embedded in the index and symbol, and the index is embedded in the symbol (Peirce 2.306, 4.447 [21]). Note the following diagram with Jakobson's terminology: Figure 1

The principle of iconicity, as based on Peirce's definitions, is critical to the reimagining of the non-arbitrariness of the linguistic sign as a relative phenomenon. Bolinger ([1], pp. 18-23), in his work on morphemes, presents interesting examples from English of phonological iconicity at the syllabic and lexical levels, including "hard of hearing" (alliterative/iconic phonological properties, [h_r/h_r], and "short circuit," [rt/r_t]), not "hard of seeing/smelling" and "long circuit." Bolinger also exposes important iconic relationships in prosody in later works and fine-tunes his approach to relative non-arbitrariness ([24], pp. 92-93). ${ }^{4}$

\subsection{The importance of the interpretant: how to talk about meaning}

Peirce posits three basic types of interpretants in the sign complex-immediate, dynamic, and final (Peirce 8. 315, 8.372, [13]). The interpretant is the level of the triadic sign where the meaning of the sign is realized:

“...the meaning of a sign is the sign it has to be translated into;" (4.132)

"creates in the mind...an equivalent sign, or perhaps a move developed sign;"

"the proper significate outcome of the sign" (4.127)

It is interesting that while linguistic applications of Peirce are rich in the use of the icon/index/symbol triad, this is not the case with interpretants. ${ }^{5}$ However, the one fundamental point that has persisted is the certainty of translation and the recognition that all translations change meanings. Lotman ([28], p. 15) does not ever use Peirce's term but makes an important argument about the inevitability of tensions that arise in any speech/communication act. In so doing, Lotman articulates a new perspective-the most valuable information derived from speech acts is a result of the translation of that which is seemingly untranslatable.

\footnotetext{
${ }^{4}$ Bolinger's work [1, 24-26] provides robust explanations for deconstructing the nineteenth-century view of form/meaning relations in language as "arbitrary" (as posited by Saussure) by exploiting iconic principles manifested in definitions that are relativized, not absolutes.

${ }^{5}$ For examples of analyses using Peircean interpretants, see Savan [13], Andrews [12, 27]. For an example of the use of interpretants to explain principles of language acquisition, see Andrews [12].
} 


\section{Cognitive neuroscience studies of languages}

"How does fMRI create images of neuronal activity? The short answer is that it does not. Instead, fMRI creates images of physiological activity that are correlated with neuronal activity" ([21], pp. 127-8).

\subsection{Understanding activations: defining the relationship between the generation of meaning(s) and activations}

Imaging techniques that involve the hemodynamic response (PET, fMRI) only measure correlates of neuronal activity and processes and not actual neuronal firings. Electrophysiological techniques (including EEG, MEG) can measure electrical activity in ensembles of neurons and changes in magnetic fields related to neuronal activity.

Invasive direct single-neuron mappings, as found in cortical stimulation mappings (CSM), are only conducted during surgery. George Ojemann, who developed the technique, conducted over 1100 surgeries that included CSM mappings to identify areas important to production and comprehension of language(s). This technique was developed in order to identify areas related to important functions of production (motor) and comprehension (sensory) in language(s) and has proven successful in preserving these functions in surgeries that require removal of tissue. Dr. Ojemann has published over 170 papers of CSM data with important conclusions about neural mappings of language and languages [29-41].

Understanding activations found in BOLD fMRI studies presents a significant challenge. ${ }^{6}$ When considering the results of fMRI studies of language(s), one finds a much broader range of activations across both hemispheres in areas not represented in the traditional Broca/Wernicke targets from the "classical model"; these results are in keeping with research findings in fMRI language studies and represent a consensus among the neuroscience community (cf. [4, 5, 45-51]). There are challenges in analyzing neural activations, and Raichle reminds us that it is:

"...impossible to distinguish inhibitory from excitatory cellular activity on the basis of changes in either blood flow or metabolism. Thus, on this view a local increase in inhibitory activity would be as likely to increase blood flow and the fMRI BOLD signal as would a local increase in excitatory activity" ([48], p. 12).

Other challenges in using fMRI for cognitive studies include the timing delay in the hemodynamic response that lags behind neuronal activity. It is essential to remember that there can be no one-to-one relationship between neural activations acquired during imaging and the subject's knowledge or ability.

Interpreting the activations recorded from ROIs in fMRI language studies is strengthened when significance can be found with behavioral data (e.g., empirical proficiency testing data) using multivariate analysis of covariance (MANCOVA). One such example is a longitudinal study of second language acquisition that also includes Common European Framework proficiency testing data [5, 45]. The use of empirical language proficiency data is particularly important for bi- and

\footnotetext{
$\overline{{ }^{6}}$ Eklund et al. ([42] , pp. 7900-7905) is one of a series of papers that discusses problems with fMRI analysis and parametric statistical methods, including "false positives" that resulted in a series of studies using the following fMRI analysis software: AFNI, FSL, and SPM. Eklund et al. note that results are more reliable for voxel-wise inference and invalid for cluster-based inference ([42], p. 7903). Additional sources that examine inter-method discrepancies in brain imaging include Katuwal et al. [43] and Bowring et al. [44].
} 
multilingual fMRI studies, where it is not atypical that a subject may demonstrate higher levels of activation in a language that they do not know well (or at all) than in a language that is the L1 or highly proficient L2. Abutalebi et al. [52] also includes language proficiency and show that it contributes explanatory power in understanding language switching and cognitive control in bi-/multilinguals. Birdsong notes that brain imaging studies demonstrate that second language (L2) proficiency, not age of acquisition, is "the strongest predictor of degree of similarity between late learners \& monolingual natives" ([53, 54] pp. 24-5).

The importance of developing ecologically valid protocols for imaging experiments is another factor that can strengthen validity in interpreting activations. Other considerations in protocol development include protocol design that lends itself to the subtractive method that is often applied in fMRI experiments and minimizing "confounding factors" ([55, 56], p. 290). Activation levels resulting from task-based fMRI, by themselves, may not be interpretable (activation levels do not necessarily correlate with knowledge). Thus, the importance of including other statistical models and empirical measurements (e.g., proficiency) becomes critical for strengthening conclusions.

Raichle [57-60] proposes the default mode network (DMN) as one approach to understanding the changes in activations where specific brain regions decrease their activity during a task condition. Gusnard and Raichle ([61], p. 689) also suggest a way to characterize "tonically active areas" by distinguishing between "functionally active" and "activated." For Raichle, the DMN is one of the most important of the hierarchical networks, and it plays a central role in coordinating among brain systems and their interactions across system boundaries. ${ }^{7}$ The DMN and other such networks point toward the heightened interest in the application and inclusion of resting state fMRI in protocols and connectivity models [62, 63]. Functional connectivity modeling and analysis in recent neuroimaging studies are an important move away from older approaches that focus on modularity and localization.

\subsection{Embodied cognition and languages}

Sensory-motor interactive modeling of language and brain systems has become an important part of cognitive neuroscientific discourse over the past 15 years. The debates concerning embodied cognition are central to acquiring and developing new methods in order to understand the neurological interface of human languages, the relevance of multimodality and functional connectivity, and a rejection of modularity for modeling the processing of language(s) in the brain. Gallese and Lakoff [15] emphasize the importance of multimodal modeling of language and brain, because this perspective not only (1) takes into account its evolutionary trajectory but (2) characterizes these linguistic structures as part of the sensory-motor system at the neuronal level. Multimodal modeling, if acknowledged, requires a rejection of the modular view of language mappings in the brain.

The central arguments presented by Gallese and Lakoff stress the importance of multimodality, including mirror, premotor and parietal neurons, and the realization of multimodalities through functional clusters ([15, 64], p. 458). Approaches based on principles of embodied cognition will play an important role in developing robust theories of brain and language(s).

As I have noted earlier, "the kind of sensory-motor alignment that Gallese and Lakoff present is but one type of the significant multimodal aspects of human language and the brain, and the cautionary statements given in Mahon and Caramazza

\footnotetext{
${ }^{7}$ For a discussion of the importance of slow cortical potentials (SCP), see Raichle ([59], pp, 182-185).
} 
[16] are important to keep in mind" (2013, p. 136). Mahon and Caramazza, while rejecting a disembodied cognition hypothesis, argue that it is necessary to understand "whether the motor system is activated due to 'leakage' of (or cascading) activation from an 'abstract' conceptual level', or occurs in parallel to (or independently of) activation of the 'abstract' conceptual level?" ([16], p. 60). While they suggest that some concepts might include sensory-motor information, they are not willing to concede the case with abstract concepts ([16], p. 60):

"For abstract concepts there is no sensory or motor information that could correspond in any reliable or direct way to their 'meanings."

While Gallese and Lakoff provide one important form of the alignment (e.g., English lexeme grasp ([15], p. 457)), one can identify a more pervasive sensorymotor synthesis in three ways:

1. The realizations of specific embodied forms of grammatical and lexical meaning as produced/articulated and perceived (cf. Bolinger's/sl/and/gr/lexemes in English—slippery, sleezy, slimy, slinky, etc.; grasp, grip, grab, grub, greed, etc.)

2. The specific gestures that accompany language-specific lexical categories and sound-based alternative systems of auditory perception (lyric and music)

3. Visual meanings given in written language (e.g., to/two/too, sea/see/C] or ideograms) that are not given in the sound forms (see also Andrews, 2013, pp. 128-137)

As noted in Andrews [45], all forms of linguistic meanings are negotiated in context via speech acts, and these speech acts "are always multiples and are embedded in... speech communities and communities of practice," which are, in the end, what one could call "the inalienable context" ([45], pp. 196, 198). And while sensory-motor systems are internally determined, there is never "language in the one" ([45], p. 198):

"Language is a consequence of humans interacting in cultural space...We are always multifaceted users of language; we play the roles of speakers, hearers and observers (sometimes simultaneously), and we as users are defined by the multiple and variegated...speech communities and communities of practice in which we language" (ibid.)

\subsection{Empiricism and interpretation of results}

"What is important in a model is not its accord with experiment, but, on the contrary, its 'ontological range,' in which it states the manner in which the phenomena take place and in which it describes their underlying mechanisms." Thom ([65], p. 111)

Strong empirical methods that yield repeatable results are an important component of achieving reliable conclusions in the analysis of neuroimaging data. Standard software programs typically used in fMRI analysis (e.g., FSL, SPM) are an important component of the statistical methods used in analysis, and these systems continue to be expanded and improved upon. Collecting behavioral data that can be used to correlate with imaging data is another important way to strengthen confidence in the results of the analysis. Below are four major points that describe 
the advantages of empirical data and analysis that includes behavioral "can do" data in opposition to more traditional experiments that put more emphasis on static, essentialist characteristics of the experimental subjects:

1.Study participants demonstrate ability (i.e., dynamic) using empirical measurement tools relevant to establishing baselines.

2. Usage of internationally recognized proficiency measurements provides quantitative data that can be understood across studies.

3. Behavioral study data enhances the CONTEXT for framing the analysis and interpretation of empirical data.

4. Given the challenges of understanding and interpreting the hemodynamic response and activations acquired in fMRI, MANCOVA and other statistical methods strengthen the validity of the analysis and emerging conclusions.

5. Essentialist categories are static, do not provide empirical data for analysis, do not reflect the importance of learning, and are not supported by neurological models of brain development and cognition.

\section{Biosemiotics, markedness, and autopoiesis: precursors to understanding the importance of multimodalities and embodied cognition}

...experience is moored to our structure in a binding way. We do not see the "space" of the world; we live our field of vision.....we invariably find that we cannot separate our history of actions - biological and social - from how this world appears to us. ([66], p. 23)

The impact of Maturana and Varela's formulation and examination of autopoiesis (a neologism) on linguistics, semiotics, and later on the cognitive sciences is quite significant. The term itself was the result of a search for a word without a history that could adequately define what they considered to be the essence of the organization of the living system-autonomy, self-reference, and "circular organization" ([66], p. xvii). In his introduction to Biology of Cognition ([66, 67], p. xv), Maturana describes how his work on vision and visual perception led him to two specific conclusions-one being the "nervous system [is] a closed network of interaction neurons" and the second being the realization that the study of cognition is "a legitimate biological problem" (ibid.). As a result, a new set of research questions emerged: how do organisms obtain information about their environments, and how is it that organisms have structures that allow them to operate in their existing environments ([66], p. xvi) $?^{8}$

One of the significant outcomes of the epistemological approach of autopoiesis for semiotics and the cognitive sciences is the reinforcement of semiotic principles that were articulated in a different context by Jakob von Uexküll $[68,69]$ and Yury Lotman $[28,70]$, which include Uexküll's Umwelt and functional circle

\footnotetext{
${ }^{8}$ Maturana ([66], p. xviii) discusses a concession he made in the Biology of Cognition that he now regretshe did not explicitly say that causal relations are not relevant in autopoiesis; rather, they are only relevant in the metadomain.
} 
and Lotman's semiosphere. In Beer's preface to Maturana and Varela's book ([66], pp. 63-72), he clearly articulates the importance of the new approach as a metasystemic synthesis that is NOT interdisciplinary; rather, this new approach transcends disciplines ([66], p. 65). This is very much in keeping with the modeling proposed by Lotman (see Umberto Eco's introduction to Shukman's translation of Lotman's Universe of the Mind, 1990). ${ }^{9}$

While we cannot provide here a full articulation of Maturana and Varela's important work, there is one other major point that must be noted in this context-their definition of the observer. One of the two guiding principles given in their 1990 and 1992 books is "everything said is said by an observer" (1990, pp. xxii, 8; 1992, p. 26). For Maturana and Varela, the observer is defined as a living system who can only be accounted for when cognition is seen as a biological phenomenon (1990, p. 9). This statement, along with their definition of four consequences of autopoietic organization (1990, pp. 80-81), ${ }^{10}$ takes us to the brink of the twenty-first century cognitive neuroscience methods and analysis as defined by perspectives that are more multimodality-oriented than modular and that give a prominent place to sensory-motor systems in explaining language processing in the brain.

\section{By way of conclusion: frames of interaction and understanding functional connectivity and neural networks (DMN and others)}

In the end, it is clear that cognitive neuroscience and neuroimaging continue to incorporate important ideas, even if it is more often than not in a nonconscious and unarticulated manner, from a range of anthroposemiotic and biosemiotic models described in the previous sections. One of the most powerful and recent outcomes of this important interaction of research methods and concepts is seen in the move away from focusing imaging analysis within regions of interest to understanding the networks and functional connectivity in operation during not only task-based fMRI but resting state fMRI. The first network that was identified is known as the default mode network (DMN) [57, 59, 60]. Current research demonstrates that there are multiple such interactive networks and the details of these networks are clearest in studying intrinsic functional connectivity in individuals, not groups [72]. The recognition of neural functional connectivity and networks is in keeping with the autopoietic approach given by Maturana and Varela, where they foresee such an outcome:

The fact that we can divide physical autopoietic machines into parts does not reveal the nature of the domain of interactions that they define as concrete entities operating in a physical universe (1992, p. 82).

As fMRI imaging methods shift to include individual and group data analysis and protocols expand from task-based to include resting state, there will be more evidence contributing to our understanding of the default network as "the apex transmodal association network" [72].

\footnotetext{
${ }^{9}$ C.H. van Schooneveld [71] draws important connections between autopoiesis and his definition of semantic dominants in human languages. For an in-depth discussion of Uexküll's Umwelt, functional circle, and Lotman's semiosphere, see Andrews [10].

10 The four major outcomes of autopoietic organization according to Maturana and Varela (including their definition of "autopoietic machines," which include living systems ([66], p. 76)) are autonomy, individuality, unities, and no inputs or outputs (only perturbations that lead to internal structural changes) ([66], pp. 80-81).
} 
The interaction of semiotics and the cognitive neurosciences has not been generally noted at the level of discrete analyses or individual experiments but becomes more obvious and prescient when the philosophical and epistemological underpinnings of the two disciplines are made explicit. That is one of the goals of the present analysis. The other is to draw attention to the importance of multidisciplinarity and the obligatory re-evaluation of disciplinary boundaries that has emerged within semiotics and the cognitive neurosciences. The major frames that support both of these efforts are found in the importance of ecological validity in research, recognition of connectivity modeling and multimodal perspectives, the re-evaluation of arbitrariness and the relative nature of non-arbitrariness, and the inalienable role of context both in neurological networks and signification systems.

\section{Author details}

Edna Andrews

Duke University, Durham, North Carolina, USA

*Address all correspondence to: eda@duke.edu

\section{IntechOpen}

(C) 2019 The Author(s). Licensee IntechOpen. This chapter is distributed under the terms of the Creative Commons Attribution License (http://creativecommons.org/licenses/ by/3.0), which permits unrestricted use, distribution, and reproduction in any medium, provided the original work is properly cited. (cc) BY 


\section{References}

[1] Bolinger D. On defining the morpheme. Word. 1948;4:18-23

[2] Poeppel D. The Cartographic Imperative: Confusing Localization and Explanation in Human Brain Mapping. In Bruhn \& Werner Bredekamp (Eds.). Bildwelten des Wissens (Ikonographie des Gehirns). 2008;6(1):1-21

[3] Hickok G, Poeppel D. Dorsal and ventral streams: A framework for understanding aspects of the functional anatomy of language. Cognition. 2004;92:67-99

[4] Poeppel D, Hickok G. Towards a new functional anatomy of language. Cognition. 2004;92:1-12

[5] Andrews E. Neuroscience and Multilingualism. Cambridge: Cambridge University Press; 2014

[6] Sebeok TA. A Sign Is Just a Sign. Bloomington: Indiana University Press; 1991

[7] Donald M. A Mind So Rare: The Evolution of Human Consciousness. New York: Norton; 2001

[8] Tomasello M. The Cultural Origins of Human Cognition. Cambridge, MA: Harvard University Press; 1999

[9] Eco U. Introduction. In: Ju M Lotman, trans. A Shukman. Universe of the Mind: A Semiotic Theory of Culture. Bloomington: Indiana University Press; 1990

[10] Andrews E. Conversations with Lotman: Cultural Semiotics in Language, Literature, \& Cognition. Toronto: Toronto University Press; 2003

[11] Lotman JM, Uspensky BA. O semioticheskom mexanizme kul'tury. In: Studies in Sign Systems V. Tartu: Tartu State University; 1971. p. 284
[12] Andrews E. Markedness Theory: The Union of Asymmetry and Semiosis in Language. Durham: Duke University Press; 1990

[13] Savan D. An Introduction to Peirce's Semiotics. Toronto: Victoria University; 1976

[14] Bucholtz M, Hall K. Language and identity. In: Duranti A, editor. A Companion to Linguistic Anthropology. Blackwell Publishing; 2004

[15] Gallese V, Lakoff G. The brain's concepts: The role of the sensory-motor system in conceptual knowledge. Cognitive Neuropsychology. 2005;22:455-479

[16] Mahon BZ, Caramazza A. A critical look at the embodied cognition hypothesis and a new proposal for grounding conceptual content. Journal of Physiology, Paris. 2008;102(1-3):59-70

[17] Jakobson R. Linguistics and poetics. In: Pomorska K, Rudy S, editors. Language in Literature. Cambridge, MA: Belknap Press of Harvard University Press; 1957/1987. pp. 62-94

[18] Jakobson R. Metalanguage as a linguistic problem. In: Rudy S, editor. Selected Writings VII. Berlin: Mouton; 1956/1985. pp. 113-121

[19] Jakobson R. Language and culture. In: Rudy S, editor. Selected Writings VII. Berlin: Mouton; 1967/1985. pp. 101-112

[20] Jakobson R. The fundamental and specific characteristics of human language. In: Rudy S, editor. Selected Writings VII. Berlin: Mouton; 1969/1985. pp. 93-100

[21] Peirce CS. Collected Papers of Charles Sanders Peirce. Cambridge, MA: Harvard University Press; 1931-58 
[22] Jakobson R. A glance at the development of semiotics. In:

Rudy S, editor. Selected Writings 7.

Berlin: Mouton; 1975/1985. pp. 199-218

[23] Jakobson RO. The Framework of Language. Ann Arbor: Michigan Studies in the Humanities; 1980

[24] Bolinger D. Intonation and its Uses: Melody in Grammar and Discourse. Stanford: Stanford University Press; 1989

[25] Bolinger D. Forms of English: Accent, Morpheme, Order. Cambridge, MA: Harvard University Press; 1965

[26] Bolinger D. Aspects of Language. 2nd ed. New York: Harcourt Brace Jovanovich, Inc.; 1975

[27] Andrews E. The interface of iconicity and interpretants. In: The Peirce Seminar Papers 2. Providence, RI: Berghahn Books; 1994. pp. 9-28

[28] Lotman YM. Kul'tura i vzryv. Gnosis: Moscow; 1992

[29] Corina DP, Loudermilk BC, Detwiler L, Martin RF, Brinkley JF, Ojemann G. Analysis of naming errors during cortical stimulation mapping: Implications for models of language representation. Brain and Language. 2010;115(2):101-112

[30] Duffau H. The anatomo-functional connectivity of language revisited. New insights provided by electrostimulation and tractography. Neuropsychologia. 2008;46(4):927-934

[31] Duffau H, Peggy GST, Mandonnet E, Capelle L, Taillandier L. Intraoperative subcortical stimulation mapping of language pathways in a consecutive series of 115 patients with Grade II glioma in the left dominant hemisphere. Journal of Neurosurgery. 2008;109(3):461-471

[32] Haglund MM, Berger MS, Shamseldin M, Lettich E, Ojemann GA.
Cortical localization of temporal lobe language sites in patients with gliomas. Neurosurgery. 1994;34(4):567-576

[33] Ojemann GA. Brain organization for language from the perspective of electrical stimulation mapping. Behavioral and Brain Sciences. 1983;6(2):189-206

[34] Ojemann GA. Cortical organization of language. The Journal of Neuroscience.

1991;11(8):2281-2287

[35] Ojemann GA, Whitaker HA. The bilingual brain. Archives of Neurology. 1978;35(7):409-412

[36] Serafini S, Friedman A, Haglund M, Gururangan S. Identification of distinct and overlapping cortical areas for bilingual naming and reading using cortical stimulation: Case report. Journal of Neurosurgery: Pediatrics. 2008;1(3):247-254

[37] Serafini S, Grant G, Haglund M, Gallentine W, Mikati M, Komisarow J, et al. Reorganization and stability for motor and language areas using cortical stimulation. Brain and Sciences.

2013;3(4):1597-1614

[38] Haglund MM, Ojemann GA, Blasdel GG. Optimal imaging of bipolar cortical stimulation. Journal of Neurosurgery. 1993;78(5):785-793

[39] Ojemann GA. Functional mapping of cortical language areas in adults-Intraoperative approaches. In: Devinsky O,

Beric A, Dogali M, editors. Electrical and Magnetic Stimulation of the Brain and Spinal Cord. New York: Raven Press; 1993. pp. 155-163

[40] Ojemann GA. The neurobiology of language and verbal memory: Observations from awake neurosurgery. International Journal of Psychophysiology. 2003;48(2):141-146 
[41] Ojemann GA, Corina DP, Corrigan N, Schoenfield-McNeill J, Poliakov A, Zamora L, et al. Neuronal correlates of functional magnetic resonance imaging in human temporal cortex. Brain. 2010;133:46-59

[42] Eklund A, Nichols TE, Knutsson H. Cluster failure: Why fMRI inferences for spatial extent have inflated false-positive rates. PNAS. 2016;113(28):7900-7905

[43] Katuwal GJ et al. Inter-method discrepancies in brain volume estimation may drive inconsistent findings in autism. Frontiers in Neuroscience. 2016

[44] Bowring A, Maumet C, Nichols TE. Exploring the impact of analysis software on task fMRI results. Human Brain Mapping. 2019;40:3362-3384

[45] Andrews E, Frigau L, Voyvodic-Casabo C, VoyvodicJ, Wright J. Multilingualism and fMRI: Longitudinal study of second language acquisition. Brain Sciences. 2013;3(2):849-876

[46] Luo H, Poeppel D. Phase patterns of neuronal responses reliably discriminate speech in human auditory cortex. Neuron. 2007;54(6):1001-1010

[47] Price CJ. The anatomy of language: A review of $100 \mathrm{fMRI}$ studies published in 2009. Annals of the New York Academy of Sciences. 2010;1191(1):62-88

[48] Andrews E. Cognitive neuroscience and multilingualism. In: Schwieter JW, editor. The Handbook of the Neuroscience of Multilingualism. London: Wiley-Blackwell Publishers; 2019. pp. 23-48

[49] Hickok G, Poeppel D. Towards a functional neuroanatomy of speech perception. Trends in Cognitive Sciences. 2000;4:131-138
[50] Hickok G, Poeppel D. The cortical organization of speech processing. Nature Reviews. Neuroscience. 2007;8(5):393-402

[51] Indefrey P. A meta-analysis of hemodynamic studies on first and second language processing: Which suggested differences can we trust and what do they mean? In: Gullberg M, Indefrey P, editors. The Cognitive Neuroscience of Second Language Acquisition. Malden, MA: Blackwell; 2006. pp. 279-304

[52] Abutalebi J, Della RPA, Ding G, Weekes B, Costa A, Green D. Language proficiency modulates the engagement of cognitive control areas in multilinguals. Cortex. 2013;49(3):905-911

[53] Birdsong D. Age and second language acquisition and processing: A selective overview. In: The Cognitive Neuroscience of Second Language Acquisition, Gullberg M, Indefrey P, editors. Blackwell Publishing; 2006. pp. 9-49

[54] Gullberg M, Indefrey P. The Cognitive Neuroscience of Second Language Acquisition. Malden, MA: Blackwell; 2006

[55] Huettel SA, Song AW, McCarthy G. Functional Magnetic Resonance Imaging. Sunderland, Mass: Sinauer Associates, Publishers; 2004

[56] Huettel SA, Song AW, McCarthy G. Functional Magnetic Resonance Imaging. 2nd ed. Sunderland, MA: Sinauer Associates; 2009

[57] Raichle ME. Functional neuroimaging: A historical and physiological perspective. In: Cabeza R, Kingstone A, editors. Handbook of Functional Neuroimaging of Cognition. Cambridge, MA: MIT Press; 2001. pp. 3-26 
[58] Raichle ME. The brain's dark energy. Scientific American. 2010;302(3):44-49

[59] Raichle ME. Two views of brain function. Trends in Cognitive Sciences. 2010;14(4):180-190

[60] Raichle ME. The brain's default mode network. Annual Review of Neuroscience. 2015;58:433-447

[61] Gusnard DA, Raichle ME. Searching for a baseline: Functional imaging and the resting human brain. Nature Reviews: Neuroscience. 2001;2(10):685-694

[62] Bijsterbosch J, Smith S, Beckmann C. Introduction to Resting State fMRI Functional Connectivity. Oxford: Oxford University Press; 2017

[63] Lee MH, Smyser CD, Shimony JS. Resting-state fMRI: A review of methods and clinical applications. American Society of Neuroradiology. 2012. DOI: 10.3174/ajnr.A3263

[64] Johnson M, Lakoff G. Why cognitive linguistics requires embodied realism. Cognitive Linguistics. 2002;13(3):245-263

[65] Thom R. Mathematical Models of Morphogenesis. Reading, MA: Benjamin/Cummings; 1983

[66] Maturana HR, Varela FJ. The Tree of Knowledge. Boston \& London: Shambhala; 1992

[67] Maturana HR, Varela FJ. Autopoiesis and cognition. In: Introduction to Biology of Cognition by H.R. Maturana, preface to Autopoieses: The organization of the living by Sir Stafford Beer. Boston Studies in the Philosophy of Science, 42. Dordrecht: Reidel; 1980

[68] von Uexküll J. Theoretische Biologie. Berlin: Springer; 1928

[69] von Uexküll J. The theory of meaning. Semiotica. 1982;42(1):25-87
[70] Lotman Yu M. Universe of the Mind. Translated by A. Shukman, Introduction by U. Eco. Bloomington: Indiana University Press; 1990

[71] van Schooneveld CH. Linguistic structure and autopoiesis. In:

Pomorska K, Chodakowska E, McLean H, Vine B, editors. Language, Poetry and Poetics. 1987. pp. 123-142

[72] Buckner RL, DiNicola LM. The brain's default network: Updated anatomy, physiology and evolving insights. Nature Reviews, Neuroscience. 2019;20(19):593-608 


\title{
Chapter 3
}

\section{Analog, Embodiment, and Freedom}

\author{
Ted Gemberling
}

\begin{abstract}
Discussions of computer technology often touch on matters of free will. Can living organisms, especially human beings, be interpreted as like computers? Much writing on computers today assumes that digital technology shows freedom of the will is illusory. Charles S. Peirce (1839-1914) had quite a bit to say about the freedom of the will and its relation to the laws of nature. This chapter provides evidence from a number of writers on computers and related matters which bears on his analysis. Peirce's category of Firstness has a great deal to contribute to our understanding of freedom as well as human responsibility, but its true meaning requires quite a bit of explanation.
\end{abstract}

Keywords: computers, analog, digital, freedom, determinism, semiotics, esthetics, embodiment, algorithms, addiction

\section{Introduction}

Lots of evidence has accumulated that online content influences people. It has even been pointed out that computer algorithms sometimes know us better than we know ourselves. They can detect our interests by the searches we do and the web pages we open. If this were not so, businesses would not advertise on the Web. But does that mean we humans are just a slower, less systematic kind of computer? How different are computers and living organisms?

Peirce's most difficult category is Firstness. It is difficult because it is about things before we really begin to think about them or even recognize their "otherness." Secondness, which consists in that otherness, and Thirdness, which contains our categorizations or general conceptions of things, are fairly straightforward. In Peirce's categorical system Firstness lies at the base of Secondness and Thirdness. Before anything is different or general, it is itself.

There is an enlightening passage where Peirce lays out the relation of Secondness to Thirdness:

I should not wonder if somebody were to suggest that perhaps the idea of a law is essential to the idea of one thing acting upon another. But surely that would be the most untenable suggestion in the world considering that there is no one who after lifelong discipline in looking at things from the necessitarian point of view has ever been able to train himself to dismiss the idea that he can perform any specifiable act of the will. It is one of the most singular instances of how a preconceived theory will blind a man to facts that many necessitarians seem to think that nobody really believes in the freedom of the will, the fact being that he himself believes in it when 
he is not theorizing. However, I do not think it worthwhile to quarrel about that. Have your necessitarianism if you approve of it; but I still think you must admit that no law of nature makes a stone fall, or a Leyden jar to discharge, or a steam engine to work ([1], pp. 89-90).

Here he is arguing against the popular "necessitarianism" of his day, which we generally call "determinism" in English today. Its claim is that every single fact of our experience is determined by natural laws. If you know the state of facts at any time, you can deduce what the facts will be at any other time by those laws ([1], p. 325). Peirce says this implies there is no real increase in diversity in the world. Whatever diversity exists today would have existed at the beginning of the universe. Natural processes only rearrange things; they do not create anything new ([1], pp. 334-335).

Now, actually, there are several objections one could make to the passage. The most obvious is that, of course, stones do fall because there is a law of nature, gravitation. What Peirce is saying is that when a stone falls, some other single entity, such as perhaps my foot hitting it, is the occasion for that law to operate. That is Secondness. He is arguing that my foot hitting the stone is not predictable by that or any other law.

A more difficult problem is his statement that no one can "train himself" to believe he cannot make certain choices. It seems people often do train themselves to believe that. In fact, maybe that is what depression consists in, the belief you cannot do things you would like to do. But I believe Peirce is speaking here in a more "ideal," philosophical sense: does the philosopher really believe he cannot make choices?

\section{Wilden on computer technology}

How we understand the human brain has important implications for the freedom of the will. In a 1972 piece, Anthony Wilden lays out a distinction between "analog and digital communication" ([2], pp. 155-195). Wilden is attempting to show what elements of electronic technology may correspond to the nervous systems of organisms, and his discussion of analog and digital brings out some interesting parallels. He says our nervous system includes both analog and digital elements, laying out in detail how nerve axons transmit messages to the synaptic connections between cells. The transmission is at first an analog one, meaning that it is about "difference" on a continuous scale. Eventually the message passed in the axon reaches a certain "threshold," and it becomes a matter of "opposition" rather than difference ([2], pp. 174-176). This is now a digital message. Wilden points out that genes are digitally coded but depend upon related enzymes, which are analog elements ([2], p. 158). Digitalization is always necessary whenever an important "boundary" or "frame" needs to be added to an analog continuum. As Wilden puts it:

[The organism] introduces a desired closure into a continuum, which distinguishes a certain "part," and by the same act constitutes himself as distinct in some way from the environment he perceives ([2], p. 174).

The digital splits the world into discrete elements and helps us experience our individuality. The connection of this concept to Secondness is clear.

In another chapter of the same book, he suggests the analog may correspond to Peirce's Thirdness, but he admits he does not understand Peirce's categories very 
well [3]. He suggests Firstness is the Real and Secondness, the Imaginary. This misconstrues them. Something imaginary is a Second when we find out it is imaginary; until then, it is an aspect of our freedom, which is Firstness. As Peirce would put it, Firstness is the "monadic" aspect of our experience. He says:

I can imagine a consciousness whose whole life, alike when wide awake and when drowsy or dreaming, should consist of nothing at all but a violet color or a stink of rotten cabbage. It is purely a question of what I can imagine and not of what psychological laws permit ([1], p. 81).

Consciousness has this monadic aspect that is complete unto itself and not dependent on anything external. Firstness is predominant in the ideas of "freshness, life, freedom" as well as feeling, as opposed to perception, will, and thought ([1], pp. 78-79). When we find out something is imaginary, we are essentially acknowledging a dyadic relation, a relation between what something is and what it is not (Secondness). There is also an element of Thirdness that comes into this, in that becoming convinced something is not real is coming to a sense of the persistence or stability of that reality ([1], p. 247). That is a triadic relation, because it involves a sense of connecting links between things, things yet to come as well as in the past. It is saying, "I will not see evidence of it in the future." Thirdness has a necessary connection to future time. For example, evolution is Thirdness because it is the emergence of things in time. Education is Thirdness because it means becoming aware of more things and different categories of things.

\section{Pre-Wilden views of analog and digital}

Wilden cites John von Neumann's classic work The Computer and the Brain ([2], pp. 157-158). Von Neumann talked about analog and digital computers but did not interpret human cognition in terms of the analog. Analog computers work by representing numbers by units of actual physical quantities, while digital machines represent them "as in conventional writing or printing, i.e. as a sequence of decimal digits" $([4]$, pp. 3,6$)$. He thought our cognition was basically digital with some ana$\log$ features ([4], p. 58). He emphasized the binary nature of nerve impulses. They were basically "on-off switches," and he put less emphasis on the threshold features Wilden emphasized ([4], pp. 40-44). What is "non-digital-like" in our brains is the result of their working statistically rather than analogically. If we imagine computing machines to have existed prior to the human brain, we might say the brain gave up precision in arithmetic to gain "an improvement in logics" ([4], p. 80). The nervous system uses two types of communication, the "non-arithmetical" and the "arithmetical." The latter includes "communications of orders," which are logical. Our nervous systems require less "logical depth" than digital computers, so statistical information is adequate ([4], pp. 76-82).

Hubert L. Dreyfus conceptualized human cognition in terms of the analog in his 1965 book Alchemy and Artificial Intelligence but appears to have given up that understanding in his later work On the Internet (2009). In the first work, he lays out three areas that digital computers are unable to handle: fringe consciousness, essence/accident discrimination, and ambiguity tolerance [5]. Dreyfus's conception of the analog appears to have influenced Wilden ([2], p. 157). One problem he lays out in some detail is language processing. It is difficult to understand language as simply a list of words in sentences constructed by rules. Dreyfus cites Wittgenstein on how our understanding of language appears to be inseparably connected to the way we live. Our lives provide us with the context that makes words and sentences 
understandable ([6], p. 33). This is an example of "tacit" knowledge and ambiguity tolerance. He cites Bar-Hillel for the view that machines can only make good translations of language if they can learn ([6], p. 35).

Dreyfus quotes a statement by Bullock on "graded synaptic potential," similar to Wilden's "threshold effects," arguing that the nervous system is a "complex analog device" rather than digital ([6], p. 56). He goes on to speculate on "wet" computers that simulate the way the human brain works, perhaps taking the form of an analog computer using ion solutions whose electrical properties change to model relationships. However, he cites Maurice Merleau-Ponty for doubts this would be adequate, since the human body as a whole plays an important role in facilitating intelligent behavior ([6], p. 59). This is the primary theme of Dreyfus's later work, On the Internet.

\section{Post-Wilden views of analog and digital}

Dreyfus has made an ongoing effort to monitor the progress of Artificial Intelligence and appears to make an effort to evaluate it as generously as possible. For example, he admits the development of Google, with its weighting of web pages by their apparent importance to searchers, shows some of his skepticism was excessive ([7], pp. 21-24). Google shows a computer can get a sort of indirect knowledge of what web pages are about without really understanding them ([7], p. 22). If a lot of searchers have shown interest in a page, that indicates something about its content. However, it says nothing about the correctness of the content. The interest of people in a page may be due to irrational factors or manipulation by the publisher.

Dreyfus says the big problem with AI is the computer's lack of "embodiment." Humans have common sense, and this is inextricably tied to our having bodies ([7], pp. 18-20). This appears to have replaced the concept of the "analog" for him. After all, analog computers are just another kind of machine. As Von Neumann showed, analog computers are used to do arithmetic ([4], p. 3). They are really just a different way to represent quantities. Our common sense comes from our not being machines.

However, there may be another sense in which the analog is relevant. Wilden pointed out that the human programmer provides a "necessary analog component to complement the amazing brute-force problem-solving capabilities of the digital computer" ([2], p. 157). Computers operate on codes, and a code as a whole is an analog of something. It is a way to get computers, with their ones and zeroes which are mostly meaningless to us, to do useful work by modeling some human activity such as writing or playing games. Von Neumann showed that digital computers have this power because they have memory ([4], pp. 19-20). This allows them to do things besides arithmetic. The programmer can instruct the computer to transform its numerical memory into something non-numerical. Nonetheless, one can argue the computer has no knowledge of the world. It is primarily a kind of mental prosthesis that allows us to perform certain functions faster and more accurately.

There is a connection between this and Peirce's semiotic theory. The computer code functions as a kind of "icon," in that its relation to a human cognitive activity is one of similarity ([1], p. 102). The skill of the programmer consists in her ability to make the program as analogous to the human activity as possible, while making sure the computer is consistently able to perform the actions. When she does not do a good enough job, the program, and perhaps the computer as a whole, "crashes."

In the book, Dreyfus makes a contrast between Plato, who pushed a "disembodied" conception of human personality, and Nietzsche, who emphasized our embodiment ([7], p. 5). Dreyfus is particularly doubtful about the efficacy of 
distance learning. He goes through the stages of learning from the novice, the advanced beginner, competence, proficiency, expertise and, finally, mastery and shows how the body and emotion are increasingly necessary as one progresses up the scale. Have not the Stoics and Descartes taught us that we make the most progress without emotion? ([7], p. 32) Dreyfus argues that learning above the stage of novice requires a level of emotion. We must want to succeed and worry about not measuring up. The teacher provides a model of commitment, and if we are not physically present with him or her, we lack the cues necessary for progress:

\begin{abstract}
If the teacher is detached and computer-like, the students will be too. Conversely, if the teacher shows his involvement in the way he pursues the truth, considers daring hypotheses and interpretations, is open to students' suggestions and objections, and emotionally dwells on the choices that have led him to his conclusions and actions, the students will be more likely to let their own successes and failures matter to them ([7], p. 33).
\end{abstract}

In a 2018 article, Beatrice Fazi attempts to build on the work of Gilles Deleuze to create a "digital esthetics" [8]. While Deleuze did not talk about computers very much, his work implied that the digital could not participate in the esthetic or creativity, central aspects of his philosophy. Digital computers depend on discreteness, on determinacy, but for Deleuze, indeterminacy was essential to life. Is there any way the digital can play a role in creativity? She surveys some attempts to make computers "creativity and esthetics friendly." One approach is to link the operation of the computer to the lived experience of users ("embedded computing"). This provides an "analog" or "embodied" supplement to the computer's cold, digital operation. Anna Munster made a particularly vivid attempt at this by emphasizing that the analog and the digital that come together in human-computer interaction are "more than the sum of their parts" ([8], pp. 12-13). Humans and computers working together have the potential to produce novel elements neither could produce on their own.

Fazi is not entirely satisfied with this solution. It is problematic because it ties the value of the digital to the analog (or embodied) elements, and she wants to believe the digital, or more precisely the computational, is valuable in itself. She calls her desired conception a "computational esthetics." This must go beyond "the discrete features of digital technologies, such as digits and pixels" to include also the "finite steps that characterize computation as an axiomatic and algorithmic method" ([8], p. 16). She discusses the work of Alan Turing in formalizing the nature of computing processes. He showed they work via precise, finite routines, but also that certain problems could not be solved in this way. They are "incomputable" because the steps they require are infinite ([8], p. 21). Gödel's Theorem showed that the computational depends ultimately on formal axioms arising from indeterminacy, since they cannot be deduced from the formal system themselves ([8], p. 20). Thus Fazi ends with a computational esthetics broadly compatible with Deleuze. The computational is valuable for its "systematizing and rationalizing logical capacity" ([8], p. 16) while not undermining indeterminacy and freedom.

\title{
5. The second cognitive revolution
}

A development bearing on all these questions is what has been called "the Second Cognitive Revolution." Dreyfus was an important person in the history of this movement [9]. Rom Harré has summarized the direction of the movement by saying the earlier Cognitive Revolution was too focused on cognition as governed by 
formal rules and schemata. It had been an advancement over earlier understandings which interpreted the mind as simply receiving external stimuli passively. We do not just respond to our environment; we also have complex "representations" of it. The movement drew on the work of Turing to conceive of the brain as an "information processing device" ([10], p. 181). It was primarily digital in nature since digital computers contain representations of the world in their memories. By the mid-80's, it was clear that a more subtle understanding of language was necessary to really understand human cognition. This involved rejecting the whole Cartesian model of thought as something internal and seeing how it functions within life as a whole, especially in its social aspects. Ludwig Wittgenstein had a major role here with his concept of "language games," of language as a sort of set of recipes rather than formalizable rules. As Harré points out, the First Cognitive Revolution had been too trapped in "the presumptions of individualism" ([10], p. 181). In fact, social cognitive processes precede individual ones.

In Dreyfus's contribution to the same volume, he argues against the concept of representation altogether ([11], pp. 39-73). Drawing on the work of Walter Freeman, he argues for what he calls a "Heideggerian" or "Merleau-Pontian" artificial intelligence ([11], p. 58) to solve the "frame problem." Both machines and living organisms encounter facts in the world, but the frame problem asks how a machine might be programmed so it can assign significance to novel facts. As he puts it, speaking of a closely related "binding problem":

How can the brain keep track of which facts in its representation of the current world are relevant to which other facts? ... [A]s long as the mind/brain is thought of as passively receiving meaningless inputs that need to have significance and relevance added to them, the binding problem has remained unsolved and is almost certainly unsolvable ([11], p. 59).

Drawing on Freeman's work with rabbits, Dreyfus, in line with his emphasis on embodiment, argues that organisms select relevant elements in the world based upon their prior experiences and purposes (feeding, defense, reproduction, etc.). He lays out Freeman's analysis of how "cell assemblies" in the animal are activated by sensory stimuli such as smell. These assemblies are self-organizing, bringing together different parts of the animal's brain and body, not just passive receptors but directed by its active concerns. Drawing on Merleau-Ponty, he calls the interaction of the organism's nervous system and the environment "basins of attraction" ([11], p. 62). The binding problem is simply a result of trying to interpret the animal from the researcher's perspective rather than that of the animal ([11] , p. 61). He suggests machines might be designed to function the same way ([11], pp. 68-73).

In the following chapter of the volume, H.M. Collins raises some serious problems with Dreyfus's proposal [12]. The difficulty is that it does not explain what is unique about humans. As Terrence Deacon argued in his Symbolic Species [13], symbolization is what is distinctive to humans. We share with animals an immediate "indexical" (in Peirce's terms) engagement with items in our environment (Seconds), but since we also use "symbols" (in Peirce's sense), involving conventional (shared) signifiers for general aspects of the world (Thirds), an element of representation seems inherent to our cognition. It would seem, in fact, that this symbolic element must be "digital" in Wilden's sense, in that it provides a stable, discrete representation of general aspects of the world while permitting us also to speak of particular things and persons (Seconds) and feelings and esthetic qualities (Firsts). As Peirce would say, it is only because we use the lower "iconic" and "indexical" forms of signs that symbols emerge as possible ([1], p. 115). The 
meaningfulness of symbols stands on their foundation. Peirce's pragmatic theory of meaning analyzes the meaning of concepts as generalizations of expected experience, which would have to take the form of indexes and icons ([1], 272-273. There Peirce seems to deny the iconic element, but if we understand the relationship between indexes and icons in his understanding, an iconic element is inseparable from indexes).

So where does that leave Wittgenstein's conception of language as a collection of recipes, inextricably linked to our "embodied" ways of living? In reality, Peirce's theory is very close to it. Words are only meaningful to the extent we have "interpretants" for them, which are our habitual and fallible ways of seeing things as we consider signs [14].

\section{Implications for free will}

Another contribution in the same volume is "The Illusion of Free Will and its Acceptance" by Giuseppe Trautteur ([15], pp. 191-203). The purpose of the article is argue for what he calls "double feel" ([15], p. 199), the apparent truth that people can be both convinced that they have free choice and realize theoretically that there is no evidence for free will. He talks at length about the scientific evidence for free will and concludes it is not there. He even cites the experiments published by Kornhuber and Deecke which showed that neural commands initiating action precede our conscious awareness of making decisions ([15], p. 194). While he is aware of the indeterminacy of microscopic quantum events, he is convinced that macroscopic events are strictly determined by natural law ([15], p. 193).

Trautteur expresses a great deal of sorrow about this and says it cannot help but undermine ethics and religion ([15], p. 200). Why are we creatures that seem to insist on this illusion? Trautteur entertains the proposals of Clore and Damasio that we are born with "markers" for "cognitive feelings" such as the sense of volition ([15], p. 198).

To respond to this I would like to go back to something I mentioned at the beginning. Peirce criticized necessitarianism for denying that there is any increase in diversity in nature. Natural laws just rearrange the preexisting diversity. $\mathrm{He}$ thought this idea was intolerable for any view of the world that attempted to understand creativity in any sense. Firstness is manifested in the variety of the world, and perhaps one could even argue that "internet addiction" is somehow dependent on it. To borrow a phrase from Dreyfus, a person addicted to online content is not "detached and computer-like" ([7], p. 33). Our ability to get addicted appears to depend on computers showing us interesting things, and this depends on diversity. Without Firstness, the internet would be a bore. Especially with the development of the World Wide Web, digital computers can convey analog information like sights and sounds. They are not just for number crunching or word processing.

Peirce's theory was that lawfulness (Thirdness) was growing in the universe. As he says:

At present, the course of events is approximately determined by law. In the past that approximation was less perfect; in the future it will be more perfect. The tendency to obey laws has always been and always will be growing. ([1], p. 358).

Perhaps we can move away from a focus on proving what determines each of our actions and consider the possibility that creativity itself is the best evidence of indeterminacy. Purely "free" choices do not have to happen constantly as long as they can happen at times. 


\section{Computer algorithms and determinism: a case study}

In a July 7, 2019 article in the New York Times, Patrick Berlinquette writes of his experiences using “The Redirect Method," a program targeting Google searchers with ads to influence searchers' behavior [16]. He acknowledges that marketers like himself profit by "exploiting impatience and impulsiveness," but he wants to show online ads can do positive things, too. "Redirect" gives counter-messages to a person's apparent interests. Berlinquette experimented on influencing two groups of troubled people, those who were suicidal and those who might become mass shooters. He was helped in setting up the programs by the experience of the National Suicide Prevention Lifeline and the Redirect Method's experiences reaching out to ISIS sympathizers. The ISIS campaign provided Google with a blueprint that shows, step by step, how to create redirect ads to influence people. Google has a suicide algorithm, but it has gaps he attempted to fill. He says he would measure the success of his algorithm by how many people clicked on his ad and called the number on his web site, linked to the national helpline. There was a similar link for people who seemed interested in perpetrating shootings.

He was quite successful with suicidal people but not with shooters. With the first, the "conversion rate," the rate of people responding, was $28 \%$ compared with the usual Google rate of $4 \%$. With shooters, the success rate was low, though he does not give an exact percentage. Why would the success rate be different for the two groups? My guess is that it is not due to some flaw in his mass shooter algorithm, but because the desires of the two groups are different. Suicidal people usually want help. If someone reaches out, they will respond. People considering mass murders are not interested in talking to anyone, or at least the chance of their wanting to is much less. The explanation lies in their inner desires rather than some external manipulation. In Peirce's terms, it is Firstness, not Secondness or Thirdness.

\section{Conclusion}

The 1975 film The Stepford Wives depicts a wealthy suburb of New York, Stepford, where wives appear to be unnaturally obedient to their husbands [17]. One wife moves to Stepford with her husband and gets progressively more worried the longer she is there. Every now and then, one of her friends suddenly changes to this unnaturally "submissive" personality. While it is a horror film, it's difficult not to laugh when the women suddenly change. In real life, no one changes that way, even gradually.

I believe the analyses laid out by Peirce, Wilden, Deleuze, and Fazi make it highly doubtful computers can actually change our values. The most they can do is take advantage of desires we already have. Under their influence, we will do some things we would not otherwise have done, but our basic personal orientations will remain intact.

\section{Thanks}

I want to thank John Meador, Dean of UAB Libraries, for funding this project. Thanks also to my colleagues Laura Simpson, Kevin Hébert, Linda Burrow, and Dorothy Ogden for encouragement and help. I no longer work with them, but Valerie S. Gordon, Scott Plutchak, Susan Matveyeva, and Nancy Deyoe also deserve thanks. Finally, my learned late friend Lee Lowrie and Dr. Marge Steiner deserve praise for making my work possible. 


\section{Author details}

Ted Gemberling

University of Alabama at Birmingham, Birmingham, Alabama, United States

*Address all correspondence to: tgemberl@uab.edu

\section{IntechOpen}

(C) 2019 The Author(s). Licensee IntechOpen. This chapter is distributed under the terms of the Creative Commons Attribution License (http://creativecommons.org/licenses/ by/3.0), which permits unrestricted use, distribution, and reproduction in any medium, provided the original work is properly cited. (cc) BY 


\section{References}

[1] Peirce CS. Philosophical Writings. New York: Dover; 1955

[2] Wilden A. Analogue and digital communication. In: System and Structure. London: Tavistock. 1972:155-195

[3] Wilden A. System and Structure. London: Tavistock; 1972. pp. 267-268

[4] Von Neumann J. The Computer and the Brain. New Haven: Yale University Press; 1958

[5] Dreyfus HL. Alchemy and Artificial Intelligence. 1965. p. iii. Available from: https://www.rand.org/content/dam/ rand/pubs/papers/2006/P3244.pdf [Accessed: 21 July 2019]

[6] Dreyfus HL. Alchemy and Artificial Intelligence. p. 33

[7] Dreyfus HL. On the Internet. 2nd ed. London: Routledge; 2009

[8] Fazi MB. Digital aesthetics: The discrete and the continuous. Theory, Culture and Society. 2019;36(1):3-26. DOI: $10.1177 / 0263276418770243$

[9] Leidlmair K. After Cognitivism: A Reassessment of Cognitive Science and Philosophy. Dordrecht: Springer; 2009. p. vii

[10] Harré R. The second cognitive revolution. In: Leidlmair K: After Cognitivism. p. 181

[11] Dreyfus HL. How representational cognitivism failed and is being replaced by body/world coupling. In: Leidlmair K: After Cognitivism

[12] Collins HM. The new orthodoxy: humans, animals, Heidegger and Dreyfus. In: Leidlmair K: After Cognitivism
[13] Deacon TW. The Symbolic Species: The Co-Evolution of Language and the Brain. New York: W.W. Norton; 1997

[14] Gemberling T. FRSAD, semiotics and FRBR-LRM. Cataloging and Classification Quarterly. 2016;54(2):138-139

[15] Trautteur G. The illusion of free will and its acceptance. In: Leidlmair K: After Cognitivism

[16] Berlinquette A. I used Google ads for social engineering. It worked. New York Times. 7 July 2019. Available from: https://www.nytimes.com [Accessed: 23 July 2019]

[17] The Stepford Wives [Internet description]. 1975. Available from: https://www.imdb.com/title/ tt0073747/?ref_=nv_sr_2?ref_=nv_sr_2 [Accessed: 23 July 2019] 


\title{
'Evolutionary Stories': Narratives as Evolutionary Tools to Describe and Analyse Animal Behaviour and Animal Signals
}

\author{
Gabriel Francescoli
}

\begin{abstract}
Animal communication studies, and Ethology itself, deal with the analysis of behaviour in a way that can be understood as an analysis of signal sequences, mainly from a qualitative point of view. Thus, the main goal of behavioural analysis is to interpret the 'semantic' content of behavioural sequences and communicative signals. Considering these analyses as narratives to be interpreted, then hermeneutics, narrative schemas and structuralist techniques could be applied. Here, I propose that in fact when exploring and decoding animal behaviour sequences, we should use narrative analysis and biosemiotic techniques to interpret a type of information processing most effective in evolution, which could be called the analysis of 'evolutionary stories'. Moreover, I think we do exactly that, but do not acknowledge it because is not considered 'hard science' (no maths involved). Nevertheless, this type of analysis seems to be the more flexible and appropriate way to interpret animal communication signals and systems, and also to interpret any general behavioural sequence, because it is mostly based on the cognitive capabilities of the involved species. This chapter will argue about the need for a re-evaluation of a cognitive and biosemiotic interpretation of behaviour and communication signals as central to biological behavioural analysis.
\end{abstract}

Keywords: behavioural analysis, narrative analysis, sign analysis, semantics, biosemiotics

\section{Introduction}

One of the more interesting issues of trying to describe and understand the behaviour and, even more important, the communicative messages of animals is the need for capturing the meaning of the messages in whole before analysing them in their constitutive parts. The process, from a scientific point of view as well as from a layman's point of view, implies the capability of observation in detail and as a whole, and also the capability of a certain empathy for the animal we are observing. This empathy is, obviously, helped by the higher proximity we have with the organism we are trying to understand, and this proximity depends not only in our proximate relationship with them in the zoological scale or 'tree', but also in the similarity of the communication channels we use to exchange signals (or information): 
the more channels we have in common, the more opportunities we have to grasp the sense of the communicative signals emitted by the observed organism.

When we do this kind of analysis with the goal of understanding the behaviour of an organism, or more specifically its communication signals, we tend to use an approach that could be identified with the hermeneutics of text analysis. We use an approach similar to that of the hermeneutic circle, in the sense that we try to understand the behaviour or signal as a whole in relation to its constituent parts, and the parts in relation to the whole. It seems to me that, in doing so, we use an interpretive (hermeneutic) approach, closely related with narrative analysis, more than a mathematical approach. This is probably due to the fact that we are trying to understand the meaning of a behavioural chain of acts or signals, and not the mechanics of the chain construction itself. Indeed, the mechanics of chain construction should (and probably will) be influenced by the meaning-making process involved in the process of chain construction, because of an issue of order: the need for building a clear succession of behavioural units or information elements constructing meaning that constrains the possibilities of sequential ordering, because in general no aleatory order is good for the task. If it is mathematically true that an equal probability in occurrence of signals can deliver the maximal quantity of information in a communication (at least, in a binary system), biological entities tend to favour construction rules and redundancy to ensure communicating the needed message and meaning against 'noise' [1].

Interpreting a sequence of behavioural acts is a process closely related, if not the same, to interpreting signals, even if the behavioural sequence is not communicative in itself, at least in the 'intentional' sense. The fact is that we humans (and more specifically, scientists), 'read' the sequence from an outsider position, trying to interpret it and to understand the 'story' the animal is telling with its behaviour. In doing so, scientists could be (and in many ways are) assisted by mathematical tools and technical devices helping our analysis capabilities, but the ultimate resource is our brain and our interpretive methods. This view is supported by Cognitive Linguistics, as the discipline assumes that our interactions with the world are mediated through the use of informational structures in the mind [2].

Even if it has been proposed that there are two different modes of thought-a narrative one directed to think about human action, and a paradigmatic mode to think about natural science and mechanisms-we know that scientists are not restricted to think about problems using only mathematics, experiments and diagrams, but that they also use narratives [3]. Understanding a story implies to examine the possible planning processes running under the story backwards, trying to find explanations about the agent's goals and plans for actions and events that we can identify in the story [3]. Indeed, as animals are far from being optimal, mathematical models of optimality are not always very useful for the task of extracting meaning from a chain of behaviour (and its context of production) and, at the same time, for evaluating the cognitive capabilities of the organisms using those signals.

I think that, in essence, when we humans interpret or read a behavioural sequence or signal from an animal of other species, in fact we try to extract meaning of those sequences in the same way as when we read a story or watch someone performing a narration. We mostly evaluate the meaning of the behavioural acts disregarding any considerations about the physical ways of the narration or their physiological characteristics; we try to understand, and also to extrapolate into the future the information gathered as a way to predict future behaviours of the subject(s). Probably many animals do the same in their heads. Those behavioural chains we read as signal sequences are what I call behavioural narratives or stories, and once they are interpreted, compared and systematized, we can say we have read evolutionary stories. 
Thus, the goal of this chapter is to think about our ways to tackle the analysis of behavioural chains, and to show how, when doing this kind of analysis, we are nearer to a narrative analysis than to a 'hard science' mathematical approach. As I said before, we are in fact discovering or telling 'evolutionary stories', and working with its semantics, pragmatics and syntax.

\section{Narrative analysis as a parallel way to interpret behaviour}

Barthes [4] proposed a method of analysis of narratives considering the sequential analysis of narrated actions and/or facts, and thought to be used into film or literary analysis fields. Briefly, the proposed analytic method was presented as the structural study of a narration - series of sentences - in order to describe it as a system of meanings, and revealing the narration from two points of view: the story, through an examination of the logic of actions and their sequential order or syntax, and the modes and times of the narration (the discourse). To understand a narration implies the (witnessed) unfolding of a story, in our case a behavioural or evolutionary story, but also the recognition of a narrative sequence, and to travel between the levels of story and discourse.

In her book about narrative analysis, Kohler Riessman [5] proposes four possible modes or approaches to the analysis: thematic analysis, structural analysis, interactional analysis and performative analysis.

Thematic analysis puts its emphasis on the content of a text (message), on what is told, and mostly uses a typology of narratives organized by theme [5].

Structural analysis of narratives puts emphasis in the ways a story is told. Even if thematic content is not disregarded, focus is put equally on the form or in which narrative devices a 'storyteller' uses and how the narrative is achieved. In this type of analysis, the importance of language (or signalling) and its referential content is high [5].

Interactional analysis emphasizes the analysis of the dialogic process between teller and listener (emitter and receiver) [5]. This kind of narrative analysis is specially suited for situations in which the 'storyteller' and the 'questioner' participate in a conversational type of exchange while constructing a narrative. While there is no dismissal of thematic content or narrative structure in this approach, the emphasis is put on storytelling as a process of co-construction [5], creating meaning in collaboration between teller and listener (that could, obviously, exchange places). In animal communication, this approach could be paralleled to the study of duetting, both in song or sound emissions as well as in visual display exchanges in sequence or chains [6], or even in communication through choruses. All these processes can enhance information transfer and meaning-making in animal signals.

Performative analysis [5] goes beyond interactional analysis, and the exchange is seen as a performance, as a narrative praxis that could be interpreted as a form of social action. This view is suggested by Kohler Riessman [5] as appropriate for studying communication practices and for detailed studies of identity construction. In humans, this can be applied to theatre and their ways of narrative, but trying to devise a parallel use of the concept in animal communication, it can be thought that this kind of 'identity construction' could be utilized by emitters while cheating, in the sense that they are 'performing' to try to convince receivers of some lines of action or situation evaluations that are not 'real', allowing the emitter to take advantage over the receiver.

As Kohler Riessman [5] says in her paper, structural analysis approaches need the examination of syntactic and prosodic features, thus this is not a type of analysis suitable for large numbers of data but very useful for detailed case studies 
and comparisons. This type of analysis can help build theories relating language (communication, behaviour) with meaning. Indeed, this author highlights that "The "truths" of narrative accounts are not in their faithful representations of a past world, but in the shifting connections they forge among past, present, and future' [5].

The analytical system proposed by Barthes [4], the one we use as a base here, is mostly of a structural kind, but contains - as far as I can say-at least some elements of the interactional type of analysis referred to above. In his paper, Barthes [4] defines a narrative as 'an organization based on relays, whose basic units can be no other than a small group of functions, which will be referred to as a sequence (in conformity with Bremond's terminology)'. In the same paper, a sequence is considered as 'a logical string of nuclei, linked together by a solidarity relation: the sequence opens when one of its terms is lacking an antecedent of the same kin, and it closes when another of its terms no longer entails any consequent function' [4], this being very similar to the behavioural analysis of sequences. If we add to these descriptions the idea that for working with sequences they need to be named (i.e., 'struggle', 'seduction', etc.), it shows that sequence analyses in narrative and in behaviour are much alike. Indeed, Barthes [4] considers that the receiver of the narrative (reader, listener, observer), while apprehending the sequence surely nominates it at least internally, and in its own way of 'thinking', depending on the species involved in the communication process.

Barthes [4] also proposed the use of three levels of description as a way to understand a narrative: the level of functions, the level of actions and the level of narration. Functions are the basic narrative unit, and should have a specific functionality in the corpus of the narration. Functions usually integrate into sequences, and those sequences make up the capital part of a narration. Actions are used to describe the characters that act in the narration, characters that are defined by what they do, by their role in the narration: receiver, sender, opponent, helper, etc. Narrations, looking at the literary process, always have a narrator and a reader, and define the code providing meaning to both narrator and reader (or, in biological terms, sender and receiver). These levels are to be viewed as a top level (narration), a middle level (actions) and a bottom level (functions). This bottom level is composed of two 'sub-levels': distributional functions (or simply functions), composed of cardinal functions or nuclei and catalysers, and integrative functions, composed of indices (that relate to character, feeling, etc.) and informants (that identify and locate in space and time).

A narrative is, then, made of functions (functional units) and, as Barthes [4] says, everything in the narrative is significant and every unit in the narrative fulfils a function and occupies a place in the chain for a reason. Functions are then the basic pieces of a narrative, and can then be paralleled to the behavioural units used in ethological sequence analysis. Thus, in ethological analysis, behavioural units have also a function and they are, usually, functionally related both to the one before and the one after it. In that sense, the act of interpreting behavioural sequences appears more as a semantic and interpretive kind of problem than one of the 'numerical' kind, even if in Ethology we can use algorithms (i.e., Markovian processes) to search for a certain order and repetition degree on a behavioural sequence's constitutive units.

In essence, behaviour is depicted through the use of ethograms based on the definition of behavioural units that compose them, those tools being the most used to describe the behavioural 'narrative', being also an 'evolutionary story', as said above, we can consider this type of behavioural description/analysis as similar to the narrative analysis proposed by Barthes [4]. If that is the case, the use of basic units of behaviour in behavioural description could be paralleled to Barthes' 
structural analysis $[6,7]$ if we accept that in ethology the narrative-the continual 'production' of behaviour by a living being-should be divided into units in order to analyse it and to approach an interpretation. These behavioural units are arbitrarily defined by the user, and their definition is based on the user's interpretation of their function and significance, acquired through observation of the whole behavioural sequence and its relation to its parts, their meaning and their order in the behavioural sequence under study (sort of a semantic processing of information), like in an hermeneutic circle [8].

As Barthes [4] discusses, narratives-because of their structure-tend to provoke a confusion between consecutive order and consequences, between time sequence and logic. This is because narrative logic accounts for narrative time, then the need for memory (cognitive memory and/or genetic memory, in biology) to put to use the narrative for communication purposes, because the belief in time as a guiding line is based on the mechanisms of memory and combinatorial discourse.

The process of behavioural analysis of sequences is then almost identical to Barthes' narrative analysis [4], considering the analysis of a narrative as the determination of different levels or 'strata' in the sequence, these levels being divided into units, and units being determined by meaning as the main criterion of analysis. The units, especially those translated into certain types of behaviour in a repeated way, can be interpreted as sub-narratives or sub-chains, acting as subordinate narratives or 'cycles' in the sequence arrangement. Repeated functions could be used to identify a 'character', characters representing types of actions making up the narrative.

The level of actions is the middle level of description that refers to characters and their participation in the narration. Characters are classified in narratives not by way of their psychology, but mostly by way of their participation in actions (i.e., communication, desire, struggle, etc.), and in biology by their role in a population or deme. Usually, actions have two sides that link actants together, like in Emitter and Receiver.

Repeated arrangements or units describing certain behavioural acts can identify 'behavioural syndromes' [9] in ethological analysis, characterizing the behaviour of certain individuals in the population, in a similar way as narratives do with some types of characters in the level of actions. Barthes [4] proposes to use these repeated actions (indices) to evaluate how certain functions contribute to character building in narrative analysis, while in behavioural analysis those syndromes contribute to the characterization of some types of behaviour-possibly also extrapolating to other areas of behaviour-in the same subject.

Processing information gathered from a chain of behavioural acts performed by other (living) subjects-in the same way other living beings do for themselvesleads to partition the chain of actions for the sake of better understanding. This is mainly an unconscious act (exception made, probably, of a scientific description), an innate act of interpretation, using our own decoding capabilities. When doing this, we are decoding a narrative.

We are then processing a chain of behavioural units or signs, analysing them and trying to interpret its significance. In fact, the observer is interpreting the chain of behavioural units (movements, etc.) as a 'narrative schema' that allows the perception or the interpretation of intentional movements or signals (probably the core of what Barthes [4] called actions) that guide to a goal [10]; thus, in doing the already mentioned hermeneutic circle interpretation of behaviour, the observer is processing a narrative in the same way we do with a verbal chain of signs when trying to interpret what another person is trying to say.

Understanding a sequence of behavioural units implies understanding the logic of the behavioural chain and at the same time the interpretation of the signs those 
behavioural units represent for the receiver or interpreter, thus understanding the narration. Bremond's ideas [11] about narrative analysis established that the logic behind the narratives' study relies on following the 'choices' made by the subject. It seems that, essentially, we can see this as a similar interpretation or hermeneutic process as the one used in behavioural biology when analysing decision-making or (even) meaning-making processes in animal subjects. Through this analysis, interpreters probably make a widespread use of the abductive syllogism referred to by Peirce [12]. Abductive guesses '..are not always correct, but they are correct far more frequently that would occur by chance' [3]. As abductive inferences are composed of two elements, an observation and a base of relevant knowledge [3], it enables the use of information 'included' in actions described as a narrative schema [10] allowing the interpretation of those actions.

The structure of the narrative sequences enhances the interpretive possibilities of receivers/interpreters because, as signalled by Barthes [4], the different levels of narrative construction and analysis are bonded together towards a progressive integration. Thus, a function has a meaning only if it takes place during the general line of action of an actant and the action performed displays its meaning when it is included into a narrative or discourse utilizing its own code.

Sequences have certain points of choice, called 'dispatchers' by Barthes [4], and these points are those in which, biosemiotically speaking, freedom of meaning could be introduced. So, from this perspective, a sequence is a 'potentially incomplete logical unit' [4], rooted in the actual context, and in need of interpretation. This interpretation, through an hermeneutic analysis that takes account of the context situation, external information and other concurrent pieces of information, could transform the 'incomplete logical unit' into a complete logical unit meaning something to a receiver/interpreter of an ongoing behavioural reality [13]. The use of external information to decode/interpret the narrative (signal or behaviour sequence) was acknowledged by linguistics when considering situations; these situations can be understood as the facts known by the receiver at the moment of the semic act, and being independent of this act [4]. In animal communication studies, these situations could be interpreted as the use of previous probabilities in a certain communicative situation, contributing to the context of the communication and the possibilities of decision-making by the subjects.

In behavioural analysis, sequences can also be analysed as units, and play a role as a simple term in another sequence. This characteristic allows the use of different (highly arbitrary, subjectively defined) units, that can be represented by 'minor' behavioural sequences acting as units on a higher level sequence, when parsing a behavioural continuum in an ethological study. This process is basic in behavioural analysis, and is highly dependent on 'sign' interpretation (decoding) by the receiver/observer, while also independent of mathematical/statistical analysis [4, $14,15]$, exception made of some grouping and sequence detecting algorithms.

The described levels [4] are bonded together using a progressive integration modality in which each function has meaning only if is integrated in the line of action of an actant, and this action takes its definitive meaning because it is being told/emitted as a part of a discourse/narrative.

\section{3. 'Reading' behavioural/evolutionary stories}

Writing about Darwin and Biosemiotics, Markoš et al. [16] said 'Thinking in terms of stories seems to be a type of 'information processing', which became most effective in evolution., alluding in this way to information managing by means of interpretive-hermeneutic - thinking, as a cognitive process. This process 
does not (necessarily) involve the use of formal mathematical or physics thinking or modelling. Recent papers propose that at least some animal brains evolved mathematical and geometrical capabilities without the need for theoretical developments $[17,18]$ but do it mostly in an holistic and intuitive way. Other studies suggest that mathematical capabilities and processing are somehow separated (in the human brain at least) from the semantic processing [19]. These authors suggest that 'the behavioural dissociation between mathematical and linguistic skills is accompanied by a major neural dissociation between math-responsive brain regions and other areas involved in language processing and semantics. Such a clear-cut separation may explain why acquired or developmental mathematical impairments often leave other aspects of language processing and comprehension untouched, or vice versa', implying that the processing systems for these two kinds of information or 'languages', even if loosely connected, are different in essence [19]. Indeed, science uses modelling and computerized simulation studies for analysing some hypothetical interpretations of reality (like animal behaviour, that is the reality we are concerned with here), while narratives are not necessarily descriptions of actions but simulations of actions running on the mind of the interpreter or 'storyteller' [3]. All the previously mentioned papers and other related evidence lead us to think about what are the real processes animal brains perform to analyse behaviour and communicative messages.

We cannot describe here a complete view of brain functioning, but in a general way we can say that nervous systems are basically organized in three systems: receiving systems (the perceptual components), response systems (the motor systems acting through muscles and skeleton, and the glands mediating hormonal response) and integrative areas (integrating, combining and comparing different streams of information, linking organs and reactions and acting as modulating systems for behaviour production) [20]. Neurons in different centres are charged with the analysis of information patterns and the decision-making for complex responses, in a way similar to that proposed by von Uexküll [21] in his functional circle model, with representational systems acting in a way that enables categorization and analysis of information (at least in birds and mammals) [22, and references therein]. In fact, as animal behaviour seems to be detected and analysed as patterns in the same way signal chains are analysed by animals, the idea of a process resembling a narrative analysis $[4,22,23]$ pops-up as a theoretical issue relevant for the practice of interpreting animal behaviour, a practice that seems to have been present in the methods used by classical ethologists [6]. These patterns or chains of signals are communicating meaning to the receiver/observer (the receiver being another animal of the same or other species, and the observer being a scientist) in the same way a narration, text, film, etc. are delivering meaningful contents to their receivers.

If we examine the statement by Markoš et al. [16], we can see that hermeneutic procedures (analysis of meaning and interpretation) are probably more powerful and evolutionarily developed than a supposed (and always collateral) mathematicalphysics analysis of the signalling concatenation. This is the way we, as a species, look at the world and take in information for analysis, and that is the scenario in which our lives and our evolution as a species have developed, and the one we have to act on and make decisions about. Cognitive Linguistics seems to support this view because one of their general concepts establish that linguistic (semiotic?) knowledge involves knowledge of the language but also knowledge of the world as mediated by language [2], thus the fundamental idea that communication (and labelling and naming) constitute the meaning-making process for our interpretation of the external world, a construct depending on our senses and information processing which allows our capability of (inter) acting towards the outside of our bodies. 
Probably, this is also true for other animals, even for all animals if we take in and examine the theories and interpretations of animal behaviour and sensing put forward by von Uexküll [21] with his Umwelt concept and his representation of the 'functional circles' intertwining animal perception and action.

I recently [13] tried to show that spontaneity in behaviour, using the definition by Tinbergen [6], could derive from the unpredictability introduced by triads and chains of triads in the process of meaning-making and interpretation argued by Peirce [24]. The previous mentioned concepts can be related because ethologists used the concept of spontaneity when describing the source of behavioural acts controlled by the Innate Releasing Mechanism, conditioning the behavioural output of an organism. Spontaneity would be introduced by the triadic relation between Sign Stimuli, Innate Releasing Mechanism and Modal Action Pattern, when coupled with other triads. This concatenation of triadic relationships could reveal some spontaneous interpretations of signs that can be facilitated or monitored by the process of triadic concatenation itself [13]. The mentioned new 'interpretations' could intervene in the process of meaning-making by producing (spontaneous) new signs for a situation, then, the relationships become 'stable' for the users, especially if new signs are responded to by receivers with an appropriate behaviour [13] These chains of triadic relationships also originate a spontaneous and continuous behavioural output that could be considered as a narrative to be sensed and interpreted (described) by the receiver/observer (interpretant). The behavioural output becomes a narrative, sort of a 'novelization' descriptive of the active life of a subject, because animals behave from their birth (or before) until their deaths, proffering a continuous chain of actions [13].

As Barthes [4] explains, the structure of a narrative functions as the structure of a musical fugue in the sense that, before a sequence is completed the initial term of a new sequence could be introduced, so the narrative pulls in new material while holding to previous material, and for our biological narrative model this implies the capability of the system to derive new actions and to create evolutionary novelties [13].

It is clear to me that this is related to the notion of 'narrative schema' [10] in the sense that actions of an actant are informative about its meaning because of the interpretation a receiver makes when sensing the sequence of events or units (functions). As Bundgaard [10] puts it, narrative schemas are '...a major principle for the combination of partial significations...' in many domains. The receiver/interpreter (especially if human) could attribute intentionality to movements and, as established by Bundgaard [10], attributing intentionality to a being is considering that being moving according to a micro-narrative program, with acts that are purposeoriented. These interpretations occur through the use of an empathic process that allows interpreters (receivers) to attribute meaning to displays and movements in an integrated chain of behaviour, mostly based on the general knowledge of the actant's behaviour and on the context in which that behaviour is expressed (including its Umwelt). This is crucial for the capability of using behavioural/evolutionary narratives to interpret animal behaviour and communication.

In this matter, it is important to consider Lakoff's ideas [25] about why hypotheses built with complex metaphors (empathic thinking and narrative schemas' embedded information interpretation) cannot be directly falsified. They could only be rejected based on interpretations of empirical observations guided by other complex metaphors, because falsifiability itself cannot be established by any method that would not rely ultimately on a shared human bias: the set of conceptual metaphors governing how people interpret observations (like narrative schemas, empathy, gestaltic processes in sensory input interpretation, and so on). These arguments could be seen as an extension of the 'embodied cognition' argument sustained by many philosophers and scholars, Lakoff included, arguing that minds 
(human mind at least) are embodied, and cognition processes are rooted mostly on 'low-level' body functions like the sensorimotor system and emotions. In addition, for cognitive linguistics, human reason is determined by our organic embodiment and by our individual and collective experiences [2] relating, at least from my point of view, these ideas to von Uexküll's functional circle and Umwelt [21] concepts, as ways to interact with the external world generating 'experiences' and allowing categorization in functional communication.

The above-mentioned interpretive processes are to be assumed as cognitive processes built in evolution, thus not necessarily included in all animal species' toolbox, because as Bundgaard [10] puts it '...recognizing movements as intentional is tantamount to recognizing basic narrative programs,.... Then, narrative schemas could be not only considered as high-order syntax processes but also as '...highly significant meaning gestalt... [10]. As this author [10] stresses, if narrative schemas are essential cognitive gestalt with meaning value, we should expect them to organize meaning in many domains, especially in relation to structures with 'intrinsic signification': morphological features interpreters/receivers specially pay attention to. Let me cite Bundgaard [10] again to clarify this point: 'The idea we expose in our article is that if in a XY-compound, the Y-term evokes some idea of purposeful action or functionality, then the X-term will specify one of the constitutive elements of a purpose-oriented process, i.e., it will take on one of the actantial roles available in the narrative schema [e.g. positive purpose (what should be obtained or furthered), negative purpose (what should be prevented), subject in charge of realizing the purpose, instrument, raw material, result (insofar as it differs from the intended result)]'. All these roles can be represented by signals or behaviours in animal behaviour sequences or communication signal sequences, thus allowing us to think that, at least in many species, we can consider narrative schemas to be applicable in interpretation from the point of view of interpreters, receivers and/ or observers, and meaning-making processes probably to be involved in message or behavioural sequence construction from the point of view of (not necessarily intentional) emitters/actants.

It is also clear that many of the behaviours used by animals-including humans, obviously-are spontaneous responses to a combination of external stimulation and internal motivation, both contributing information to a decision-making system. The decision-making system that weighs the inputs to offer an output is often an unconscious mechanism, responding to evolutionary rules that tend to preserve certain 'values'.

In that sense, Kaplan et al. [26] have shown (for humans) that narratives can support what they call 'protected values' that are non-negotiable for users, can transcend logic or rational choice models, and also transcend cost-benefit considerations. This information derived from human subjects studies can eventually be extrapolated to animal communication systems if we accept that there could be 'protected values' embedded in animal signs. These protected values should refer to survival issues and/or highly valuable behaviours, and can put 'out of order' many models of behaviour based in 'economical' cost-benefit paradigms.

This same study [26] shows that reading about protected values leads to increased use of brain parts related to semantic rule retrieval, because those protected values reveal fixed principles (originally fixed—or modal—action patterns? [6]) rather than (unconscious) calculations of costs and benefits. This could mean that, all processes being similar in non-human animals, there are some behaviours that could have 'fixed' or 'innate' elements of interpretation, especially if behaviour is seen as a narrative.

Kaplan et al. [26] also mention that there is evidence from human studies that points to the intervention of some brain zones related to: social cognition, internally 
directed processing, self-directed processing, and 'mental time travel'. These zones are activated when individuals deal with narratives involving the above-mentioned 'protected values'.

Then, some brain regions activate when social emotions and moral dilemmas are present, and those regions are the suspects of playing a critical role in representing complex emotions dependent on the knowledge of social conventions. These studies were performed in humans [26], but nevertheless we can wonder if similar processes could operate in other animals' sign evaluations. Indeed, these brain regions activated when social emotions and moral dilemmas are present could be also activated-in a 'mirror neurons' sort of way-when processing information or judging attitudes and behaviours of their species, helping and/or biasing our interpretations. The above-mentioned facts and interpretations could be taken as evidence, or at least as a probability, that our brains and the brains of other species are prepared (probably pre-wired) by evolution to process information acquired through their senses and interpret it with the aid of an emotional (empathic) and natural (external) framework, as when interpreting a narrative or a story, mainly pointing to meaning interpretation through a sort of (if not a real) hermeneutic process. Possibly this kind of processing is not optimal (as some of our theories-wrongly, from my point of view-seem to model) but are more real and more naturally 'unpredictable', better describing biological reality; they are 'evolutionary stories'.

Bundgaard [10] supports that narratives we compose from our observation of other subjects' behaviour are not arbitrary, because not any pattern of movements can trigger an 'acceptable' interpretation (for the meaning-making system of the interpreter) except if they are temporally correlated in a specific way. If the right temporal correlations are presented in the sequence of units proffered by an emitter, a narrative 'scene' is built, and the information contained in it could be perceptually extracted constituting (or at least appearing as) goal-oriented actions. These facts imply, at the same time, that some (intentional or probably intentional) actions seem to be built through characteristic modes or styles of 'presentation' allowing a sort of direct perception of intentionality or causality that will end, depending on its range of action, in a meaning-making process for the analysis of behavioural sequences or 'evolutionary narratives'.

\section{Conclusions}

Taking all the previous arguments into account, we can examine many of the parallelisms existing among classical behavioural analysis [6] and narrative (structural) analysis [4] that lead to assume that when describing and interpreting animal behaviour and/or communication, we are, in fact, telling (reconstructing) 'evolutionary stories'. Importantly, the fact of telling stories does not mean that our interpretations of animal behaviour obtained by these methods/means are not scientific, because the capability of understanding behaviour and signals of animals in a scientific way does not depend on the higher or lower level of mathematical formality of the description or interpretation, but on the ability to understand/ decode the information present in the 'stories' animals tell through their behaviour, and in the contextualization of those stories through hermeneutic analysis.

The idea of Umwelt introduced by von Uexküll is fundamental in our possibilities of interpreting animal behaviour and animal signals [27]. This is because, the capabilities of meaning-making in a signalling system each species has depend on their sensory capabilities, and the relationship between perception and actionhighlighted by the Umwelt concept - is related to their sensory abilities (also part of the Umwelt). In a similar way to what Cognitive Linguistics does essentially for 
humans only [2], biologists (supported by the 'narrative' view here expressed and by the concepts taken from von Uexküll's work) should study the communication systems and behaviour of animals as if they were 'grammatical' phenomena whose characteristics are determined by a combination of internal (structural and motivational) and external (biological and non-biological) contextual factors.

Then, we need to have a similar Umwelt to that of the species being studied (or at least some means to access the sensory capabilities needed if different from our own) to be capable of decoding the information exchanged through animal behaviour signals or narratives.

The preceding argument derives from the idea that the older language of all is the language of life [28] expressed through genetic codes and biological signals, thus through semiosis, a process that is thought to be ancestral to all life, and probably a process that defines life. As Sebeok's ideas of semiosis in nature linked to von Uexküll's concepts relating the internal and external world of animals and their abilities to produce signals, their ideas have developed into a new science initially known as Zoosemiotics, and later theoretically rounded as Biosemiotics.

The argument of this chapter is mainly about the way we should look to animal behaviour and communication if we want to understand what animals do and why, and how they can cooperate and compete, by the understanding of the messages they use and their real meaning. Here I argue that in fact that is what we do, as scientists, because we tend to interpret animal behaviour and signals as if we were reading (or listening to) a story. Thus, the type of analysis we can apply through formal narrative analysis and/or cognitive linguistics analysis to animal behaviour is similar to the way we in general examine the world and our own communication system, and depends on our abilities of interpretation and decoding. Indeed, maybe many other animal species use similar 'cognitive devices' (through an embodied type of cognition) to code/decode their communication signals' meaning and construct an image of the external world.

Finally, we can say that the possibility of interpreting behaviour and/or animal signals will depend on our capability to empathize with other species and on our decoding abilities towards the behavioural sequences constituting informational units we can understand as 'evolutionary stories'.

\section{Acknowledgements}

The author wants to acknowledge partial funding for the publication of this manuscript by PEDECIBA (Uruguay).

\section{Conflict of interest}

The author declares that he has no conflict of interest. 


\section{Author details}

Gabriel Francescoli

Ethology Section, School of Sciences, UdelaR, and PEDECIBA Biology,

Montevideo, Uruguay

*Address all correspondence to: gabo@fcien.edu.uy

\section{IntechOpen}

(c) 2019 The Author(s). Licensee IntechOpen. This chapter is distributed under the terms of the Creative Commons Attribution License (http://creativecommons.org/licenses/ by/3.0), which permits unrestricted use, distribution, and reproduction in any medium, provided the original work is properly cited. $(\mathrm{cc}) \mathrm{BY}$ 
'Evolutionary Stories': Narratives as Evolutionary Tools to Describe and Analyse Animal...

\section{References}

[1] Harms WF. Information and Meaning in Evolutionary Processes. Cambridge: Cambridge University Press; 2004. p. 268

[2] Geeraerts D, Cuyckens H. Introducing cognitive linguistics. In: Geeraerts D, Cuyckens H, editors. The Oxford Handbook of Cognitive Linguistics. Oxford: Oxord University Press; 2007. pp. 3-21

[3] Oatley K. Inference in narrative and science. In: Olson D, Torrance N, editors. Modes of Thought: Explorations in Culture and Cognition. New York: Cambridge University Press; 1996. pp. 123-140

[4] Barthes R. Introduction à l'analyse structurale des récits. Communications. 1966;8:1-27

[5] Kohler Riessman C. Narrative Analysis. Vol. 30. Newbury Park, California, USA: Sage; 1993. p. 79

[6] Tinbergen N. Létude de l'instinct. Paris: Payot; 1953. p. 308

[7] Chandler D. Semiotics the Basics. London: Routledge; 2007. p. 307

[8] Oxford Reference. Hermeneutic circle [Internet]. 2019. Available from: https://www.oxfordreference. com/view/10.1093/oi/ authority.20110803095932789 [Accessed on: 27-06-2019]

[9] Sih A, Bell AM, Chadwik Johnson J, Ziemba RE. Behavioral syndromes: An integrative overview. The Quarterly Review of Biology. 2004;79:241-277

[10] Bundgaard PF. The cognitive import of the narrative schema. Semiotica. 2007;165:247-261. DOI: 10.1515/ SEM.2007.042

[11] Bremond C. La logique des possibles narratifs. Communications. 1966;8:60-76
[12] Santaella L. Abduction: The logic of guessing. Semiotica. 2005;153:175-198

[13] Francescoli G. A semiotic interpretation of the innate releasing mechanism concept and other ethological triadic relations. Biosemiotics. 2017;10:461-468. DOI: 10.1007/s12304-017-9306-7

[14] Lehner N. Handbook of Ethological Methods. New York: Garland STPM Press; 1979. p. 403

[15] Bakeman R, Gottman JM. Observing Interaction. An Introduction to Sequential Analysis. Cambridge: Cambridge University Press; 1997. p. 207

[16] Markoš A, Grygar F, Kleisner K, Neubauer Z. Towards a Darwinian biosemiotics. Life as mutual understanding. In: Barbieri M, editor. Introduction to Biosemiotics. The New Biological Synthesis. Dordrecht: Springer; 2008. pp. 235-255

[17] Vallortigara G. Comparative cognition of number and space: The case of geometry and of the mental number line. Philosophical Transactions of the Royal Society B. 2018;373:20170120. DOI: $10.1098 /$ rstb.2017.0120

[18] Zorzi M, Testolin A. An emergentist perspective on the origin of number sense. Philosophical Transactions of the Royal Society B. 2018;373:20170043. DOI: $10.1098 /$ rstb.2017.0043

[19] Amalric M, Dehaene S. Cortical circuits for mathematical knowledge: Evidence for a major subdivision within the brain's semantic networks. Philosophical Transactions of the Royal Society B. 2018;373:20160515. DOI: 10.1098/rstb.2016.0515

[20] Ryan MJ, Wilczynski W. An Introduction to Animal Behavior. New York: Cold Spring Harbor Labratory Press; 2011. p. 258 
[21] von Uexküll J. Theoretical Biology.

New York: Harcourt, Brace; 1926. p. 362

[22] Auletta G. Cognitive Biology.

New York: Oxford University Press;

2011. p. 854

[23] Francescoli G. Are verbal-

narrative models more suitable than

mathematical models as information

processing devices for some behavioral

(biosemiotic) problems? Biological

Theory. 2019;14:171-176. DOI: 10.1007/

s13752-019-00323-9

[24] Queiroz J, El-Hani CN. Semiosis as an emergent process. Transactions of the Charles S. Peirce Society.

2006;42:78-116

[25] Lakoff G, Johnson M. Philosophy in the Flesh: The Embodied Mind and its Challenge to Western Thought.

New York: Basic Books; 1999. p. 624

[26] Kaplan JT, Gimbel SI, Dehghani M, Immordino-Yang $\mathrm{MH}$, Sagae K, Wong JD, et al. Processing narratives concerning protected values: A cross-cultural investigation of neural correlates. Cerebral Cortex. 2017;27:1428-1438. DOI: $10.1093 /$ cercr/ bhv325

[27] López-Varela A. Introductory chapter: Semiotic hauntologies of ghosts and machines. In: López-Varela A, editor. Interdisciplinary Approaches to Semiotics. London: IntechOpen; 2017. pp. 3-14. DOI: $10.5772 /$ intechopen. 69858

[28] Barbieri M. What is biosemiotics? Biosemiotics. 2008;1:1-3 


\title{
Assessment of Perception of Physical Environment in the Context of Cognitive Maps and Experiences
}

\author{
Orkun Alptekin and Hasan Unver
}

\begin{abstract}
Experiences in the physical environment awaken different perceptions in different people and enable the formation of an environmental image in people's minds during and after use. The campuses are also the physical environments in which students from different cultural, ethnic, and social backgrounds spend part of their lives during their education. In the formation of the environmental image, it is important that the students choose, organize, and add meaning to what they see in line with their own needs and goals. In this way, the image formed in the minds of the students limits what is seen, while emphasizing what is important according to their own mental orientation. In this context, the students are asked to draw the cognitive maps of the Meselik Campus of Eskisehir Osmangazi University. The obtained cognitive maps are examined, and the image elements used are evaluated statistically. As a result of the evaluation, it is seen that the students emphasize the reference points and the roads first. In this study, cognitive maps of first and fourth grade architectural students were evaluated separately and then compared with each other in order to determine the change of time factor in students' perception and the effect of architectural education on expression techniques.
\end{abstract}

Keywords: cognitive map, urban memory, legibility, architectural education

\section{Introduction}

The physical environments shaped according to the needs of the societies contribute to the formation of different environmental images in their minds by arousing different perceptions in individuals during and after use. The environmental images formed in the minds of individuals may vary depending on the physical, social, and cultural characteristics of the individuals and their experiences [1]. The reason for this variability is that individuals choose, organize, and add meaning to what they see by establishing a personal relationship with their physical environment according to their needs and goals [2]. The image formed in the individual mind limits what is seen, while at the same time it allows some to be seen more. In this context, the perception of the physical environment varies according to time, situation, and people. 
Perception is the interpretation of the sensory data coming from the sensory organs of individuals through a mental process in order to become a meaningful whole [3]. While individuals remain indifferent to some of the data coming from sensory organs, others are interested and curious [4]. In this context, the perception of the physical environment also varies according to the individual's interest, curiosity, and experiences. Even different experiences of the individual over time may cause the individual's perceptions of the physical environment to differ.

Perception, which is one of the main fields of study of psychology, is mostly seen as environmental perception or spatial perception in studies related to city and architecture [5]. Spaces containing physical concrete components become meaningful with the experiences in the minds of individuals and become an abstract image. This abstract image, which emerges as a result of the perception of the individual, helps to create an image and identity of the place in the minds of individuals. The image and identity of the space formed in the minds allow individuals to define, perceive, and use the space. The increase in the experiences and the time spent in the space also contributes to the development of the image and identity in minds [6].

Perception process, symbolic, visual, emotional, and selective perception [7]; or cognitive/mental and sensory perception [8] is classified in various ways. However, these classifications are of similar content, and it is emphasized that the data obtained from the physical environment through the senses are coded, conceptualized, stored, and remembered in different ways specific to the minds of each individual in line with the needs, expectations, and value judgments of individuals. The physical environment containing concrete data is experienced with sensory perceptions and forms the cognitive perception by being shaped in the mind of the individual. The formation and development of cognitive perception is affected by the time spent by the individual in the space, the place in the mind, storage, and remembering the place in accordance with his experiences [5]. In this context, the concretely perceived space that meets the physiological, psychological, and social needs of individuals gains meaning abstractly through experiences in the individual's mind [9].

Architects and urban planners, who are the organizers of space, can influence the process of creating an image of a space-specific identity in the minds of the users, paying attention to the interaction of external stimuli while creating the environmental image. It is the form, color, or arrangement that makes the image of the space vividly identifiable and keeps it in memory for a long time. However, the form, color or arrangement used by architects and urban planners will gain meaning with the perceptions and experiences of the users and will take place in their memories. In this context, researchers used the cognitive maps included in Tolman's [10] study in order to determine the perception style of the places depending on the users' experiences. In cognitive maps, the images that occur in the minds of individuals experiencing and living in the process [11] are expressed by drawing techniques [12]. In other words, it is a way of expressing a psychological process in which individuals process, store, encode, and recall the data obtained from places as a result of their experiences.

On an urban scale, Lynch classified urban images perceived by individuals in five groups as paths, edges, districts, nodes, and landmarks as shown in Table 1. In his study according to these classifications, he states that individuals who experience less space describe regional elements and ways, and those who experience more describe consecutive elements and reference points. In addition, the study emphasizes that the relationship between the individual and the place is in interaction and that identity, structure, and meaning are important in the formation of the image of the place [13]. 
Assessment of Perception of Physical Environment in the Context of Cognitive Maps...

DOI: http://dx.doi.org/10.5772/intechopen.90660

\begin{tabular}{ll}
\hline Paths & Shared travel corridors, e.g., streetscape \\
\hline Edges & Linear and enclosing but not functioning \\
\hline Districts & Large spaces with common features \\
\hline Nodes & Major points where behavior is focused \\
\hline Landmarks & Distinctive features used for reference \\
\hline
\end{tabular}

Table 1.

Categorization features of cognitive maps [14].

In another study supporting Lynch's work, regional type maps with sequential and spatial elements emphasizing paths and consecutive elements are highlighted in the drawing of cognitive maps [15]. Then, respectively, Moore [16], Hardwick et al. [17], Downs and Stea [11], and Herman and Siegel [18] conducted similar studies using adults and children. Afterward, Siegel and White [19] stated that the paths and reference points experienced by individuals are mostly used in cognitive maps and that the elements depicted in cognitive maps increase with experience. Herman et al. [20] also found that the number of images remaining in the mind increased with experience in cognitive maps drawn by college students in different time periods. In addition, it was seen that male students used more reference points than female students. In his study, Kuipers [21] proposes that a cognitive map consists of five different types of information: topological, metric, route definitions, fixed features, and sensory images.

In recent years, in many researches in Turkey, in order to identify individual elements of the environment of perception and memory, cognitive maps are used. Ülkeryıldız et al. [22] found that in the cognitive maps of foreign students, predominantly sequential drawings and reference points and paths were included. In this context, the data obtained differed from Lynch's description of regional elements and paths of individuals with little experience in space. Then, Topçu and Topçu [23] used cognitive maps to determine the perceptual and spatial legibility of Selcuk University Campus and to develop suggestions for improvement.

Karadağ and Turgut [24] posed questions to the students of the Faculty of Literature to determine the perception of İzmir's urban environment and tried to determine their level of satisfaction with the city. In this study, the students were asked to write the associations related to İzmir and reflect them on cognitive maps. The data obtained were digitized by statistical methods and transferred to tables and graphs. In this way, the differences and similarities in the perception of the city were tried to be determined comparatively according to the educational and cultural background and interests of the students.

Özdemir requested the first and fourth grade architecture and engineering students to draw cognitive maps of the city of Yozgat using Lynch's urban images. In the study, it was stated that the number of elements in cognitive maps increased as experience and education increased. In addition, it was seen that architecture students depicted the city by drawing more details than engineering students: fourth grade architecture students, while drawing spaces with linear and curved lines, more detailed; first grade architecture and fourth grade engineering students, scattered way of expressing the places connected by the roads. In this study, the issue that should be considered is the effect of architectural education on the cognitive maps containing more details. In spite of their four-grade education, engineering students have used expression techniques similar to those of architecture students who have not received education [6].

Öztürk examined the cognitive maps of university students who experienced the city for a short time and individuals over the age of 60 who have experienced the 
city from past to present in order to determine the images of Eskisehir. In this study, individuals who experienced the city in different periods were selected in order to determine the changing city memory elements [25].

In another study conducted in Eskisehir, first grade students of architecture were asked to draw cognitive maps of their campuses by using paths, edges, nodes, districts, and landmarks to determine the level of perceivability, imageability, and legibility of settlement by the students. Then, by the evaluation of cognitive maps of the students, it is seen that landmarks are located in the memory of most of the individuals. Then, paths, districts, nodes, edges, and educational buildings are listed respectively in cognitive maps [26].

Cognitive maps have been the subject of many studies in order to determine individuals' perception of space. The cognitive maps obtained in these researches were classified and analyzed in the context of Lynch's urban images, and, thus, the perceptions of the individuals were determined. However, these findings have been made as a result of comparing the data of urban images with each other. In these studies, the data obtained from the comparison of urban images are interpreted, and it is stated that experiences affect the perception of space. In this context, in this study, first of all urban images, then each physical image is classified and analyzed in more detail. In addition to these analyses, elements other than urban image classifications in cognitive maps were statistically analyzed. These analyses were conducted to measure the effects of experiences on cognitive maps. In addition, the effects of architectural education on the perception of space were determined by classifying visual expression techniques in cognitive maps.

\section{Material and method}

The main material of the study is university campuses, and the sampling area is the Meselik Campus, where administrative, cultural, and social centers of Eskisehir Osmangazi University (ESOGU) are located. In this study, first and fourth grade architecture students who have taken 1 year of compulsory English preparatory education in Meselik Campus and then completed 4 years of architectural education in Bademlik Campus were selected. In this context, Meselik Campus becomes the location where students benefit from all their facilities for a year, while they use a limited number of courses, internships, various administrative works, and social facilities for the remaining 4 years.

In the study, first and fourth grade architectural students were selected as a sample in order to evaluate the contribution of architectural education and to measure the impact of the settlement process on cognitive maps. In this context, as seen in Table 2, 58 first grade (44 females and 14 males) and 37 fourth grade students (23 females and 14 males) in architecture are requested to draw the campus plan by using drawing techniques how the imaginary elements of the campus are located in their memories. As drawing techniques, any two- and three-dimensional representations; plans, façades, and mass works; written or numerical definitions, and colored or black and white expression techniques are permitted.

Firstly, the number of elements in the cognitive maps drawn by the students according to the imaginary elements such as paths, nodes, edges, districts, and landmarks was calculated, and then the obtained data were transferred to the charts and evaluated. As the data were evaluated, because of the numerical differences between male and female students, the percentages of proportional values between male, female, and all students were used in the tables when making comparisons. Then, in order to determine the effect of experiences on the perception of space, the image elements are also classified and compared as shown in Figure 1. 

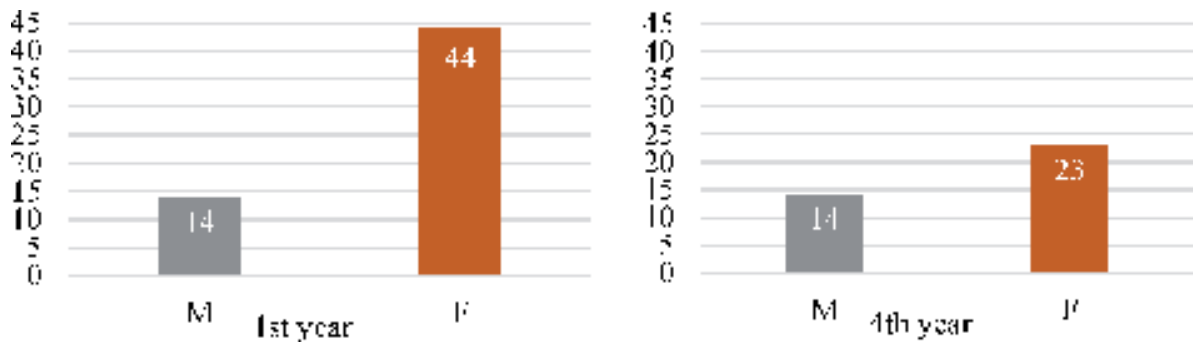

Table 2.

Numbers of first and fourth grade participants.

Finally, written and graphic expression techniques used in cognitive maps were determined, and the effects of architectural education on expression techniques and the scope of cognitive maps were investigated.

\subsection{Paths}

In order to make a detailed analysis of the paths in the cognitive maps, all arteries and secondary roads in the Meselik Campus are stated with different colors: three arteries (red, green, and yellow) and six secondary roads (blue, pink, cyan, purple, white, and brown) in Figure 1. Red and green arteries are started from the two main gateways with nodes A and B. As one of the main routes, the red path covers the entire campus from the east to west end, and the other one is the green path that starts at the north gateway routing firstly at the north-south direction and then continues with a sharp curve to the west. It also covers nine nodes (A, C, D, E, F, G, H, K, N).

All the paths drawn in the cognitive maps were counted and classified, and the data obtained were transferred to the graph shown in Table 3. When the data is evaluated, the cognitive maps of the first grade architecture students mostly include the main arteries stated by red and green, which are the main walking and vehicle paths of the settlement. Then, the paths stated in blue, purple, yellow, and cyan colors were drawn, respectively. The paths stated in white, brown, and pink are rarely drawn. Similar results were obtained when evaluated as male and female students.

In the cognitive maps of fourth grade architecture students, the paths indicated by red, green, blue, white, yellow, brown, pink, purple, and cyan were drawn, respectively. The representation of the paths in the fourth grade students' cognitive maps emerges at a much higher rate than the ones in the cognitive maps of the first grade students. While the paths indicated by blue, white, and brown are almost not included in the cognitive maps of the first grade students, they are in higher rates in the cognitive maps of the fourth grade students.

When the results obtained are evaluated, the paths expressed in red and green, which are the main arteries of the campus, are the paths that are remembered in the minds and processed on cognitive maps. The first reason is that these paths are the main transportation arteries, and the second reason is that the Foreign Languages department where the students are educated is located between these two paths. However, it is noteworthy that the proportion of first grade students is about half that of the fourth grades. The reason for this is that the meaning of the cognitive map for the students is limited to the structures, and therefore they are generally used as secondary components when trying to define the structures. The reason why the paths stated with blue, white, and brown are more frequently used on the cognitive maps of the fourth grade students is related to the fact that these paths were used more in the fourth year because of the connection between 


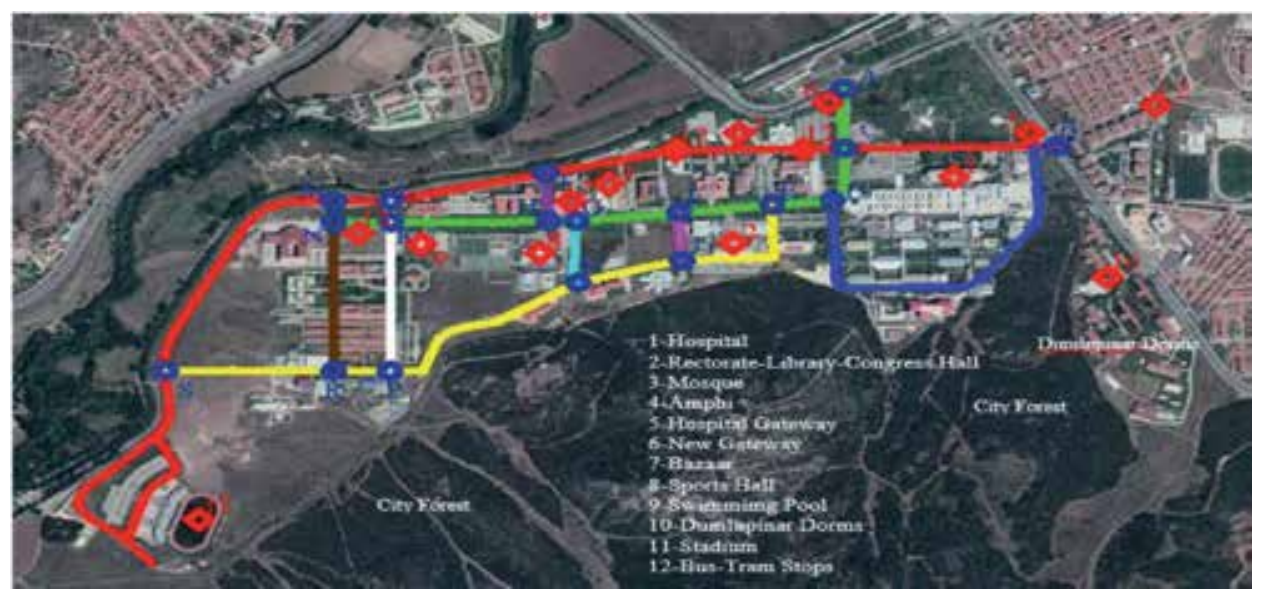

Figure 1.

Paths, nodes, and landmarks of ESOGU Meselik Campus.

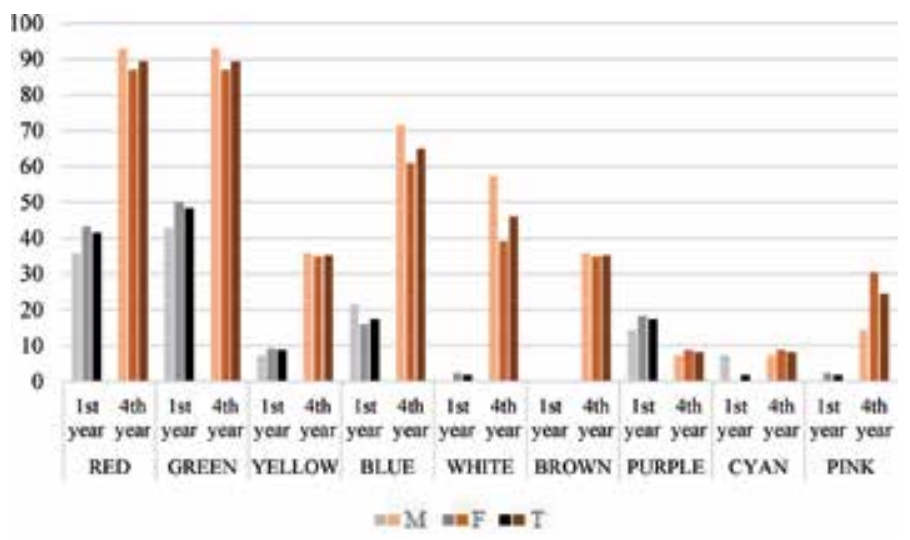

Table 3.

Path expression ratios (\%) of first and fourth grade students.

the engineering faculty and the vacant land they measured during the topography internship process. As a result, the low percentages of paths in the cognitive maps of the first grades are that students have not experienced the campus so much to think holistically, think regionally and think the structures in their minds, and think the paths as the elements that connect them. The higher percentages in the fourth grade are related to the positive impact of architectural education and the fact that they have experienced every part of the campus.

\subsection{Nodes}

All nodes are named in alphabetical order from $A$ to $S$, in order to make a detailed analysis of the nodes in the cognitive maps as shown in Figure 1. As can be seen in Table 4, nodes listed from A to I can be seen in cognitive maps of first grade students, while all of them can be seen in cognitive maps of fourth grade students.

Nodes A and B are important intersections where all pedestrian and vehicle traffic of the campus passes. Of these, $A$ is used more frequently by municipal busses and vehicles, while $B$ is frequently used by pedestrians due to the presence of tram stops that provide transportation from the city to the campus. The majority of the first grade students provide transportation to the campus by tram, while the fourth 


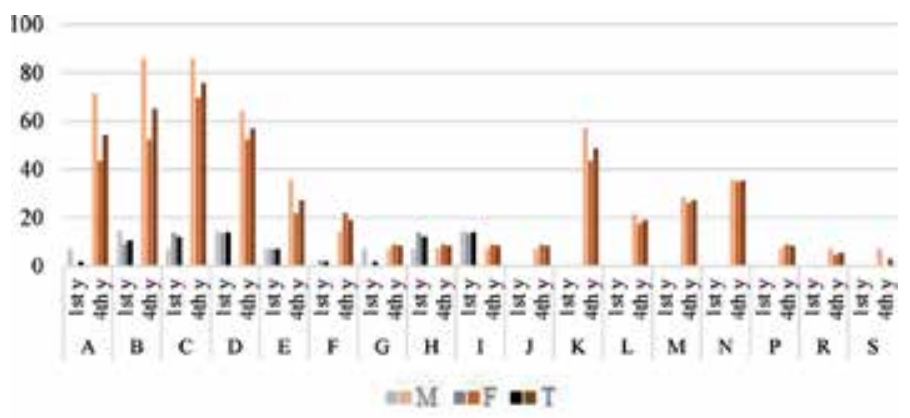

Table 4.

Node expression ratios (\%) of first and fourth grade students.

grade provides transportation from Bademlik Campus to Meselik Campus by busses. That is why A node is expressed at first grade students' sheets with a little ratio and big ratio at fourth grade students' sheets.

Node $\mathrm{C}$ is the most important intersection of two main arteries, and node $\mathrm{D}$ is one of the most popular intersections of the whole campus. After entering the campus, node $\mathrm{C}$ and node $\mathrm{D}$ are the intersections where the distribution is provided and the passage is obligatory. In this context, they are largely shown in the cognitive maps of both groups, due to their locations.

Nodes G, H, and I, which are located next to the Foreign Languages building where the first grade students receive their English preparatory education, are shown in their cognitive maps depending on the frequency of use. The reason why Nodes E and F and G are shown more than Nodes G, H, and I in the cognitive maps of the fourth grade students is that the fourth grade students used the cyan path where these intersections are located more than the first grade students. While nodes from $\mathrm{J}$ to $\mathrm{S}$ were not included in the cognitive maps of the first grade students, they were highly drawn in the cognitive maps of the fourth grade students due to their excessive use during the internship period. In the cognitive maps of the fourth grade, Nodes G, H, and I were expected to be higher depending on the experience, while nodes experienced during the internship were drawn at a higher rate. In the cognitive maps of the fourth grade, Nodes G, H, and I were expected to have a higher rate due to the experience during the preparatory education process, whereas nodes experienced during the internship period were drawn at a higher rate.

\subsection{Edges}

The Meselik Campus is bordered by Gençlik Boulevard in the east, Ulusal Egemenlik Boulevard and the Porsuk River in the north, the Porsuk River in the west, and the forest in the south, as shown in Figure 1. The east, north, and west edges also separate the campus from the built environment.

In cognitive maps, first grade students expressed only the roads and walls that form the interface of the campus with the city as edges as shown in Table 5. On the other hand, the fourth grade students expressed the roads to a great extent as edges, then the forest, walls, city, and Porsuk River, respectively. Because of the Boulevards' public transit function, both, as the east and north-east edges, have the highest ratios at first and fourth grade students' cognitive maps. The reason why the forest and the Porsuk River, which is an important image of the city of Eskisehir, is not included in the cognitive maps of the first grade students is thought to be due to the lack of ability of students to think and draw on an urban scale, and both of them are not actively used as recreational areas in the campus. 


\subsection{Districts}

There are four areas that carry the characteristics of a district at the campus as shown in Table 6. These are the rectorate square surrounded by the rectorate, library, and conference halls, the bazaar where the cafes and restaurants are located, the ceremonial square where official ceremonies are held, and the ATM square where all the cash machines of the banks (ATM) can be used.

When cognitive maps were evaluated in districts, Rectorate Square is stated with highest ratio both at first grade students' and fourth grade students' cognitive maps. The reason why the Rectorate Square is drawn more is that the library and the rectorate building, where the student affairs and data processing departments are located, are frequently used by students. In addition, the Rectorate Square is located next to the green path that is most commonly drawn on cognitive maps.

In the cognitive maps after the Rectorate Square, the first grades drew Bazaar Square and Ceremonial Square; the fourth grades drew Ceremonial Square, Bazaar Square, and ATM Square, respectively. The reason why the first grade students did not draw ATM Square in cognitive maps was that all the ATM were moved to the Bazaar Square 1 year before their arrival at the campus. In this context, despite the fact that it is a large area with parking and green spaces and is located on the most expressed green path in cognitive maps, ATM Square was not drawn by the first grade students. The reason for this is thought to be that they could not establish a semantic relationship in their minds about the field.

The Bazaar Square across the Department of Foreign languages, in which both groups of students were educated, ranked second in the cognitive maps of the first grade and third in the fourth grade. The Ceremonial Square is included in the cognitive maps of both groups, because it is located in node $\mathrm{C}$, where the most drawn green and red paths intersect. In the fourth grade, the reason why ceremonial square is drawn more than the bazaar is that they spend less time in the Bazaar and see more Ceremonial Square in the last 3 years. In addition, when the data is evaluated, it is seen that the female students in the fourth grade remember the rectorate, ceremonial, and bazaar squares and the first grade female students remember the bazaar more than the male students.

\subsection{Landmarks}

Landmarks are structures that determine the identity of the urban area, have a high potential for users to remember, and help people to navigate. There are

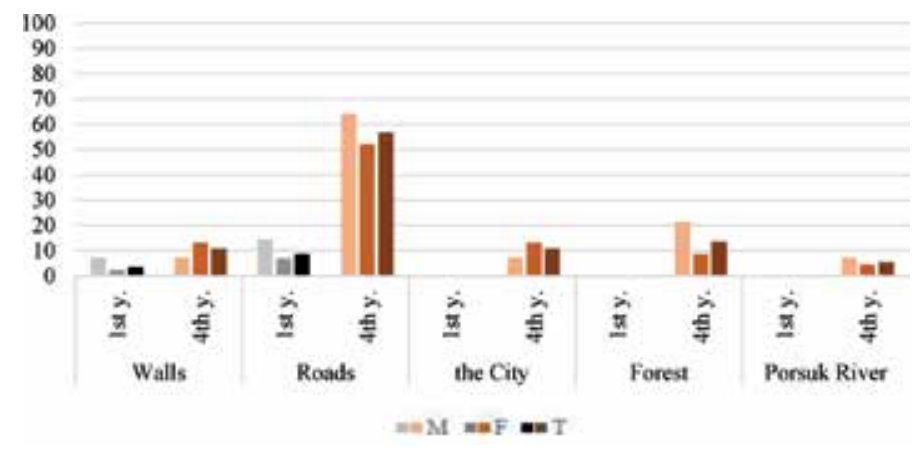

Table 5.

Edge expressions of first and fourth grade students. 


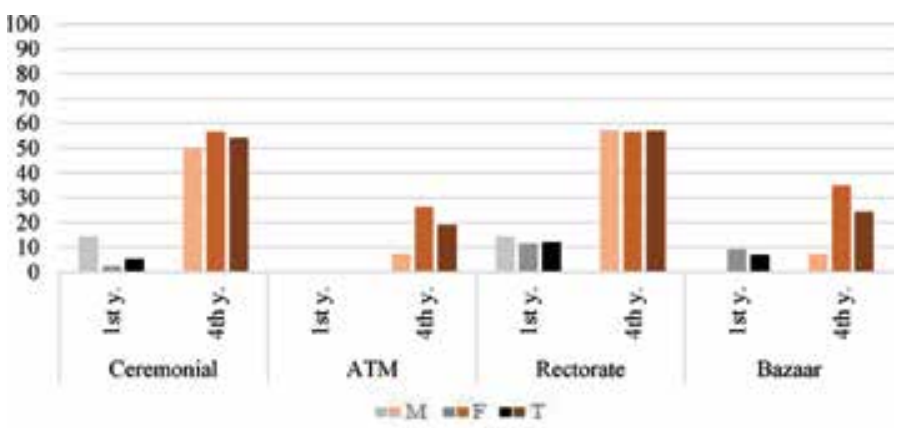

Table 6.

District expressions of first and fourth grade students.

12 buildings in the Meselik Campus that conform to the definition of landmark as shown in Figure 1: amphitheater, two gateways, Central Bazaar, Sports Hall, Dumlupinar Dorms, Rectorate-Library-Congress Hall Complex, hospital, and bustram stops located in and around the campus area.

The hospital is an important landmark for both the city and the campus as it is located at the entrance of the campus, being the highest building of the campus and being used by the city in general. In this context, the hospital ranked $94.59 \%$ in the cognitive maps of the fourth grade and ranked fourth in the cognitive maps of the first grade. The reason why the first grade students rank the hospital as the landmark in fourth place is that they have shown the most commonly used areas in the campus more on cognitive maps as seen in Table 7.

The complex consisting of the rectorate, library, and congress center was in second place in both groups due to the fact that it contains the functions frequently used by the students and is located above the green main artery which is highly drawn in the cognitive maps.

Another important landmark is the mosque which is highly perceptible as it is located at the entrance of the campus, differs in architecture from other buildings, and attracts attention as a place of worship. This landmark, like the hospital building, has a high rate in cognitive maps of the fourth grade and a lower rate in the first grade. However, both the hospital and the mosque were drawn more in the cognitive maps of the first grade students than the other landmarks.

Gateways are shown by both groups of students. However, as previously mentioned in the nodes, depending on the intensity of use, higher levels of hospital gateways were shown in the cognitive maps of the first grade, and new gateways were shown in the cognitive maps of the fourth grade.

Sports Hall is shown by the first-rate female and male students at a similar rate, with $57.14 \%$ by the fourth grade male students and $26.09 \%$ by the female students, which is an interesting example in terms of having the highest ratio difference between landmarks. The reason for this is that the fourth grade male students frequently use the football fields at Sports Hall.

Amphitheater and the stadium have low expression rates in both student groups between landmarks. One of the reasons for this is that the stadium is located in the farthest part of the campus and the amphitheater cannot be perceived because it is surrounded by walls. The second reason is that these places were not used by the students. In addition, male students did not show the amphitheater in the cognitive maps of the first grade students, and some of the female students did. 


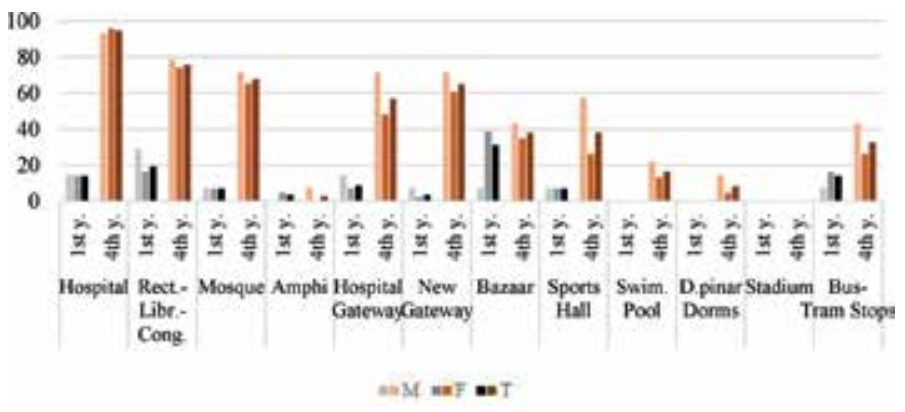

Table 7.

Landmark expressions of first and fourth grade students.

\subsection{Other expressions}

In the study, all components that do not meet the definition of urban image components in cognitive maps are evaluated in Table 8 under the heading of other expressions. In this context, the rate of processing of other buildings which are not landmark but located in the campus is in the first place in the cognitive maps of the fourth grade and second in the cognitive maps of the first grade. On the other hand, life experiences rank first in the cognitive maps of the first grades and second in the fourth grades.

Life experience classification has been created, because users embody the places they use instantaneously or continuously and the good or bad memories they live in their cognitive maps. In both groups, female students processed life experiences more in cognitive maps than male students. In the cognitive maps of the fourth grade, it is thought that the reason that other buildings function more than life experiences is that they draw the area in the form of a site plan due to architectural education. Also, for the same reason, unused land and recreation and construction sites were not included in the cognitive maps of the first grade, but were included in the cognitive maps of the fourth grade.

Erasmus Registration Office, which is the liaison office for overseas education, is shown on cognitive maps of the fourth grade, not on the cognitive maps of the first grade. This is due to the fact that fourth grade students visit the building frequently in order to study abroad.

\subsection{Expression techniques}

In order to evaluate the effect of architectural education in the transfer of the places remembered in mind to cognitive maps by drawing, the representation techniques in cognitive maps were determined in both groups and are shown in Table 9. As a result of the evaluation, in the context of the expression of the field, $27.58 \%$ of the first grade students and $83.79 \%$ of the fourth grade students benefited from the black, white, or colored site plan drawings.

Both two- and three-dimensional expression techniques were used to express the structure and structure groups. The first grade students used the $2 \mathrm{D}$ facade drawings at a rate of $5.17 \%$, while the fourth grade students preferred this technique at a rate of $45.95 \%$. In this technique, first grade students did not benefit from color, while fourth grade students used colors at a high rate. This proportional difference is thought to be related to the fact that first grade participants cannot fully visualize the field in their minds and that they do not yet know the concept of the site plan.

The three-dimensional expression technique was used $75.86 \%$ in the cognitive maps of first grade students and $89.19 \%$ in fourth grade students. As in the 


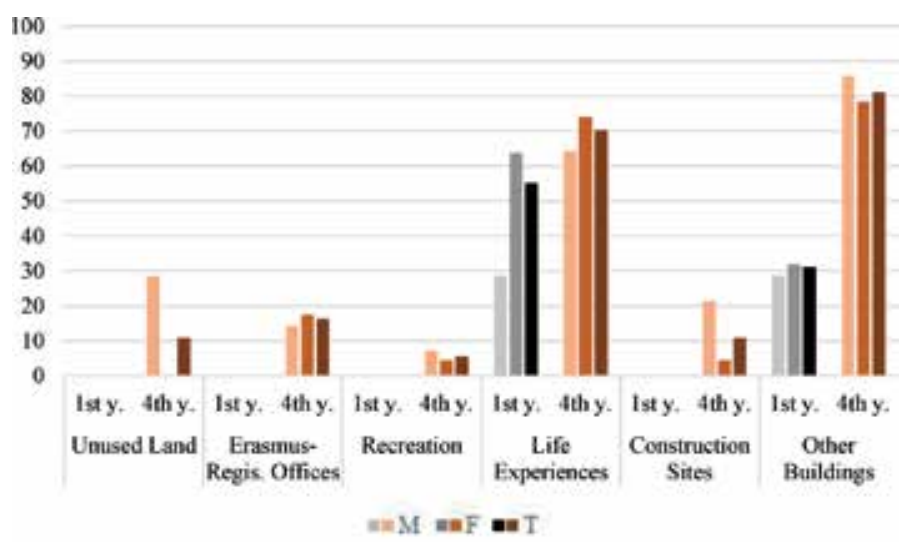

Table 8.

Other expressions of first and fourth grade students.

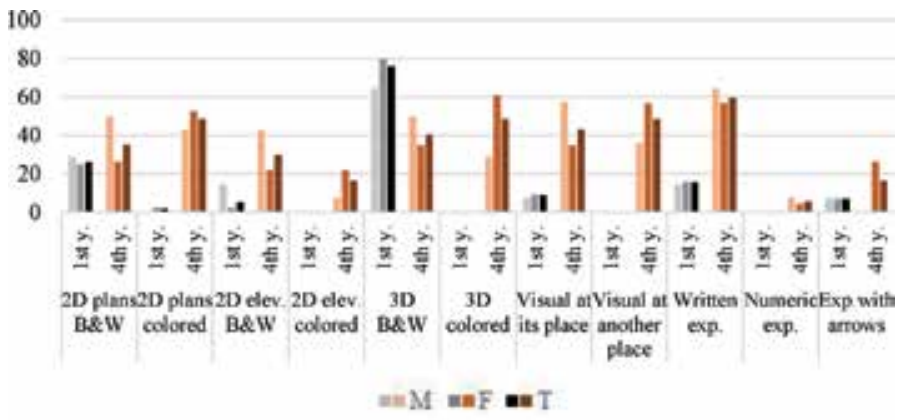

Table 9.

Expression technique ratios (\%) of first and fourth grade students.

two-dimensional facade expressions, it was found that while the first grade students did not use color in this technique, $48.65 \%$ of the fourth grade students used color. Also, in all the demonstrations, female students used colors more than male students.

While only $8.62 \%$ of these two- and three-dimensional visuals are integrated and present in the site plan, this ratio is $43.24 \%$ for fourth grade participants. In addition, while the fourth grade participants positioned these visuals at a location different from where they should be in the site plan by $48.65 \%$, the first grade participants positioned all the structures as they were in the site plan. However, this is due to the fact that first grade students draw less structures on a regional scale.

In addition, $15.52 \%$ of the first grade participants used written expressions and $6.90 \%$ of them used descriptive arrows, while $59.46 \%$ of the fourth grade participants used the manuscript. Therefore, while the 4-year space, architecture and technical education is expected to reduce writing and expression, on the contrary, due to architectural education, because of the attempt to draw cognitive maps in the form of the site plan, the writings on the drawings have been more than expected.

\subsection{Imaginary elements}

In this part of the study, the number of paths, nodes, edges, districts, landmarks, and other elements are determined and shown in Table 10 proportionally. 
The percentages of the total number of items found in the cognitive maps of first grades are $15.33 \%$ with paths, $14.37 \%$ with other elements, $8.91 \%$ with landmarks, and $6.03 \%$ with districts, followed by 4.36 and $2.41 \%$ with nodes and edges; in the cognitive maps of fourth grades are $44.44 \%$ with paths, $41.22 \%$ with landmarks, $38.51 \%$ with districts, and $32.43 \%$ with other elements, followed by 27.98 and $19.46 \%$ with nodes and edges, respectively.

In both groups of students, nodes and edges took the last place, respectively. The reason for this is that, as shown in Table 5, the city, the forest, and Porsuk River, which are defined as border elements, are not drawn in the maps. Interestingly, although paths were the most drawn elements in both groups, the rate of drawing of nodes found at the intersections of paths was very low. The reason for this is that the roads drawn are not continuous, and most of the nodes are on the roads which are not drawn. In the cognitive maps of the first grade students, other elements are in the second place, followed by landmarks and districts, because they mostly draw the region where they are educated. In the fourth grade, because they tried to draw the entire settlement, the landmarks took the second place, followed by districts and other elements.

\section{Results and discussion}

The results obtained from the study show that first grade students who have less experience in the campus draw in spatial style and fourth grade students draw in sequential style. In this context, it is seen that the two display techniques mentioned in previous studies take place [15]. Lynch states that as the experience of space increases over time, these two display techniques change in place in the individual [13], while Spencer and Weetman state that this situation is shaped according to the tasks of individuals [27]. In the context of these two different opinions, when the data obtained in the study are evaluated, it is seen that a result similar to both opinions is obtained. In the study, with the experience and time, the number of fields and elements shown in the cognitive maps of fourth grade students increased. However, the reason for this increase was not the elaboration of the same spaces, but the increase of the spaces experienced by the students. If only the experience and time factor were effective, in the cognitive maps of the fourth grade, the Foreign Languages department and the Bazaar should be drawn at a higher rate, while the spaces in the minds were drawn at a higher rate as a result of new tasks and experiences. In this context, both views were supported in different contexts.

In the study, in accordance with their own experiences and perspectives, the students selected some of the physical environment elements in the campus and reflected them to their cognitive maps within the framework of the fiction and order they created. In this context, as Lynch states [13], students have formed an identity of the campus by making sense of some of the physical environment they see within the framework of their own feelings, thoughts, and experiences.

In studies conducted on cognitive maps, it is seen that individuals' drawings are classified and evaluated according to urban images. In this study, all kinds of elements such as drawing, writing, sign, and symbol, which are not considered as urban images in the cognitive maps of the students, were also evaluated. The data obtained as a result of the evaluation are classified under the other expression category. The issue that draws attention in this category is that students express their experiences and memories by writing them on cognitive maps, although they are not requested from the students. The other remarkable issue is that many buildings that do not have landmark characteristics in the cognitive maps of the students have more place than landmarks. In this context, it is thought that students 


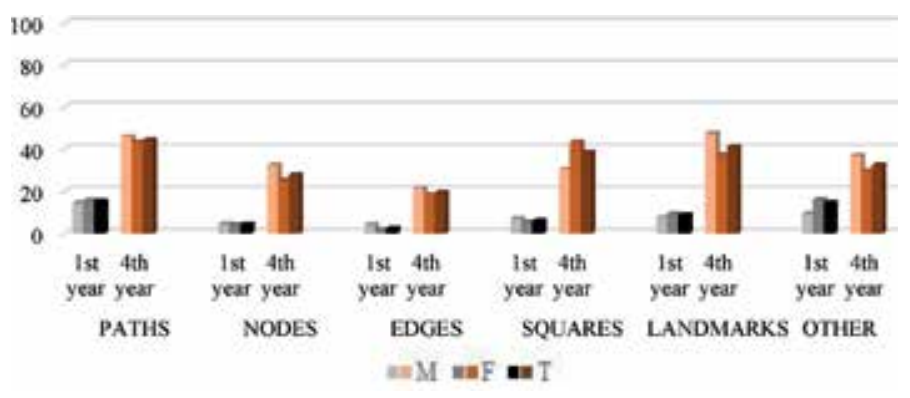

Table 10.

Percentage distributions according to imaginary elements.

describe many structures as landmarks in their minds by associating them with their experiences.

In the study, if the assessment was made only in the context of urban images, it could be said that paths and landmarks were more involved in the students' minds. However, when each element in the cognitive maps is evaluated, the proportion of the places in which students load meaning according to their own lives is almost equivalent to landmarks. In addition, it is seen that the students draw the paths that they walk or see in the form of a route and transfer the structures that interest or load meaning on this route to their drawings.

Landmarks on their routes or experienced are more often in the drawings, whereas landmarks they have never seen and experienced are less common. In this context, it can be assumed that the results obtained from the studies conducted with cognitive maps aimed at determining the urban identity may vary with the sample group used. For example, it can be said that the perception of the city and the identity of the city will differ in the minds of a group of tourists coming to the city with tour companies and a group of tourists visiting the city with their own means. Tourists who travel with the tour company guide experience the paths and landmarks in the company's travel program, while the other group of tourists will have a perception of the city in accordance with their own route and sightseeing. In addition, the formation of the urban identity that will take place in the minds of the individuals traveling with the guide will be shaped according to the route drawn by the guide. However, even in this case, each individual will perceive what he or she sees, hears, and lives and will create a different urban identity in his or her mind. However, even the city identity formed in this case will be shaped by the guide. A similar situation can be observed for this study. When the sample group is selected from different groups such as students from different departments, administrative or academic staff, urban people, the perception of the campus, and the perception of identity in minds will change because, as stated in the study, the urban images in the cognitive maps show changes in line with the experiences. Even if the same study is repeated with the same sample group years later, the results may differ depending on the new experiences.

In this study, the effect of architectural education on the formation of cognitive maps is also investigated. In this context, in line with the data obtained, it is seen that students' drawing skills and architectural perspectives are effective in the formation and elaboration of cognitive maps. In this context, the ability of individuals to draw and use visual techniques can affect the results obtained from cognitive maps. In the context of female and male students, it can be said that girls use more colors and try to add meaning to spaces with written expressions. However, there was no significant difference in the overall study. 


\section{Conclusions}

Cognitive maps provide the ability to determine the perception of the physical environment in which individuals live according to their experiences. The emergence of this perception is influenced by what the individual lives, sees, hears, and reads. However, it will not be sufficient for studies to determine the urban identity on an urban scale. Because, as Twersky pointed out in his work, the "cognitive map" metaphor does not reflect the complexity and richness of environmental knowledge [28]. In order to reach a scientific conclusion in the context of urban identity in the cognitive maps, it is necessary to increase the number of individuals used in the subjects such as age, gender, and education. In addition, data obtained from cognitive maps should be supported by questionnaires. However, even the results obtained from such a study using cognitive maps may change over time.

In the study, it is seen that experience is more important than time factor in the formation of perception of physical environment. If only urban images were compared, the fact that fourth grade students drew more elements and details in their cognitive maps could be related to the time factor. However, when each urban image is evaluated in detail, it is seen that this interpretation is wrong because, in a small urban area such as a campus, students who spent both 1 and 4 years showed the physical environment they experienced in their cognitive maps. In this context, it is seen that the experience factor is more important than the time factor in the increase of the data obtained in cognitive maps.

\section{Author details}

\section{Orkun Alptekin* and Hasan Unver}

Faculty of Engineering and Architecture, Department of Architecture, Eskisehir Osmangazi University, Eskisehir, Turkey

*Address all correspondence to: orkunalptekin@outlook.com

\section{IntechOpen}

(C) 2019 The Author(s). Licensee IntechOpen. This chapter is distributed under the terms of the Creative Commons Attribution License (http://creativecommons.org/licenses/ by/3.0), which permits unrestricted use, distribution, and reproduction in any medium, provided the original work is properly cited. (cc) BY 


\section{References}

[1] Proshansky HM, Fabian AK, Kaminoff R. Place-identity: Physical world socialization of the self. Journal of Environmental Psychology. 1983; 3, 1:57-83

[2] Pløger J. Millennıum urbanismDiscursive planning. European Urban and Regional Studies. 2001;8(1):63-72

[3] Arkonaç SA. Psychology: Science of Mind Processes. 2nd ed. Istanbul: Alpha Publications; 1998. 510p (Turkish)

[4] Eren E. Organizational Behavior and Management Psychology. 12th ed. İstanbul: Beta Publications; 2010. 642 p (Turkish)

[5] Güleç Solak S. Space-identity interaction: A conceptual and theoretical view. Manas Journal of Social Research. 2017;6(1):13-37. (Turkish)

[6] Özdemir EE. Experience changing urban space perception and urban image: Example of architectural and engineering students. TMD International Refereed Journal of Design and Architecture. 2016;07:42-54. (Turkish)

[7] İnceoğlu M. Attitude, Perception and Communication. Istanbul: Beykent University Publications; 2010. (Turkish)

[8] Yazıcıoğlu HZ. An analysis of the spatial character of streets as an urban space in the context of walkability [thesis]. Istanbul: Istanbul Technical University, Institute of Science and Technology; 2010. (Turkish)

[9] Kahraman MD. The concept of habitability and spatial quality in terms of human needs and spatial availability. Planning. 2014;24(2):74-84. (Turkish)

[10] Tolman EC. Cognitive maps in rats and men. Psychological Review. 1948;55(4):189-208
[11] Downs RM, Stea D. Cognitive maps and spatial behavior: Process and products. In: Downs RM, Stea D, editors. Image and Environment. Chicago, IL: Aldine; 1973. pp. 8-26

[12] Evans GW. Environmental cognition. Psychological Bulletin. 1980;88:259-287

[13] Lynch K. The Image of the City. Cambridge: MIT Press; 1960

[14] Jones T. Spatial Cognition: Learning What has been 'Learnt' from Cognitive Maps. 2006. Available from: https:// people.bath.ac.uk/pssds/CinC 2006 Lecture2.pdf [Accessed: 29 October 2019]

[15] Appleyard D. Styles and methods of structuring a city. Environment and Behavior. 1970;2:100-117

[16] Moore GT. Theory and research on the development of environmental knowing. In: Moore GT, Golledge RG, editors. Environmental Knowing. Stroudsburg, Penn: Dowden, Hutchinson, \& Ross; 1976

[17] Hardwick DS, McIntyre CW, Pick HL. The content and manipulation of cognitive maps in children and adults. Monographs of the Society for Research in Child Development. 1976;41(3):166

[18] Herman JF, Siegel AW. The development of cognitive mapping of the large - scale environment. Journal of Experimental Child Psychology. 1978;26:389-406

[19] Siegel AW, White SH. The development of spatial representations of large-scale environments. In: Reese HW, editor. Advances in Child Development and Behavior. Vol. 10. New York: Academic Press; 1975

[20] Herman JF, Kail RV, Siegel AW. Cognitive maps of a college campus: 
A new look at freshman orientation. Bulletin of the Psychonomic Society. 1979;13(3):183-186

[21] Kuipers B. The cognitive map: Could it have been any other way. In: Pick HL, Acredolo LP, editors. Spatial Orientation: Theory, Research and Application. New York: Plenium Press; 1983. pp. $345-360$

[22] Ülkeryıldız Ü, Arsan ZD, Akış T. Change of the perception of the environment by experience of the city in mind maps of students. BAÜ Journal of Science. 2009;11(1):72-82. (Turkish)

[23] Topçu KD, Topçu M. Visual presentation of mental images in urban design education: Cognitive maps. Procedia - Social and Behavioral Sciences. 2012;51:573-582

[24] Karadağ A, Turgut HA. Research on perceptions of university students in urban environment: The Izmir case. Geographical Sciences Journal. 2013;11(1):31-51. (Turkish)

[25] Öztürk AC. Reading experiments of Eskisehir's past and present city memory on cognitive maps. İdealkent Memory and Urban Conservation II Special Issue; 2016. pp. 23-41. (Turkish)

[26] Alptekin O. A Reading attempt of the urban memory of Eskisehir Osmangazi University Meselik campus via cognitive mapping. IOP Conference Series: Materials Science and Engineering. 2017;245:1-10

[27] Spencer C, Weetman M. The microgenesis of cognitive maps: A longitudinal study of new residents of an urban area. Transactions of Institute of British Geographers New Series. 1981;6(3):375-384

[28] Tversky B. Cognitive maps, cognitive collages, and spatial mental models. In: Frank AU, Campari I, editors. Spatial Information Theory:
A Theoretical Basis for GIS. COSIT 1993. Lecture Notes in Computer Science, vol. 716. Berlin, Heidelberg: Springer; 1993 


\title{
Semiotic Architecture of Viral Data
}

\author{
Berna Leticia Valle Canales \\ and Julio César Chavarría Hernandez
}

\begin{abstract}
In the last 5 years, there has been great debate about digital communication and its role in electoral politics. The question on everyone's mind is: can viral and massive information on social networks change the voting tendencies and behavior of people? We expose a series of theoretical points from the perspective of semiotics and systemics, to understand these communication phenomena, which are hallmarks of the twenty-first century. We also include some cases of semiotic and systemic orientation and our proposal about natural and artificial communication through viral cascades.
\end{abstract}

Keywords: digital communication, elections, networks, semiotic, fake news

\section{Introduction}

This text deals with the new discourses of reality in which the main characteristic is the integral, ecological, and holistic vision. It is a worldview where everything is connected to everything. Such is the systemic approach. The idea of a system covers a general type of concepts, conceived by man as complex models of coherence, more or less identifiable and permanent in the real world $[1,2]$.

Semiotics is the doctrine of all signs, and a sign is something that is in place of something else in any of its properties. This definition creates a path to understanding the randomness of the meaning considering that 'something else' could be referring to anything in terms of technology for memory; for example, the writings and encrypted algorithms have an enormous diversity. Under this view, semiotics integrates Charles Sanders Peirce pragmatism thinking and ideas. From the semiotic framework, a sign is the meeting ground of the relations between elements of two systems, the transmitter, and the receiver, and only can happen in the social community. Each of these elements is entitled to enter-under given coded circumstances-into other correlation and thus form a new sign [3]. Instead, semiosis is a process in which an entity acquires meaning as icon, index, or symbol. Semiosis is a process of structural coupling between the elements of different systems. These systems are (A) a set of possible behavioral responses, (B) a set of states of things in the world, and (C) a set of signals correlated by arbitrary combining.

The term architecture refers to the frame of digital communication. This structure can reach a lot of levels: the defined libraries of algorithms, the processes that they can do, the time of the spread of bits, and the meaning of the data coded on bits. However, the level of our interest is the semiotic one or the meaning coded. We watch a massive response between bits, data, and receivers only on the semiotic 
level. The theoretical issue of this kind of behavior is the continuous change of the meaning of the information point-to-point until it becomes fake in opposition to reality. The social importance of this behavior is the impact of the offline world. A lot of massive news turns into political and cultural energy: anger, despair, and polarization. Therefore, the control of digital communication is a topic of political power than nations and agents take advantage of them.

It should be noted that, with the development of Web 3.0, the semiotic processes have changed. Digital technologies, in addition to providing interaction and updating in real time, stimulate the development of long-range semantic networks, the interaction of large databases, and increasingly efficient algorithms to navigate [4]. This has caused effects or by-products. Super viral information of networks or cascade is the best example of this kind of outgrowths without control. The cascades are the best example of viral data, and we refer to them in the next pages.

The debate about cascades is if the tendency of information in a network is natural or not. The informal expression of social inclination in digital communication is trending. It refers to a topic currently popular or widely discussed on social media websites; they are today's top trending topics.

Current studies about digital propaganda have proved that some trendings are controlled by human trolls, bots, and algorithms. Most of them have political and hybrid warfare purposes [5-12].

But in this chapter, we will not go deep into political science. Instead, in the theoretical arena of systems research, Prigogine [13] postulated that dissipative systems are dynamic nonequilibrium open systems with internal gradients. They keep their low entropy condition stable by transporting matter and energy beyond their frontiers. They consume energy and present matter and energy cycles. Dissipative structures develop complexity exporting and dissipating entropy to their environment [14-16].

The systems we deal in social sciences, humanities, and arts are open systems. Open systems are those that transform one type of energy, matter, or information into another, as they adapt to their environment. The classic mechanic theory defines that in all open systems, change is irreversible. The shifts within open systems generate all kinds of disturbances at the atomic level, which lead to disorder in the molecular structures until the social macrolevel. These variances into the matter, energy, and information are an irreversible process. This process produces a kind of disorder in the fundamental structure and it is measured by its entropy.

According to Claude Shannon as Ilya Prigogine, entropy or disorder can be characterized as a statistical measure $[13,17]$. Shannon's entropy "is a statistical parameter which measures, in a certain sense, how much information is produced on the average for each letter of a text in the language. If the language is translated into binary digits ( 0 or 1 ) in the most efficient way, the entropy $\mathrm{H}$ is the average number of binary digits required per letter of the original language" [17]. Our writing system has 26 letters to represent many languages. But if I use my alphabetic keyboard to do a translation to a writing system that only has 2 digits, as binary, I have to count how many times the digits of binary systems I need to combine to reach the best codification. The average of binary system required for each letter is 4.6. The formula is very simple: $\log _{2} 26=4.6$ bits per letter, which means that 4.6 bits is approximately the number of times the two digits can appear to represent each one of the 26 letters. In that way, entropy is a statistical quantification of how many entities we need to interpret System 1 with entities of System 2.

The concept of entropy used by Prigogine is a measure of the degree of knowledge we have of a system. Its function is to know the current status of any system. In theoretical sense, at the beginning of the universe, entropy was very low; in 
other words, a certain type of order governed the beginning of all things. Thus, the evolutionary tendency toward order through disorder becomes a universal reaction that returns to the origin of everything [13].

In this case, we are talking about digital communication, one of the most ordered systems in the planet. Shannon's information theory establishes that to measure information it is necessary to calculate the range of the data produced by the source. In this approach, quantifying the spread of a text message is the best way to do that task. But Shannon's theory is not designed to explain the changes into meaning [18]. Occasionally, the sense of a message could be switched from its original meaning, by two factors: first, a translation effect, for example, if we do not speak or understand the coding language, and second, an exposition influence. Both factors are context condition of the communication and are not issues from communication theory. The dynamical behavior of meaning in social network has two features: move and stream thoughts. This dual behavior allows expanding or shading off the original meaning until twisting it.

The big question is if human behavior responds to laws of thermodynamics. The hypothesis of this paper postulates that semiosis organizes thoughts as networks, and networks help to dispel entropy and generate order. This happens through an intricate structure of individual and collective relationships. As proposed by Luhmann [19] in his time, we understand communication systems as relations between the relationships of semiotic systems.

The new existing analysis of information propagation in virtual environments overcame the impossibility of proofing such hypothesis. Today, it is possible to track the trajectories of information exchange through the topology of these networks, as described by the mathematician Barabási [20] and the physicist Albert [21]. It is also possible to apply Duncan Watts and Steven Strogatz's [22] small world networks, or through the sophisticated methods in Stanley Wasserman and Kethrin Faust's [23] classic book. The postulate "any two people can be connected in a maximum of six steps" of the sociologists Jeffrey Travers, Stanley Milgram [24], and Mark Granovetter [25, 26], is the basis for the applications of modern network theory. Our dissertation comes from this postulate too.

We postulate that the cascades are a kind of natural dissipative structures in the cultural level. The implication of this postulate is that mechanical laws of nature lead to cultural and social processes of semiosis.

This dissertation is argumentative and revolves around communication within cultures. We are interested in debating two aspects:

1. Does the difference between personal and collective interpretations result in dissipative structures?

2. Does culture generate information cascades to keep its dynamic equilibrium?

For all that has been said so far, readers have in their hands a text that consists of three parts (apart from this introduction and subsequent conclusions). In the first part, we deal with the concept of macroscopic communication level; the second part deals with the microscopic levels of communication; and, finally, we discussed dissipative structures of communication. In this way, the first two parts of this essay are theoretical-methodological; while, the last part, applies the concepts proposed throughout the text to specific cases. We present our preliminary results, to discuss whether it is possible or not to control trends with viral information. 


\section{The macroscopic level of communication}

The prefixes "macro-", "mega-," and "micro-" can be a source of inaccuracy and confusion. Rosnay [27] implemented "macroscopic" as a conceptual instrument for the scale of observation and experience related to social phenomena, where life develops, and the scale in which ecological systems interact with socioeconomic environments. Within the systemic-cybernetic approach, an attempt to unify terminology has been in progress since the 1960s. Currently, the proposal uses the concepts "macrocosm," "megacosm," and "microcosm". In this way, there are three scales in which culture operates: temporal limits, limits of interpretation, and limits of life. Therefore, the processes of signification obey the laws of thermodynamics, the physical laws of the universe, and the complex structures by which we exchange and create meaning. In other words, social systems, at least complex social systems, generate events. These autogenerative processes would be located in the middle between biology, which includes the neuronal interactions of individual semiosis and interpretant signs, and the accidental developments that occur as a result of random encounters between systems and events. While the individual system responds to disturbances with its own determinism or internal laws, the ecosystem responds randomly or decentralized [28]. In this sense, the difference between event and element is basic, because "the notion of an element is a spatial ontology, while the notion of an event is a temporal ontology" [28].

Some systemic philosophers such as Brier [29], Wilber [30, 31], and Laszlo [32] named this model as "ecosystemic." Each of these authors has proposed a different scheme to represent the ecosystemic model with the different scales of time, life, and interpretation. Our theoretical-methodological proposal is that the trajectory of a particular meaning can be measured as a probabilistic trajectory along these temporal, interpretive, and life scales. From this perspective, based on the phenomenology of Peirce's experience, semiosis is the process by which a thing acquires meaning in such a way that the evolution and continuous adaptation of the signs, in the form of networks or semiotic systems, limit the time of semiosis [19, 33].

Therefore, deep symbolic correlations depend on person-to-person contacts, and long-range correlations are defined by their longevity in years. Luhmann [33] applied the mathematical formula for the growth of superconnected networks to characterize the organizational systems constituted by decision-making. These systems are interconnected by themselves through semiosis, which results in an isomorphism ${ }^{1}$ with the structural coupling treated by Maturana [34]. In that sense, like Luhmann, we agree with the idea that we are not talking about structural coupling based on a closed process of self-reference [33].

Systemic-semiotics is based on the first-order cybernetics definitions by Guddemi [35]. Guddemi explains that the evolution of the concept sign is associated with Peirce's phenomenology of experience and associates the construction of signs with Maturana's [34] structural coupling, which is a path that enables the evolution of categories of experience: from pure experience or firstness, to second experience or secondness, to the third category or thirdness. In cybersemiotics, firstness is everything that expresses something as a level of consciousness and that habilitates the capacity to distinguish the objective of communication from its medium. Secondness corresponds to the classification of reality; it is the establishment of meaning, which depends on the biological properties of individuals. Thirdness is the socio-communicative interaction between individuals and can only be possible across social interaction; it is where the acknowledgement of the other takes

\footnotetext{
${ }^{1}$ We understand isomorphism is "a correspondence of elements one to one, preserving the operational characteristics of the systems involved" [36].
} 
place. Brier [37] argues that it is not possible to "generate knowledge without first accepting the reality of the other, your own body and consciousness, as well as the language you use" [37].

Systemic-semiotics is based on Guddemi's interpretation of Peirce's phenomenology of experience, unlike cybersemiotics, in which principles stem from biosemiotics and Luhmann's triple autopoiesis [33, 35, 37, 38] Nevertheless, the full consequences of these principles have yet to be determined, as does the role of cybersemiotics and systemic-semiotics in systems research. Deeper research needs to be conducted into Maturana's structural coupling in order to understand the difference between cybersemiotics and systemic-semiotics approaches:

"The organization of a system is only one aspect of the relations occurring in its structure and does not exist independently from the structure in which it happens. A system maintains its class identity and remains the same under these circumstances, even if its structure changes, but only if, throughout the structural changes, the system's organization is preserved" [34].

Structural coupling is critical to understanding the direction in which changes occur and the moment they affect the levels of other scales. For example, the disproportionate growth of cells in a next-one-up structural level, the tissue, can produce far-reaching changes, which, in turn, affect the next fundamental tiers, as in metabolism or a living organism's development:
"I have named structural coupling to the dynamics of congruent structural changes that occur in a spontaneous way between systems in recurring actions (in fact, recursive), as well as the coherent structural dynamics that result from it. Living systems, as well the non-living environment in which they recursively interact, are systems structurally determined, with plastic structures that follow a course of change that emerges modulated by the flow of its interactions. As a result, living systems and their non-living environment change conjoined and congruently, forming a biosphere in the form of a multidimensional network of reciprocal structural coupling which emerges spontaneously as a result of the conservation of the autopoiesis of the living systems" [34].

Cybersemiotics, as a type of second-order cybernetics, proposes an idea in which the production of signification in biological systems depends on structural coupling. Therefore, the study of meaning in humans must aim to complete the lack of knowledge about "the self-organization of cognition and the structural coupling of observers" $[39,40]$. According to Brier [37], Peirce's semiotics combined with a cybernetic and systemic vision, such as that of Luhmann's, is what constitutes the cybersemiotics framework. However, an ontology based on Luhmann's theory of socio-communicative beings can only conceive biological systems autopoiesis. These systems perform complex tasks with an efficiency as yet out of the reach of artificial systems. In this way, the cybersemiotics theoretical background cannot solve the incommensurability among machines, consciousness, and artificial intelligence.

Bearing in mind that, in natural communication contexts, each iteration of the microcosm (the individual) with the macrocosm (the collective) involves feedback, and this process is evidence of how we update meanings with external data from our minds and personal experiences. Apparently, it is the cultural way in which we correct our mistakes or change our minds for decision-making. The systemic postulate is based on the idea that it is only at the level of macroscopic communication that semiosis is carried out, that is, the acquisition and updating of meanings. In traditional studies on transmission and acquisition of content, manipulation of behavior, and 
insertion of consumption patterns, the macroscopic level is omitted, because behavior is thought to be an area for psychology or marketing. However, significant communication or the process of significance [41] is carried out at the macroscopic level.

Communication, at the macroscopic level, is the process of transmitting information from one point to another, whether it is in the public, private, individual, or collective, where the range of possible states is assigned to code and decode $[42,43]$. For theoreticians such as Lacalle and Landowski, sociosemiotic concepts such as public and private spheres place communication in the center as an interface that regulates the transit of meaning between them. Furthermore, in social systems, communication implies conditions for assigning meaning within a range of possible states of the receiver, and this limit is cultural [44-46].

The methodological objective of the application of these sociosemiotic categories is to measure the degree of visibility of the subject in the communicative processes. Consequently, the visibility of the subject in the media defines the relations between the message and the communication channels through which the receivers get the information. In other words, the media largely determine the difference between the individual and collective interpretation of a sign, message, or speech and leave an evidence of that [47].

For semioticians like Charo Lacalle and Eric Landowski, the methodological objective of their socio semiotical categories is "to measure the degree of visibility of the subject in the communicative processes" [42]. Currently, in communication outlets hosted in social network's websites, the degrees of visibility of individuals are self-evident, whereas, over the twentieth century and the beginning of this century, the visibility of individuals as a concept was an empirical topic not yet comprehended. From a systemic approach, we can distinguish several scales in which "empirical individuals communicate, and systems of meaning make communication processes possible" [48]. Provisionally, we can divide the visibility of interactions as scales of semiotic organization: culture, society, community, and kinship, which we will explain below.

Culture refers to those interactions that correspond to the set of values and standards of a social system. These values and norms act as parameters of collective order and include beliefs (religious, esthetic, ethical, and philosophical), legal systems, political ideologies, technical practices, prevailing economic attitudes, etc. Culture polarizes strongly almost all individuals in the system, through reciprocal conditioning of behavior, which in turn. "The basic values and the resulting adaptative norms correspond to the autopoietic character of a given sociosystem, which must however adapt to internal and environmental change. It strongly polarizes nearly all the individuals in the system, through reciprocal behavioral constraints and, in turn, generates the behavior and attitudes needed to maintain its global coherence and efficiency and in some extreme cases secures its very survival" [1]. This graph relation corresponds to the organization of systems, suprasystems, and subsystems in which a social institution like language operates, as well as codependences and relevant points of interaction that can be observed [49], shown in Figure 1 as collective and public networks.

Society involves the interaction of human systems using parameters of order. Keynon De Greene [50] explains the use of order parameters as follows: when applied to complex living systems, the establishment of order describes evolutionary limits and warnings for the survival of the system. The parameter order belongs to a macroscopic, emergent collective field, in which critical points of an infinite number of microlevel interactions occur. The parameter of order expresses the stochastic generation of new structural change, as well as the deterministic maintenance of the established situation or its structural constancy. The appearance of the parameter of order represents a significant loss for the degrees of freedom at the microlevel, so that the microlevel behavior follows the parameter of order. Languages, theories, 


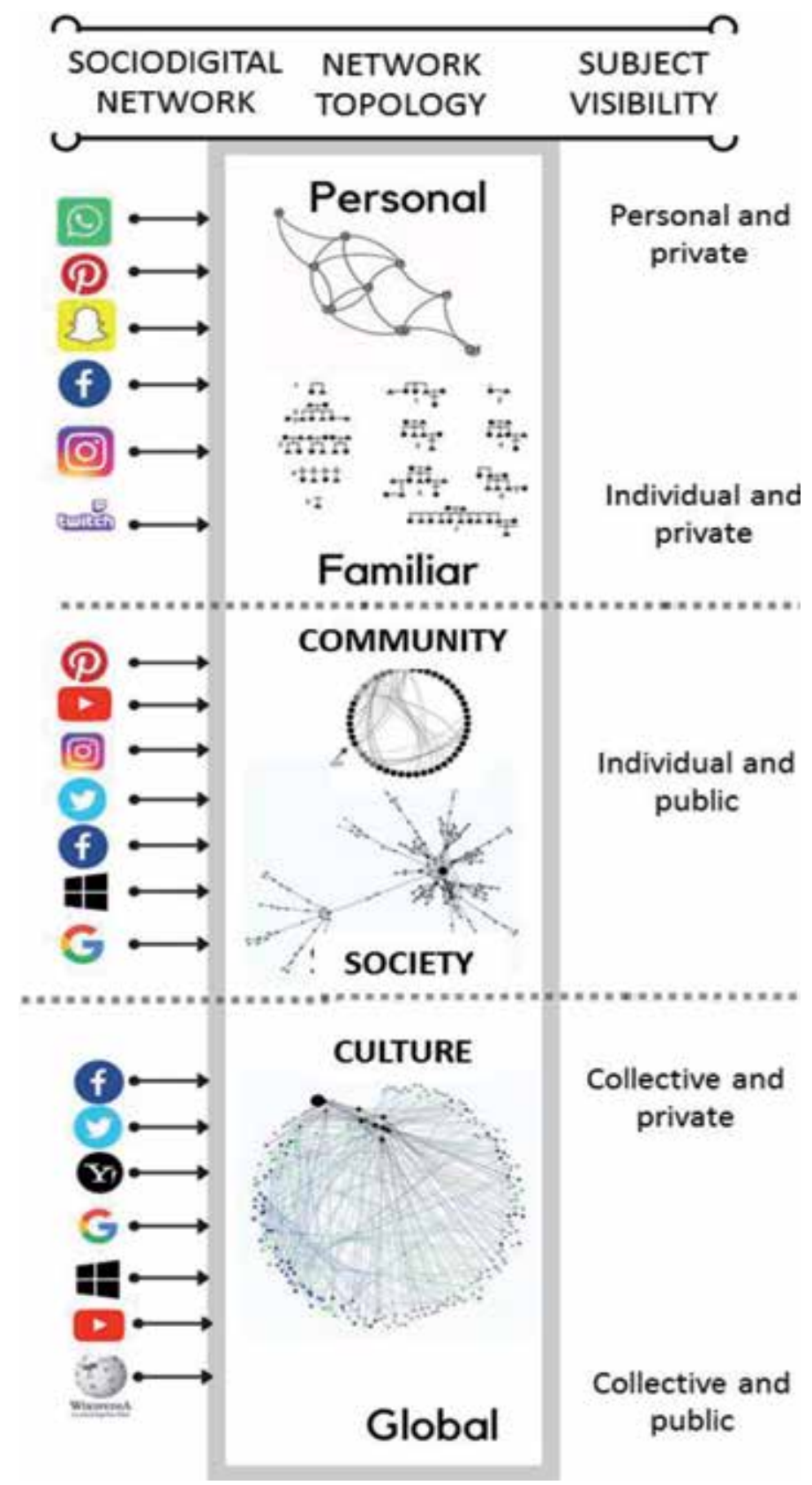

Figure 1.

The sociodigital networks and their macroscopic interaction: culture, society, community, family. Source: authors.

religions, political belief systems, economic belief systems, as well as scientific and social belief systems, such as the Newtonian paradigm, are exemplary parameters of order, shown in Figure 1 as collective and private networks.

Community, in this sense, is a type of interaction between empirical individuals who share frames of reference, similar epistemologies, and the realization of similar tests to ascertain reality in a way that mutually validates their knowledge [51]. Communities are about "the structure made of interconnected individuals who live in similar environmental conditions" [52]. Individual members do not "necessarily have to be identical, even if they are all of the same general types. They may 
very well perform different functions" [1]. Miller's theory of living systems places communities as interconnected organizations that, in turn, combine with societies [53-56] more individuals who share an identity and a common purpose, and who are committed to the joint creation of meaning through interaction [1], shown in Figure 1 as individual and public networks.

The most stable social interactions occur within the family or kinship level. They have a lot of variety of states and are the atomic units of analysis to study communities. This type of organization regulates two types of relations, according to classic theory: consanguinity and affinity relations [57]. However, approaches like Dziebel's [58] and Fortes's [59] from a systemic perspective consider kinship as a regular or egocentric network, asserting the origin node, and focused on a single family member called ego [60]. Thus, kinship relationships in a virtual or physical community are the basis of cultural networks study, shown in Figure 1 as personal and private networks.

Figure 1 is intended to clarify how the isomorphism of interaction operates across different communication interfaces and impacts the communication process. Isomorphisms from the biologic scale toward the social scale correspond to the interaction from real networks in the "network topology" column versus the social network website in the first column. Signs circulate across different scales of the network; therefore, they do not have the same communication level or share similar interactions, resulting in sign meaning not being the same as in their original semiosis.

According to Vallée [61], the multidisciplinary or transdisciplinary character of systems theory has, as its fundamental purpose, the finding of the structural isomorphisms between systems that belong to different disciplines or between representations of the same order. Wiener [62] refers to such isomorphisms as mere homomorphisms in his cybernetics work. The search for this type of isomorphism, or proper homomorphism, has led to the concept of a model that allows for the representation of a category of systems.

Nowadays, in the digital media of communication, the degree of visibility is evident through its network topology. While, in the past century, the concept of visibility and its graduation in the empirical subject was poorly understood. Note that the social network website Facebook operates across all scales, and consequently, the intimacy, privacy, and anonymity of individuals are exposed. For this reason, other social network websites where intimacy is not at risk have become more popular among young people [42].

A methodological division of the scales of symbolic organization is as follows: culture, society, community, and family, which have been explained widely in other essays [42].

Just as shown in Figure 1, and in Table 1, with these scales, it is possible to know the trajectory of a meaning through its network topology [42].

Cybersemiotics advances that interactions are necessarily evolutionary, which is also congruent with the systemic-semiotics approach. Within the types of interaction described above, social systems are integrated and constituted. In human communication, an expression serves as evidence of autopoiesis of consciousness. The changes of connectivity across networks are proof of the need to structure communication in the form of intentional relationships with entities beyond the self.

The homomorphisms of interaction are individual-private, individual-public, collective-private, and collective-public, all of which determine the type of semiosis and the visibility of individuals. Interaction occurs within culture, society, community, and family, that is, regular networks within semiotic organization.

Figure 1 also illustrates the qualitative aspects referring to the nodes and their meanings, and quantitative features such as nodes of influence involving objects, 


\begin{tabular}{clll}
\hline $\begin{array}{l}\text { Empirical } \\
\text { subject }\end{array}$ & $\begin{array}{l}\text { Sociosemiotical } \\
\text { concept }\end{array}$ & $\begin{array}{l}\text { Communicative } \\
\text { process }\end{array}$ & Sociodigital network \\
\hline Individual & Private & Intimate diary & Facebook, Snapchat, Pinterest \\
\cline { 2 - 4 } & Public & Public figure & $\begin{array}{l}\text { Twitter, Instagram, Facebook, } \\
\text { Pinterest }\end{array}$ \\
\hline Collective & Private & $\begin{array}{l}\text { Intimate community, } \\
\text { closed groups }\end{array}$ & $\begin{array}{l}\text { Online conversation services: } \\
\text { WhatsApp, Skype, Facebook, } \\
\text { Pinterest }\end{array}$ \\
\cline { 2 - 4 } & Public & Public opinion-experts & $\begin{array}{l}\text { YouTube, Facebook, Flickr, Blogs- } \\
\text { Tumblr, news, informative media }\end{array}$ \\
\hline Source: Valle Canales [49]. & & \\
\hline
\end{tabular}

Table 1.

Visibility of the subject in sociodigital networks.

persons, or signs as well as their degree of connectivity. The behavior of interactions is represented as an isomorphism of interaction network along with its homomorphisms.

In short, when messages operate at the macroscopic level, communication processes become irreversible, and the evidence is the events they generate. These events are an effect or by-product of the interaction of different sets of messages, experiences, and coherence with specific environments. Mathematically, we can abstract them and analyze them as cascades or dissipative structures.

The rule that operates at the macroscopic level is the following:

Rule 1: when a difference of interpretation is large enough, between the individual and the collective, cascades of viral information arise, in which hundreds, thousands, or millions of subjects share facts (true, suspicious, or false). In this way, a situation of nonequilibrium or instability of the original message creates long-range correlations.

However, before entering the dissipative structures, we will briefly recount what happens at the microscopic level. In other words, we will talk about the instability of the original message.

\section{The microscopic level of communication}

Semiotics studies the variety of possible semiosis [43]. Meanwhile, semiosis is the process of cooperation between three entities: a sign, its object, and its interpretant [48]. We can know these three entities in three ways: the concrete or existing object; the immediate object or the sign that the interpretant evokes in his mind in the form of an image of the concrete object; and the logical interpretant or the final meaning of the existing object. This process continues through the correlation with other signs in the mind of the interpreter, who is an empirical subject, and is expressed through a more complex sign (known as a symbol) that has a correspondence with the concrete object and various signs. Think of a politician and now meditate on the specific politician of your choice; think of all the ways you can communicate those ideas in your culture, and there you will have all the signs that make up the meaning of the politician you thought of.

Social networks function as mediators of meaning; this is a type of predicate: probably, or probably, or possibly the existing object is something in accordance with the elements provided by the media $[47,48]$. But, in sociodigital networks, a meaning can be interpreted in a different way from the original message. This phenomenon is studied through interpretive semiotics $[45,63]$. In interpretive 
semiotics, the transfer of meanings is a recursive process that generates new interconnections between semiotic systems [64]. For this reason, in the fake news factory, we can find several examples of interpretative semiotics, to be noticed: translation processes, change of linguistic code, construction of verisimilitude, or naive iconism [41].

The transfer of messages from one subsystem to another modifies the original meaning accordingly. This process is very important, since it allows the classification of objects from an original semiosis to a current semiosis, coherent with the culture, space, and time of each individual $[45,47]$. Peirce defined semiosis as an action or influence, which is or implies a cooperation between three subjects: a sign, its object, and its interpretant $[47,48]$. This relative influence of three is not fixed in any way to the action between pairs. In this way, the interpretant signs belong to the microscopic level; that is why they are unstable, because, isolated, they are incomplete. They always require an object and a sign-vehicle. In the macroscopic communication circuit, a message can acquire different interpretations than those initially thought by the transmitter to communicate. In other words, the original semiosis will never be the same as the final semiosis once the subject introduces his message in the scales of macroscopic communication: family, community, society, and culture.

Based on the cultural perspective of Eco, the meanings change through the symbolic means of each culture. In this way, the information acquired in a virtual environment, by balancing its variety of states with the concrete known environment, generates by-products as a form of entropy to balance the interpretation of the contents. The semiotic competences of dictionary and encyclopedia define the possible ranges of the interpretation of each individual [45]. In order to codify signs, the competence of the sign production must respond to the conventions of each culture; this is the encyclopedic competence. On the other hand, the competence of dictionary operates on a personal level; it depends on our experiences and personal knowledge [41, 65].

According to Charles Sanders Peirce, the sign, object, and interpretant sign only can occur as an effect of social interaction. This trivalent interaction is the semiosis, and the result is the meaning. Consequently, semiosis needs a cultural environment and individual experience. All these processes are components of phenomenology of experience. In this way, human understanding begins at a personal scale and consolidates at the macroscopic level. At that level, we will find what, within the theory, is called a sign, the minimum unit of meaning (mum), or semiotic function. For example, the signs of different languages for the entity "political candidate"

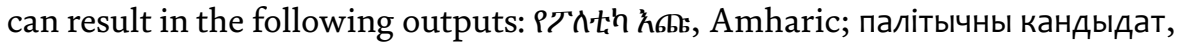
Belarusian; ผู้สมัครทางการเมือง, Tai. In that way, there is a sign with the condition of a concrete and dynamic object. In other words, the object is the entity to which the sign refers. In the previous example, through experience, we know that the object "political candidate" can take a great variety of concrete assignments within a given space and time. In this way, this entity interacts and exists within a macroscopic (where it is enunciated) and microscopic (which enunciates) environment. In the third place, an interpretive sign is missing, and that sign depends on the interpretative qualities of each person. In theoretical terms, the interpretant sign cannot be known unless someone opened someone else's head and says: "Look! Here is the sign-political candidate". However, it would be the sign "political candidate" of that time and moment, and not of this other time and moment.

The rule that operates at the microscopic level is as follows.

Rule 2: if the concrete object and the interpretant sign are separated, it is due to its inconsistency with the macroscopic context. As the difference of states in the 
interpretation gets bigger, the distance between them will grow exponentially as they circulate within the macroscopic level until reaching different regions. Thus, the approximation to equilibrium is the result of the decrease in the difference of interpretations, and this implies a transformation in the original semiosis. Consequently, the initial information has been modified; the objective and object of the original system can become completely different from its intention, emotion, or reason.

\section{The dissipative structures of communication}

Digital communication is a system of dynamic states designed to create information, whose by-product is entropy. Therefore, a way to dispel such entropy is necessary. The main objective of incorporating these presuppositions is due to the isomorphism that we have used throughout this text to explain how viral information and its social action emerge. We talk about Ilya Prigogine's theory about dissipative structures [13-16]. Ilya Prigogine postulated that matter and energy are transformed throughout a trajectory that begins at a microscopic and unstable level. The next level is the irreducible statistics by which a rupture in the temporal symmetry takes place; that is, once it enters this process, neither matter or energy can be reduced. Finally, at the macroscopic level, energy and matter find balance, and the final result is irreversible [13].

This succession, instability (chaos) $\rightarrow$ probability $\rightarrow$ irreversibility, involves properties of probabilistic evolution that can be measured [13]. In the dimension of culture, that evidence is observed through virtual environments and their statistical evolution in their network topology.

Under these criteria, we understand dissipative structures as by-products of an interpretative semiosis, which operates when there's a big difference in the interpretation between the public and the private. These structures are what network literature calls information cascade. Sun et al. [66] were the first to research this type of cascade phenomena with real Facebook data. According to these authors, the models of statistical evolution have contributed to the comprehension of how diseases are transmitted and, also, of how ideas between people are transmitted through diffusion structures. These can be small chains at the level of a family or peer conversation, or it can very well scale to the famous cascades of viral information, which, in its more outstanding cases, have effects on the objects of a concrete environment, and over the objects of a virtual environment [67].

From theory, network's interaction and topology allow observing the time of propagation of false or fake news, so that it is possible to place them within the Harry Wiener index [68].

According to the Wiener index ${ }^{2}$ there are at least two network structures through which the news can be disseminated: (1) a structure that has great depth; the propagation is slow and from person-to-person but, in a moment, it reaches a concentration point that triggers a rapid viral spread; (2) the second structure implies a rapid propagation, of long-range but little depth and its lifetime is very short.

The first kind of structure is known as "string-like," while the second kind is commonly denominated "viral" [69-72]. Nevertheless, it must be noted that the behavior itself of the propagation shows a notable difference between an artificial and a natural viralization.

\footnotetext{
${ }^{2}$ Wiener index carries the name of Harry Wiener; in his time [68], he named it "number of trajectory." It is the most antique topological index related to molecular ramification.
} 


\subsection{Artificial viralization}

During Mexico's federal elections in 2018, information played an important role in the campaign period for the presidential office. This reached such extensions that 97 communication companies asked for the initiative "Verificado" [73], to confront the amount of false news circulating through digital media. The origin of this project refers to two circumstances: the first was a citizen effort facing the 2017 earthquakes in Mexico City; secondly, in response to a growing concern about the possible intervention of foreign governments in the electoral process [74-76].

The following are the three parameters used by the Verificado team to choose the news: (1) news of the 2018 electoral period; (2) news shared more than a thousand times; and (3) false, misleading, or unverifiable news for its content. The data corresponding to "false news" had 155 entries; some are grouped into a single note, and seven of them are not news but announcements [73]. We grouped the data by name; for that, it was necessary to determine the width in the variation in the amount of news propagated per day. It should be considered that the period between March 12 and June 30,2018 , consists of 110 days, while the official period of the campaign lasted only 89 days: from March 30 to June 27, 2018. Therefore, the generation of false viral news was not continuous, but only a few days of the race. Of the complete sample, only eight of the 155 false messages were published around 24 million and 350 thousand times by Facebook ${ }^{3}$ accounts in the span of 6 days. That makes them superviral news. However, the number of times shared, their viral propagation period (from 6 to 80 days), and the content of the notes show that they constitute an anomalous case; it is not natural in human communications. It is remarkable that the content of these eight superviral fake news, which managed to be shared by Facebook accounts millions of times, refers to candidates different from those of the ruling party.

Five were on Andrés Manuel Lopez Obrador, two on Ricardo Anaya, and one on Jaime Rodriguez Calderon "El Bronco"; none mentioned the official party candidate (PRI). According to the data found in Verificado-2018 and the Facebook counting algorithm, it is shown that the total of false and misleading information was shared 120 million times. The main theme was a campaign against the former presidential candidate, Andres Manuel Lopez Obrador, who, despite the viralization of false information, won the elections. Illuminated by the data, and contrary to what some North American academic circles have predicted about the manipulation of behavior through viral information, the result in Mexico was in the opposite direction. In the particular case, everything indicates that there is no interaction between people; we are dealing with an algorithm of propagation between ghost accounts (or web robots).

A social network study carried out by Alber-Laszlo Barabasi and Peter Ruppert [76], which Aristegui Noticias (digital news) presented during the 2018 electoral campaign [77], shows several important qualities of the ghost accounts that fictionally followed the candidates: at least $50 \%$ of the accounts were bots. These accounts would, mainly, promote positive publicity about the PRI candidate and, also, propagate negative information about other candidates they followed (especially about the candidate of the Movimiento de Regeneración Nacional, [MORENA]). These all mean that someone made an effort to create an informatic automata to repeat fake information millions of times within a closed system; this is no different from repeating a name thousands of times in an empty room (or in our mind). In structural terms, this does not reach out of the microscopic level of communication. In most cases, this information caused laughter or disgust; only in the least cases, it caused the wished effects of a modification in behavior in favor of a candidate.

3 This number was obtained through Facebook's algorithm: https://graph.facebok.com. 


\subsection{Natural viralization}

A case of natural viralization, during the same elections, was \#NoAlPeriodismoSicario (no to hitman journalism). On a macroscopic scale, a person can share a fauxto, ${ }^{4}$ what is colloquially known as a meme. On 5 May, the journalist Ricardo Aleman shared a meme with the heading: "Les hablan" (they are talking to you). Next, the text in the image read: "A John Lennon lo mató un fan. A Versace lo mató un fan. A Selena la mató una fan. A ver a qué hora chairos" (John Lennon was killed by a fan. Versace was killed by a fan. Selena was killed by a fan. We are waiting, chairos). In a matter of hours, a reaction was viralized against the communicator with \#NoAlPeriodismoSicario. The version of the journalist was that sharing this fauxto was a warning for the alluded candidate. According to his interpretation, the viral response against him was evidence of a violation of his freedom of speech [78]. This case had a microscopic stable message; in the personal and familiar context of the journalist, magnicide ideas are funny. However, on a macroscopic level, by interacting and establishing diverse trajectories in networks, the meaning of a dark joke became a call to assassinate the candidate. On the macroscopic level, the journalist has the editorial voice of several media. This is why it resulted unthinkable, for network users, the conduct of this communicator in ethical terms.

The difference between the interpretation of the communicator and the interpretation of the users was huge, even contrary. On the microscopic scale, the category and class of the message of the journalist are protected by his freedom of speech. After the cascade effect, which included him being fired of several media, the journalist shared a series of answers to excuse his actions: "Televisa decidió cancelar la relación laboral con Ricardo Alemán! No la comparto pero la respeto. Toda empresa tiene derecho a contratar a quién convenga a sus intereses! Ganó el linchamiento y el reclamo de censura! Los demócratas de Morena!!!" (Televisa decided to cancel the work relation with Ricardo Aleman. I do not share it but I respect it. Every company has the right to hire whoever matches their interests! The mob law and the claim of censorship won! The democrats of MORENA) [79].

This is not the first phenomenon of such nature seen in Mexico. Just like the journalist, Ricardo Aleman, TVUNAM's former director, Nicolas Alvarado [80], was in the middle of a controversy for a comment he published on national media (concrete and virtual). The mediatic mob law these people were subject of has a close relation to the dissipative structures that are generated around their original messages. Entering the macroscopic scale, they are exposed to natural forces of tension and distension, which we observe as probabilistic evolution in the network models. In this sense, the information generated, the contents that emerge, and the changes of the concrete original object not only modify the behavior of people but can also have social action as an effect. These long-range effects are those that permit to see a new political class coming, one completely different from that of the twentieth century.

According to the data of the Verificado-2018 site, in total, the false and misleading information was shared 120 million times. Its central theme was a campaign against the candidate Andrés Manuel López Obrador, who despite the virality of the information won the elections.

The INE (Federal Electoral Institute), the electors list of Mexico consists of $41,316,706$ women and $44,637,006$ men, that is $85,953,712$ million citizens. However, in the 2018 election, only 56,611,027 citizens voted.

\footnotetext{
${ }^{4}$ Friggeri et al. [67] define fauxto as an analysis unit of cascades, which corresponds to an image that has been intentionally altered; the image can be a picture or a heading, for example, a quote or a saying. They are called colloquially "meme."
} 
The candidate with the highest number of false news spread on the networks obtained 30,113, 483 votes, in other words, $53 \%$ of the electoral preference voted by Lopez Obrador. The other two candidates of the National Action Party (PAN) in alliance with the Party of the Democratic Revolution (PRD), and the official party (PRI) obtained 22 and 16\%, respectively. The implications of this fake news anonymous behavior are at least two:

Some American politicians and scholars predicted that there exists a supposed manipulation of human behavior through viral and false information in the networks. The result in Mexico was in the opposite direction to its predictions.

The debate about the cascades of viral information is still valid. Is the massive data capable of transforming people's behavior? Is it possible to change the voting trend with fake news?

The explanation belongs to a microscopic level. The answer is into the processes of spread within social and cultural interactions.

The social and cultural scenarios are two types: digital and fleshly. A virtual environment consists of matter, energy, and mainly information. Meantime, a concrete situation is composed of primary material, energy, and less information.

The microscopic level has a probabilistic evolution over macroscopic interactions. This feature allows measuring the semiosis evolution through statistical concepts applied to Network theory. The principal notion is the 'dynamic temporal network' (dtn) [70] because data of a dtn set mathematical topologies. It is possible to predict the probabilistic evolution of cascades across five topologic properties [70]: features of the content, root characteristics of the original poster, sharing characteristics, structural characteristics, and temporary characteristics.

These properties are necessary to generate viral behavior. From the scope of systemic-semiotics, they are semiotic units. It is essential to know the limits of our analysis, which in this case are the smallest parts of significance. Umberto Eco called the minimum unit of meaning. They resemble the everyday objects of a culture insofar as they participate in semiosis. The minimum unit of meaning has an upper and a lower limit of interpretation. In this way, there is a logic of understanding within the microscopic level and it becomes different at the macroscopic level.

These fluctuations of significance are the structures of the meaning. The minimum unit of meaning changes with the semantic attributes of each category and class, and the relationship shifts all the time between the sociosemiotic interfaces. They only can occur in a natural network, viral or not.

\section{Conclusions}

Systems research is divided into three important categories: systems thinking, systems science, and systems engineering. Following this argument, the cybersemiotic approach serves as a systems thinking ontological foundation that studies consciousness. On the other hand, the systemic-semiotics approach is a foundation for systems science that studies semiosis. Systems research is a new way of doing science, sometimes called "postmodern" science, although in quite a different sense than the meaning of postmodernity in the liberal arts. The incorporation of semiotics and cybersemiotics as components of systems research occurred at a time when those disciplines were broadly fragmented and divided, in particular semiotics, and were confronted in open debate with formal linguistics. In other words, the rules of cooperation, and the consolidation of axioms and epistemic concepts about the 
processes of semiosis, surpassed a fragmented scientific community to such an extent that in some scientific circles it is often said that philosophy, its actions, and epistemic concepts are extinct.

Transdisciplinarity, nonetheless, demonstrates how knowledge evolves for the benefit of intelligence in new environments. The inscription of semiotics within the foundations of systems science alongside meta-theories, meta-methodologies, ontology, epistemology, axiology, category theory, and praxiology, among others, situates it in its rightful position to answer a most important question: how and why do we signify reality?

Semiotics is the doctrine of all signs, and a sign is something that is in place of something else in any of its properties. This definition creates a path to understanding nature's randomness and poses the real phenomena as open problems. Under this view, semiotics integrates Charles Sanders Peirce pragmatic thinking and ideas.

Systems research, cybersemiotics, and systemic-semiotics are very close to one another: cybersemiotics' scope is an important foundation of systems thinking because of its basis as a second-order cybernetics, rooted in human context and interest in intentionality. On the other hand, a systemic-semiotics' scope is a foundation of systems science and is related to a first-order cybernetics.

About the original question of this essay, is it possible to control electoral preferences through viral information-false, misleading, or true? Yes, but only when the interaction and the degree of communicative efficiency are through real individuals and not through bots. In the cases of natural viralization, it was possible to change and modify behavior, even to lead a population toward social action. On the contrary, the cases of artificial viralization are equivalent to repeating a message a million times inside an empty room.

In essence, we measure the efficiency of a communicative situation. How reliable are we communicating? Abstractly, a dynamic system of equilibrium is a kind of communicative event " $e$ ". It is equal to the sum of its communicative efficiency " $\eta$ " and its entropy " $\xi$ ". Under the rule (1): When a difference of interpretation is large enough, between the individual and the collective, cascades of viral information arise, in which hundreds, thousands, or millions of subjects share facts (true, suspicious, or false), as shown in Formula 1:

$$
e=\eta+\xi
$$

The initial entropy in an original semiosis is 0 , but as soon as it comes into contact with the macroscopic level, that entropy can grow or decrease according to the difference between the original interpretation and the massive interpretation. Therefore, entropy would be the sum of all the information chains around a category, class, and relationships between them. The rule that operates at the microscopic level is the rule 2: if the concrete object and the interpretant sign are separated, it is due to its inconsistency with the macroscopic context. As the difference of states in the interpretation gets bigger, the distance between them will grow exponentially as they circulate within the macroscopic level until reaching different regions. Network theory allows the trackability of the probabilistic evolution as shown in Formula 2:

$$
f(x)=R
$$

In the formula, $f(x)$ is a function that changes over time. The result is numerous interconnected nodes, defined by $(R)$ [70]. The final size of the cascade is the size of $f(x)$. Within the statistical properties of cascades, the increase always responds 
to exponential growth. It usually is characterized as a power law. The probabilistic evolution is $(P)$ and has a growing rate. It is the representation of the inverse of the percentage of nodes, raised to the approximate amount of information cascades or total dissipative structures, as shown in Formula 3:

$$
P=\frac{1}{R^{\xi}}
$$

The probabilistic evolution in the macroscopic level shows that the consequent results are irreversible, as the theory predicted [13-16, 28]. Because the communication circuit operates as follows: The initial stage of the signs begins with a message entering into the channel of conversation. The user conduces to match up all the uncertain data through gathering and connecting knowledge with his experience. This behavior creates control parameters. And it is followed by data that emerge attenuated or amplified.

It is the stage of the initial semiosis, and at this time, the semiosis is weak.

The next phase is the generation of disturbances or dissipative structures. Whether they arise or not will depend on the discords between individuals and the interpretation of information. Then, the processes can be measured with the tools of the graph and network theory (as propagation processes).

Finally, the difference between individual interpretations generates dissipative structures as an output.

A complex system has a complex behavior only at the collective, macroscopic level. So it is made up of public, private, collective, and individual networks and without central control, that is without leaders. This property allows generating parameters of control for messages. Consequently, it modifies the behavior of the people.

The decentralized control properties account for the sudden emergence of newly organized states of information, such as discovering new words or meeting in a lynching. Meanwhile, human trolls and web robots have leader, central objective, and centralized control. Accordingly, it is unlikely that an artificial network, such as a web robot, will manage to change people's behavior on its own. They repeat a message in an empty box.

This kind of advertisement campaign is based on creating bots to repeat massively false information inside a closed room, and it comes from the sentence attributed to the Nazis: "repeat a lie with enough frequency and it will become true." The saying attributed to the Nazis preserves a remote relation to an irrational vision from the twenty-first century. Youngsters of this new century are conscious that the effects, in reality, do not depend on wishing something a thousand times, saying hundreds of times a name, or sharing thousands of times a news in an empty room.

The interaction with reality has changed the rules of communication. The clearest example of the new communicative situation of the Web 3.0 was that the only candidate that played the rules of Web 3.0 took the themes of national interest from the macroscopic level and made them his political banner. Even a narrative about a "mafia of power" emerged, the victims of said mafia and their heroes. The narrative of the mafia of power consolidated itself as a consequence of thousands of dissipative structures along a territory during a long period of 15 years. It generated virtual and concrete networks, long-range and deep, with string-like structures.

In our opinion, natural long-range and deep networks are the reason for the massive vote for a candidate, just as it is the reason for the colossal failure of publicity without theory. Thus, the next step in a cybersemiotic investigation or systemic semiotics cut should be about the role of the natural long-range and deep networks in the semiosis process. 


\section{Author details}

Berna Leticia Valle Canales* and Julio César Chavarría Hernandez

Instituto Politécnico Nacional, Escuela Superior de Ingeniería Mecánica y Eléctrica, Mexico City, Mexico

*Address all correspondence to: bvallec1200@alumno.ipn.mx

\section{IntechOpen}

(c) 2020 The Author(s). Licensee IntechOpen. This chapter is distributed under the terms of the Creative Commons Attribution License (http://creativecommons.org/licenses/ by/3.0), which permits unrestricted use, distribution, and reproduction in any medium, provided the original work is properly cited. $(\mathrm{cc}) \mathrm{BY}$ 


\section{References}

[1] François C, editor. International Encyclopedia of Systems and Cybernetics. Vol. 2 vol. Alemania: Walter de Gruyter; 2004

[2] Valle B, Murillo S, Badillo I, Peón I, Morales O, Tejeida R. Esbozo de la semiótica con perspectiva sistémica. Comunicación y Sociedad. 2015;24:215-242

[3] Eco U. A Theory of Semiotics. London: Macmillan; 1976

[4] Hendler J. Web 3.0 Emerging. Journal. 2009;42(1):111-113. DOI: 10.1109/MC.2009.30

[5] McIntosh S. Kyiv, international institutions, and the Russian people: Three aspects of Russia's current information campaign in Ukraine. Journal of Slavic Military Studies. 2015;28:299-306. DOI: 10.1080/13518046.2015.1030263

[6] Khaldarova I, Pantti M. Fake news: The narrative battle over the Ukrainian conflict. Journalism Practice. 2016;10(7):891-901. DOI: 10.1080/17512786.2016.1163237

[7] Lanoszka A. Russian hybrid warfare and extended deterrence in eastern Europe. International Affairs. 2016;92(1):175-195

[8] Angstrom J. Escalation, emulation, and the failure of hybrid warfare in Afghanistan. Studies in Conflict \& Terrorism. 2017;40(10):838-856

[9] Swimelar S. Deploying images of enemy bodies: US image warfare and strategic narratives. Media, War \& Conflict. 2018;11(2):179-203

[10] Waldman T. Strategic narratives and US surrogate warfare. Survival. 2019;61(1):161-178
[11] Turenne N. The rumor spectrum. PLoS One. 2018;13(1):e0189080

[12] Hybrid Warfare Analytical Group of Ukraine Crisis Media Center, $\mathrm{H}$. (2018, September). How Russian Media Foments Hostility Towards The West. Retrieved from: https://disinfoportal. org/wp-content/uploads/ReportPDF/ How_Russian_Media_Foments_ Hostility_Toward_the_West-min.pdf [Accessed: 01 March 2019]

[13] Prigogine I. Las leyes del caos. Barcelona: Crítica Editorial; 1993

[14] Prigogine I. Time, structure, and fluctuations. Science. 1978;201:777-785. DOI: 10.1126/science.201.4358.777

[15] Prigogine I, Nicolis G. On symmetry-breaking instabilities in dissipative systems. The Journal of Chemical Physics. 1967;46(9): 3542-3550. DOI: 10.1063/1.1841255

[16] Nicolis G, Prigogine I. Fluctuations in nonequilibrium systems. Proceedings of the National Academy of Sciences. 1971;68(9):2102-2107. DOI: $10.1073 /$ pnas.68.9.2102

[17] Shannon CE. Prediction and entropy of printed English. Bell System Technical Journal. 1951;30(1):50-64

[18] Shannon CE. Communication in the presence of noise. Proceedings of the IEEE. 1998;86(2):447-457

[19] Luhmann N. Sistemas sociales: lineamientos para una teoría general. Barcelona: Anthropos; 1998

[20] Barabási AL. Linked: The New Science of Networks. Cambridge: Perseus Publishing; 2003

[21] Albert R, Barabási A. Statistical mechanics of complex networks. 
Reviews of Modern Physics.

2002;74(1):47. DOI: 10.1103/

RevModPhys.74.47

[22] Watts DJ, Strogatz SH. Collective dynamics of 'small-world'networks. Nature. 1998;393(6684):440. DOI: $10.1038 / 30918$

[23] Wasserman S, Faust K. Social Network Analysis: Methods and Applications. Vol. 8. Cambridge: Cambridge University Press; 1994

[24] Travers J, Milgram S. The small world problem. Psychology Today. 1967;1(1):61-67

[25] Granovetter M. Threshold models of collective behavior. American Journal of Sociology. 1978;83(6):1420-1443. DOI: $10.1086 / 226707$

[26] Granovetter MS. The strength of weak ties. American Journal of Sociology. 1977;78(6):1360-1380. DOI: $10.1086 / 225469$

[27] Rosnay DJ. Hacia una visión global. España: Editorial AC. Madrid; 1975

[28] Morin E. Le retour de l'événement. Communications. 1972;18(1):6-20

[29] Brier S. Cybersemiotics: Why information is not enough! University of Toronto Press; 2008

[30] Wilber K. Sexo, ecología, espiritualidad. Madrid: Gaia; 1997

[31] Young JZ. A Model of the Brain. Oxford: Oxford University Press; 1964

[32] Laszlo E. Evolution: The Grand Synthesis. Boston: Shambhala Publications; 1987

[33] Luhmann N. Organización y decisión, autopoiesis y entendimiento comunicativo. Barcelona: Anthropos; 1997
[34] Maturana H. Autopoiesis, structural coupling and cognition. Cybernetics \& Human Knowing. 2002;9(3-4):5-34

[35] Guddemi P. Autopoiesis, semeiosis, and co-coupling: A relational language for describing communication and adaptation. Cybernetics \& Human Knowing. 2000;7(2-3):127-145

[36] Beer S. Management Science. London: Aldus; 1968

[37] Brier S. Cybersemiotics: A new foundation for transdisciplinary theory of information, cognition, meaningful communication and the interaction between nature and culture. Integral Review. 2013;9(2):220-263

[38] Brier S. Levels of cybersemiotics: Possible ontologies of signification. Cognitive Semiotics. 2009;4:28-63

[39] Brier S. Cybersemiotics. Why Information is Not Enough. Toronto: University of Toronto Press; 2008

[40] Vidales C. Building communication theory from cybersemiotics. Cybernetics and Human Knowing. 2017;24(1):9-32

[41] Eco U. Tratado de semiótica general. Barcelona: Lumen; 2000

[42] Valle B, Morales O. Networks in modern rituals: An ethnographic method. In: Rituals: Past, Present and Future Perspectives. New York: Nova Publishers; 2017

[43] Peirce C. Collected Papers of Charles Sanders Peirce, Volume I-VI. Cambridge: Belknap Press of Harvard University Press; 1974

[44] Lacalle C. El espectador televisivo. Los programas de entretenimiento. Barcelona: GEDISA; 2003 
[45] Landowski E. Jeux optiques. In:

Actes Sémiotiques. Documents, III (22).

Université de Limoges: Limoges; 1981

[46] MacKay DM. Machines and

Societies. Man and his Future. Great

Britain: J \& A Churchill LTD.; 1963

[47] Peirce C. Obra filosófica reunida

Tomo II (1893-1913). CDMX: FCE; 2012

[48] Peirce C. Pragmatism. In: The Essential Peirce: Selected Philosophical Writings, Vol. 2. Indiana: Indiana University Press; 1998

[49] Valle B. Lo individual y lo colectivo en las TIC. Isomorfismos con el pasado y perspectivas de la era digital. Revista Iberoamericana de Comunicación.

2017;33:103-152. Universidad

Iberoamericana

[50] Greene K. Can systems dynamics be theoretically improved and, if so, does it matter practically? Systemas Research. 1994;11(3)

[51] Holzner B. Reality Construction in Society. Cambridge, Mass: Schenkman; 1968

[52] Thayer L. Communication systems. In: Laszlo E, editor. The Relevance of General Systems Theory. New York: Braziller; 1972

[53] Miller J. Living systems: Basic concepts. Behavioral Science. 1965;10

[54] Miller J. Living Systems. New York: McGraw Hill; 1978

[55] Miller J. Can systems theory generates testable hypothesis? Systems Research. 1986;3(2)

[56] Miller J. Introduction: The nature of living systems. Behavioral Science. 1990;35(3)

[57] Morgan L. Systems of Consanguinity and Affinity of the Human Family. Washington:

Smithsonian Institution; 1871

[58] Dziebel G. The Genius of Kinship.

New York: Youngstown; 2006

[59] Fortes M. The Web of Kinship among the Tallensi. London, New York: International African Institute and Oxford University Press; 1949

[60] Wasseman S. Social Network Analysis. Methods and Applications. Illinois: University of Illinois, UrbanaChampaign; 1994

[61] Vallée R. Sur les “eléments propres”. de H. von Foerster. Rev. Internat. Systémique. 1987;1(1)

[62] Wiener N. The Human Use of Human Beings: Cybernetics and Society. Boston: Houghton Mifflin; 1954

[63] Pellerey R. Comunicación: Historia, usos e interpretaciones. Barcelona: UOC; 2015

[64] Shuo-Yu C. Autopoiesis and interpretive semiosis. Biosemiotics. 2011;4(3):309-330. DOI: 10.1007/ s12304-011-9115-3

[65] Eco U. Lector in fábula-la cooperación interpretativa en el texto literario. Barcelona: Lumen; 1999

[66] Sun E, Rosenn I, Marlow C, Lento T. Gesundheit! modeling contagion through facebook news feed. Conference on Weblogs and Social Media: AAAI; 2009

[67] Friggeri A, Adamic L, Eckles D, Cheng J. Rumor Cascades. Association for the Advancement of Artificial Intelligence; 2014

[68] Wiener H. Structural determination of paraffin boiling points. Journal of the American Chemical Society. 1947;1(69):17-20. DOI: 10.1021/ ja01193a005 
[69] Goel S, Anderson A, Hofman J, Watts DJ. The structural virality of online diffusion. Management Science. 2015;62(1):180-196. DOI: 10.1287/ mnsc. 2015.2158

[70] Cheng J, Adamic L, Dow A, Kleinberg J, Leskovec J. Can cascades be predicted? In: Proceedings of the 23rd International Conference on World Wide Web. 2014. pp. 925-936. DOI: $10.1145 / 2566486.2567997$

[71] Cheng J, Adamic LA, Kleinberg JM, Leskovec J. Do cascades recur? In: Proceedings of the 25th International Conference on World Wide Web. 2016. pp. 671-681. DOI: $10.1145 / 2872427.2882993$

[72] Cheng J, Kleinberg J, Leskovec J, Liben-Nowell D, State B, Subbian K, et al. Do diffusion protocols govern cascade growth?. 2018. arXiv preprint arXiv:1805.07368. Recuperado de: https://arxiv.org/abs/1805.07368

[73] Verificado. Verificado-2018. 2018. Recuperado de: https://verificado.mx/

[74] Allcott H, Gentzkow M. Social media and fake news in the 2016 election. Journal of Economic Perspectives. 2017;31(2):211-236. DOI: 10.1257/jep.31.2.211

[75] Shane S, Goel V. Fake Russian Facebook accounts bought $\$ 100,000$ in political ads. The New York Times. 2017. Recuperado el 6 de septiembre de 2017 de: https://www.nytimes. com/2017/09/06/technology/facebookrussian-political-ads.html

[76] Ruppert P. Bots and their influence during the Mexican presidential election-A network science perspective. Maven7u. 2018. Recuperado el 20 de Junio de: http://maven7us.com/ bot-analysis/

[77] Muñoz-Ledo R. Los bots y su influencia en la elección presidencial mexicana: Albert-László Barabási. Aristegui Noticias. 2018. Recuperado el 20 de Junio de 2018 de: https:// aristeguinoticias.com/2006/mexico/ los-bots-y-su-influencia-en-la-eleccionpresidencial-mexicana-albert-laszlobarabasi/

[78] Villamil J. El periodista Ricardo Alemán sugiere en tuit asesinar a AMLO y desata oleada de críticas y condena. Revista Proceso. 2018. Recuperado el 06 de mayo de: https://www.proceso. com.mx/533026/el-periodista-ricardoaleman-sugiere-en-tuit-asesinar-aamlo-y-desata-oleada-de-criticas-ycondena-generalizada

[79] Redacción de "El Universal”. Televisa termina relación laboral con Ricardo Alemán tras polémica en Twitter. El Universal. 2018. Recuperado el 06 de mayo de 2018: http://www.eluniversal. com.mx/nacion/sociedad/televisatermina-relacion-laboral-con-ricardoaleman-tras-polemica-en-twitter

[80] Redacción Animal Político. Tras dichos contra Juan Gabriel, Nicolás Alvarado deja TV UNAM y Conapred le pide disculpa pública. 2016. Recuperado el 01 de septiembre de: https://www. animalpolitico.com/2016/09/renuncianicolas-alvarado-la-direccion-tv-unam/ 



\title{
Sources of Computer Metaphors for Visualization and Human-Computer Interaction
}

\author{
Vladimir L. Averbukh
}

\begin{abstract}
This chapter is devoted to finding sources for metaphors of computer visualization and human-computer interaction. Computer metaphor is considered the basic idea for the development of interfaces, visualization views, and scenarios of visualization and interaction. Global metaphors map the main design idea. These ideas depend on global events and changes in society, art, and science. In the "precomputer" era, such ideas formed the basics of cartography, engineering drawings, and drawing function graphs on the Cartesian plane. When designing visualization and interactive systems, computer metaphors use "magic features" beside analogies with daily life. Nowadays ideas of visualization are often based on "gamification." This approach presupposes creating tools that provide software engineers with an interface similar to that of computer games. In this chapter, ideas drawn upon fairy tales, science fiction books, fantasy films, and other similar spheres are considered as sources of computer metaphors. Such metaphors are very interesting when designing visualization systems based on virtual reality.
\end{abstract}

Keywords: computer metaphor, visualization, human-computer interface, fairy tales, magic features, fantasy

\section{Introduction}

The chapter analyzes the sources of computer visualization metaphors and human-machine interaction. The metaphor essence consists of interpretation and experience of the phenomena of one sort in terms of the phenomena of other sort.

A metaphor is the main idea of forming the types of visualization views, interfaces, and scenarios of visualization output and interaction with it.

Metaphor sources are objects of the surrounding world, scientific ideas, ideas derived from literature, folklore, sci-fi cinema, computer games, etc.

Metaphorization is based on interaction structures of source and target domains. In the process of metaphorization, some objects of target domain are structured on an example of objects of target domain, and there is a metaphorical mapping (projection) of one domain onto another. That is how the metaphor can be understood as a map from source domain onto target domain, and this map is strictly structured [1]. Metaphor ideas are often based on real life as well as on abstract scientific ideas. Worth mentioning are such examples of pre-computer era visualization as cartography, engineering graphics, and Cartesian coordinates, which 
played a crucial role in the development of modern civilization. Cartesian coordinates were the basis for the idea of computer graphics during the first period of its development. The use of new ideas is connected with developing the means for human-computer interaction. It is in this field that such metaphors as a light button and light button menu appeared. The most well-known and still popular desktop metaphor is also connected with interfaces intended to provide interaction in office work computerization. The desktop metaphor is almost entirely based on office work realities. However, there is a double-click, which can be called a magic feature and is unparalleled in real life. Further, such magic features were added in a whole range of metaphors used in computer visualization systems. The emergence of virtual reality as an environment for computer visualization made the use of metaphors relevant. Conditions inherent to virtual reality are somewhat similar to magic and science fiction. That is why fairy tales and sci-fi in literature and cinema may become an interesting source of new metaphors.

Below we shall discuss the main ideas of pre-computer visualization, the potentials of metaphors based on real-life phenomena and on scientific ideas. Then we shall analyze the potentials of fairy tales as sources of metaphors. We shall also provide several examples of metaphors based on science fiction and discuss the evolution of visualization from a comic book to immersive cinema.

\section{Global visualization metaphors}

The concept of metaphors is popular in publications on computer visualization and human-computer interaction. One may reveal the following two cases of using this concept:

A metaphor as the basic idea of data presentation, the idea of convergence of entities of a computer system, and a source domain.

A metaphor as the idea of interaction with the [virtual] environment created by computer systems.

The following hierarchy of computer metaphors is considered:

- Global metaphors of design

- Basic visualization and interface metaphors

- Local metaphors

Global metaphors map the main design idea. For example, considering the world as a "super office." (The whole world is an office, and all the men and women are merely clerks in it).

Let us consider global visualization metaphors. These ideas depend on global events and changes in society, art, and science. We are interested in global metaphors that have a visual ("pre-computer" and computer) representation. These ideas formed the basics of cartography, engineering drawings, and function graphs on the Cartesian plane.

We review the interference of metaphorical ideas and the challenges facing economy, science, and education in the past and now.

Modern cartography is the result of geography development and a prerequisite for the Age of Exploration. The use of the Mercator projection and the grid of parallels and meridians in the modern age is a great achievement in the visualization of geographical and navigation data. 
Variations of geographical metaphors are used now in data visualization and software visualization systems.

Engineering drawing is the product of the Industrial Revolution, its prerequisite and an important tool. Multiple views and projections, a set of rules depicting product features, compile a certain explicit code.

Engineering drawing in the form of CAD systems is an integral part of computer tools of modern engineers.

One of the most powerful visualization ideas of the modern age is the idea to draw function graphs in Cartesian coordinates. The idea of function reflects rather abstract concepts, but due to graph drawings, even very young students may become familiar with them.

2D and 3D graph drawings are the bases of modern scientific visualization and an important part of data and software visualization [2].

\section{Computer metaphors}

For a start, let us revise the way things were in the field of human-computer interface before the emergence of visual metaphors. In those times software engineers (who comprised the basic quota of users all over the world) still remembered working with bulky computer consoles. Command-line interface prevailed in interactive systems. For instance, text editing commands included operation indication, the number of source line (sometimes the number of a symbol in the line as well), and (if necessary) the new text for correction or pasting. Such an interface, although it required from the user to keep in mind a continuously changing text, and despite occasional mishaps with saving the changes, was tolerable enough for professionals. Graphic displays gave a new impetus to human-computer interaction. Along with the tools of data visualization, program interface tools came into use. Based on that, light buttons (an output primitive used to emulate a functional key) and light button menu came into exploitation. With their help one could easily interact both with the program's system and with the user's program.

The mass arrival of personal computers simply could not have happened without the emergence of visual interaction tools, new devices, and brand-new concepts of interface organization with the user, for example, the concept of direct manipulation.

The concept of direct manipulation was suggested in the early 1980s by Professor B. Shneiderman, a famous expert in the field of computational sciences, who combined and analyzed new trends in organizing the interface. Currently, this concept prevails in interface design.

B. Shneiderman determined the following features of an interface created on the basis of the direct manipulation concept:

\section{Continuous depiction of the object of interest}

2. Physical actions (manipulations with the mouse, joystick, touch screen, etc.) or using a functional keyboard instead of commands with complex syntax

3. Quick operations, divisible into steps and allowing resets, with an instantly visible effect on the object of interest

The essence of this approach to interface creation is in making the user perceive their activity as direct manipulation with the objects displayed on the screen, rather than as a dialog with the computer regarding these objects. Instead of using 
command language to describe operations with objects, the user manipulates visible perceptions of these objects on the screen.

The interface metaphor is considered as the basic idea of convergence and similarity between model objects of an applied field and interactive objects. The role of an interface metaphor is to facilitate better understanding of interaction semantics, as well as to provide a visual idea of dialog objects and define the set of user manipulations with them.

The interface metaphor in this respect is seen as the basis of the semiotic system, which in turn underlies the interactive language. With the help of this language, the user forms their task and achieves the solution by means of a computer. The interface metaphor does not only help describe abstractions but also structures the understanding of a new applied field and defines objects of the interactive [visual] language [3].

The most recent global metaphor is the basis of modern computerization. For a variety of economic and social reasons, people at the end of the twentieth century understood the world around them not as a workshop where employees work but as an office where clerks and managers spend their time. The cornerstone of a desktop metaphor success is tightly linked with this change in the awareness of the world. Results of modern computerization (and the desktop metaphor) reflect global ideas of modern "postindustrial" world. However, "office" interfaces generate office activity techniques in such "non-office" domains as medicine or education. This often involves non grata effects.

Originally, this metaphor was offered for office automation systems, but then its use was expanded for operating systems interfaces. These ideas were linked with enduser programming, as the means for office clerks and managers to simplify their work using computers.

The desktop metaphor became the most frequent practice in the 1990s. This metaphor is in many respects the basis of modern visual interfaces. The success of a desktop metaphor, undoubtedly, is connected not only (and not so much) with the natural figurativeness of icons that are [not always] clear to users but with logicality and systematic nature of all activities within visual environments based on this metaphor.

The formula of a desktop metaphor is described in [1]. Apart from borrowing office work realities, this metaphor has a "magic" idea: all actions within the system are made by means of double-clicking on icons.

Significantly, desktop metaphor extensions toward an office desk metaphor, office space metaphor, and a filing cabinet metaphor were not very successful, despite interesting solutions and the use of several magic features.

\section{Fairy tales and science fiction as a source for metaphors}

By providing calculation results, visualization ensures interpretation and analysis of the acquired data. The following subfields of computer visualization can be distinguished: scientific visualization, software visualization, and information visualization. Scientific visualization presupposes using the means of computer graphics and human-computer interaction to provide data on objects, processes, and phenomena, modeled in scientific calculations. Software visualization means a combination of methods of using graphics and human-computer interaction tools used for better understanding of phenomena and for efficient exploitation of the software, as well as for specification and presentation of software objects in the process of program creation. The term information visualization relates to visual description 
and presentation of abstract information acquired as a result of gathering and processing data of different types and functions.

Typically, scientific visualization uses traditional (pre-computer) methods of displaying mathematical, physical, chemical, biological, and other models (e.g., two-dimensional and three-dimensional function graphs). Sometimes the imagery natural and/or typical for a given application is also used, for example, molecule presentations in modeling chemical processes. Traditional imagery, sometimes borrowed from the pre-computer static graphics, is also used in information visualization. One may conclude that the use of metaphors in scientific and information visualization is limited.

Computer metaphors became most widely used in software visualization systems. These metaphors are based on objects and phenomena of the real world or on models derived from specific branches of science. Among these metaphors the most popular are spatial metaphors: the city metaphor or the landscape metaphor and their variations in particular. Spatial (three-dimensional) metaphors are actively applied in developing presentation views in visualization systems used for monitoring, testing, and debugging parallel and distributed programs, as well as programs for processing events and providing reactions to them. These metaphors are widely used in the systems based on virtual reality [4-7].

Using a city metaphor presupposes structuring the input data by means of internal city structure containing separate blocks, streets, and buildings. The naturalness of metaphors causes both simplicity of orientation in space and navigation ease. In software visualization systems within a city or a landscape, metaphor transport arteries are often used to represent control flows and data flows, as well as various connections between objects and program components. When using these metaphors in the systems based on virtual reality, a flight over the city is possible. There are examples of software visualization systems based on an extended city/ building/room metaphor with the use of teleportation for immediate relocation between city districts or buildings representing different elements of a big software complex.

A cosmic metaphor in its modern sense, with a heliocentric worldview, is chosen as an idea for a visual programming medium. At the same time, parts of the entities of the program are represented as planets, their satellites, rings (like the rings of Saturn), and other elements of outer space. It seems that in the case of virtual reality application, the most archaic $3 \mathrm{D}$ version of a geocentric model may be more convenient, with the Earth represented as being flat and celestial bodies located on hemispheres covering the flat Earth [8].

Based on scientific views, a molecule metaphor in particular can be used to visualize performance traces and graphs for parallel programs. This metaphor provides representation view of a large volume of structured data. Interpreting a physical molecule (particle) metaphor and its modifications is generally simple and natural, although it requires certain (basic) knowledge of physics from the user. Moving and navigation can be executed by means of flying around the molecule (or a set of particles). This means, a molecule metaphor, in the same way as a city/ landscape metaphor, includes some magic or fantastic features.

The paper [9] describes the original brain metaphor, which is used for animated representation of a parallel program performance. The idea of visualizing brain activity when presenting it with some stimuli is transferred onto a program or an application's performance visualization (activating procedures and functions, input/output, etc.). Let us note that this metaphor does not have any magic features; possibly, this is what hampers perception of a large volume of information based on it. 
Currently the idea of gamification has been gaining popularity. It implies the use of computer game ideas in non-gaming fields of application. When developing software visualization systems, this approach presupposes creating tools that provide software engineers with an interface similar to that of computer games. The paper [5] discusses a software visualization system based on virtual reality with the use of virtual reality. A city metaphor is the basic metaphor for this system. However, both the imagery and the method of interaction in the system strongly resemble popular computer games.

Gamification in software visualization system development based on virtual reality is also mentioned in the paper [10]. An environment based on virtual reality is described, which should provide work with the structures of a program code using city metaphors and cosmic metaphors for visualization, navigation, and program code data transfer in an interactive mode. Games have been released that have demonstrated the potential of gamification for the purposes of enhancing the understanding of structural dependencies and code modularization.

Thus, everyday reality, scientific ideas, and modern computer games serve as sources for metaphors. Further, we shall look at fairy tales and science fiction, where objects with magic features are used and characters have magic abilities, as sources. Magic ideas described in fantasy novels or in literary processed folklore fairy tales are the most functional and consequently the most useful ones for our purposes.

An important issue when forming scientific and, in particular, computer metaphors is the question of where to find the source [11,12]. The description of the constructive procedure of searching and/or generating interface metaphors is presented in [13]. This multistage procedure provides (among other things) the consideration of application domains, user tasks, and user characteristics.

Interest to "magic" in connection with HCI and interface metaphors has been shown in the early 1990s. Significant attention has been given to the concept of "magic features." This concept in the context of HCI was introduced for the first time by [14].

The issue of magic and magic features as a source for metaphors when developing interactive visual software complexes is also discussed in the paper [15] (see also [16]).

The word "magic" is very popular as part of metaphoric names for interface techniques, for example, a "magic lens," a "magic mirror," a "magic lancet," etc. In [17] a number of specific examples from stage magic are presented, and application of its principles and techniques in human interface design is discussed. The article [18] is devoted to sources of metaphor for tangible user interfaces. Authors suppose magic and paranormal phenomena could be a fruitful place to look for new metaphors for tangible user interfaces. Also, voodoo magic is considered an interesting idea for interfaces with virtual objects. In [19] Voodoo doll technique is used as a two-handed interaction technique for manipulating objects at a distance in immersive virtual environments.

Ideas for interface metaphor design, linked with magic fairy tales, fantasy, and science fiction novels, are described in a number of articles. In [20], for example, the magic metaphor of a flying carpet is mentioned, but in [21] the metaphor of a magic carpet is realized, for instance, moving in the virtual reality environment. In [22-26], the ways of using a "magic wand" are described. A magic wand is considered a manipulation metaphor to form an interface in systems with elements of virtual reality. Interesting ideas of wonder objects (e.g., a magic mirror) were proposed (and realized in prototype versions) for storytelling in modern museums [27]. In [28] an information system using a city metaphor is described. In this system, magic/fantastic opportunities are used on a regular basis. Among these 
opportunities there is "tunneling through space" presenting the typical adoption from science fiction. Rooms with "magic windows" may also be considered as a magic (science fiction) feature. A "magic window" is an interesting expansion of a well-known information wall metaphor.

Here we consider fantastic magic features, selecting the samples that are fruitful for interface and visualization metaphors.

Magic transport: In fairy tales and science fiction novels, one can find:

a. Teleportation-an instant movement by means of verbal influence (spell) or by means of manipulations with any objects or uses of such devices as teleports

b. A rather slow movement by means of magic transport. A magic transfer may take place both for subjects and for (animated and inanimate) objects of magic

Magic navigation means: An example is a milestone with a magic legend or a magic clew, following which one may reach Fairyland.

Magic communication means: An example is a magic mirror tuned on an interesting character for his/her protection or observation.

Magic (additional to normal) opportunities for manipulations with objects, processes, and even natural phenomena. In some options a superpower, invincibility, etc. Generally speaking, one can use the term "magic power" (or "superpower"). These manipulations and powers may be executed through spells and objective magic, as well as through the universal manipulator, a magic wand.

One can set out the general class of magic objects as objects possessing "magic properties." Thus, magic expansion of usual functionality is possible (for example, seven-league boots), as well as attributing additional, unusual in real life functions to objects (for example, Aladdin's magic lamp used to summon, activate and neutralize magic beings). For the purpose of magic objects used as manipulators, transport and communication means one can also use the term "magic tools."

Magic transformations of objects: As an example, one may consider the construction of palaces by the Genie in the Arabic fairy tale or the transformation a pumpkin into the carriage for Cinderella.

Similarly to magic objects, magic subjects may be set out, i.e., evil, good, or neutral (with respect to the characters) magicians possessing superpowers. (As an option-magic anthropomorphic beings, e.g., fairies, gnomes, trolls, genies, etc.)

Magic transformations of persons: In fairy tales such transformations may be spontaneous, unexpected for the characters, or they may result from magic actions (some magic spells or manipulations). These transformations can be carried out in view of sympathetic magic (i.e., magic based on a certain similarity).

Our attention was focused on two "magic-fantastic" metaphors from the novels (and also the films) about Harry Potter. These are speaking and moving portraits and the Marauder's Map, which even showed people's movements on it. In this case, portraits of dead people are the active objects. They may address the living characters of the novel without requests and even move from one portrait frame to another to pay visits to each other. The map continuously traces and shows the location of the person under observation.

There are many active, anthropomorphic, and speaking characters in fairy tales and in science fiction novels such as Golem, robots of K. Capek and I. Asimov, and so on. Similarly, there are numerous variations of magic/fantastic means of navigation and search both in fairy tales and in fantasy. 
In these magic metaphors, visual characteristics are not as important as spontaneous activity inherent to generated objects and subjects. Spontaneous activity can be considered the means of imitating reasonable behavior. Of importance is also the character's existence independently of users, imitating reasonable behavior. In sci-fi and popular scientific literature and films such active computer, "subjects"

appeared several decades ago. In modern computer practice, agents who are active under their own initiative frequently cause irritation. We started our research of active intellectual agents to understand what, why, and where active intellectual agents have to do.

The idea of an "active" map showing a real landscape and movements of objects was considered. The "activity" of a map can be connected to events, in the same way as in navigating systems: moving around, turning, crossing, and so on; but "activity" can also be spontaneous, connected with time events. Another idea that may be possible is the development of an "active" scheme of a protected apartment or territory. In this case tracking systems and "highlighting" persons may be necessary. Movements of all characters without exception may be shown on the scheme, and labels will allow identification. In the context of the given ideas, it may be noted that works in this direction, on the basis of such systems as GPS, are underway and there are examples of interactive maps serving as guide advisers. Moreover, now it is easy to develop speaking anthropomorphic avatar agents, and there are many examples of such implementations.

We have decided to link the idea of active agents based on a metaphor of a speaking portrait with the expert system. The point is that an active agent with its (possibly) importunate activity is authorized only in the case of teaching systems. The logic of project development led us to the following idea of an "active textbook." This textbook has to be able to analyze the student's behavior in the process of studying, for example, the time of reading, manipulations with the text, and so on. Based on these analyses, the "active textbook" may detail teaching material, search new data sources, or turn to other things. The analysis of a user behavior may be accomplished at a syntactic level (at a level of operations with a mouse and a keyboard, eye tracking, etc.) and on a semantic one (monitoring opened files or sites, running applications, recording events, etc.). Such analysis and elements of programming by demonstrations will allow our system to learn how to teach in the process of its use and to operate in the given direction "independently." It is also possible to supply the system with adviser functions. The system will be like an intelligent human adviser and will not impose its opinion but provide recommendations and solutions. This human-like behavior may be provided by psychologically driven slowdowns in the system's activity.

Expansion of a city metaphor used in software visualization systems is suggested by means of adding active agents by inputting parameters into certain functions and methods. The agents can move around the city, determining the locations where they are used and changed and the way the process of algorithm work plays out. This way, an extended metaphor creates such additional properties as the opportunity to observe software objects inside buildings or rooms, reflecting particular entities while active agents move around the city.

In visualization systems based on virtual reality environments, there are such tasks where complex manipulations with objects are necessary, for example, pulling something out, cutting, or zooming in. As a metaphor of the tool for such tasks, first of all, the idea of a magic wand comes into designer's mind. However, a magic wand does not have differentiated actions and hence requires the means to change operating modes. In specialized systems, it is more natural to use specialized "magic tools." For example, in medical information system as manipulator's metaphor, the idea of a "magic lancet" is offered. The lancet allows to "dissect" this or that 
organism area for profound exploration. When "dissecting” any human organism object, all physical changes are visualized, as if we did it in a reality. In case of a combination of a "magic lancet" metaphor with a three-dimensional model of a human body, one may obtain the virtual model of operations, and a prototype system of information visualization for medical purposes is in progress now. Systems based on this metaphor may be used, for example, to teach surgery [29].

Science fiction may be an implicit source of metaphors used to control visual objects in virtual reality environments. Thus, for instance, the paper [30] describes an environment for an experiment studying psychological states in virtual environments. A user has to manipulate cubes to compose a given pattern. These cubes in the virtual environments are "caught" with a special trap, in which an antigravity movement mode to a necessary point or a cube rotation mode may be activated. When using a special command, the cube rises over the virtual table and flies in the location set by the user.

Our preliminary research shows the applicability of "magic" metaphors for tasks in interactive systems and systems based on virtual reality environments. For example, the search of metaphors for movements in virtual environments may require magic transportation techniques, such as teleports and flights of various types (the flying carpet, the flying ship, Roc, a winged horse). Metaphors of intellectual agents-informants may also be based on magic means of navigation.

In fairy tales and science fiction novels, one can find a lot of magic phenomena, such as magic knowledge, war magic, fulfillments of desires, telepathy and thoughtreading, etc. But we do not know for sure yet, whether these features are useful for metaphor search. However, for a choice of metaphors for manipulations with objects and processes in virtual environments, "the war magic" may be of interest. War magic is connected with transferring the events taking place in the magical world into reality. For example, any variations of "magic chess," where games with chess pieces are transferred into land battles, or the "naval" military magic where models of fight in a vat of water are transferred into sea battles. One may find these ideas (partially close to voodoo magic) in a number of folk and literary fairy tales.

Note that folk fairy tales are governed by rigorous logic of plot development and a choice of characters. By the way, in literary fairy tales and fantasy novels, this logic is also typically observed.

Analysis shows that exotic "magic" metaphors may be used to form any interface features. However, implementation of interactive systems on their basis may be both complex and contradictory. Magic metaphors are frequently transformed into abstract interface opportunities, losing the appreciable connection with initial ideas. For example, in case of a speaking portrait metaphor, the anthropopathy of an agent turned out to be unnecessary. But it is necessary to endow it with the function of a magic assistant/conductor into the world of knowledge. Of course, the transmuted abstractness of metaphors is an advantage rather than a defect of their use. In the systems created, for example, for office automation or for end-user programming, the presence of magic interface manuals may appear as a distracting or even irritating factor. However, using such "magic features" as automatic return of electronic analogs of paper documents on their place at the end of processing may be carried out without any special warnings even for non-expert users. Such features are well-conformed to common sense of clerks and do not demand unnecessary efforts during operations. Infringement of magic logic due to any absurd ideas or too farfetched subjective likeness may lead to serious mistakes. Sharp criticism of interface metaphors as such is connected with the infringement of magic logic in the early version of Apple's interface (using the trash can metaphor to eject disks) [14]. 


\section{Metaphors for systems based on virtual reality}

Virtual reality environments were initially used for aviation and space simulation training systems. They gained widespread use in entertainment systems and computer games. They are also used in medicine and psychology for therapeutic purposes. We are interested in virtual reality as a basis for computer visualization systems development. The imagery used in virtual reality systems can be adopted from the imagery inherent to a certain computer model. However, for software visualization, systems based on virtual reality metaphors are typically used. Such systems can benefit from (or even require) fairy tale features described above. In this respect, we are interested in interface metaphors which are applied in virtual reality.

The role of interface metaphor is to promote the best understanding of interaction semantics and to determine the visual representation of dialog objects and a set of user manipulations with them. A metaphor, considered as a basis of the sign system, in turn underlies a dialog language. A user articulates the problem with the help of this language and achieves solution from the computer. The metaphor helps to describe abstraction and provide structural understanding of a new applied area but also assigns dialog [visual] language objects. Interface metaphors may be considered a special case of scientific metaphor used for generating new or additional senses to understand new facts and phenomena.

Virtual reality is characterized by a set of specific states, above all, presence, involving a human perceiving themselves inside a virtual environment with various features. Due to experiencing presence, a person finds themselves in situations similar to those of fairy tales and science fiction, even if no magic metaphors were applied (e.g., finding oneself inside a brain or a molecule). In such conditions, the use of magic features described above is reasonable, both for navigation and movement in a virtual environment and for interaction with the objects of this environment.

A project of a virtual environment designed for modeling visual search in large space may use either emerging magic signs or talking objects to facilitate user navigation. In virtual reality systems, a magic wand may be useful as an interface metaphor to point at objects and interact with them. The idea of teleportation is interesting in virtual reality systems for movement organization, as it provides the possibility of instant movement to a new virtual scene.

\section{The butterfly effect}

Interesting metaphors may be adopted from science fiction works. Thus, a time machine metaphor and a butterfly effect metaphor were used in a project of an environment for adjusting parallel programs dealing with software visualization systems [31].

One may consider time as an axis that is analogous to traditional spatial axes. And the event stream may be depicted along this axis. Any change in this stream may break the whole chain of cause-and-effect relations. In this case, the idea of traveling in time in both directions seems to be natural. One may consider a set of parallel processes as consistent streams of events flowing and changing along this time axis. In this case, effects of an event in the process cause a reaction, affecting both the process in which it has occurred and other processes. It is possible to correct errors by going back in time along the axis and interfering with the sequence of events at the moment. This approach can be described as the "time machine" 
metaphor. Note that the use of the time machine metaphor does not require any knowledge of the source (science fiction novels). We have developed a prototype of a visualization component for a parallel process control and representation system. This system can be used for debugging parallel programs. We use 3D imagery to visualize processes. Processes are represented by color cylinders connected with each other by thin "threads" (similarly to visual representations in the VisuaLinda system [32]). Globules representing data move along these threads. The states of processes are depicted by colors. A user may navigate along the time axis and change the processes'states. The time machine metaphor may be considered similar to a traditional record player metaphor. However, in the case of a time machine, there is a possibility of event changes described by the well-known butterfly effect metaphor, which is connected with the situation when a small change of initial conditions causes significant and often unpredictable effects.

A time machine metaphor seemed promising for software visualization of parallel computing. However, after analyzing its implementation, this impression may change. In this case further development of fully fledged debugging and visualization facilities for parallel programs is needed, for example, trapping events, online visualization, and other tools similar to those implemented in the debuggers of the 1990 s, such as $[33,34]$. These metaphors may also be applied in the systems of software visualization based on virtual reality [31].

\section{Visualization texts: From interactive comics to motion pictures with immersion}

Present-day comics and manga may be described in terms of visual texts. You can describe rich and complex languages of pictorial art based on natural imagery, but in this case, the task of a detailed language description is rather complex and often uncertain. One can also describe complex and weakly formalizable dynamic languages of cinema and animation. Similarly, one can define graphical texts associated with computer visualization. The examples of those visualization texts are:

- Isolated displays

- Dynamic, logically related shot changes with the inclusion of interaction

- Animations also with the inclusion of interaction

The goal of visualization is to leverage the existing scientific methods by providing new scientific insight into visual methods. Virtual reality environments are actively used to practice leaping into a new quality of cognitive visualization. Virtual environments are characterized by such features as egocentric points of view and user-centered, often multisensory, interactions. Virtual reality environments are dynamic, rather than static. The user's experience of the virtual world may combine a visual channel with auditory or haptic feedback. Immersion and sense of presence (the feeling of "being there") are factors which define virtual reality. The sense of presence distinguishes virtual reality from "traditional” 3D computer graphics. Users "immersed" in virtual reality control the graphics output. Users may also participate in adaptive control of the application system. The essence of virtual reality is in the interaction between the user and the virtual environment. The interpretation principle for graphical texts was formulated as follows: interpretation of such texts is possible only if the "readers" of the text have external information. 
This principle is similar to the principle of intuitive use. The interpretation principle is very important in the case of visualization based on virtual reality.

One may consider the evolution from comic-like visualization methods to controlled animation-like movies and from these movies to full insight and controlled immersion processes. In its own right, visualization languages of virtual reality may be considered; however, a visualization language in the case of "immersion movies" becomes much more complicated and needs further description. It appears that a new quality of visualization can be achieved primarily through the following media:

\section{Immersion in virtual reality}

\section{Creation of an interactive "movie"}

\section{Presence of a controlled and modifiable "screen story" ("movie" script)}

The language of this script is the language of visualization description (and possibly of visualization depiction-in the case of visual languages). The languages have to support history tracing, including visualization and interaction traces and fixing insight experiences. Examples of "immersion movies" will be used in computer visualization systems.

\section{Conclusion}

The issue of finding the sources arouses a whole range of questions. First, an assessment of metaphor applicability is necessary both for the given applications and for a specific task. When assessing the applicability of a metaphor, one should evaluate the way this metaphor can depict the features of a certain application, for which the visualization system is built. However, imaging precision does not necessarily guarantee success for the system. For example, a brain metaphor, precisely depicting the work of a parallel program, is not very convenient in terms of perception, which strongly hampers visualization perception. Magic features are useful in addition to the complex of computer metaphors but are not sufficient. There are examples when a metaphor, for various reasons, was not successful even after introducing these features. Gamification is an interesting idea. However, the question remains whether game components risk distracting the user from their intellectual activity by putting them into a silly, playful mood. Distraction from the main task may also be caused by the magic features of metaphors, especially in environments based on virtual reality. When using virtual reality, one should also analyze the potential user states in terms of increasing or decreasing performance. All these thoughts show that research of substantial user groups is necessary. It is worth noting that in case of software visualization, this research is relevant, as there is a considerable number of tasks and a significant number of experts. 


\section{Author details}

Vladimir L. Averbukh

Krasovskii Institute of Mathematics and Mechanics UrB RAS, Ural Federal

University, Yekaterinburg, Russia

*Address all correspondence to: averbukh@imm.uran.ru

\section{IntechOpen}

(C) 2019 The Author(s). Licensee IntechOpen. This chapter is distributed under the terms of the Creative Commons Attribution License (http://creativecommons.org/licenses/ by/3.0), which permits unrestricted use, distribution, and reproduction in any medium, provided the original work is properly cited. (c) BY 


\section{References}

[1] Averbukh VL. Semiotic analysis of computer visualization. In: Interdisciplinary Approaches to Semiotics. Rijeka, Croatia: InTech; 2017. pp. 97-133

[2] Averbukh V. Global visualization metaphors. In: Abstracts of 2nd Conference and Exhibition on Semiotics and Visual Communication. Lemesos, Cyprus: University of Technology; 2015. p. 2015

[3] Shneiderman B. Direct manipulation: A step beyond programming languages (abstract only). ACM SIGSOC Bulletin. 1982;13(2-3):143

[4] Romano S, Capece N, Erra U, Scanniello G, Lanza M. On the use of virtual reality in software visualization: The case of the city metaphor. Information and Software Technology. 2019;114:92-106

[5] Merino L, Ghafari M, Anslow C, Nierstrasz O. CityVR: Gameful software visualization. In: IEEE International Conference on Software Maintenance and Evolution (ICSME TD Track). 2017. pp. 633-637

[6] Vincur J, Navrat P, Polasek I. VR City: Software analysis in virtual reality environment. In: 2017 IEEE

International Conference on Software Quality. Reliability and Security Companion. IEEE; 2017. pp. 509-516

[7] Schreiber A, Misiak M. Visualizing software architectures in virtual reality with an island metaphor. In: Chen J, Fragomeni G, editors. Virtual, Augmented and Mixed Reality: Interaction, Navigation, Visualization, Embodiment, and Simulation. VAMR 2018. Vol. 10909 of Lecture Notes in Computer Science. Springer; 2018. pp. 168-182

[8] Averbukh V, Averbukh N, Vasev P, Gvozdarev I, Levchuk G, Melkozerov L, et al. Metaphors for software visualization systems based on virtual reality. In: De Paolis L, Bourdot P, editors. Augmented Reality, Virtual Reality, and Computer Graphics. AVR 2019. Vol. 11613 of Lecture Notes in Computer Science. Springer; 2019. pp. $60-70$

[9] Palepu VK, Jones JA. Visualizing constituent behaviors within executions. In: Proceedings of the 1st Working Conference on Software Visualization (VISSOFT). IEEE Computer Society. 2013. p. 4

[10] Oberhauser R, Carsten L. Gamified virtual reality for program code structure comprehension. The International Journal of Virtual Reality. 2017;17(02):7988

[11] Averbukh VL. The origins of computer metaphors. Survey and analysis. In: Blashki K, editor.

Proceedings of IADIS International Conference "Interfaces and Human Computer Interaction 2010" (Part of the IADIS Multi Conference on Computer Science and Information Systems 2010). Freiburg, Germany: IADIS Press; 2010. pp. 391-395

[12] Kuhn W. Metaphors create theories for users. Lecture Notes in Computer Science. 1993;716:366-376

[13] Dinesh K. Visualization of Interface Metaphor for Software: An Engineering Approach. India: Birla Institute of Technology and Science (BITS); 2005

[14] Kay A. User interface: A personal view. In: Laurel B, editor. The Art of Human-Computer Interface Design. Reading, Massachusetts: Addison-Wesley; 1990. pp. 191-207

[15] Averbukh VL. Magic fairy tales as source for interface metaphors. Journal HCI Vistas. 2008;IV. UX Design/ Article 9.December 
[16] Averbukh VL. Magic Fairy Tales as Source for Interface Metaphors. 2008. Preprint at ArXiv:0811.1974

[17] Principles TB. Techniques, and ethics of stage magic and their application to human lnterface Design. In: Proceedings of the ACM INTERCHI93 Conference on Human Factors in Computing Systems. Amsterdam. 1999. pp. 355-362

[18] Svanaes D, Verplank W. In search of metaphors for tangible user interfaces. In: Proceedings of DARE 2000 on Designing Augmented Reality Environments. 2000. pp. 121-129

[19] Pierce JS, Stearns BC, Pausch R. Voodoo dolls: Seamless interaction at multiple scales in virtual environments. In: Proceedings of the 1999 Symposium on Interactive 3D Graphics Atlanta, Georgia, United States. 1999. pp. 141-145

[20] Poupyrev I. 3D interaction strategies and metaphors. 2001. Available from: http://people.cs.vt.edu/ $\sim$ bowman/3dui.org/course notes/siggra ph2001/metaphors.pdf

[21] Zhai S, Kandogan E, Smith BA, Selker T. In search of the 'magic carpet': Design and experimentation of a bimanual 3D navigation Interface. Journal of Visual Languages and Computing. 1999;10:3-17

[22] Ciger J, Gutierrez M, Vexo F, Thalmann D. The magic wand. In: Proceedings of the 19th Spring Conference on Computer Graphics Budmerice, Slovakia SESSION: Virtual Reality. 2003. pp. 119-124

[23] Metaphor Design KK. Case study of an animated programming environment. In: Proceedings of the 1995 Computer Game Developer Conference April. Santa Clara, California. 1995. p. 241
[24] de Sousa AMF, Morimoto CH. 5* magic wand: An RGBD camera-based 5 DoF user interface for 3D interaction. In: 2015 XVII Symposium on Virtual and Augmented Reality. IEEE; 2015. pp. 15-22. DOI: $10.1109 /$ svr.2015.10

[25] Henschke M, Gedeon T, Jones R, Caldwell S, Zhu D. Wands are magic: A comparison of devices used in 3D pointing interfaces. In: 14 th International Conference on HumanComputer Interaction (INTERACT). Cape Town, South Africa. 2013. pp. 512-519

[26] Abaci T, de Bondeli R, Cger J, Clavien M, Erol F, Guti'errez M, et al. Magic wand and the enigma of the sphinx. Computers and Graphics. 2004; 28:477484

\section{[27] Rawat TJ. WONDER OBJECTS} magic and interactive storytelling. In: Proceedings of ECHISE'05, Held in Conjunction with PERVASIVE'05. Munich, Germany; 2005. pp. 91-96

[28] Dieberger A. Navigation in Textual Virtual Environments using a City Metaphor. Vienna University of Technology. 1994. Available from: h ttp://homepage.mac.com/juggle5/ WORK/publications/thesis/ThesisPDF. html

[29] Averbukh VL, Bakhterev MO, Baydalin AY, Gorbashevskiy DY, Ismagilov DR, Kazantsev AY, et al. . In: Asai K, editor. Searching and Analysis of Interface and Visualization Metaphors. Vienna: InTech; 2008. pp. 49-84

[30] Averbukh N. Subjective-situational study of presence. In: Proceedings of "Augmented and Mixed Reality. Designing and Developing Virtual and Augmented Environments" Conference. Vol. 8525 of Lecture Notes in Computer Science. Crete. 2014. pp. 131-138

[31] Averbukh VL, Bakhterev MO, Manakov DV. Evaluations of visualization metaphors and views in 
the context of execution traces and call graphs. Scientific Visualization. 2017; 9(5):1-18. Available from: http://svjournal.org/2017-5/01/index.php? lang=en

[32] Koike H, Takada T, Masui T. VisuaLinda: A framework for visualizing parallel Linda programs. In: Proceeding 1997 IEEE Symposium on Visual Languages. IEEE; 1997. pp. $174-178$

[33] Hood R. The $\mathrm{p} 2 \mathrm{~d} 2$ project: Building a portable distributed debugger. In:

Proceedings of the SIGMETRICS Symposium on Parallel and Distributed Tools. 1996. pp. 127-136

[34] May J, Berman F. Retargetability and extensibility in a parallel debugger. Journal of Parallel and Distributed Computing. 1996;35(2):142-155 


\title{
The Biolinguistic Instantiation: Form to Meaning in Brain/Syllable Interactions
}

\author{
Noury Bakrim
}

\begin{abstract}
We propose, in this chapter, a language model anchored in the relation between immanence and manifestation based on points of view. Within this realm, the biolinguistic instantiation implies both biosemiotic Interpretability and evolutionary symbolism. Furthermore, being one of the five points of views (representation, analysis, catalysis, instantiation, and formantization), it is the principled topology of the thematic/schematic relation between structure and world. We exemplify in this case, the empirical background of syllables and consonant clusters (phonesthemes). From our findings, we seek hypothetically to investigate the instantiation of dual stream dynamics (dorsal/ventral) as the projection (internal structure) of symbolic rules we have observed on the external structure: mirror/ deletion and buckling models of onset/codas, on the one hand, and agentive features such as $[+/-$ source], on the other hand; these rules are supposed to form lexicon's storage and computation. Our heuristic basis will be the relevance of the mirror neuron system for both dual stream model (HicKok/Poeppel) and frame/ content theory (McNeilage). Emphasis will be put on universal/typological implications of instantiation in Berber and English.
\end{abstract}

Keywords: biolinguistic instantiation, points of view, form iconicity, MNS, dual stream model, internal/external language structure

\section{Introduction}

The recent project of unifying biolinguistics and theory of language expresses the endeavor to both understanding how evolution has led to internalized structures bearing pronounceable/comprehended forms and how these forms are not mere projections but precisely innate acquisition models encountering performance and intentionality. Therefore, represented representation within a much larger semiotic principle predisposes the way language is instantiated on output forms based on the event structure. Henceforth, we consider the internalization of a dynamic ontological principle as correlated to bio-physiological-cognitive and social structures unifying the framework of explaining iconicity-motivation (within the linguistic strict distinction of form and meaning) and the semiotic function between expression and content levels of the semiotics-object. Moreover, empirical verifiability is increasingly reshaping our consideration of relevant levels on the linguistic structure. 
The study of language is then orientating us toward a new scientificity within both verifiability and structure interfacing (internal/external): this new episteme includes the consequence of redefining not only the object of language but also its relations to its supplements, to evolution and brain impairments. Thus, the tensions arising between the real object and its analytical components, more specifically the discrepancies between bidirectional representation and analytical geometries, imply a new consideration of the linguistic event, its hierarchies and the instantiation. We will in the following chapter present our results stemming from both empirical data and theoretical development on both linguistic and semiotic inquiries of the relation between form-meaning and consciousness.

\subsection{A signifying gestalt: the biolinguistic instantiation as one point of view/the neurophysiologic point of view}

In the horizon of the structuralist turn, analysis has been an important consequence of an intuition rethinking another domain: the consequence of hypothetic-deductive methodology on the definition of the real object grounding in the methodological object. First, the consequence of both representational phonology meeting the isolation of psycholinguistic empirical tokens but also inscribing language in a potential acquisition actant suggesting since the generativist turn that immanence is also a result of a biolinguistic instance [1] whose analytical component is both universal and competence/performance derivability. On the other hand, the semiotic principle, epistemologically, split up—so to speak-in paradigmatic/syntagmatic axes of analysis contributes by a new turn to emphasize the double static/dynamic structure of signification/meaning and the semiotic specificity of being a represented representation.

Beyond reflexivity principle or the consciousness basis of the semiotic principle—its object language-and beyond metalinguistic operations [2, 3], we owe this specificity to the observer/gestalt structure where schematization implies the predisposition/disposition of both mediation-interpretability. Henceforth, triggered by the semiotic principle (SP, semiotic function and semiotic stratification hierarchy), the points of view are the observer/epistemic link between real and structural object within the relation between immanence and manifestation. This link is not a faithful relation, it is defined by optimality rules, visibility/invisibility, ordering and inversion, markedness and co-selection.

\subsection{The parallax ${ }^{1}$ of language gestalt: defining the theoretical framework of points of view}

We postulate in the following insight a framework of analysis/catalysis, representation, formantization and instantiation.

\subsubsection{The structural point of view: analysis/catalysis}

We define the structural points of view of analysis/catalysis as the following: first, the condition of articulation to refer to its own immanent event of distinctiveness/significativeness deriving its levels from form selection, value as being extracted and abstracted from the continuum in virtue of certain rules defined by the structural network of functions. Analysis is the human computational faculty of

\footnotetext{
${ }^{1}$ Ref. [4].
} 
structuring language referring to its immanent laws. Secondly, catalysis considered within the distinction between the empirical process and the theoretical system is the analytical component of the syntagmatic chain supposing both the deepest level of taxemes (deeper than class and feature) and a surface (in praesentia), underlying scheme (in absaentia) in a double constitution of the linguistic text. Hence, the structural point of view is the differential gap between analysis and catalysis on manifestation level.

\subsubsection{The point of view of representation}

Representation within the gap between perception (analysis) and apperception [5], articulation/production but also the gap between recursivity [6] and reflexivity (meta-linguistic, etc.) is the cognitive (also memory-based) and recognition condition of language faculty oriented by an internal interpretability principle that mediates the relation between hierarchical levels and merge operations of input-output dynamic. Both conceptual-semantic and phonological-phonetic (acoustic) representations interact grounding in the "need" to open computational modules by cognitive ones (acquisition for instance).

\subsubsection{The point of view of formantization}

The perspective of the use as a level of manifestation has not been entirely embedded in the realm of language sciences, Hjelmslev formants have been sporadically defined as the material expression of morphemes (content level). Let us assume that some purposes related to this issue have been split between concrete and non-distinctive but obligatory features $[7,8]$ who attributed the first to the norm and the latter to the use. Furthermore, more recent accounts are divided between a new acquisitional constructivism, a non-generativist theory of acquisition [9-11] and sociolinguistic theories such as cognitive sociolinguistics. Greimas and Courtes [12] consider formants as figures of the expression chain corresponding to a unit of content level which enable it to be full sign (lexical morpheme or word), the latter within semiosis. Moreover, Chomsky's formatives [13] are minimal syntactic units that could be derived into lexical and grammatical morphemes represent on the surface level the realization of a specific performance that obey strict phonological rules mapped on the phonetic string (deleting/ inserting) [14].

It is the distinction between lexicon (conceptual component) and the computational component that emphasizes formative output rules as extrinsic ordering depending on merge operations binding both components. Henceforth, formation rules including emptiness/invisibility rules but also extrinsic ordering and adjustment rules imply the mapping of lexicon on the surface and the mapping of this latter on the use. Free selection (sometimes called monemes by Martinet) has the following implications for our consideration:

- First, the articulation of frame/content theory in its evolutionist account for the syllable emerging from organic gestures (we will later ground in an articulatory phonological approach) [15-17] enables to think out the segmental content within a precedence of the gestural syllable as put by McNeilage [17], a hierarchical level grounding in facial/Jaw and mandible gestures acting as premotor gesture, pointing the possibility of their sub-segmental aspect (articulatory phonology considers indeed the difference between gestural and featural levels as the basis of segment analysis) [18]. 
- Secondly, the overlap and competition between gestures plays in both approaches the role of a lexical device of distinctiveness in the representation. Beyond the debate between $\mathrm{C} / \mathrm{F}$ theory and articulatory phonology, the precedence of the gestures implies the role of content or the segment as less deeper unit in the representation than gestures/syllable frame. From another perspective, namely the forming form (forma formans), formantization belong to the mapping of the enunciative-predicative meta-linguistic operations on the syntagmatic chain.

\subsubsection{The point of view of instantiation}

We refer herein to a distinction between analysis/structure and instantiation where the immanent/computational structure referring to its own abstraction/ articulation levels is schematic/system-based and instantiation is its counterpart, a formal system dynamics inscribing the world in the structure. Stated in these terms, instantiation is the condition of the double significance (Benveniste's semantic and semiotic significances) which would mean: first, syntactic determination (syntagmatic rules) and enunciative-predicative world/situation regulation. Secondly, systems enabling the formal presentification of the structure (social, biological, physical, etc.). On the other hand, beyond ontological-praxeological constitution of any signification [19] instantiation is not an active use of the structure oriented by pragmatic-communicative intention or causality but rather a mediation between a manifestation level and its state of the world [20] understood in a nonreferentialist, non-causal perspective. It is the dynamic interpretable object of a semiotic utterance principle determined by both representation and regulation. In our morpho-dynamic approach, this mediation relates the continuous and the discontinuous as a forming form linking intentionality/bios and/or the unconscious to the structure. We assume that the presence of the structure does not depend on itself as for analysis/catalysis (derivation/deduction) but on these specific elements:

- Instance: level of the formal presence of language under the form of a dynamic act.

- Instantiators: situational/positional taxemes, articulators/gestural principles, brain connections, drives ... are active elements of the signifying process.

Henceforth, we will refer to the biolinguistic instantiation as the biophysiological symbolic and formal dispositive in both its extra/intra-structural presence based on a hypothesis of schematization (predisposition/disposition).

\section{The biolinguistic hypotheses of world/structure instantiation: phonesthemes and syllables (from perspective into perspective)}

The following framework presents the results of an ongoing research that will appear in a book on this subject. The experiment consisted in the participation of 20 French EFL (English as a Foreign Language) and Berber language students (Kabyle Students taking Tachelhit language course at the INALCO/Paris) who have answered both an acquisition questionnaire and a multiple test including: a recognition test in three components (cognates, speech errors and co-selection couples), a narrative test (consonant clusters and semantic frames) and an acoustic test.

Grounding in the former background, we would like to present our hypotheses based on the frame of syllable iconicity and phonosthemes as world/structure schemes, distinguishing it from motivation being the praxeme of the world within 
the structure. Put in its semiotic frame, more precisely the frame of asymptotic semiosis (peircian iconicity) [21], prosodic [22] and linguistic iconicity [23, 24], though metaphorized by the firstness mode are nonetheless not overlapping the Peircian sense, that is to say the positivity of the presence in virtue of a certain first impression of world/perception analogy. Hence, Jakobsonian iconicity refers to the form miming form, or the form miming the meaning (exophoric vs endophoric terms of W.Nöth). linguistic iconicity relates doubly to other concepts and apprehension modes given the fact that the link between language (as a semiotic principle) and natural languages but also the link between natural languages and their proper actualization is not saturated, not entirely covering iconicity knowing that it relates variably to world references (virtual or actual ones) and to uttering/use relating to the orientation/schematization of the structure.

\subsection{The gestural/neuronal mapping and schematization of the syllable}

\subsubsection{The gestural/articulatory postulate}

Based on the theoretical frame of both gestural/articulatory phonologies $[25,26]$, we consider that the syllable relies on both a gestural frame, discrete oppositions analyzed under schematic scores of natural classes upon which segmental content is realized. On the other hand, lexical access draws on gestural frames for the representation of distinctiveness suggesting dynamic parameters of articulatory events that could be relevant for typological selections (formants and possible specific contrasts) from the point of view of the target/pointing schemes of the tongue.

Evidence from acquisition but also neurobiological evidence (McNeilage) will be addressed in the following purpose. On the other hand, the fairly evidence of C-center Effect [27] of consonant initial phasing with the vowel and their counter coda (anti-phasing, intra-clustering and only postvocalic phasing of the first consonant) shows a clear gestural organization of syllable patterns producing the phonotactic structure but more widely suggesting that the computation of this phasing is to be found in both neural mirroring effect and dual stream models of speech processing.

\subsubsection{The neuronal postulate}

The discovery of Mirror neurons in Monkeys (F5 premotor and parietal area) by Rizzolati and Arbib [28] has led to the discovery of a system (MNS) or mirror regions supporting imitation and mapping of action onto cognition, important consequences on both motor/gestural systems have been found. Moreover, evidence stemming from pathological impairment perspective based on theoretical/ epistemological considerations is to be emphasized. To refer to some of the major contributions in this field, we can consider the following list: [29-37].

Beyond the good links between the MNS and current biolinguistic theories, ${ }^{2}$ we would like to evoke two aspects relying on the distinction between neural scheme (signified) and the MNS (the signifier). Moreover, MNS hypothesis is the epistemological result of Arbib's Schema theory [38], it grounds neurocognition in a symbolic schematism of a sensory-motor component (or perceptual/active models). The model suggested by Arbib et al. may introduce the schematic basis embedded in its brain circuitry. Instantiation, likewise merge operations of the minimalist program [39] in its biolinguistic component, is a combination/assemblage of instances

\footnotetext{
${ }^{2}$ We should nonetheless notice some criticism coming from one of the two founding scientists of dual stream model of speech, namely Hicock, in the Myth of Mirror Neurons: the Real Neuroscience of Communication and cognition).
} 
that map the Mirror Neurons onto the Mirror system. We reproduce herein Arbib's model [40]:

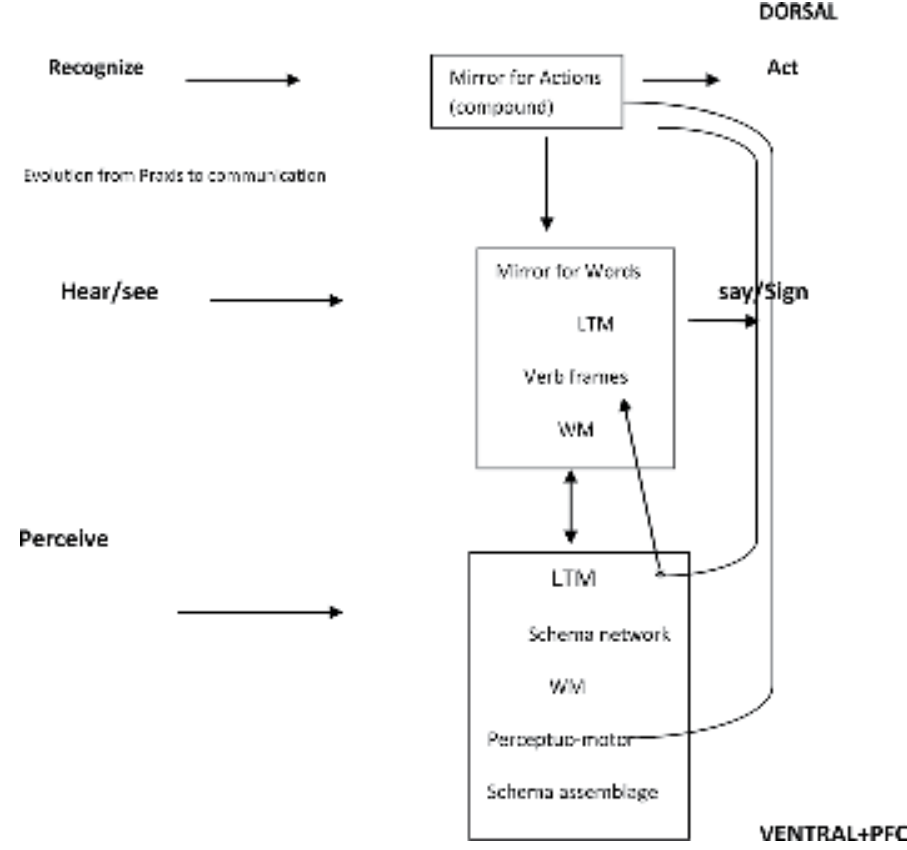

On the other hand, conceiving a grammar as the one called construction grammar by the model to address semantic operations of action and the mirroring implies for us, or better said for the model I seek to anchor in biolinguistics, the distinction between phonological/prosodic processes (analysis) of the syllable as being its proper form/structure (iconicity) and the semantic schematization (motivation) of structureto-meaning predisposition. We face, in this case, two hypothetical processes:

\subsubsection{Structure imitating structure}

It exists separately from acquisition and its MNS (mirror neuron system) thanks both gestural/computational and taxemic orientation of the syllables (class/inventory relations) embodying the potential catalysis and content placement in formantization. Thus, based on a neurocognitive model of an internal syllabary [41], we would like to term the bio-syllable that map the mirror system on both sequencing/phasing representations and their semantic instructions for both lexicon and syntax. In this case, the bio-syllable in the brain is the instantiation of the underlying scheme by mirror neurons enabling the semantic structure to imitate the phonological/prosodic structure.

Furthermore, the mirror model for the syllable suggests not only gestural/segment representation and lexical-semantic schematization but rather a gestural lexicon model of mirroring we will exemplify later on within English onset-coda clusters $(/ \mathrm{spl} /, / \mathrm{zl} /)$ or reduplication patterns in Berber, for instance $\left(\mathrm{c}_{\mathrm{a}} \mathrm{c}_{\mathrm{b}} \mathrm{v}_{1} \mathrm{c}^{\prime}{ }_{\mathrm{b}} \mathrm{v}_{1}\right)$.

\subsubsection{An acquisition/recognition model}

The interaction between analysis/catalysis and recognition is based on the interactions of Working Memory/Long term Memory. It enables us to think out both acquisition/recognition models as an interaction between computational and conceptual/ cognitive components. Input/output relations rely on imitation models partly discussed by Billard and Arbib [42] that require a schematic assemblage (in our case, a 
conceptual syllabary as posited by Brendel et al. [43] and the imitation component (motor, concept representation) [44]. Moreover, Vihman [45] argues that the acquisition of babbling patterns relies on an articulatory filter matching prosodic exponense/acoustic signal to segmental organization. The involvement of motor imitation based on mirror system provides the empirical/theoretical framework.

The Mental Syllabary Model in its form is related to psycholinguistic lexical access; it argues that speakers have access to high frequency syllables through a mental syllabic/lexical model that triggers motor representation. High/low frequency syllables (or the syllable frequency effect) are studied from the perspective of word-final syllable sensitiveness in the mental lexicon in respect to Naming Latency and its processing time.

We postulate that the interaction of catalysis/analysis, processing/recognition shaping the acquisition draws on mirror neurons which enables mental syllable mapping on perpectuo-motor/semantic sensitive frames of the lexicon.

\subsection{Dual stream model: connections and networks}

To provide a brief definition of Hicock and Poeppel's Dual Stream Model of Speech [46-50], we will sum it up in the following: it is a model that seeks a neurofunctional anatomy of language based on the understanding of partly overlapping, partly distinct neural circuits: speech (perception) is believed to lie primarily [49] on neural circuits, bilaterally in the superior/temporal lobes whereas speech production relies on a fronto-parietal/temporal circuits (left hemisphere dominant). First designed to understand vision (ventral recognition/dorsal sensory-motor integration), it has become a model embedded in both normal/pathological understanding of the dorsal stream as responsible of phonological/prosodic translation of speech signals into articulatory representation in the frontal lobe, whereas the ventral stream (superior and middle portions of the temporal lobe) processes speech signals for comprehension (speech recognition).

A sub-hypothesis will help us work out the concept of biolinguistic instantiation within the bio-syllable frame:

\section{- Categorial recognition/processing:}

Evidence has been shown by the model $(2007,2012)$ that parts of the STS are important for representing phonological information during word processing: psycholinguistic variables such as Phonological Neighborhood Density or the number of words that sound similar to a target word. On the other hand, an interface (focal system) serves as a computational mediation mapping phonological representation and distributed conceptual representation; it is rather storage of relational information (isomorphism, form-to-form).

\section{The bio-syllable: from typological models in iconicity and instantiation}

\subsection{The phonological-prosodic (lexical) model of iconcity in English and Tachelhiyt Berber}

We should first emphasize that we deal with iconicity in English and Berber from a phonological/prosodic perspective. English phonosthemes [51] belong to phonotactic clustering at the interface of phonological and prosodic derivation processes. They represent important clues for the lexicon (distinctiveness for instance), although they cannot be considered as morphs and they are not represented as such [52], they occur 
at phono-morphological errors across potential sensitive allomorphic processes. Furthermore, dealing with Berber [53] reduplication iconicity, we should first pinpoint the reason why we would not apply a morphological auto-segmental model proposed by McCarthy and others $[54,55]$ to study templatic languages. We consider the semitic root $[56,57]$ as a category to study Berber reduplication, emphasizing nonetheless that this last has been adapted [58] by early berberologists under the influence of semitic epistemology and not from an internal point of view.

Moreover, reduplication has been posited by the grammars rather as a reconstruction method widely interested in defining the morphological structure of the root/scheme of the verb (biliteral/triliteral roots), leading to a heterogeneous dealing between the definition of the etymon (diachronic, non-analytical object) and the verbal root lacking morpho-semantic thematicity unlike Arabic and Hebrew morphology (Hebrew Binyanim and Arabic awzān). Thus, what have been called Berber roots are, in our consideration, verbal individual consonantal templates of a formative principle (formantization) enabling flectional and reduced derivational processes. An example from this heterogeneous fact is the following table:

\begin{tabular}{llll}
\hline $\begin{array}{l}\text { Template } \\
\text { "Root"/ } \\
\text { example }\end{array}$ & $\begin{array}{l}\text { Allomorphic } \\
\text { form }\end{array}$ & $\begin{array}{l}\text { Phono-morphological } \\
\text { process }\end{array}$ & Lexical distinctiveness \\
\hline $\begin{array}{l}\text { GN }-\mathrm{g}^{\mathrm{w}} \text { nenni } \\
\text { (aorist: rolling) }\end{array}$ & No & Yes (reduplication) & No (diachronic or dialectal) \\
\hline $\begin{array}{l}\text { GN - gn (aorist: } \\
\text { sleeping) }\end{array}$ & Yes & Yes (tensing/g/) & $\begin{array}{l}\text { Flectional-aspectual (ign (perfect he } \\
\text { slept/ ar iggan continuous he's sleeping) }\end{array}$ \\
\hline
\end{tabular}

From which we can conclude that Berber reduplication [59] (except expressivity driven forms) is purely iconic in the sense that a segment of the lexical template undergoes a semantic process that implement its meaning or motivates it across its phono-lexical constituents (describing the process, the case in its aspectual nature, intensity, result, etc.). Henceforth, we will deal with lexical intra-reduplication patterns on their CV skeletons as following:

\begin{tabular}{|c|c|c|}
\hline $\begin{array}{l}\text { Formative-verbal individual } \\
\text { root }\end{array}$ & $\begin{array}{l}\text { Reduplicative pattern (with lexical } \\
\text { melody) }\end{array}$ & Inventory \\
\hline $\mathrm{C}_{\mathrm{a}} \mathrm{C}_{\mathrm{b}}$ & $\mathrm{C}_{\mathrm{a}} \mathrm{C}_{\mathrm{b}} \mathrm{V}_{\mathbf{1}} \mathrm{C}_{\mathrm{b}}^{\prime} \mathrm{V}_{\mathbf{1}} / \mathrm{C}_{\mathrm{a}} \mathrm{C}_{\mathrm{b}} \mathrm{V}_{\mathbf{1}} \mathrm{C}_{\mathrm{b}}^{\prime} \mathrm{C}_{\mathrm{b}}^{\prime} \mathrm{V}_{2}$ & $\begin{array}{l}\text { RF/RG/SM: RG ---rgagi: } \\
\text { shake and tremble }\end{array}$ \\
\hline $\mathrm{C}_{\mathrm{a}} \mathrm{C}_{\mathrm{b}} \mathrm{C}_{\mathrm{c}}$ & $\mathrm{C}_{\mathrm{a}} \mathrm{C}_{\mathrm{b}} \mathrm{V}_{\mathbf{1}} \mathrm{C}_{\mathrm{b}}^{\prime} \mathrm{C}_{\mathrm{B}}^{\prime} \mathrm{C}_{\mathrm{c}}$ & $\begin{array}{l}\text { ZMG/CTL: ZMG ---- } \\
\text { Zmummeg: smile pleasantly }\end{array}$ \\
\hline $\mathrm{C}_{\mathrm{a}} \mathrm{C}_{\mathrm{b}} \mathrm{C}_{\mathrm{C}} \mathrm{C}_{\mathrm{d}}$ & $\mathrm{C}_{\mathrm{a}} \mathrm{C}_{\mathrm{b}} \mathrm{C}_{\mathrm{C}} \mathrm{C}_{\mathrm{B}}^{\prime} \mathrm{C}_{\mathrm{d}}$ & SKRS ---- Skerkes: to lie \\
\hline
\end{tabular}

If this reduplication could be defined as an example for iconicity (or analytical one), in the sense of Downing and Stiebels [60], phonosthemes present stable quantitative syllabic-prosodic patterns on phonotactic levels (onset/coda positions or on both) based on the following rules:

\begin{tabular}{lll}
\hline Phonotactic position & Taxemes & Cluster/lexical inventory \\
\hline Onset $(2 / 3$ rules) & $\mathrm{T}_{1}(\mathrm{O})$ & /spr/, /st/: spread, stare \\
\hline Coda $(2 / 3$ rules $)$ & $\mathrm{T}_{2}(\mathrm{C})$ & $/ \mathrm{mbl} /, / \mathrm{zl} /:$ mumble, dazzle \\
\hline Onset.coda $(2 / 3.1$ and $2 / 3.2$ rules $)$ & $\mathrm{T}_{3}(\mathrm{O} . \mathrm{C})$ & $/ \mathrm{fl} / . / \mathrm{s} /, / \mathrm{gr} / . / \mathrm{pl} / \mathrm{:}$ flush, grapple \\
\hline
\end{tabular}




\subsection{Iconicity and instanciators}

Our approach, whose frame we have presented earlier, grounds in iconicity defined as form/structure imitation and form/structure schematization of meaning from a non-morphological perspective. We would henceforth adopt the framework of gestural scores and phonological-prosodic representations of both English clusters and Berber sequences.

\subsubsection{English typological processes}

\subsubsection{English $2 / 3 \mathrm{C}$ and $\mathrm{O} / 2.3$}

We focus in the following both phonosthemic rules from the perspective of gestural scores (subsegment) and syllabic structure:

- $2 / 3$ cluster rules $(\mathrm{T} 1(\mathrm{O}))$ : inventory example $(/ \mathrm{sp} /$ in $<$ spell $>)$

We adopt the approach of articulatory phonology considering gestures as potential units of sub-segmental events [61-63]. We thus describe gestural taxemes that enable segment insertion models in iconicity:

- The gestural scores for word initial <spell >:

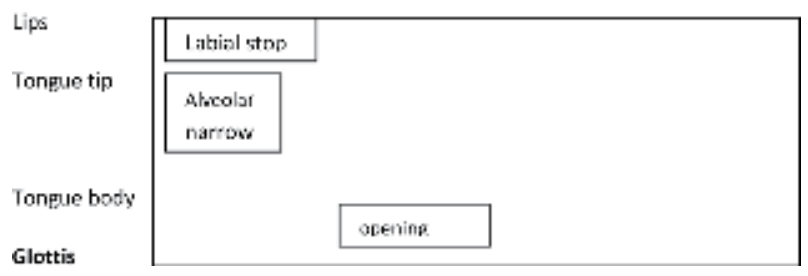

- Featural/prosodic structure /spell/

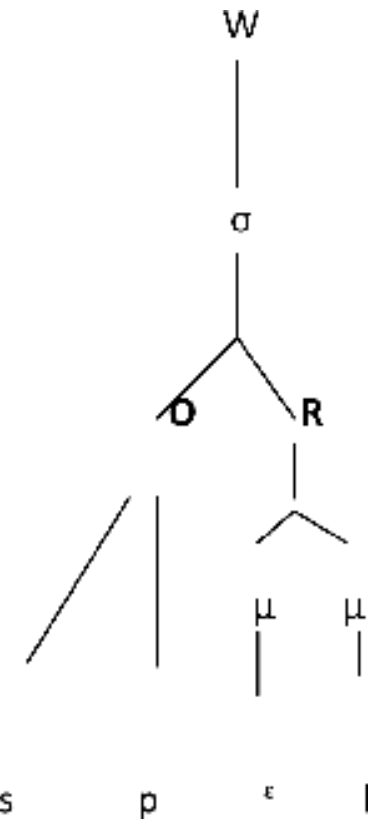


- T2 (C): gestural /feature prosodic structures: <puzzle>
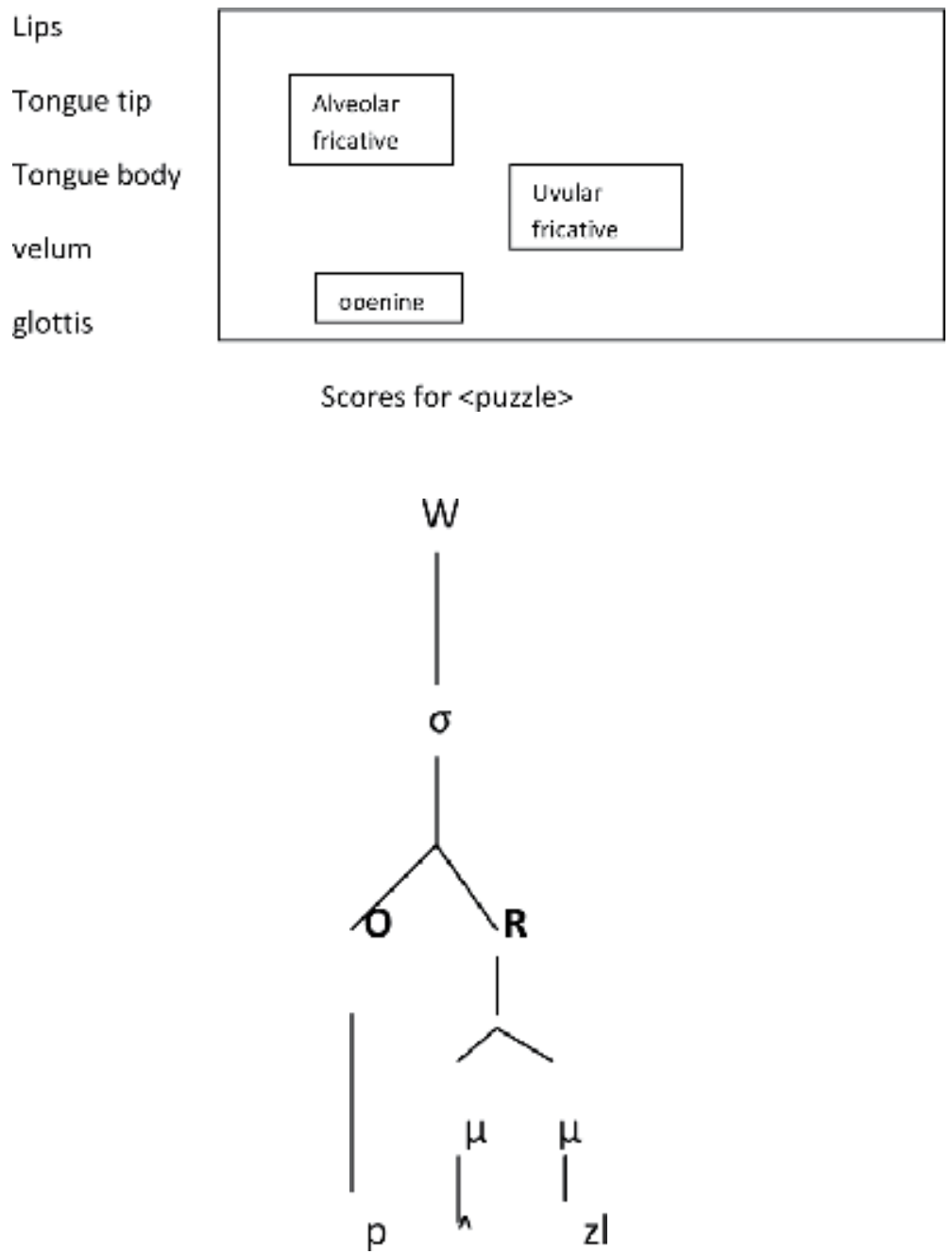

Based on both gestural and phonological/prosodic structures, we would first pinpoint that the phasing rules of prevocalic/postvolcalic consonants (see Browman et al.) in clusters are restricted by the vowel (the so called C-center effect) which makes both coda-onset consonants dependent on vowel (nucleus) timing. We then hypothesize a lexical timing process related to sensitiveness. This would bring us to analyze both mirroring effect of $2 / 3$ rules and their permutations within the phonotactic frame.

\subsubsection{Phonotactic and lexical-semantic iconicity}

\subsubsection{Onset deletion-adding rules: $2 / 3$ clusters}

We hypothesize that 2/3 onset rules in English are gestural/featural deletion modes adding/deleting rules from both lexicon/syllable analysis oriented toward semantic clustering and conceptual framing of the verbs. We first, would like to underline that seen from the segmental point of view, addition/deletion rules of SSP 
principle [64] are preserving or violating rules that stipulate sonority instructions for the representation on both coda/onset positions $[65,66]$. Other approaches suggest some of these rules could be intuited from the lexicon [67]. Furthermore, instructions from moraic weight and sonority principle can explain why these rules are not preserved by many natural languages as shown by Zec [68].

\subsubsection{3/2 deletion principle: English onsets}

$/ \mathrm{skr} / \rightarrow / \mathrm{kr} /$

- Gestural instructions: deleting the alveolar fricative and opening the glottis.

- SSP principle: preserving SSP for the syllable peak.

- Sequencing deletion: from the sonority hierarchy rule (321): obstruent stops 3 (OS) —obstruent fricative $2(\mathrm{OF})$-Approximants (A)
a. Only $2(\mathrm{OF})>3(\mathrm{OS})<1(\mathrm{~A})$
b. And $3(\mathrm{OS})<1(\mathrm{~A})$

Are elicited adopting the frame of both optimality theory [69] and the sonority/ weight derivation hierarchy, (a) and (b) optimal rules we emphasize in the following:

- First, abrupt rise in sonority is more preferred [70, 71]

- Then, mora-sonority hierarchy as claimed by D. Zac (2003) may also explain this case:

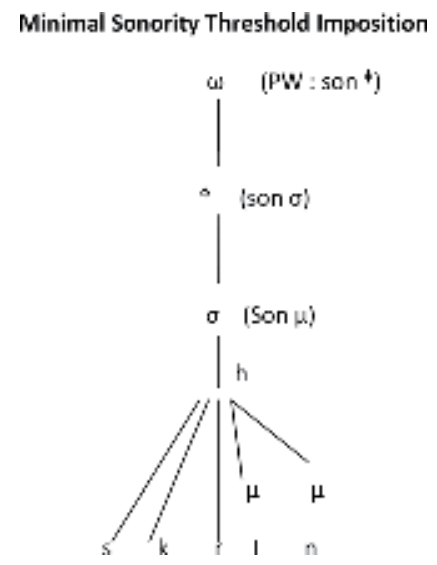

Where: weight is ruled by head/constituents and hierarchy levels on the syllable. It also emphasizes the lexical basis of deletion/adding principle.

\subsubsection{2/3 deletion principle: English codas}

$/ \mathbf{m b l} / \rightarrow / \mathbf{b l} /$

Gestural principle:

- Closing/opening the glottis 
SSP principle

- Preserving the SSP postvolcalic coda

Sequencing deletion: from the rule 321

Obstruent Stop OS (3) ------ A (2)

Only: $\mathrm{N}(1)>$ OS (3) $<$ A (2)

And OS $3<$ A 2

Are elicited.

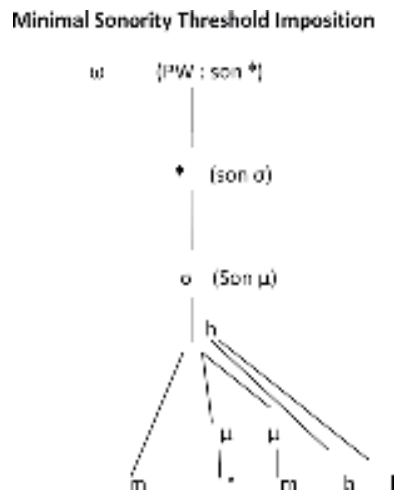

After defining the deletion/adding rules from gestural to computational levels and instructions, we address in the following section the sequencing permutation models.

\subsubsection{Inversion rules framework and Sequencing Permutations (SQP)}

- T $1(\mathrm{O}) / \mathrm{T} 2(\mathrm{O}): \mathrm{T} 1(\mathrm{C})$ and inventories:

Many inversion rules have been suggested as universal rules of onset/coda positions [72]. On the other hand, we have adopted a mathematical permutation model to address the phonotactic gestural/featural components and their class selections.

If the set $\mathrm{E}_{\mathrm{CO}}$ is the set of natural articulatory classes defined by its sonority scale for the syllable, then the group of possible permutation in $\mathrm{E}$ is a bijection of $\mathrm{E}$ on $\mathrm{E}$ and $I_{d e}$ is the identity of the set $E_{c o}$

$E_{c o}\left\{A_{o s}, B_{o a}, C_{o f}, D_{n}, E_{a}\right\}$ respectively stops, affricates, fricatives, nasals, approximants

For instance, we can multiply cycles considering the rightmost cycle first:

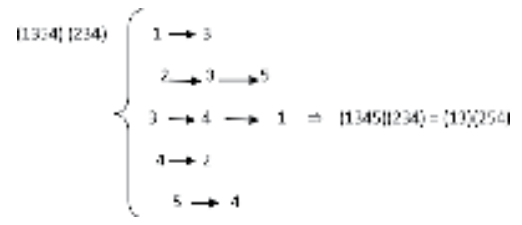

Representing a universal set of articulation (evidence has been shown elsewhere that the universal SSP is retrieved to recognize words in segmentation [73]. Thus the basic relation could be patterns permitted, geometrically and algebraically, and schematized in the Cayley table for pentagon and cyclic notations (rotations and reflections for D5) [74]. 
Possible universal clustering on onset/coda positions could be calculated within these forms either using a schematic rotation with a selection value or deriving algebraically the orbit and the cycles from a set of 1 to $n$ elements (1-5).

Furthermore, this universal principle grounding in both SSP and categorical perception [75] — nonetheless, the last study brings another evidence of variable categorical behavior in perception for clusters. It relies on a more biological robust basis for neural processing of categories, along with the gestural combinatory basis allowing us to predict from what we term SQP (sequencing permutation model) a specific language selection on the binary computation level:

\begin{tabular}{|c|c|c|c|}
\hline $\begin{array}{l}\text { Positions/ } \\
\text { clustering }\end{array}$ & $\begin{array}{l}\text { English permutation-class } \\
\text { clusters for the syllable- }\end{array}$ & $\begin{array}{l}\text { Cluster inventory for } \\
\text { selecting iconicity clusters }\end{array}$ & Lexical inventory samples \\
\hline \multirow[t]{6}{*}{ ONSET } & \multirow{6}{*}{$\begin{array}{l}(3,5)^{1},(3,1,5),(3,4),(1,5) \\
(3,1),(5,5)\end{array}$} & - $(3,5): / \mathrm{fl} /, / \mathrm{sl} /, / \mathrm{rr} /, / \mathrm{sw} /$ & - Flee, slide, shrink, sway \\
\hline & & $\begin{array}{l}\text { - }(3,1,5): \text { /spl/, /spr/ /skr/,/ } \\
\text { str/, /skw/ }\end{array}$ & $\begin{array}{l}\text { - Splay, spread, scream, } \\
\text { stray, squeeze }\end{array}$ \\
\hline & & - $(3,4): / \mathrm{sm} /, / \mathrm{sn} /$ & - Smack, sneeze \\
\hline & & $\begin{array}{l}\cdot(1,5): / \mathrm{gl} /, / \mathrm{gr} / / \mathrm{kl} /, / \mathrm{tw} /, \text { / } \\
\mathrm{br} /, / \mathrm{kw} /, / \mathrm{pl} /, / \mathrm{bl} /, / \mathrm{dr} /, / \\
\\
\theta \mathrm{r} /\end{array}$ & $\begin{array}{l}\text { - Gleam, grab, clap, twine, } \\
\text { breath, quell, plug, blur, } \\
\text { draw, throw }\end{array}$ \\
\hline & & - $(3,1): / \mathrm{sp} /, / \mathrm{st} /, / \mathrm{sk} /$ & - Spare, stare, skip \\
\hline & & - $(5,5):$ /wr/ & - Wrap, write \\
\hline \multirow[t]{9}{*}{ CODA } & \multirow{9}{*}{$\begin{array}{l}(3,1,5),(4,1,5),(3,5),(1,5), \\
(3,1),(4,1),(5,3) \text { and } 3,2 \\
\text { singletons }\end{array}$} & - $(3,1,5):$ /stl/ & - Whistle \\
\hline & & $\begin{array}{l}\cdot(4,1,5): / \mathrm{mpl} /, / \mathrm{ndl} /, / \mathrm{mbl} / \\
, / \mathrm{g} \mathrm{gl} /, / \mathrm{l} \mathrm{kl} /\end{array}$ & $\begin{array}{l}\text { - Rumple, bundle, rumble, } \\
\text { mingle, rankle }\end{array}$ \\
\hline & & - $(3,5): / \mathrm{zl} /, / \mathrm{fl} /$ & - Dazzle, shuffle \\
\hline & & $\begin{array}{l}\cdot(1,5): / \mathrm{kl} /, / \mathrm{gl} /, / \mathrm{bl} /, / \mathrm{dl} /, \text { / } \\
\quad \mathrm{pl} /\end{array}$ & $\begin{array}{l}\text { - Tackle, juggle, wobble, } \\
\text { saddle, ripple }\end{array}$ \\
\hline & & - $(3,1): / \mathrm{ft} /$ & - Shift, lift \\
\hline & & $\begin{array}{l}\cdot(4,1): / \mathrm{mp} /, / \mathrm{mb} /, / \mathrm{nd} /, \text { / } \\
\mathrm{nt} /\end{array}$ & - Bump, comb, send, hint \\
\hline & & $\cdot(5,3) / \mathrm{lv} /$ & - Delve, halve, shelve \\
\hline & & • 3 singl.: / $/$ & - Dash, mash, lash \\
\hline & & - 2 singl. $/ \mathrm{t} \int /$ & - Pitch, patch, catch \\
\hline
\end{tabular}

${ }^{1}(1,2,3,4,5)$ stand for these universal articulatory classes: $1-A_{o s}, 2-B_{o a}, 3-C_{o f}, 4-D_{n}, 5-E_{a}$.

Moreover, we only focus in this article on onset/coda processes of clustering knowing that coda.onset structures of iconicity bear an important dimension in both lexical distinctiveness/statistics but also in argument and semantic structure. We also exclude singletons from our clustering perspective; the frame would be different on both onset/coda positions.

\subsubsection{Onset structure}

Beyond any statistical account of onset (English), we notice other permutation processes between T2-T3 forms already discussed in the abovementioned addition/ deletion frames. Without, any symmetrical or mirroring effect, do these forms specify any phonological/prosodic or semantic processes? 
- Sonority principles/stress

From onset cyclic permutations $(3,1,5),(3,5),(1,5),(3,1),(3,4)$ we can notice the important role of prevocalic approximants $(\mathrm{r}, \mathrm{j}, \mathrm{w}, \mathrm{l})$ matching both gestural $\mathrm{C}$-center phasing and SSP principle (increasing sonority at the contact with the nucleus). Only one cluster cycle is violating SSP ( 3,1 /fricative stops), it relies on the laryngeal feature (voicing) harmony on onset, lexical onset/coda unvoiced/voiced co-occurrences seem to be the rule of a harmony balance.

Stress considerations are more sensitive to the hypothesis of stress-sonority interactions and the so called sonority driven stress which integrates stress information in a supra-segmental-prosodic level [76]. Stress Encapsulation Universals seems to be violated in sonorant clusters and feature $[+/-$ sonorant $]$ can be derived in stress. Onset structures are then supposed to influence vowel stress of the syllable.

What is the iconicity principle from this phonological/prosodic information on both computation of the lexicon based on the hypothesis of the bio-syllable and mental syllabary. Instructions implying both conceptual frames (verb frames: language/world segmentation) and semic structures (language semantic structure) seem to map (onto) and distribute lexical semantic meaning on the phonological prosodic structure based on these previous hypotheses:

\subsubsection{First hypotheses}

- Clusters are valence—case determining which derive the verb argument

- Clusters indicate the diathesis distribution of the process

- Clusters can specify the aspect

\subsubsection{Second hypotheses}

- Position specifies classematic categories integrating both encyclopedic and sublogic principles of the semantic structure

- Position can specify the case and actant roles within the process

- Position could be articulated (onset/coda) in resultative processes adding iconic markers on coda position

- Recognition in acquisition is sensitive to both encyclopedic/lexeme instructions and opts for catalysis.

To describe the semantic articulation of both general/specifying, lexeme/encyclopedia frames we will define some patterns on onset position. We first postulate that these distinctions relate to the nature of syllable/gesture interaction as encoding both concepts and semantic structure of the lexicon relying on bioschematic principles to be discussed more accurately in the next section. Secondly, encyclopedic instruction integrates both taxemic (sememic taxemes) organization of the verb or its sememic segmentation of the action continuum specifying its semantic organization and its distribution nuclei as a cognitive frame-this specificity distinguishes verb sememes from other sememes-[77-79]. 


\subsubsection{Onset semantic structure for iconicity}

\subsubsection{2/3 clustering permutations}

Beyond the debate between lexicon (defining the dictionary) and encyclopedia that opposes structuralists, cognitive semanticists and semioticians [80-83] as to what distinguishes the cognitive frame from proper semic/sememic or semantemic/ classematic poles of morpheme/lexeme boundaries [84, 85], recent analytical accounts in minimalism/syntax and biolinguistics focus on the biosemiotic nature of meaning and action merge specification [86] within the debate of C-I interface (conceptual-intentional interface) [87, 88]. Since foundational Millikan's notion of Biosemantics, we gained more interest in the way teleological/Intentional categories are mapped on both biological/structural forms to shape meaning. Moreover, recent studies [89] based on neuro-imaging integration, attempt to link non-linguistic and linguistic information to syntax levels or Syntax Driven Semantics.

We would like to propose a frame of the semantic mapping based on permutative computation on the intersection of multilayer semantics [90] on lexeme/morpheme interactions. These permutations select iconic cues on the lexicon encoded on both bio-schemes "instantiation" and the structure in a modular way:

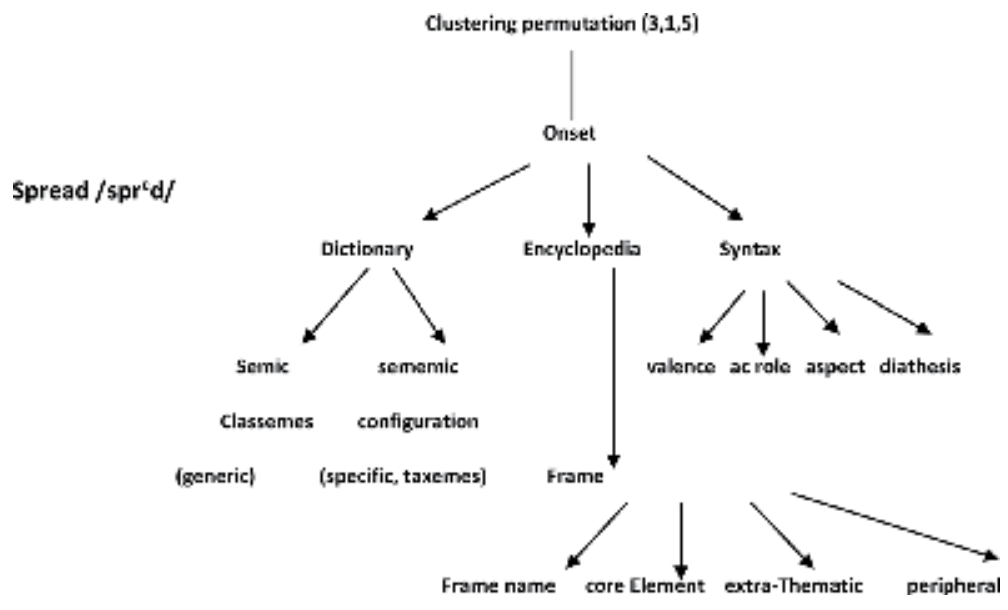

The semantic-conceptual structure of Spread /spr/ (multilayer frame): "he spread a tomato bowl on the floor then stared at his friend mopping reddish vegetables" (from an experiment: Bakrim 2019 in progress).

- Dictionary:

Semic classemes: [+action], [+source], [+predicate], [+manner], [+ process], [+target]

Sememic configuration (specific taxemes): //external//, //release//, //target//, //topic//

- Encyclopedia (Frame):

Frame name: Dispersal, Core elements: agent, cause, individuals, result, ---, Peripheral: place 


\section{- Syntax} causation

Valence: bivalent, role, agent, aspect: discontinuous, diathesis: subject/object

Stare /st/: $(3,1)$

- Dictionary:

Semic classemes: [+state], [+source], [+predicate], [+manner]

Sememic configuration (specific taxemes): //external//, //axis//, //intent//, //focus//, //perception verb//

- Encyclopedia (Frame):

Frame name: active perception, Core elements: perceiver, phenomenon, direction, extra-thematic: depictive, location of protagonist Peripheral: place, purpose, duration

- Syntax

Valence: bivalent, role agent, aspect: continuous, diathesis: subject-object causation

Deletion/addition clusters operating on permutative selection patterns imply semantic specification (semic, taxemic and encyclopedic). On the other hand, this specification entails reversely a lexical description model able to distinguish morphological and lexicological processes form frame/domains.

Iconicity of coda permutative structures

- "John whistled oddly in the backyard. Puzzled, Jack came out to see"

Whistle /stl/: $(3,1,5)$

- Dictionary:

Semic classemes: [+sound], [+source], [+predicate], [+manner], [-target]

Sememic configuration (specific taxemes): //external//, //unaddressed//, //indiscrete//, //topic//

- Encyclopedia (Frame):

Frame name: make noise, Core elements: noisy event, sound, sound source extra-thematic: circumstances, depictive, location of the protagonist Peripheral: manner, place

- Syntax

Valence: monovalent, role agent, aspect: continuous, diathesis: intransitive

Puzzle /zl/: $(3,5)$

- Dictionary:

Semic classemes: [+target], [+state], [+manner], [-source], [+voice] 
Sememic configuration (specific taxemes): //emotion//, //exclamative//, // passive//, //reaction//

\section{- Encyclopedia (Frame):}

Frame name: stimulated emotion Core elements: event, experiencer, stimulus extra-thematic: circumstances, depictive, explanation, result Peripheral: time, degree, manner

\section{- Syntax}

Valence: bivalent, role patient, aspect: discontinuous, diathesis: passive causation

We, first, should pinpoint that coda-onset permutations contrast verb argument nature with the frame of non-action (non-motor frame) lexicalizing the specification of sensory stimulus /target forms and world description. The verb has multilayer frames whereas, on the syntactic levels, the process and its roles present, on coda forms, more specific semantic forms. We would like to summarize those modes in the following:

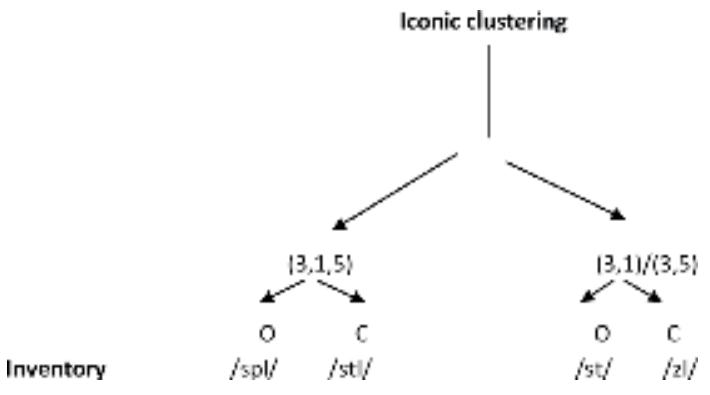

Segmental/prosodic parameters: labial/dental commutation (onset), voicing correlation (coda), SSP violating/peak maintaining-Sonority-weight derivedsusceptible of sonority driven stress on the lexical level

\section{Semantic contrasts}

Major contrasts: sensory-motor/source-target/cause-result, extra-somaticsomatic

On-coda: action-emotion, actant and aspect shift, position specifications, strong-weak, assertive-speculative

On-On: tension—release, reflexive-repercusive, reactive-active

Coda-coda: external-internal, causation-affection, aspect shift,

\subsubsection{Gestural-featural organization of reduplication: Tamazight (Tachlhiyt Berber)}

We have already emphasized the non-morphological relevance of the root frame to account for lexical level description. Both its partial productivity, the lack of a wide representation of triconsonantal patterns in the Berber lexicon but also the lack of morphological-semantic thematicity unlike other Semitic languages (Berber is a Hamito-Semitic language). Thus, phonetic-phonological processes are more adapted to these candidates of "pure iconicity."

Studies [91] relying on gestural organizing patterns of reduplication emphasize the copying of contiguous gestures in the representational process 
deriving the computation of the form. Berber reduplication studies, draw on the morphological point of view [92] although pinpointing both copying and geminating processes. Furthermore, typological reduplication forms have been traced back to a well-established diachronic/synchronic structure [93]. We will focus on demonstrating how copying gestures on the gestural level and binding syllables by gemination (moraic representation) are the basis of iconic process mapping from onto meaning without recurring to morphological processes. $[94,95]$.

\section{- Gestural scores and gesture copying of the second consonant in Tachlhyit Berber}

We would present the lexical forms of second consonant reduplication (first and second pattern):

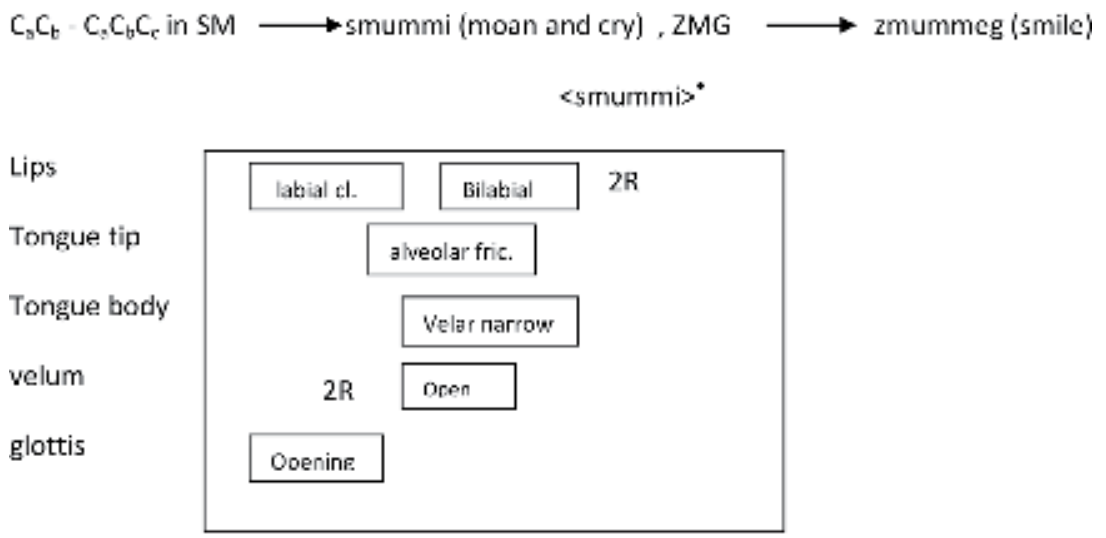

$\cdot 2 \mathrm{R}$; is the reduplication of the pesture.

Gestural copying of the second consonant

<zmummeg>

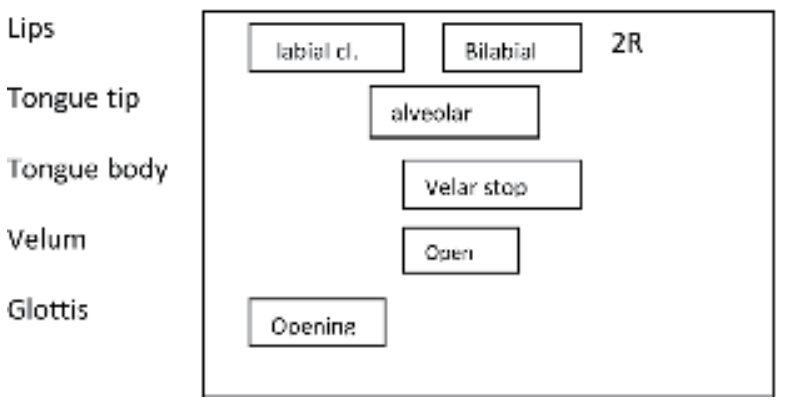

- The phonological/prosodic structure: the binding

We represent herein the binding structure of both lexical forms. 

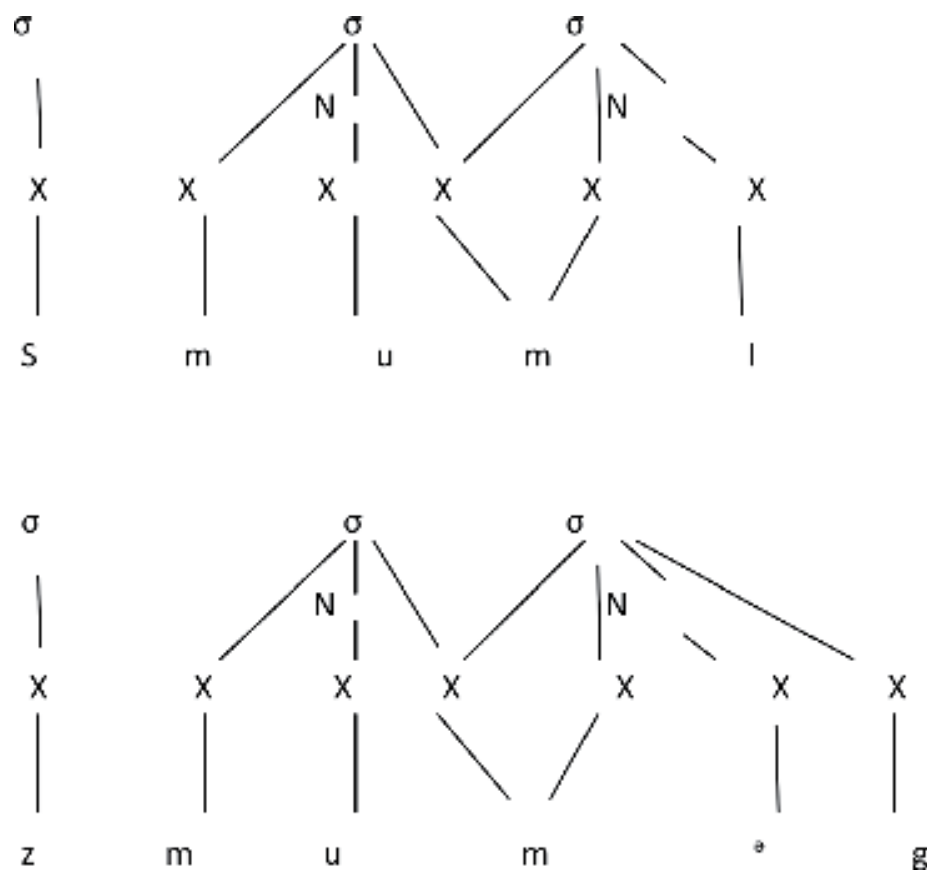

The role of ambisyllabic frame is well known to analysts who have scrutinized typological Berber forms [94], its representation of Berber geminate consonants evokes length as a criteria between phonetic implementation/acoustic realization and phonological representation. Moreover, copying and gestural sensitive reduplication would be strongly ruled by minimalist hypotheses of language evolution explained by new insights into internal merge/external merge relations: the mapping principle advocated by Safir [96] postulates that some of the syntactic specific and insensitive relations may have been designed as an evolutionary shift first, from the recursive embedding to interpretable structures generated by merge relations.

From our hypothesis, we postulate that copying and binding as two computation instructions may explain one of the aspects of the bio-syllable as represented representation: for syllable frame, combinatorics is a strong mathematical hypothesis related to neural representation of neuron firing pattern [97].

Neural encoding principle may have preceded on the evolutionary level the semiotic principle of sensory-motor symbolic on which the dynamic frame of the represented representation may have derived its interpretive states embedded hierarchically or modularly either in an evolutionary mathematical abstraction arising as a language faculty [1] (upper Paleolithic) or in a non-linguistic state of evolution [98].

The copying-binding relation could be treated as a case of combinatorial patterns parallel to clustering languages, both related by a principle enabling a mediation between morphological variation [99] and form-to-form structures encapsulating a copy of their own making-so to speak.

Furthermore, the gestural dimension within both dynamic/combinatorial aspects and its organic sensory-motor shape (articulatory/phonatory and respiratory systems) suggests a hypothetical mathematical topology of both formants/ resonance place and manner.

\section{Sequencing iconcity in Berber reduplication}

Before addressing our specific point, we would first expose the question of replication as model of reduplication from both biological/mathematical models and 
those underlying them [100]: for instance, Kolmogorov's contribution to study nucleation probabilities. Sequencing with duplication models (and clustering) understood in a complex dimension suggests for us the following dimensions:

1. Parameters for physical phasing and space distribution (phonetics/acoustics)

2. Probability of a minimal (e) let it be a phonological/prosodic event of copying/ binding in a language A (Berber, in this case) on a maximal pattern of both semantic and phonetic continua

3. The probability $q$ that the reduplicated $d$ would license the reduplicant $R_{d}$

4. The licensing capacity of $\mathrm{D}(\mathrm{s})$ (s for segment) is the probability density of this origin to permit bidirectional bifurcation (binding and gemination or doubling)

From Kolmogorov general complexity theorem

$$
\begin{aligned}
& \mathrm{K}_{\mathrm{tu}}(\mathrm{w})=\min \mathrm{l}(\mathrm{p}) \\
& \mathrm{P}: \mathrm{t}_{\mathrm{u}}(\mathrm{p})=\mathrm{w}
\end{aligned}
$$

Where $t_{u}$ is any universal Turing machine or (cognitive-brain computation) that can both read the input and the description (the hypothetic device to read a string $\mathrm{w}$ in any articulatory domain), min being the minimal length or program that outputs $\mathrm{w}$. Then $\left(\mathrm{C}_{\mathrm{t}}\right.$ is the hypothetic-analytical representation of $\mathrm{w}$ or the event of reduplication on both lexicon/phonetic dimensions). We obtain [101]:

$$
\mathrm{K}_{\mathrm{E}}(\mathrm{w})=\mathrm{K}_{\mathrm{tu}}(\mathrm{W})+\mathrm{C}_{\mathrm{t}}
$$

This probability would be topologically calculated as an integral function whose limits are to be defined on time limits (phasing limits) $-\infty /+\infty$ :

$$
\int_{-\infty}^{+\infty} P \mathrm{i}(\mathrm{t}) \mathrm{dt}=\mathrm{qi}
$$

Being $\mathrm{q}_{\mathrm{i}}<1$ the condition under which a reduplication is not possible.

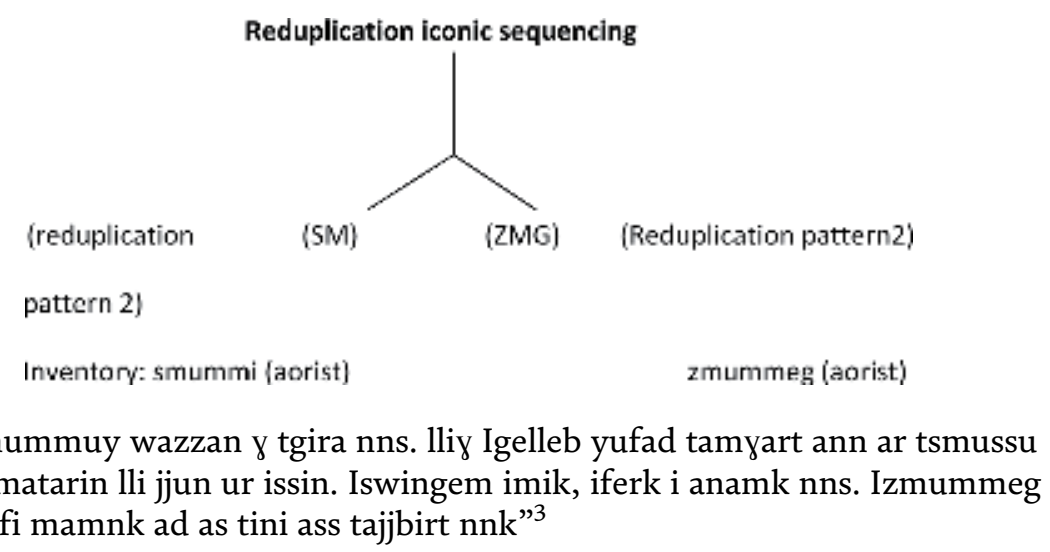

\footnotetext{
3 The child cried behind his back. When he turned, he found the same woman desperately gesturing unknown signs. He paused to guess the meaning of the conveyed message then he soon understood the point. It made him smile for he noticed that she couldn't find a way to tell him fasten the bag" (from an experiment in progress .....).
} 


\section{Reduplication and the semantic structure}

Smummi:

- Dictionary:

Semic classemes: [+expression], [+manner], [+target], [+sound], [+ change]

Sememic configuration (specific taxemes): //externally manifested//, // strident//, //involuntarily affecting//, //cry//

- Encyclopedia (Frame):

Frame name: communication noise Core elements: speaker, voice extrathematic: internal cause Peripheral: Manner, place, degree

Valence: Monovalent, role agent aspect: continuous, diathesis: intransitive

\section{Zmummeg:}

\section{- Dictionary:}

Semic classemes: [+expression], [+manner], [+source], [-sound], [+change]

Sememic configuration (specific taxemes): //externally manifested//, //light//, //voluntarily//, //discrete//

- Encyclopedia (Frame):

Frame name: making faces Core elements: agent, body part extra-thematic: cognate event, depictive, location of the protagonist, path of gaze Peripheral: degree, time, external cause

\section{- Syntax}

Valence: monovalent, role agent aspect: discontinous diathesis: intransitive

We will discuss both semantic implication of iconicity later on in our conclusions.

\section{The internal gestalt and its perspectives: the biolinguistic instantiation or "from the internal to the external language"}

As we have discussed it before, structure-world is a de-squared Gestalt of both the semiotic principle and sensory-motor schemes of mapping world onto meaning and meaning onto world. Before presenting a language model of instantiation, we would like to sum up some of the principles and hypotheses of the bio-syllable as dynamic-static "nucleus" of the represented representation, as sensory-motor, social, psychological mediation between nature and culture that enables both form principle of language and the self-reflection loop of world-structure (including iconicity).

\subsection{The syllable in the brain and the represented representation}

Beyond analysis/derivation as a part of deductive, generative or meta-linguistic rationality of a hypothetic object but also beyond the object in its real dimension (the existence of such linguistic object in our hypothesis), the syllable exemplifies a language model at the interface of evolutionary and sensory-motor semio-genesis that enables us to think out the linguistic gestalt in the following terms: 
- the gestural sub-segmental organization is a topological-neurobiological model of instantiation

Represented representation is this complex schematization of a mapping model suggesting first the topological mathematical organization of the articulatory/vocal tract organic principle. Beyond the formant principle and its acoustic physical implication, the gestural mode of speech, on the syllable-lexicon level is a topological model of dynamics (morpho-dynamics) that articulates formal representations of speech production/perception in a bidirectional way: what would be the implication of the permutation in a topological space represented by vocal tract/articulatory systems on form and selection events? It supposes a biological/topological interface of both semio/morphogenesis [102]. On the other hand, mental lexicon/mental syllable have been suggested as models of both generative syntax and phonological specification of the syntactic device. From the psycholinguistic point of view [103], both encoding/computing may enhance the acoustic realization of words.

It entails the activation of a neural image of structure imitating structure and structure imitating the world (anamorphosis and morphosis). Iconicity would then be a specific module for internal lexicon and syntactic structures.

We would henceforth expose a threefold model of instantiation:

- Instantiation as event

- Instantiation as schematization

- Instantiation as functional modularity

\subsection{Instantiation as an event}

We distinguish herein between a unitary speech event (or experience) and the complex neural/anatomical network of its processing in a way that activates both semantic and phonological consciousness on a predisposition scheme to link contingent continuum and discrete representation/articulation.

Within the semio-genesis on both continuum/discrete, form/substance levels, the biological instantiation of speech relies likewise the situational basis of an uttering event (enunciation) on the spatial/temporal parameters of representation and articulation. Beyond the phenomenological event of its intentionality, neurobiological instantiation is the set of coordination enabling the co-construction of both articulatory-semantic events of speech [104], from/into structure and from/into world.

- Event structure for bidirectional representation: production/perception of the lexis

- Event structure for lexical—semantic components:

We hypothesize specific neural networks on both motoric/conceptual regions of the brain enabling the computation of a space-time event of speech on gestural/ articulatory levels. It triggers both memory/lexicon sub-events of speech (retrieval, lexical basis for gestures and articulation, Formant calculus and phasing but specifically gestural pointing and targeting). Interaction adjustment parameters enable then a referential event of speech biologically instantiated.

- Event structure for lexical-encyclopedic representation: 
We already know the evidence of construction grammars and verb argument on the link between action verb semantics and mirror neuron system [33, 104]. It implies graphs for visual/linguistic mapping, both universal and typologically determined [105]. Activation and inhibition relate event structure thank either neural group connections (mental inhibitors) or allow a flow of ions (synaptic frame).

\subsection{Instantiation as schematization}

Neural schematization has been posited as a theoretical model called Schema theory by Arbib's et al. [106], arguing that this last is the basis for cognitive knowledge or a system of schemata enabling the relation between action and interpretation. Production/perception neural maps are responsible of translating cognitive schemata (or their assemblage) of speech components into sensory-motor images.

\subsubsection{Neural maps for sequencing}

Copying a phonological—prosodic form onto gestural levels require specific schemas for sequencing, neural maps for copying/deleting or copying/binding enabling both the gestural-phonological interface, the gestural-lexical interface for a determined sequence. It has been proven that mirror neurons form hidden sequences [107] of sensory-motor observed/enacted actions.

\subsubsection{Hierarchization}

The representation of hierarchical language schemas (trees, skeletal events, semantic arborescence, featural arborescence, etc.) is a computational model supported by both computation vs algorithm distribution of minimalist syntax theory and many recent theories of language [108]. Motor hierarchy and abstraction hierarchy ground in mirror neurons frame or adopt other neurocognitive approaches. Links have been advocated between Mirror neuron system and the motor theory of speech perception within the consideration that hierarchy in instantiation relates always on the role of abstract higher levels. This model of consciousness and abstraction [109] includes motor control hierarchy and representation (derivation) into one framework. Moreover, a strict distinction is needed between anatomical location and hierarchy principles. Beyond actual dual models of speech (DIVA model [110]). We will thus refer to the hierarchical model of Dana Ballard suggesting a specification of speech sensory-motor brain abstraction.

\begin{tabular}{lll}
\hline \multicolumn{3}{c}{ Operating system } \\
\hline Sensory-motor representation & Analytical-computation \\
\hline Selection & Gestures probabilities/scores & Segmental/auto-segmental analysis/events \\
\hline Runtime & Phasing sequences/co-articulation & Prosodic derivation (accent/weight) \\
\hline Behavior & $\begin{array}{l}\text { Framing the gestural model of the } \\
\text { lexicon }\end{array}$ & $\begin{array}{l}\text { Morpho-lexical distinctiveness/conceptual- } \\
\text { semantic frames }\end{array}$ \\
\hline Routines & Acoustic spectral modulation & Acoustic formant/harmony analysis \\
\hline Calibration & Motor control circuitry & Feed-forward/feedback systems \\
\hline Neural level & Mapping/mirror neuron system & Neural scheme \\
\hline
\end{tabular}




\subsection{Instantiation as functional modularity}

We consider dual stream models as the expression of an epistemic link between consciousness (proto-consciousness) and functional anatomy, more specifically, brain streams and circuitry. This expression, let us say its heuristic robustness, is in considering lateralization and brain anatomical mapping as a set of interpretive networks for language and speech processing. Two recent approaches of dual stream have been dealing with theoretical/empirical (including normal/pathological speech behavior) with the significance of dual distribution for phonology/semantics or for the bidirectional conditions of the representation. We will in the following scrutinize the functional networks of DIVA-model (Direction into Velocities of Articulators), and the Dual Stream Model of Language (dorsal-ventral) before scrutinizing their functional networks:

\begin{tabular}{|c|c|c|c|c|}
\hline $\begin{array}{l}\text { Field/ } \\
\text { pattern }\end{array}$ & Principle & Brain articulation model & $\begin{array}{l}\text { Brain interface } \\
\text { models }\end{array}$ & Brain topology \\
\hline $\begin{array}{l}\text { Phonetics/ } \\
\text { phonology }\end{array}$ & $\begin{array}{l}\text { - Dorsal-ventral } \\
\text { stream (DSM) } \\
\text { - Control system } \\
\text { (feed-forward/ } \\
\text { feedback) } \\
\text { (DVM) }\end{array}$ & $\begin{array}{l}\text { - High order networks/ } \\
\text { articulatory } \\
\text { phonological networks } \\
\text {-conceptual } \\
\text { ( (DSM) } \\
\text { - Circuitry (DVM) }\end{array}$ & $\begin{array}{l}\text { - Interfacing sensory- } \\
\text { motor links } \\
\text { - Mapping (DVM) } \\
\text { - Conceptual } \\
\text { interfacing }\end{array}$ & $\begin{array}{l}\text { - Lateralization } \\
\text { (left-dominant/ } \\
\text { bilateral (DSM) }\end{array}$ \\
\hline Semantics & $\begin{array}{l}\text { - Ventral stream } \\
\text { (DSM) }\end{array}$ & $\begin{array}{l}\text { - Combinatorial network } \\
\text { (DSM) } \\
\text { - Conceptual network } \\
\text { (DSM) }\end{array}$ & - Lexical interface & $\begin{array}{l}\text { - Wide } \\
\text { distributed } \\
\text { (DSM) } \\
\text { - Weak left } \\
\text { hemisphere bias }\end{array}$ \\
\hline
\end{tabular}

Beyond Instantiation, both models suppose a complex functional modular and anatomic modularity when connectivity is a map that enables us to read out what we call "the internal gestalt of language." We will deal henceforth with the purpose of modularity/connectivity ${ }^{4}[111,112]$. We should emphasize the fact that brain relies on a complex gestalt organization ranging from randomness, small worldness to modularity [113].

The dual stream model of speech is fairly well designed based on a clear modular organization with graphs and nodes specifying edge relations, interests in speech processing involve regions and linkedness of highly important notions.

Mathematically speaking, a modular structure could be conceptualized throughout Poisson's Model of distribution (Reference ... .) based on the following equation:

$$
P(X=x)=\frac{\lambda^{x} e^{-\lambda}}{x !}
$$

$x$ is a sequence: $\mathrm{x}=0,1,2,3 \ldots ; \lambda=$ number of the occurrences in the interval; and $e=$ Euler's constant $\simeq 2.71828$.

Connectivity is also the probability of a node event that could be either added or deleted on the network:

\footnotetext{
${ }^{4}$ We use the term modularity to refer to the gestalt A with a specific task, processing, ruling function, innately anchored, neurally defined and not assembled.
} 
Node:

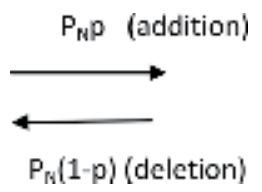

Edge:

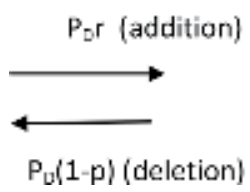

We could then consider the modularity of the dual stream model, thus also a certain conceptualization of the internal language based on the aforementioned considerations:

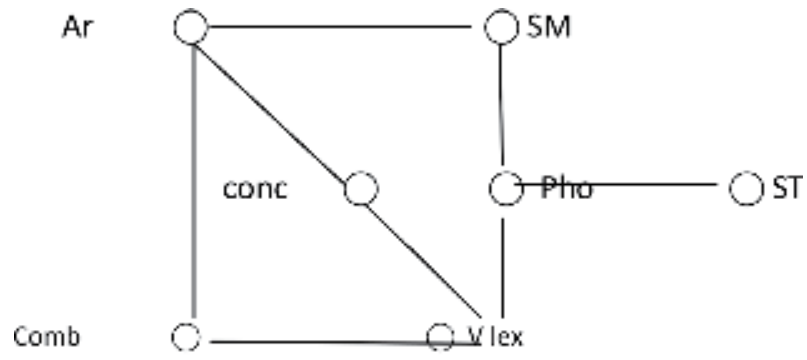

Modularity of Dual Stream Theory

Ar: articulatory network, SM: sensorimotor interface, Pho: phonological network, ST: spectrotemporal analysis, Vlex: lexical interface, Comb: combinatorial network, Conc: conceptual network.

We consider first connectiveness of physiological (brain-anatomy/motor control) and physical (physical/acoustic mapping) as determined by an isolated edge the network. Moreover, the links between nodes are more important within: first, dorsal processes than between ventral processes. The functionality of articulatoryphonology-lexical nodes is more specific and less hypothetical than the articulatorylexical connectivity.

How to read out this modularity?

This modular structure, or the internal gestalt verifies our first postulate of a "de-squared" object between phonological/phonetic and lexical/semantic process of meaning. Isomorphic processes between content form and expression form are covering the real gestalt object which is a world/structure of an embodied language.

Therefore and targeting the specific case of iconicity, we think that the complexity of the object and its points of view orientate us toward a biological mode of meaning within a third order beyond nature and culture: the bios.

\subsubsection{Some conclusions on iconicity and biolinguistic instantiation}

Based on our previous discussion of instantiation as being a point of view grounded in the relation of the linguistic gestalt to itself and to the world, we could, within the debate of iconicity referring to the Plato-Aristotle discussion and to its relevance for us, hypothesize these following levels: 


\subsubsection{The structure from within or the embodied representation}

Deriving from our previous modular discussion, we understand both dynamic onto-biology and proto-consciousness as the condition upon which the structure is instantiated mapping the organic network on the representational/analytical network and these lasts on production/perception. The modular internal gestalt, desquared and complexified, along with the articulartory-phonatory topology provide a good understanding of the way language has been adopting an evolutionary inclusion principle that enables, beyond semiotic articulation, the instantiation of external structures by internal ones. Far from being a simple faithful neural instantiation of a schematic construct, it is rather the instantiation of a world/structure and a structure/structure principle whose good example we can encounter in the relation between language faculty and competence/performance. If instantiation is not a mechanistic enaction, a fortiori its biolinguistic point of view, it can be considered as a trace-bearing point of view that shapes both the surfacing forms and the link between points of view creating the perspective of world-structure, structure-structure links.

\subsubsection{Iconicity is a sub-case of a biolinguistic projection}

We should, first of all, retake our former postulate relating to iconicity as being distinct from motivation. Iconicity supposes a mode of articulation that could not be regarded as an "abnormal" link between distinctiveness and significativeness -though relying on the lexicon-it is a proper mode of schematizing structure-to-structure processes. Back to my Berber case, semantics of reduplication, both language and cognitive frame semantics considered, the reduplication event-likewise clusteringpoints out the gestalt principle of the lexicon as both intersection and hierarchy of multiple components: the probable adjustment of the internal sensory-motor computation to a twofold model of neural and gestural coordination on the lexical level indicating the relation of the event (internal spatial-temporal network) to a signifying function. Iconicity would be then, more than a rhetorical relation within world-structure resonances; the specific selection of a sequencing organization patterned as a biolinguistic projection.

\subsubsection{The real object is a complex internal-external structure (a Gestalt)}

Our epistemic aim, with the framework of the point of view, is to emphasize the role of proto-consciousness as a biological symbolic system underlying the philosophical-psychological consciousness in the evolutionary integration of sensitive world schemata and sensory-motor principles. The existence of the analyticalrepresentational (computational) dimension of both language faculty and its semiotic principle as an object-method, partly embodying the recognition of biolinguistic structures or supposing the logical-formal deduction is one point of view of the analytical faculty (Universal Grammar/competence) grounded in biolinguistic schemes. The mutual projection relations (their bidirectional links) between this hypothetical object and what we call the real object defines also the complex relations between language immanence and manifestation. On the other hand, modular relations on the internal language level suggest modular relations between the points of view on the object. 
The Biolinguistic Instantiation: Form to Meaning in Brain/Syllable Interactions DOI: $h$ ttp://dx.doi.org/10.5772/intechopen.89943

\section{Author details}

Noury Bakrim

University of the People, Pasadena, United States of America

*Address all correspondence to: bakrim_noureddine@yahoo.fr

\section{IntechOpen}

(C) 2020 The Author(s). Licensee IntechOpen. This chapter is distributed under the terms of the Creative Commons Attribution License (http://creativecommons.org/licenses/ by/3.0), which permits unrestricted use, distribution, and reproduction in any medium, provided the original work is properly cited. (c) BY 


\section{References}

[1] Chomsky N. Language and Mind. Cambridge: Cambridge University Press; 2006

[2] Culioli A. Pour une Linguistique de l'énonciation, 1/2/3. Paris: Orphys; 1999

[3] Bakrim N. Readability facing the irreducible otherness: Translation as a third dimension toward a multilingual higher education. International Language of Cognitive and Language Sciences. 2019a. (Submitted)

[4] Zizek S. The Parallax View. Cambridge: MIT Press; 2006

[5] Hermans P. A.J. Greimas: maître de la fiducie. Raccommoder sens et (con) science. Paris: BoD Publications (Semiosis); 2019

[6] Chomsky N. The Minimalist Program. Cambridge, MA: MIT Press; 1995a

[7] Hjelmslev L. Essais Linguistiques. Paris: Minuit; 1971

[8] Coseriu E. Sistema, Norma y Habla. Montevideo: Universidad de la Republica; 1952

[9] Tomasello M. Beyond formalities: The case of language acquisition. The Linguistic Review. 2005a;21:183-197

[10] Tomasello M. Constructing a Language: A Usage-based Theory of Language Acquisition. Cambridge: Harvard University Press; 2005b

[11] Pütz M et al. Cognitive Sociolinguistics: Social and Cultural Variation in Cognition and Language Use. John Benjamins: Amsterdam/ Philadelphia; 2014

[12] Greimas AJ, Courtes J. Sémiotique: Dictionnaire Raisonné de la Théorie du Langage. Paris: Hachette; 2010
[13] Chomsky N. Some methodological remarks on generative grammar. In: Aksedal JO et al., editors. Noam Chosmky and Language Description. Amsterdam: John Benjamins Publishing Company; 2010

[14] Chomsky N. Topics in the Theory of Generative Grammar. 5th ed. The Hague/Paris: Mouton; 1978

[15] MacNeilage PF. The frame/content theory of evolution of speech production. Behavioral and Brain Sciences. 1998;21:499-546

[16] MacNeilage PF, Davis BL. Baby talk and the emergence of the first Words. Behavioral and Brain Sciences. 2004;27: 517-518

[17] McNeilage PF. Particulate speech: The emergence of the phoneme from syllable Frame structure. In: Symposium on Language Evolution. SU: The Royal Swedish Academy of Science; 2011

[18] Browman C, Goldstein L. Articulatory Phonology: An Overview. Phonetica. 1992;49:155-180

[19] Bakrim N. Du faire: pour une théorie morpho-dynamique de l'énonciation. (Submitted)

[20] Bakrim N. Between projection and result: A model of cognitive representational activity. Semiotica. Revue Internationale bilingue de l'association internationale de Sémiotique. 2020

[21] Peirce CS (trans. G.Deledalle). Ecrits sur le signe. Minuit; 1978

[22] Fonagy I. Physei/Thesei, l'aspect évolutif d'un débat millénaire. In: Faits de langue. Motivation et iconicité; 1993. pp. 29-45 
[23] Jakobson R. Quest for the Essence of Language. In: Selected Writings, World and Language. Vol. 2. The Hague: Mouton; 1971. pp. 345-359

[24] Nöth W. Semiotic foundations of iconicity in language and literature. In: Fischer O, Nänny M, editors. The Motivated Sign. 2001. pp. 17-28

[25] MacNeilage PF. Baby talk and the emergence of the first Words. Behavioral and Brain Sciences. ibid. 1998;27:517-518

[26] Browman C, Goldstein L. Some notes on syllable structure in articulatory phonology. Phonetica. 1988; 45:140-155

[27] Honoroff DN, Browman C. The center or edge: How are consonant clusters organized with respect to the vowel. In: Elenius K, Branderup P, editors. Proceedings of the 13th International Congress of Phonetic Sciences, Stockholm, Sweden. 1995. pp. 552-555

[28] Rizzolati G, Arbib M. Language within our Grasp. Trends in Neuroscience. 1998;21:188-194

[29] Arbib M, Bonaiuto J, editors. From Neurons to Cognition via Computational Neurosciences. Cambridge: MIT Press; 2016

[30] Schwartz JL et al. The common language of speech perception and action: A neurocognitive perspective. Revue Française de Linguistique Appliquée. 2008;XIII(2):9-22

[31] Hamzei F et al. The dual loop model and the human mirror system: An exploratory combined fMRI and DTI study of the inferior frontal gyrus. Cerebral Cortex. 2015;26(5):2215-2224

[32] Rizzolati G, Craighero L. Language and mirror neurons. In: Gaskell G, editor. The Oxford Handbook of
Psycholinguistics. Oxford: Oxford University Press; 2007

[33] Arbib M. From mirror writing to mirror neurons. In: Doncieux S et al., editors. From Animals to Animats 11. Berlin: Springer; 2010a. pp. 1-12

[34] Arbib M. The mirror system hypothesis on the linkage of action and languages. In: Arbib M, editor. Action to Language via the Mirror Neuron System. Cambridge: Cambridge University Press; 2006

[35] Arbib M. How the Brain got Language: The Mirror System Hypothesis. Oxford: Oxford University Press; 2012

[36] Keysers C, Gazzola V. Hebbian learning and predictive mirror neurons for actions, sensations and emotions. Philosophical Transactions of the Royal Society B. 2014;369:20130175

[37] Rogalsky C et al. Are mirror neurons the basis of speech perception? Evidence from five cases with damage to the purported human mirror system. Neurocase. 2011;17:178-187

[38] Arbib M. Schema theory. In: Schapiro SC, editor. The Encyclopedia of Artificial Intelligence. Hoboken: Wiley-Interscience; 1992. pp. 1427-1443

[39] Chomsky N. ibid. 1995

[40] Arbib M. From mirror writing to mirror neurons. In: Doncieux S et al., editors. From Animals to Animats 11. Berlin: Springer; 2010b. pp. 1-12

[41] Levelt WJM et al. A theory of lexical access in speech production. Behavioral and Brain Sciences. 1999;22:1-75

[42] Billard A, Arbib MA. Mirror neurons and the neural basis for learning by imitation: Computational modeling. In: Stamenov M, Gallese V, 
editors. Mirror Neurons and the Evolution of Brain and Language. Amsterdam: John Benjamins Publishing Company; 2002. pp. 343-352

[43] Brendel B et al. Does our brain house a "mental syllabary"? An fMRI study. In: Proceedings the 8th International Seminar on Speech Production (ISSP). 2008. pp. 73-76

[44] Mishra RK, Mohan A.

Understanding the role of mirror neurons in learning language: A review of studies. Journal of Indian Psychology. 2016;3(3):88

[45] Vihman MM. The role of mirror neurons in the ontogeny of speech. In: Stamenov M, Gallese V, editors. Mirror Neurons and the Evolution of Brain and Language. Amsterdam: John Benjamins Publishing Company; 2002. pp. 305-314

[46] Hicock G, Poeppel D. Dorsal and ventral streams: A framework for understanding aspects of the functional anatomy of language. Cognition. 2004; 92(1-2):67-99

[47] Hickok G, Poeppel D. The cortical organization of speech production.

Nature Reviews Neuroscience. 2007;8: 393-402

[48] Hicock G. The cortical organization of speech processing: Feedback control and predictive coding, the context of a dual-stream model. Journal of Communication Disorders. 2012;45(6): 393-402

[49] Hicock G. The functional neuroanatomy of language. Physical Life Review. 2009;6(3):121-143

[50] Hicock G. The Myth of Mirror Neurons: The Real Neuroscience of Communication and Cognitive Network. WN Norton and Company; 2014
[51] Waugh LR, Jakobson R. The Sound Shape of Language. Bloomington:

Indiana University Press; 1987

[52] Noury Bakrim. ibid. 2019c. p. 2. Manuscript in progress

[53] Dell F, Elmedlaoui M. Syllables in Tashlhiyt Berber and in Moroccan Arabic. Dodrecht: Kluwer Academic Publishers;

[54] McCarthy J. Formal Problems in Semitic Phonology and Morphology.

Cambridge: MIT; 1979

[55] Lahrouchi M. Gémination, réduplication et gabarits dans un langage secret du berbère tachelhit. JEL. $2004 a$

[56] Haddadou MA. Dictionnaire des Racines Berbères Communes. Alger: Haut Commissariat à l'Amazighité; 2006/2007

[57] Ridouane R. Geminates at the junction of phonetics and phonology. Laboratory Phonology, 2010;10:61-91

[58] Chaker S. "Racine”, L’encyclopédie Berbère. Fascicule XL. 2017;40:

6732-6745

[59] Inklas S, Downing LJ. What is reduplication? Typology and analysisPart 1/2: The typology of reduplication. Language and Linguistics Compass. 2015;9(12):502-515

[60] Downing LJ, Stiebels B. Iconicity. In: Trommer J, editor. The Morphology and Phonology of Exponence. Oxford: Oxford University Press; 2013

[61] Browman C, Goldstein L. Articulatory gestures as phonological units. Phonology. 1989;6:201-251

[62] Chitoran I, Goldstein L. Testing the phonological status of perceptual recoverability: Articulatory evidence from Georgian. In: 10th Conference of 
Laboratory Phonology (LabPhono). 2006

[63] Byrd D, Saltzman E. Speech production. In: Arbib M, editor. The Handbook of Brain Theory and Neural Networks. Cambridge: MIT Press; 2002. pp. 1072-1076

[64] Blevins J. Syllable: Typology. In: Brown K, editor. Encyclopedia of Language and Linguistics. Amsterdam: Elsevier; 2006

[65] Sherwin S. The sonority sequencing principle in interlanguage phonology.

Working Papers in Linguistics. 1999;6: $55-74$

[66] Hayes B. Interpreting sonorityprojection experiments: The role of phonotactic modeling. In: ICPhS XVII. 2011

[67] Van de Vijver R, Baer-Henney D. Sonority intuitions are provided by the Lexicon. In: Parker S, editor. The Sonority Controversy. Berlin-Boston: De Gruyter; 2012

[68] Zec D. Prosodic weight. In: Féry C, Van de Vijver R, editors. The Syllable in Optimality Theory. Cambridge: Cambridge University Press; 2003

[69] Prince A, Smolensky P. Optimality Theory: Constraint Interaction in Generative Grammar. Hoboken: WileyBlackwell; 2004

[70] Selkirk E. Phonology and Syntax: The Relation Between Sound and Structure. Cambridge MA: MIT Press; 1984

[71] Clements GN, Keyser SJ. CV Phonology: A Generative Theory of the Syllable. Cambridge, MA: MIT Press; 1983

[72] Steriade D. The syllable. In: Frawley W, editor. Oxford
Encyclopedia of Linguistics. Oxford: Oxford University Press; 2002

[73] Ettlinger $M$ et al. The effect of sonority of word segmentation: evidence for the use of a phonological universal. Cognitive Sciences. 2012;36(4):665-673

[74] Bona M. Combinatorics of Permutations. New York: Chapman and Hall; 2016

[75] Kronrod Y et al. A unified account of categorical effects in phonetic perception. Phsychonomic Bulletin \& Review. 2016;23(6):1681-1712

[76] Rasin E. The stress-encapsulation universal and phonological modularity. In: GLOW Main Session. Leiden University; 2017

[77] Rastier F. Sémantique Interprétative. Paris: PUF; 1987a

[78] Fillmore C. Frame semantics and the nature of language. Annals of the New York Academy of Sciences. 1976;280(1): 20-32

[79] Fillmore C et al. The FrameNet Construction. In: Boas HC et al., editors. Sign-based Construction Grammar. Stanford: CSLI Publications; 2012

[80] Eco U. Kant et l'Ornithorynque. Paris: Grasset; 1997

[81] Putsejovsky J, Jezek E. Qualia Structure. In: Putsejovsky J, Jezek E, editors. A Guide to Generative Lexicon Theory. Oxford: Oxford University Press; 2016

[82] Wierzbircka A. Semantics: Primes and Universals. Oxford University Press; 1996

[83] Peeters B. Setting the Scene: some recent milestones in the lexiconencyclopedia debate. In: Peeters B, editor. The Lexicon-Encyclopedia Interface, Current Research in the 
Semantics/Pragmatics Interface 5.

Amsterdam: Elsevier; 2000. pp. 1-55

[84] Rastier F. ibid. 1987b

[85] Touratier C. Morphologie et Morphématique: Analyse en Morphèmes. Aix-en-Provence: Presses Universitaires de Provence; 2002

[86] Fujita K. Recursive merge and human language evolution. In:

Roepper T, Speas M, editors. Recursion: Complexity in Cognition (Studies in Theoretical Psycholinguistics). Berlin: Springer; 2014

[87] Behr J. Introduction to Biosemantics. Unpublished document. 2011

[88] Millikan R. Biosemantics. Journal of Philosophy. 1989;86(July):281-297

[89] Hinzen W, Poeppel D. Semantics between cognitive neuroscience and linguistic theory: Guest editors' introduction. Language and Cognitive Processes. 2011;26(9):1297-1316

[90] Kann K et al. Verb argument structure alternations in word and sentence embeddings. Proceedings of the Society for Computation in Linguistics (SCiL). 2019;2:287-297

[91] Angermeyer P. Copying contiguous gestures: An articulatory account of bella coola reduplication. University of Pennsylvania Working Papers in Linguistics. 2003;9(1):1-34

[92] Lahrouchi M. JEL Domaines Actes des 5ème journées d'études linguistiques. In: Crouzet $\mathrm{O}$, Demirdache H, Wauquier-Gravelines S, editors. 07-12. Nantes: université de Nantes; 2004b

[93] Ratcliffe RR. Drift and noun plural reduplication in afroasiatic. Bulletin of the SOAS. 1996;59(2):296-311
[94] Louali N. L’ambisyllabicité des consonnes géminées: le cas du berbère (tachelhit). Nancy: XXIV Journées d'Études sur la Parole; 2002

[95] Dell F, Elmedlaoui M. Syllables and Gemination in Imperfective Stems in Tachelhiyt Berber. Brill's Journal of Afroasiatic Languages and Linguistics. 2013;5(1):1-34

[96] Safir K. Viable syntax, rethinking minimalist architecture. Biolinguistics. 2010;4(1):35-107

[97] Curto C et al. Analysis of combinatorial neural codes: An algebraic approach. In: Robeva R, Macauley M, editors. Algebraic and Combinatorial Computational Biology. Cambridge: Academic Press; 2018

[98] Dehaen S, Amalric M. Origins of brain networks for advanced mathematics in expert mathematicians. PNAS. 2016;113(18):4909-4917

[99] Ackerman F, Malouf R. Parts and wholes: Patterns of relatedness in complex morphological systems and why they matter. In: Analogy in Grammar: Form and Acquisition. Oxford: Oxford University Press; 2009. pp. 54-82

[100] Retkute R et al. Mathematical modeling of genome replication. Physical Review. E, Statistical, Nonlinear, and Soft Matter Physics. 2012;86(301):031916

[101] Marcolli M. Languages and complexity. Winter 2015. C.S 101

[102] Papadopoulos A. Topology and biology: From aristotle to thom. In:

Dani SG, Papadopoulos A, editors. Geometry in History. Berlin: Springer Verlag; 2019

[103] Baayen RH. Storage and computation in the mental lexicon. In: Jarema G, Libben G, editors. Oceanic 
Linguistics. Cambridge: Elsevier; 2007. pp. 81-104

[104] Kemmerer D. Action verbs, argument structure constructions and the mirror neuron system. In: Arbib M, editor. Action to Language via the Mirror Neuron System. Cambridge: Cambridge University Press; 2006

[105] Lakoff G. The neural theory of metaphor. In: Gibbs R, editor. The Metaphor Hansbook. Cambridge: Cambridge University Press; 2008

[106] Arbib M et al. From Schema Theory to Language. New York: Oxford University Press; 1987

[107] Molnar-Szakacs I et al. Observing complex action sequences: The role of the fronto-parietal mirror neuron system. Neuroimage. 2006;33(3):923-935

[108] Grafton ST et al. Evidence for a distributed hierarchy of action representation in the brain. Human Movement Science. 2007;26(4):590-616

[109] Ballard DH. Brain Computation as Hierarchical Abstraction. Cambridge: MIT Press; 2015

[110] Tourville JA, Guenther FH. The DIVA model: A neural theory of speech acquisition and production. Language and Cognition Processes. 2011;26(7): 952-981

[111] Sternberg S. Modular processes in mind and brain. Neuropsychology. 2011;28(3-4):156-208

[112] Rapp B, Tao Y. The role of functional modularity in recovery from chronic aphasia. In: Frontiers in Human Neurosciences: Academy of Aphasia 56 Annual Meeting, Montreal. 2019

[113] Medaglia JD. Graph theoretic analysis of resting state functional MR imaging. Neuroimaging Clinics of North America. 2017;27(4):593-603 



\title{
Computational Model for the Construction of Cognitive Maps
}

\author{
Larisa Yu. Ismailova, Sergey V. Kosikov \\ and Viacheslav E. Wolfengagen
}

\begin{abstract}
The chapter considers an option for solving the problem of storing data in the Web environment and providing an access to the data, taking into account their semantics, i.e., in accordance with the nature of the tasks solved by users of different classes. The proposed solution is based on the use of presentation of the data in the form of semantic networks. As the main technical tool for describing access methods, the chapter proposes cognitive maps (CMs), which can also be considered as semantic networks of special type. When access is done, the presentation of information consistent with the semantic description of the user is provided. The suggested method of constructing CMs is based on the intensional logic. The solution is presented in the form of a computational model, which provides for the construction of CM's dependence on the parameter. The proposed method of parametrization makes it possible to take into account the semantic characteristics of users of various classes. Some CM constructions for problem domain description are presented. A method for semantically oriented naming of CMs is proposed. The method is based on building of a functor of special type.
\end{abstract}

Keywords: cognitive maps, access method, semantic network, interpretation, computational model, intensional logic, functor

\section{Introduction}

As Web technologies progress the task of developing tools for the data organization and storage in a web environment assumes ever greater importance [1]. In the pre-network single-user environment, the prevailing way to organize data was a hierarchically organized file structure. Still this method was convenient for not all tasks (in particular, it did not directly provide the possibility of simultaneous classification of various information objects according to various foundations). However, in the whole, it covered a rather wide class of applications.

The situation changed thanks to network technologies, when information objects turned out to be associated with different users, who applied in general different principles for placing, searching, and processing. Thus, the rigidly defined hierarchies were replaced by network structures that determine the connections of information resources set by various ways. The connections may arise due to the different reasons, and this assumes the need, firstly, to process them in different ways and, secondly, to take into account the meaning of the data and their connections when processing. Thus, the data become essentially semantic in nature. 
The semantic measurement of data structures leads to the necessity to change respectively the methods of their description, searching in the environment of such structures and manipulating them [2].

The need to use semantically rich network structures requires to develop semantically oriented methods for describing data structures and their processing, in particular, the definition of semantically oriented search methods [3]. Different users must work with different fragments of data, which are determined by the goals of their work, the source data that is necessary to achieve the goals, a set of appropriate access rights, etc. All this raises the problem of providing access to data, which should take into account both the class of the user, getting the access, and its characteristics, as well as the semantics of the data, to which the access is allowed, in particular, providing a user-friendly representation of the data.

The means of describing users and the means of their access to data, considering the specifics of the tasks to be solved, must combine power enough to distinguish the relevant elements of the description and simplicity. It makes it possible to practically use the descriptions without cumbersome instrumental kits. The means of description should fix the user's view on the subject area, which should be sufficiently detailed to describe the classes of problems to be solved, but without redundant detailing that might lead to an increase in the volume and complexity of the description. The use of cognitive maps (CMs) seems promising in this aspect.

Cognitive maps are diagrams used to visually organize information. Various works define the cognitive maps in various ways. For example, CM's can be used to represent spatial relations and determine the mutual position of information elements in a physical environment. CMs also can be used to represent abstract information and to map it to the spatial (usually planar) view. In this case CMs are connected with the presentation of information described as mind maps, which, thus, can be considered as a specific instance of CMs. As a rule, CMs represent information in the form of a hierarchical structure. It is also possible to represent connections between nonadjacent elements of the structure, which brings CMs closer to the network representation of information. The elements of the structure are connected by arcs, which, as a rule, are not specifically marked. The connections represented by arcs can use the order of homogeneous nodes that are on the same level of hierarchy. This allows to provide not only structural information but also, for example, information on the sequence of actions for solving any task.

Using CM to describe the characteristics of the user, including his typical tasks, allows to perform this description in the early stages of designing an information system. The study in the field of cognitive psychology allows us to characterize CM as a means of knowledge structuring, consistent with the human way of thinking in solving practical tasks. For this reason the $\mathrm{CM}$ can be used to fix ideas about the user and his tasks up to creating a formal domain model, moreover, as one of the tools for developing such a model.

Semantically oriented structures for data presentation are proposed for solving user's problems. It is worthwhile to choose the representing structure in the form of a semantic network [4]. The semantic network is understood as an oriented graph consisting of nodes and marked arcs. The nodes correspond to concepts, i.e., notions of various degrees of generality, presented in the network. The arcs correspond to the connections of the concepts among themselves, and the marks of arcs determine the way of interpreting the connections. As a rule, arcs are lined not randomly but in accordance with certain patterns representing stereotypical sets of connections (frames).

The semantic network may be of a tree-structured nature or include treestructured fragments in its composition, but it does not mean the network necessarily has this form. Therefore, the semantic network (SN) is actually a more general structure for the representation of knowledge about the domain than CM. Following 
this, the description of the user and his view on the subject area using a cognitive map can be considered as a specific instance of the semantic network. The transition from $\mathrm{CM}$ to the description in the form of a semantic network can be performed using two basic operations: (1) recovering unclear marks on arcs in CM and (2) deriving semantic network configuration patterns corresponding to the CM fragment.

The interpretation of $\mathrm{CM}$ as a special type of semantic network at a conceptual level provides the inclusion of the user in the conceptual model of the domain as part of it. The works on semantically oriented data representation $[1,4]$ show that the model should include constructions that describe the relationship between the semantics of user characteristics and the semantics of the data being processed.

Such model provides the user with data for processing in accordance with the set of his powers and the nature of the problem to be solved. When the model is represented as a whole in the form of a semantic network, its considered part can be represented as a control subnet, which provides the computation of query results in accordance with the specified parameters.

One of the critical tasks in organizing access and processing semantically oriented data is the preservation of semantics while working with resources [5]. The resources, on the one hand, exist for a long time, and this makes their repeated use possible, and, on the other hand, they usually have a dynamic nature, i.e., they can be modified, updated, etc., at any point in time. In this case the change is possible of both the data about separate facts, processes, etc. in the area described by the resource set and the general semantic characteristics of the data. The change is also possible of both the data itself and the links, i.e., the dynamic arising of new links, changing the semantics of existing links and other information objects.

The changes in semantics can both save the logical continuity of a network and violate it. This chapter understands the logical continuity as the preservation of a set of general constraints (including informal ones) placed on the contents of the network. Maintaining logical continuity during network modification requires dynamic checking of constraints when performing operations that change the semantics of the network in order to prevent actions that destroy the semantics.

For supporting the changes, the most important factor is that the semantics can be changed both unintentionally (by chance) during the work and maliciously. In the latter case, the goal may be to get unauthorized access to information-receiving or changing of the information. For this reason the support of the semantic integrity of the network suggests, in particular, restricting the user's access to information in the network. Such a restriction may include both usual restrictions on writing or reading and more complicated semantically motivated constructions. For example, the possibility to change data in the network only in a strictly determined way or every change must be associated with the information that identifies the user who made the changes.

The development of tools for supporting the network access operations involves describing the semantics of a system of interconnected resources by a formalized way, which makes it necessary to introduce the concept of a semantic network as a formal analogue of a resource system [6]. The capabilities of network access tools and their restrictions are shown in the form of a model of access tools to the SN. The necessity to implement tools for supporting access operations leads to the fact that the model must be of a computational nature. The development of such a model is expected to provide the ability to construct a semantically correct system of support for access to the SN, including the ability to specify semantically consistent access restrictions, which makes the task of developing a computational model for supporting access operations relevant. The need for data processing, including the designation of queries, suggests the development of a theoretical basis for constructing a computer information system that provides both the logical 
correctness of data interpretation and the construction of appropriate computational procedures. For this purpose this chapter uses the formalism developed on the basis of intensional logic [6]. The computational aspect is ensured, in particular, by the possibility to include the means of a typical lambda calculus into the logical system under consideration.

The necessity to take into account the subjective view on the semantic network requires modeling the dependence of the interpretation of the system's structures on the subject. This requirement is considered in the intensional logic by defining an interpretation structure using a parameter, the assignment point. The value of each construction corresponds to specified parameter value. In this case the constructions of the language of intensional logic are divided into extensional and intensional ones. The value of the composite extensional construction at the specified assignment point is a function of the values of its constituent structures at the same assignment point. The determination of the value of the intensional composite constructions requires determining the values of its constituent constructions on the entire set of assignment points or on some of its subsets.

To take into account the interpretation of various entries of an information object requires the construction of models of interpretation dependence on the context. The context determination can also be performed using intensional constructions. In this case, it is possible to use intensional operators or constantsintensions of higher orders.

The applied method of parameterization allows to take into account the semantic characteristics of users of various classes.

This chapter is structured as follows. Section 2 describes some approaches to the definition and construction of cognitive maps; special attention is paid to the degree of use of semantic information. Section 3 contains a statement of the problem of supporting the language of description of cognitive maps and means of its interpretation and offers a solution as a variant of the language of intensional logic. Section 4 describes the use of cognitive maps in the description of the problem area on the example of dependent types. In Section 5 we propose an approach to build a support system of cognitive maps on the basis of adjoint functors. In conclusion, the results are summarized briefly.

\section{Related work}

The use of CMs for setting management methods of access to the distributed semantic network assumes the study of their expressive potential in the whole. In this connection approaches to formal definition of CM's semantics cause special interest. The diversity of approaches is reasoned not least by the fact that different researchers use the term "cognitive map" in various meanings.

The CM's applications cover different areas: sociology, economics, medicine, international relations, etc. Among the problems solved by CMs, the following ones can be singled out: (i) problems of conceptual modeling, especially in the context of initial understanding of problems in weakly structured subject areas; (ii) problems of further modeling of subject areas, especially if it is necessary to describe the dynamics; and (iii) management problems in the subject area. Some lines of research and application of CMs are shown in Figure 1.

Nevertheless, along with all the diversity of tools for creating CMs, including those widely disseminated ones, FreeMind [7], MindMeister [8], MindManager [9], Cacoo [10], MindMup [11], XMind [12] etc., only a small part of them can be considered as tool kits for cognitive modeling based on CMs or a ready-to-use tool for supporting cognitive architectures. 


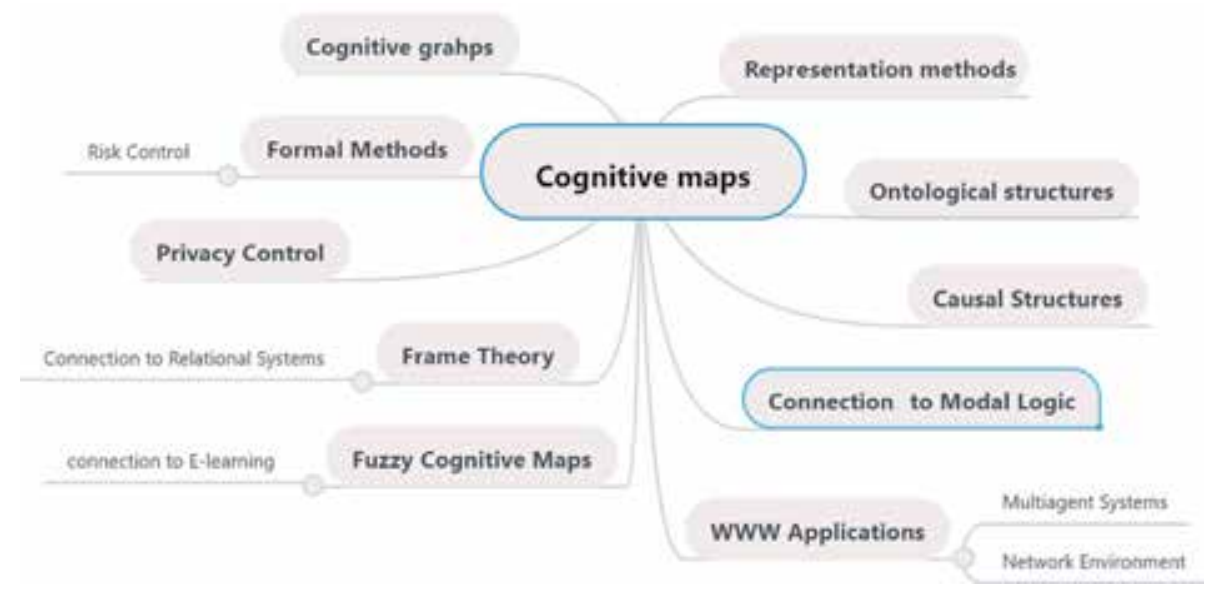

Figure 1.

Lines of research and application of CMs.

Regarding this some lines of research in the field of cognitive modeling should be mentioned. The work [13] proposes the most common approach. According to the approach, the cognitive modeling is "a line based on a knowledge-intensive interdisciplinary methodology for solving applied problems through cognitive maps with more or less support to special information technologies." In this case the cognitive map is understood as a formalized model of the situation that reflects the knowledge and/or beliefs of the subject, individual or collective, about the causeeffect impacts between the important factors of the situation.

Within the considered line, the formal models of CMs relate to the questions of reducing the risk, introduced by the human factor, when solving problems in various subject areas using CMs. The work [13] proposes an option of describing the approaches to the formal definition of the methods of interpreting CMs. This work distinguishes two approaches to the interpretation of CMs: descriptive (pinning methods of understanding the notions of the subject area) and normative (fixing the methods of solving problems in the subject area), which trace back to the approach accepted in the work [14]. The first approach aims to use CMs for developing an internal model of a man's knowledge about a certain situation. The second approach suggests CMs of different types as normative models (schemes or rules) for the external presentation of knowledge about situations.

In general, depending on the objective of the study, the details of the CM's definition differ from each other; in particular, CMs may have a different structure. In the whole within the formal approach, the CM definition is often extended to a cognitive graph. For example, the work [15] considers the structure of spatial knowledge that arises from the study of a new spatial environment and gives grounds for generalizing CMs up to cognitive graphs. The studies of the optimization of CM's representation adjoin the works of this type. Thus, the work [16] proposes a three-dimensional representation of CMs. The representation is based on the selection of the node kernels and daughter nodes, the nodes being located in three-dimensional space and being represented by balls of different radius. The proposed representation, as stated, enhances the cognitive clarity of the representation, which is interpreted as the ease of its intuitive understanding.

A cognitive map or, with a graph-based approach, a cognitive graph can represent parts of systems with a cognitive architecture and in this way be put in one or another cognitive architecture. The work [17] describes some cognitive architectures, the method of description giving an opportunity to think about the 
compatibility of the presented architectures with the formalism of cognitive maps. The abovementioned work understands the cognitive architectures as software systems that might think about problems in different areas, develop ideas, adapt to new situations, and reflect upon themselves. To this end, the cognitive architectures are trying to provide evidence of which specific mechanisms successfully reproduce intellectual behavior and thereby contribute to cognitive science.

The considered paper emphasizes three large classes of cognitive architecture's character-coded, emergent, and hybrid ones. The character-coded systems represent concepts using characters that can be manipulated using a given set of operations. The emergent architecture assumes the use of multi-node parallel models, in which the flow of information is represented as the propagation of signals between the nodes. The hybrid architecture combines both approaches, but this combination can be made in different proportions. It is obvious that the system based on cognitive maps in this classification must be referred to the character-coded architecture.

The flexible way to represent data with different degrees of abstraction using CMs grounds the possibility of data using to represent ontological information. The work [18] considers how CMs can be used for the work in the situation when the information is missing or is unreliable in e-commerce. The paper presents a knowledge management system based on CMs and ontology and also proposes a framework solution for joint use of information along with the use of a common repository based on CMs. Using CMs provides modeling of a virtual environment by generating and checking the sequence of events that take place in the environment when modeling.

An interesting use of the CM's capabilities to represent dynamic information is the modeling of cause-effect (causal) relationships. Thus, the work [19] identifies the cognitive nature of a business model designated for a cognitive representation that describes business development activities. Attention is also drawn to the causeeffect structure of the business model, that is, the model of cause-effect relationships which, according to top managers or entrepreneurs' view, connects the creation of value and activities for its creation. The conceptualization and analysis of business models as cognitive maps can shed light on four important properties of the causal structure of a business model: levels of complexity, focusing and clustering, which characterize the causal structure, as well as the mechanisms underlying causal relationships shown in this structure.

There were some attempts to model CMs with the help of more general modallogical contexts. The work [20] proposes an interpretation of cognitive maps, correlated with elements of large-scale spatial environment, for constructing geometrically impossible environments. Then the constructed CMs are proposed for joint interpretation with geometrically possible maps. Such an interpretation logically corresponds to the possibility of considering the interpreted cognitive map from different points of view, and the case of geometrically impossible interpretation is not excluded in advance.

The CM's use in the network environments (in particular, in WWW) is based on the CM's capabilities to represent information in a form that allows storing some nodes of map on separate nodes of the computational network, as well as parallel processing of stored information. Thus, for example, the work [21] is a description of the CM's use for working in a multi-agent environment. The strength of this work is the exact semantics of CMs, based on relational algebra according to [22]. Unfortunately, the constructed semantics has a very special form due to the chosen ad hoc three-valued logic system. Nevertheless, within the framework of the chosen semantics, it is possible to construct the forms for representation (when describing the subject area) of the agents' point of view on cognitive maps, as well as to determine decision-making procedures for such agents. 
A somewhat different approach is adopted in the work [23], where cause-effect relationships are modeled based on interactive cognitive maps. A cognitive map is considered as a family of cognitive models. The models can be computed in parallel by exchanging data between themselves. In such conditions, the network implementation becomes natural, which also allows to hide data that a particular component "does not want" to make it visible to other components. The paper takes up the position that the adoption of the CM's network model leads to the construction of the CM's ecosystem, the development of which is managed by cognitive agentssystem components.

Apart are fuzzy cognitive maps. This rapidly advancing branch, develops the formalisms of cognitive maps. In the general case, a fuzzy cognitive map is defined as a set of nodes and links, the nodes being associated with the concepts of the domain, and links to causal relationships between concepts. Each node is associated with the degree of the presence of a concept in a situation-a number or an element of a qualitative scale with which a number is associated. The nodes of the graph also associate with numbers that determine the degree of influence of one concept to another. A positive number corresponds to an increase in the presence of the corresponding concept and a negative one to its decrease.

The specified fuzzy cognitive map can serve to model the dynamics of a situation. To do this the initial degree of the concept's presence in the situation is set. Then the changes of the degrees of presence are determined in accordance with the links of the graph as the sum of the corresponding degrees of influence. The given process is repeated iteratively until it reaches the specified time limit. The experiments demonstrate that three main types of behavior are possible: (1) stabilization, i.e., convergence at a given point; (2) way out to the cyclic mode; and (3) chaotic behavior, characterized by the absence of limit modes.

An approach based on fuzzy cognitive maps is exampled in the work [24]. This paper shows the use of cognitive maps for making the decision, which is understood as the choice of a single decision or a group from the given set of alternatives. The cognitive maps are used thanks to their ability to explain the applied process of thinking. The work studies the process of convergence of cognitive maps and their application for decision-making.

The fuzzy cognitive maps can be used in different domains, including optimizing the learning process. One of the optimization techniques is to analyze data from learning management system logs and to identify patterns of users' behavior related to the content. The work [25] proposes the use of fuzzy cognitive maps to model the behavior of users of learning management systems. The proposed model describes the user's interaction with the content of the system and can be used to forecast the reaction of users to its training, test, and practical elements.

The relational approach to the construction of CM's semantics is gradually getting more of dissemination. So, besides the already cited work [21], the relational approach is also accepted in the work [26], in which dynamic models of fuzzy relational cognitive maps are analyzed. A frame-based approach, accepted, for example, in [27], can be considered as a generalization of the relational approach. In this case the frames are considered as stereotypical structures that provide orientation in the physical or conceptual space. In addition to the orientation, the choice of path can be provided, which corresponds to the solution of the planning problem. The frame approach is a synthesis of graph representations and cognitive maps and solves problems connected with explaining orientation-based behavior on graphs or maps or when they are used in parallel.

The frame approach can be successfully applied both in systems with common objectives and in systems oriented to specific applications. Thus, the work [28] solves the problem of presenting historical knowledge on the basis of CMs, 
practically, on the basis of the frame approach. Actually, the CM's models are characterized as a specific type of dialectic interaction of logical and graphic forms of knowledge representation.

The considered work contains a detailed classification of cognitive maps. Thus, depending on the construction technology, they distinguish (1) associative maps or mind maps based on associations and (2) conceptual maps that serve to represent the connections of concepts between them. Among the mind maps are the maps identified as follows:

1. Dyadic, containing two alternative branches

2. Complex (poly-categorial), the number of branches in which is not limited (in practice it is convenient to have from three to seven branches)

3. Mnemonic, used to create an easily remembered image

4. Creative

5. Collective (e.g., developed during the implementation of joint creative projects)

\section{Artistic}

It is easy to see that the classification is based on various reasons, which makes it possible to set the task of clarifying the classification of CMs both for cognitive modeling and developing the formalizations oriented to their analysis, processing, and software generation.

All described applications may be characterized by one common feature-they are either not based on the use of formal semantics and use CMs as a convenient representation of knowledge about the subject area for informal analysis or, at best, use CMs as a tool for determining a finite state machine of a special type. However, such an approach seems to unreasonably narrow the scope of CM's application. It seems more reasonable to consider cognitive maps as the formalism, providing, on the one hand, pinning informal considerations about the described subject area and, on the other hand, obtaining more or less formalized descriptions that are compatible with descriptions in modeling languages or even programming languages.

An important sphere of application of solutions based on cognitive maps is information support for legal applications. For example, the work [29] analyzes the findings and contributions of existing research in the field of decision-making about the confidentiality, and it proposes to fill up the gaps in the modern understanding by applying a cognitive architecture to model confidential decision-making. In order to solve the issues related to confidentiality, it is necessary to consider aspects of human cognition, using, for example, the methods used in human-computer interaction and computer science research.

\section{Intensional language for CM's description}

\subsection{Intensional CMs}

An essential characteristic of the semantic network of the species considered in this chapter is the possibility of linking the structures corresponding to CMs with logical formulas of a certain kind. Because the meaning of the CMs depend 
essentially on time, subject, etc., the logic appropriate for the basis for the interpretation of CMs must be explicitly focused on the consideration of semantic factors. Intensional logic can be chosen as such logic.

The intensional logic allows to operate with the formulas containing functional abstraction and application of function to arguments. Thus, it is possible to obtain the value of CM's structures using the evaluation. The result of the computation can also be represented as a CM's construction. In this case, the value depends on the parameter-the assignment point-which gives the CMs an intensional character.

The need for an intensional description of CMs leads to the problem of determining the language means of parameterized computation of semantic network structures as the task of developing methods to support a specialized language for describing the semantic network and means of its interpretation, which should provide:

1. The definition of means of interpretation of CM's structures on the basis of their assigned semantic characteristics

2. The definition of interpretation methods as specialized CMs, which can be embedded in objects that parameterize the interpretation

3. The definition of general limitations on interpretation methods, as well as procedures for the harmonization of interpretations that ensure the implementation of the imposed restrictions

The solution of the problem is supposed to be obtained on the basis of a combination of methods of intensional logic to describe the language and applicative methods of interpretation to compute the values of CMs. At the same time, it is possible to describe some constructions of the domain model in the form of CMs. The chapter presents a description technique on the example of dependent types.

Support to the implementation of intensional descriptions CMs requires the use of methods which agree with the methods of the description of the CMs. In this chapter, a functor technique is used for this purpose. The specialized functors are determined to represent CMs in supporting the programming environment. The definition is based on the adjoint functors.

The research method centers on the systematic use of the formalization of CM with the further determination of the semantics of the constructed formal objects. The object formalization is carried out using methods of intensional logic by constructing an intensional language to describe the objects that compose the CM. The intensional nature of the language makes it possible to take into account the contexts of objects used. The means of intensional logic provide for both the definition of objects, the interpretation of which is independent of the context (extensional objects) and objects of a different kind, and the interpretation of which requires consideration of one or more contexts (intensional objects). The intensional operators serve as the tools for setting contexts.

The semantics of objects is determined by the means of category theory. The use of category theory ensures a sufficient general definition of semantics, on the basis of which types of changes in the domain can be taken into account. Changes, in particular, can affect the domains of change of the variables of the CM description language, forming the so-called variable domains. Taking into account the changes allows describing the dynamic subject areas of the same CM, which in practical terms saves the efforts spent on developing and debugging the descriptions of CM use.

The analysis of methods of CM use to describe the subject areas consists of systematic consideration of the applied formalized methods and the identification of stereotypical structures used to describe objects and situations specific to a 
particular domain. Considerable interest is caused by the study of general categorical constructions, such as functors and natural transformations, in their application to CM. In particular, the adjoint functor construction can be used to describe abstract types of the data associated with CM nodes.

\subsection{Intensional language}

The intensional language contains tools for describing the nodes and links of $\mathrm{CM}$. The description in the intensional language is a formalized object, matched to $\mathrm{CM}$. Such an object can be used both for constructing the semantics of CM and (in practical terms) for representing $\mathrm{CM}$ for the purpose of storage and processing. The use of formalized objects also provides for syntactic and semantic control of objects, which makes easier their debugging and maintenance.

Types are assigned to the expressions of the intensional language; thus, the type $e$ corresponds to the node of CM and the type $t$ to the link between specific nodes. A set of language expressions is defined as an inductive class. This method of setting ensures the definition of CM construction operations from separate parts. The description of the language as a whole follows the paper [6]. The interpretation of language expressions is also set with the help of induction for the construction of an interpreted expression.

\subsubsection{Types}

The set of types of $r$ is defined inductively:

1.e $\in Y$, which is interpreted as the entity type.

2.t $t$, which is interpreted as the type of sentence.

3. If $a, b \in Y$, then $\langle a, b\rangle \in Y$ and $\langle s, a\rangle \in Y$, where $s$ is interpreted as the type of meaning.

4. There are no other types.

Types represent the sets of elements to interpret CMs or their fragments.

\subsubsection{Language}

We will use the enumerable set of variables and (infinite) set of constants of each type $a$. If $n$ is a natural number and $a \in r$, then $v_{n, a}$ is the $n$-th variable of type $a$, and $\mathrm{Con}_{a}$ is a set of constants of type $a$.

The language includes a set of meaningful expressions $M E_{a}$ of each type $a$. It is defined recursively:

1. $v_{n, a} \in M E_{a} ; \operatorname{Con}_{a} \subseteq M E_{a}$.

2. If $\alpha \in M E_{b}$ and $u$ is a variable of type $a, \lambda u \alpha \in M E_{\langle a, b\rangle}$.

3. If $\alpha \in M E_{\langle a, b\rangle}$ and $\beta \in M E_{a}$, then $\alpha(\beta) \in M E_{b}$.

4. If $\alpha, \beta \in M E_{a}$, then $\alpha=\beta \in M E_{t}$.

5. If $\varphi, \psi \in M E_{t}$ and $u$ is a variable, then $\neg \varphi,[\varphi \wedge \psi],[\varphi \vee \psi],[\varphi \rightarrow \psi],[\varphi \leftrightarrow \psi], \forall u \psi$, $\exists u \psi, \square \psi, W \psi$, and $H \psi \in M E_{t}$. 
6. If $\alpha \in M E_{a}$, then $[\wedge \alpha] \in M E_{\langle s, a\rangle}$.

7. If $\alpha \in M E_{\langle s, a\rangle}$, then $\left[{ }^{\vee} \alpha\right] \in M E_{a}$.

8. There are no other meaningful expressions.

The language is the main technical tool to write formulas that are in the correspondence with CMs or their fragments. The set of formulas, however, is wider than the set of CMs.

\subsubsection{Interpretation}

Now let us introduce interpretation of intensional language. Let $A$ and $A s g$ be sets; $A$ is a set of entities (or individuals), and Asg is a set of assignment points. Define the set $D_{a, A, A s g}$ of possible denotates of type $a$ :

$$
\begin{aligned}
& D_{e, A, A s g}=A, \\
& D_{t, A, A s g}=\{0,1\}, \\
& D_{\langle a, b\rangle, A, A s g}=D_{b, A, A s g}{ }^{D_{a, A, A s g},} \\
& D_{\langle s, a\rangle, A, A s g}=D_{a, A, A s g}^{A s g} .
\end{aligned}
$$

As a rule, sets $A$ and $A s g$ are fixed. Under these conditions, we denote $D_{a, A, A s g} \equiv D_{a}$. We treat the interpretation as an ordered tuple:

$$
\mathfrak{A}=\langle A, A s g, F\rangle,
$$

where

1. $A$ and $A s g$ are non-empty sets.

2.F is a function whose domain is a set of constants.

3.If $a \in Y$ and $\alpha \in \operatorname{Con}_{a}$, then $F(\alpha) \in D_{a, A, A s g}{ }^{A s g}$.

We treat $\mathfrak{A}$-assignment as a function $g$, whose domain is a set of variables, such that when $u$ is a variable of type $a$, then $g(u) \in D_{a, A, A s g} . G[x / u]$ means $\mathfrak{A}$-assignment:

$$
g[x / u](v)=\left\{\begin{array}{l}
x, \text { if } u \equiv v \\
g(v) \text { otherwise }
\end{array}\right.
$$

We define the intension $\alpha^{\mathfrak{A}, g}$ and the extensional $\alpha^{\mathfrak{A}, A s g, g}$ meaningful expression $\alpha$ when using the usual recursive definition. Complete form of definition is presented in [1]. The intension is the possible value of $\mathrm{CM}$, and interpretation is a tool for the evaluation of CMs.

\section{Problem domain description with $\mathrm{CMs}$}

The interpretation of the constructions, composing the $\mathrm{CM}$, is made up in the framework of type theory with dependent types of functions and pairs. The interpretation of CM is considered as an object, the type of which can be constructed. 
In the framework of the type system, a judgment can be expressed that an object has a particular type, or that two objects are equivalent. The equivalence of objects implies the equivalence of the corresponding CMs. The types of system objects are constructed in the form of an inductive class, and this allows deriving the properties of objects from the properties of their parts.

We consider two basic types of judgments:

$$
\begin{gathered}
a: A, \\
a=b: A .
\end{gathered}
$$

The judgment of the first form is interpreted as " $a$ is an object (CM) of type $A$." The judgment of the second form is interpreted as " $a$ and $b$ are objects (CM's) of type $A$, equal by definition." Judgments can depend on assumptions of the form $x$ : $A$. The collection of all such assumptions forms context for the judgment.

We use for the expression " $A$ is a type" the formal notation $A: U$. Here $U$ is a universe. Elements of the universe are types. We consider $U$ as the type big enough to hold all the types that are necessary for the description of a given class of CMs, but we do not consider it as holding all possible types. Inaccurate definition of $U$ can lead to paradoxes (e.g., if we consider $U: U$ ). It is possible to show that $U$ can be defined in the type theory without paradoxes, but the proof of this fact is beyond the scope of the present work. $U$ can be used for the representation of collection of types varying over a given type $A$.

In the type theory, we can construct new types from given ones. New types are equipped with functions for their construction and computation. The first construction is a function type. From the types $A$ and $B$, we can construct the type $A \rightarrow B$ of functions with the domain $A$ and codomain $B$. The construction rule for the elements of this type is called lambda abstraction. If we assume that $x: A$ and consider the expression $F: B$, then

$$
(\lambda(x: A) \cdot F): A \rightarrow B .
$$

We can omit the type for the variable and write $\lambda x . F$. We adopt the usual convention that $\lambda$ makes the variable bound and the variable which is not bound is free.

The computation rule for this type is

$$
(\lambda x . F) a=F[x:=a],
$$

where $F[x:=a]$ is a result of a substitution of all free occurrences of $x$ to $a$. The pattern of CM for the functional type is show in Figure $2 \mathbf{a}$; the process of currying is shown in Figure $\mathbf{2 b}$.

The next construction is a dependent function type. The elements of such type are functions whose codomain may depend on the element of the domain to which the function is applied. From the type $A: U$ and family $B(x): A \rightarrow U$, we can construct the type $\prod_{x: A} B(x): U$. If we have an expression $F: B(x)$ depending on $x$ : $A$, then

$$
(\lambda(x: A) \cdot F): \Pi_{x: A} B(x) .
$$

We can apply a dependent function $f: \Pi_{x: A} B(x)$ to an argument $a: A$ to obtain an element $f(a): B(a)$. In particular, we can define functions taking types as arguments. This possibility leads to the representation of polymorphic functions. The pattern of CM for dependent functional type is shown in Figure 3a. 


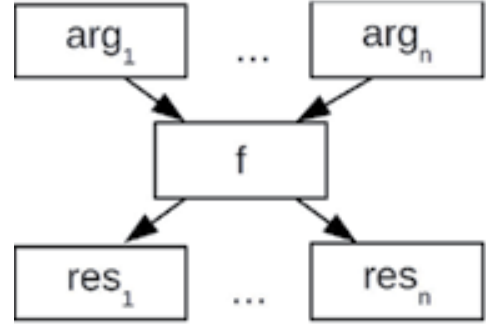

(a)

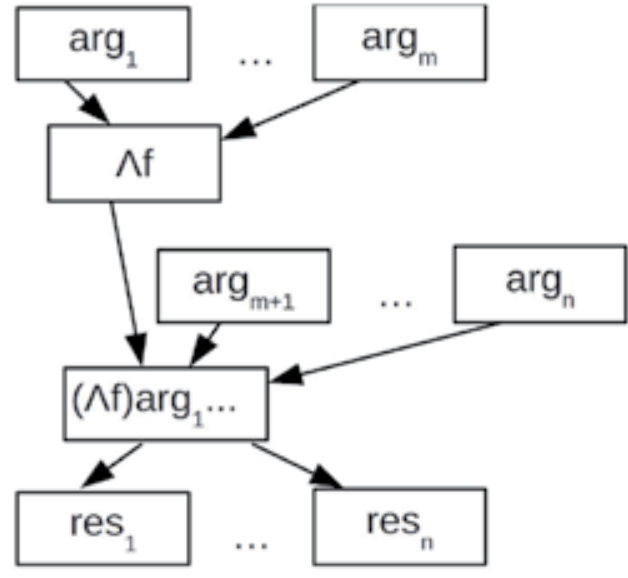

(b)

Figure 2.

The pattern of functional type: (a) multiargument function and (b) curried function.

The next construction is Cartesian product type. From the types $A$ and $B$, we can construct the type $A \times B$. We also consider a product type with arity 0 , which is called the unit type $1: U$. For $a: A$ and $b: B$, we can construct $(a, b) A \times B$. The unit type has one element which we denote $*: 1$.

For the computation with product types, we have to define functions which have the elements of $A \times B$ as arguments (i.e., the function $f$ of the type $A \times B \rightarrow C$ ). Hence we consider such elements as pairs, and we can make computations on such element with the function $g: A \rightarrow B \rightarrow C$ taking the components of the pair as arguments. Then we can define $f$ as follows:

$$
f(a, b)=g a b .
$$

We can consider the universal case and define the function

$$
\operatorname{rec}_{A \times B}: \Pi_{C: U}(A \rightarrow B \rightarrow C) A \times B \rightarrow C
$$

with the equation

$$
\operatorname{rec}_{A \times B} C g(a, b)=g a b .
$$

With this function, for example, we can define projections:

$$
\begin{aligned}
p & =\operatorname{rec}_{A \times B} A(\lambda a . \lambda b . a) \\
q & =\operatorname{rec}_{A \times B} B(\lambda a \cdot \lambda b . b)
\end{aligned}
$$

Similarly for the unit type 1 , we have

$$
\operatorname{rec}_{1}: \Pi_{C: U} C \rightarrow 1 \rightarrow C
$$

with the equation

$$
\operatorname{rec}_{1} C c *=c .
$$

The pattern of CM for Cartesian product is shown in Figure 3b. 


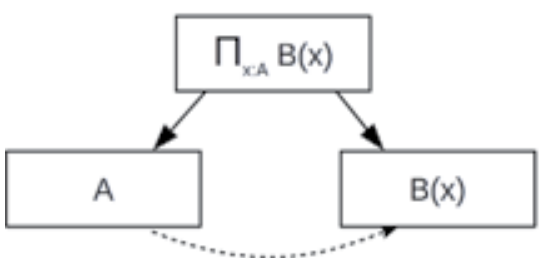

(a)

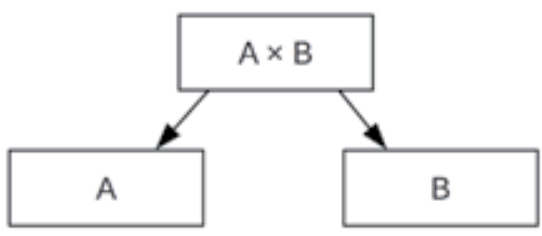

(b)

Figure 3.

The pattern of CM for (a) dependent functional type and (b) Cartesian product.

The Cartesian product represents pairs which components have independent types. So the next construction is dependent pair type. From the type $A: U$ and family $B: A \rightarrow U$, we can construct the type $\Sigma_{x: A} B(x): U$. The construction on the dependent pair is generalization of the construction for product types. To define a function over a dependent pair type $f: \Sigma_{x: A} B(x) \rightarrow C$, we provide a function $g$ : $\Pi_{x: A} B(x) \rightarrow C$ via the defining equation

$$
f(a, b)=g a b .
$$

Similarly to the Cartesian product, we can define

$$
\operatorname{rec}_{\Sigma_{x: A} B(x)}: \Pi_{C: U}\left(\Pi_{x: A} B(x) \rightarrow C\right) \rightarrow\left(\Sigma_{x: A} B(x)\right) \rightarrow C
$$

with the equation

$$
\operatorname{rec}_{\Sigma_{x: A} B(x)} C g(a, b)=g a b .
$$

The pattern of CM for dependent pair type is shown in Figure 4a.

The last construction that we consider here is the sum type. From the types $A$ and $B$, we can construct the type $A+B$. We also consider a sum type with arity 0 , which is called the empty type $0: U$. There are two ways to construct the elements of $A+B$, one is $\operatorname{inl}(a): A+B$ for $a: A$ and another is $\operatorname{inr}(b): A+B$ for $b: B$. The empty type has no elements.

To construct a function $f: A+B \rightarrow C$, we need functions $g: A \rightarrow C$ and $h$ : $B \rightarrow C$. Then $f$ is defined via the equations

$$
\begin{aligned}
& f(\operatorname{inl}(a))=g a, \\
& f(\operatorname{inr}(b))=h b .
\end{aligned}
$$

So we can consider the universal case

$$
\operatorname{rec}_{A+B}: \Pi_{C: U}(A \rightarrow C) \rightarrow(B \rightarrow C) A+B \rightarrow C
$$

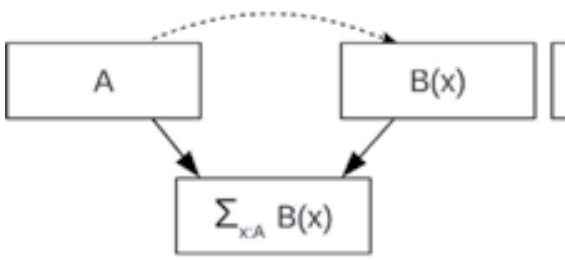

(a)

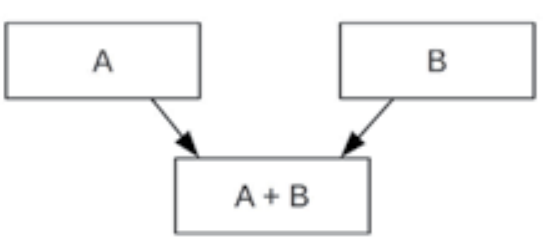

(b)

Figure 4.

The pattern of CM for (a) dependent functional type and (b) Cartesian product. 
with the equations

$$
\begin{aligned}
& \operatorname{rec}_{A+B} \operatorname{Cgh}(\operatorname{inl}(a))=g a, \\
& \operatorname{rec}_{A+B} C g h(\operatorname{inr}(b))=h b .
\end{aligned}
$$

The pattern of CM for sum type is shown in Figure $4 \mathbf{b}$.

\section{Naming functors and their properties}

Analysis of the proposed CM formalization suggests identifying the structure of $\mathrm{CM}$ models defined in the framework of type theory. The practice shows that an adequate approach in constructing such models is the category theory. At the same time, the model is built in the selected category using its objects and arrows. The objects are matched to the types used when constructing the CM, and arrows are matched to the nodes and links of the CM. Depending on the definition of a category, its objects can carry an additional structure within themselves. They can be put into line with the characteristics of the modeled domain.

Common constructions of the category theory can be used to introduce and process the $\mathrm{CM}$ constructions that are of interest from both a fundamental and a practical point of view. One of such constructions is the adjoint functor. It turns out that the conjugation scheme allows the transition from an "atomic" description of model objects, in which we distract from their internal structure to the description that takes into account such a structure. A back transition is also possible.

From a fundamental point of view, the mentioned feature provides the CM scaling, that is, folding the nested CM into a separate node and back deployment. From a practical point of view, this possibility corresponds to the definition of an abstract type of data within the framework of a programming system. In this case, the functors that implement conjugation provide a transition from the description of an abstract object or from the name of the object (which in the programming system corresponds to the address of the object in memory) to the representation of the object. This justifies their title as "naming" functors.

\subsection{Adjunction}

The traceability of the interpretation of various entries of an information object (CM or its fragment) requires constructing models of interpretation depending on the context. When the CM is placed in a programming environment (e.g., Java), the context is formed by the constructions chosen to represent the CM fragments, as well as the associated data. The context dependency can be traced basing on the use of the technique of variable domains, which are functors.

Practical implementation of the system supporting the work with CMs requires selecting a method of their representation by the programming structures, such as arrays or strings. A link to the filled-in fragment of the representing structure can be given as an index in the structure, which may be considered as a special naming structure. The work with CM necessitates a transition from the name of the CM fragment to its value and backward, i.e., naming and dereferencing the CM fragments. To ensure the completeness of the computational model, it must provide a transition from the naming constructs to the content of the representing constructions and back.

Because of this, it looks attractive to develop technology, (1) coordinating with the general structure of the computational model, i.e., presented in the form of a functor; (2) making possible to name structures and methods of working with 
named structures; and (3) providing the ability to display on the structures of the programming system. Further on, it will be shown that in some cases the naming may be associated with the presenting CM's constructions in a categorically invariant manner. The corresponding categories contain structures of a certain type as objects, and the mappings between objects that preserve their structure serve as arrows. The construction of the required type model uses the concept of adjunction.

Definition. Adjunction between categories $\mathcal{C}$ and $\mathcal{D}$ is the four-tuple $\langle F, G, \varphi, \psi\rangle$, where $F$ is a functor $\mathcal{C} \rightarrow \mathcal{D}, G$ is a functor $\mathcal{D} \rightarrow \mathcal{C}$,

$$
\mathcal{C} \underset{G}{\stackrel{F}{\rightleftarrows}} \mathcal{D},
$$

function $\varphi$ (correspondingly $\psi$ ) to every pair of objects $c \in O b(\mathcal{C}), d \in O b(\mathcal{D})$ puts in correspondence the mapping $\mathcal{D}(F c, d) \rightarrow \mathcal{C}(c, G d)$ (correspondingly $\mathcal{C}(c, G d) \rightarrow \mathcal{D}(F c, d)$ ), natural according to $c$ and $d$, and in this case $\varphi \circ \psi=1$, $\psi \circ \varphi=1$.

Remark. So, $\varphi_{c, d}$ and $\psi_{c, d}$ set the bijection

$$
\mathcal{D}(F c, d) \cong \mathcal{C}(c, G d)
$$

which is natural in $c$ and $d$.

The given definition needs to be explained. Mind that the natural transformation from the functor $\mathcal{S}: \mathcal{C} \rightarrow \mathcal{D}$ into the functor $T: \mathcal{C} \rightarrow \mathcal{D}$ is the mapping $\mu$, putting in correspondence with every object $a \in O b(C)$ the arrow $\mu_{a}: S a \rightarrow \operatorname{Ta} \in \operatorname{Ar}(D)$ in such a way that for each arrow $f: a \rightarrow b$ from $\operatorname{Ar}(C)$, the diagram

$$
\begin{array}{lll}
S a & \stackrel{\mu_{a}}{\rightarrow} & T a \\
\downarrow S f & & \downarrow T f \\
S b & \stackrel{\mu_{b}}{\longrightarrow} & T b
\end{array}
$$

commutates, i.e., $T f \circ \mu_{a}=\mu_{b} \circ S f$.

Also mind that with the help of $\mathcal{C}(a, b)$, the set of arrows is designated as the arrows of category $\mathcal{C}$ with start in the object $a$ and the end in the object $b$ (under the "set" we understand the set in that model of set theory, in which the category $\mathcal{C}$ is defined). In such a way, $\mathcal{C}(-,-)$ is the mapping of the pair of objects of the category $\mathcal{C}$ into the sets. This mapping is an object mapping of bifunctor (i.e., of a functor from two parameters), contravariant in the first argument and covariant in the second one. In full this bifunctor is defined as follows:

$$
\begin{aligned}
& \mathcal{C}(a, b)=\{f \in \operatorname{Ar}(\mathcal{C}) \mid f: a \rightarrow b\}, \\
& \mathcal{C}(h, k)=k \circ f \circ h .
\end{aligned}
$$

In accordance with the following diagram

$$
a^{\prime} \stackrel{h}{\rightarrow} a \stackrel{f}{\rightarrow} b \stackrel{k}{\rightarrow} b^{\prime}
$$

where $h: a^{\prime} \rightarrow a, k: b \rightarrow b^{\prime}$.

To give a formalized representation of this functor, it is convenient to pass over to the dual category $\mathcal{C}^{o p}$. Then the functor defined above turns out to be a functor from $\mathcal{C}^{o p} \times \mathcal{C} \rightarrow \mathcal{S e t}$. 
Now let us consider the constructions $\mathcal{D}(F c, d)$ and $\mathcal{C}(c, G d)$ from the definition of adjunction. Absolutely similar to the previous, they may be considered as object mappings of bifunctors $\mathcal{D}\left(F_{-},-\right)$and $\mathcal{C}\left(-, G_{-}\right)$, acting from $\mathcal{C}^{o p} \times \mathcal{D}$ in Set in accordance with the following rule:

$$
\begin{aligned}
& \mathcal{D}(F-,-): \mathcal{C}^{o p} \times \mathcal{D}^{F^{o p} \times I d} \rightarrow \mathcal{D}^{o p} \times \mathcal{D} \rightarrow \text { Set }, \\
& \mathcal{C}(-, G-): \mathcal{C}^{o p} \times \mathcal{D} \stackrel{I d \times G}{\rightarrow} \mathcal{C}^{o p} \times \mathcal{C} \rightarrow \text { Set. }
\end{aligned}
$$

Totally these functors are set by the following way:

$$
\begin{gathered}
\mathcal{D}(F a, b)=\{f \in A r(\mathcal{D}) \mid f: F a \rightarrow b\} \\
\mathcal{D}(F h, k)=k \circ f \circ F h,
\end{gathered}
$$

with the diagram (containing the arrows from $\operatorname{Ar}(\mathcal{D})$ )

$$
F a^{\prime} \stackrel{F h}{\rightarrow} F a \stackrel{f}{\rightarrow} b \stackrel{k}{\rightarrow} b^{\prime},
$$

and

$$
\begin{gathered}
\mathcal{C}(a, G b)=\{f \in A r(\mathcal{C}) \mid f: a \rightarrow G b\} \\
\mathcal{C}(h, G k)=G k \circ f \circ h,
\end{gathered}
$$

with the diagram (in $\operatorname{Ar}(\mathcal{C})$ )

$$
a^{\prime} \stackrel{h}{\rightarrow} a \stackrel{f}{\rightarrow} G b \stackrel{G k}{\rightarrow} G b^{\prime}
$$

where $h: a^{\prime} \rightarrow a \in \operatorname{Ar}(\mathcal{C})$ and $k: b \rightarrow b^{\prime} \in \operatorname{Ar}(\mathcal{D})$.

It is indicated in the definition of adjunction that the mappings $\varphi$ and $\psi$ are natural transformations of the above defined functors (i.e., arrow in the category Funct $\left(\mathcal{C}^{o p} \times \mathcal{D}\right.$, Set $\left.)\right)$, and this finetunes the phrase " $\varphi$ and $\psi$ are natural for $c$ and $d$." Let us consider the diagrams that describe this naturality:

$$
\begin{array}{ccc}
\mathcal{D}(F c, d) & \stackrel{\varphi_{c, d}}{\rightarrow} & \mathcal{C}(c, G d) \\
\downarrow \mathcal{D}(F h, k) & & \downarrow \mathcal{C}(h, G k) \\
\mathcal{D}\left(F c^{\prime}, d^{\prime}\right) & \stackrel{\varphi_{c^{\prime}, d^{\prime}}}{\rightarrow} & \mathcal{C}\left(c^{\prime}, G d^{\prime}\right)
\end{array}
$$

The arrow in the category $\mathcal{C}^{o p} \times \mathcal{D}$ is the pair of arrows $\langle h, k\rangle$, where $h: c^{\prime} \rightarrow$ $c \in \operatorname{Ar}(\mathcal{C})$ and $k: d \rightarrow d^{\prime} \in \operatorname{Ar}(\mathcal{D})$. We have

$$
\mathcal{C}(h, G k) \circ \varphi_{c, d}=\varphi_{c^{\prime}, d^{\prime}} \circ \mathcal{D}(F h, k) .
$$

The values of the considered functors are ordinary sets; this is why the above written correlation binds ordinary functions on sets. Thanks to this it is possible to compare the values of functions on an arbitrary element of their definition, which is the function $f \in \mathcal{D}(F c, d)$ (i.e., $f: F c \rightarrow d \in A r(\mathcal{D})$ ), i.e., to apply both parts of the equality to this function. We get

$$
\begin{gathered}
\left(\mathcal{C}(h, G k) \circ \varphi_{c, d}\right) f=\left(\varphi_{c^{\prime}, d^{\prime}} \circ \mathcal{D}(F h, k)\right) f \\
\mathcal{C}(h, G k)\left(\varphi_{c, d} f\right)=\varphi_{c^{\prime}, d^{\prime}}(\mathcal{D}(F h, k) f) \\
G k \circ \varphi_{c, d} \circ \circ=\varphi_{c^{\prime}, d^{\prime}}(k \circ f \circ F h)
\end{gathered} .
$$


Schematically the action $\varphi$ may be shown as follows:

$$
\begin{aligned}
& A r(\mathcal{D}): \quad \varphi_{c^{\prime}, d^{\prime}}\left(\quad F c^{\prime} \stackrel{F h}{\rightarrow} \quad F c \quad \stackrel{f}{\rightarrow} \quad d \quad \stackrel{k}{\rightarrow} \quad d^{\prime} \quad\right) \\
& \operatorname{Ar}(\mathcal{C}): \quad \quad c^{\prime} \stackrel{h}{\rightarrow} \quad c \stackrel{\varphi_{c, d} f}{\rightarrow} \quad G d \stackrel{G k}{\rightarrow} G d^{\prime} .
\end{aligned}
$$

The drawn ratio is equivalent to the combination of two of its private cases:

$$
G k \circ \varphi_{c, d} f=\varphi_{c^{\prime}, d^{\prime}}(k \circ f), \quad \varphi_{c, d} f \circ h=\varphi_{c^{\prime}, d^{\prime}}(f \circ F h),
$$

and to work with which is somehow easier than with the initial ration as each of them contains only one additional arrow.

Absolutely similar the condition of naturality for $\psi$ is expressed as follows:

$$
\begin{array}{ccc}
\mathcal{C}(c, G d) & \stackrel{\psi_{c, d}}{\rightarrow} & \mathcal{D}(F c, d) \\
\downarrow \mathcal{C}(h, G k) & & \downarrow \mathcal{D}(F h, k) \\
\mathcal{C}\left(c^{\prime}, G d^{\prime}\right) & \stackrel{\psi_{c^{\prime}, d^{\prime}}}{\rightarrow} & \mathcal{D}\left(F c^{\prime}, d^{\prime}\right)
\end{array}
$$

or

$$
\mathcal{D}(F h, k) \circ \psi_{c, d}=\psi_{c^{\prime}, d^{\prime}} \circ \mathcal{C}(h, G k) .
$$

Selecting the arrow $g \in \mathcal{C}(c, G d)$ (i.e., $f: c \rightarrow G d \in A r(\mathcal{C})$ ), we get

$$
\begin{gathered}
k \circ \psi_{c, d} g \circ F h=\psi_{c^{\prime}, d^{\prime}}(G k \circ g \circ h), \\
k \circ \psi_{c, d} g=\psi_{c^{\prime}, d^{\prime}}(G k \circ g), \quad \psi_{c, d} g \circ F h=\psi_{c^{\prime}, d^{\prime}}(f \circ h),
\end{gathered}
$$

schematically

$$
\begin{aligned}
& \operatorname{Ar}(\mathcal{C}): \quad \psi_{c^{\prime}, d^{\prime}}\left(\quad c^{\prime} \quad \stackrel{h}{\rightarrow} \quad c \quad \stackrel{g}{\rightarrow} \quad G d \stackrel{G k}{\rightarrow} G d^{\prime} \quad\right) \\
& \operatorname{Ar}(\mathcal{D}): \quad \quad F c^{\prime} \stackrel{F h}{\rightarrow} \quad F c \stackrel{\psi_{c, d g}}{\rightarrow} \quad d \stackrel{k}{\rightarrow} d^{\prime} .
\end{aligned}
$$

In case of adjunction, the functor $F$ is named left adjoint to the functor $G$, and $G$ is right adjoint to the functor $F$. To make the remembering easier, note that in the bijection $\mathcal{D}(F c, d) \cong \mathcal{C}(c, G d)$, the functor $F$ is applied to the argument in the left position and $G$ is applied to the argument in the right position.

In the given definition the category, Set plays a special role as a category, in which the sets of arrows are defined for $\mathcal{C}$ and $\mathcal{D}$. This restriction can be overcome: to define a category, another category can be used as a basis, and this category should be additionally conditioned.

\subsection{Samples of naming constructions}

Let us consider some examples of naming constructions based on adjoint functor.

\subsubsection{Arrays (vectors)}

One of the standard representing constructions in practical programming languages for complex structures of data, including CMs or their fragments, is an array or vector. The bunch of possible vectors forms a linear space.

Let us consider a common structure of linear space. Let $K$ be a field and Vect $_{K}$ be the category of linear (vector) spaces over the field $K$, whose objects are vector 
spaces and arrows are linear mappings between them. We will consider not only finite-dimensional but also infinite-dimensional spaces. This practically means that we do not limit the dimension of the represented CM. In this situation we assume that the elements of the infinite-dimensional linear space are finite linear combinations of the vectors of the space with coefficients from the field $K$ (in accordance with the fact that we do not specify on the space any topology and, thuswise, convergence). In this scenario, obviously, the axioms of the linear vector space turn out to be fulfilled.

Let us consider the functor $G:$ Vect $_{K} \rightarrow$ Set, which associates with each vector space of its underlying set, i.e., the set of vectors of this space, considered as nonfactorable (structureless) objects. Obviously, $G$ is a functor; it is the so-called neglecting, erasing, or forgetful functor, which is so named because it forgets the structure of objects of the initial category or its part.

To make it clearer, let us consider the vector space $B$ and suggest that the vectors $b_{i}$ form a basis in it. Then each vector of the space $B$ can be expressed as $v=$ $\sum_{b_{i} \in B^{\prime} \subset B} k_{i} b_{i}$, where $k \in K$ and $B^{\prime}$ are finite. As a result of the action of the functor $G$

, the space $B$ is transformed into the set $G B$ consisting of the same elements as the underlying set of $B$. The vector $v$, considered as an element of $G B$, will be written in the form $\ulcorner v\urcorner$, where the angle brackets $\ulcorner\ldots\urcorner$ show that we consider the object as having no internal structure (i.e., and actually form the name of the corresponding object or, more precisely, an expression describing this object). The arrows $g \in A r\left(\mathcal{V e c t}_{K}\right)$ are transferred to "the same" arrows, considered on the sets, i.e.,

$$
G g(\ulcorner v\urcorner)=\ulcorner g(v)\urcorner .
$$

The considered functor has the left adjoint $F: \mathcal{S} e t \rightarrow \mathcal{V e c t}_{K}$. The functor $F$ for every set $A$ forms vector space, in which the elements of the initial set $a \in A$ are the basis and are considered as their formal finite linear combinations $\sum_{a_{i} \in A^{\prime}} k_{i} a_{i}$, where $k_{i} \in K$ and $A^{\prime} \subset A$ are finite. The function $f: A \rightarrow B$ is mapped by the functor $F$ into linear operator, which acts on the basic vectors of the space $F A$ (i.e., on the elements of the set $A$ ) in the same way as the function $f$ (i.e., transforms $a \in F A$ to $f(a) \in F B$ ), and on linear combinations $a \in A^{\prime} \subset A$ it continues formally according to the linearity:

$$
F f\left(\sum_{a_{i} \in A^{\prime}} k_{i} a_{i}\right)=\sum_{a_{i} \in A^{\prime}} k_{i} f\left(a_{i}\right) .
$$

It is easy to check that the given definition really specifies the functor.

To establish the adjunction it is necessary to specify $\varphi$ and $\psi$ and after it to check their naturalness. Since $\varphi: \mathcal{V} e c t_{K}(F A, B) \rightarrow \mathcal{S e t}(A, G B)$, we need to consider the arrow $f: F A \rightarrow B$ and put into correspondence with it the arrow $\varphi f: A \rightarrow G B$. It's easy to do due to $F A$ containing all linear combinations of the type $\sum_{a_{i} \in A^{\prime} \subset A} k_{i} a_{i}$, and it also contains, in particular, such linear combinations, where $A^{\prime}=\left\{a_{i}\right\}$ and the corresponding $k_{i}=1$. Then we can write

$$
\sum_{a_{i} \in\left\{a_{i}\right\}} 1 \cdot a_{i}=1 \cdot a_{i}=a_{i}
$$

Such elements can be identified with elements of the set $A$. Since $f$ is given on all elements of the set $F A$, it is also set on the elements identified with elements of the set $A$, and it puts into correspondence with them some elements of the set $B$. But $\varphi f$ must be specified on the elements of the set $A$ and associate them with some elements of 
the set $G B$. It is easy to see what these elements are: they must correspond to the initial elements of $B$ under the correspondence given by the functor $G$. Formally

$$
(\varphi f)(a)=\ulcorner f(a)\urcorner,
$$

where $a \in A$.

Let us check the naturalness of $\varphi$. For this purpose we consider the arrows $h: A^{\prime} \rightarrow A$ and $k: B \rightarrow B^{\prime}$, where $A, A^{\prime} \in O b($ Set $)$ and $B, B^{\prime} \in O b\left(V_{e c t}\right)$. We have $f^{\prime}=k \circ f \circ F h$ : $F A^{\prime} \rightarrow B^{\prime}$, this is why $\varphi f^{\prime}: A^{\prime} \rightarrow G B^{\prime}$. Two arrows are equal in the category Set if their values are equal on every element of their domain. Let us consider the element $s \in A^{\prime}$ and compute on it the values of the arrows forming the naturality diagram:

$$
\begin{aligned}
& \varphi(k \circ f \circ F h)(s)= \\
& =\ulcorner(k \circ f \circ F h)(s)\urcorner= \\
& =\ulcorner k(f(F h(s)))\urcorner= \\
& =\ulcorner k(f(h(s)))\urcorner
\end{aligned}
$$

and

$$
\begin{aligned}
& (G k \circ \varphi f \circ h)(s)= \\
& =G k((\varphi f)(h(s)))= \\
& =G k(\ulcorner f(h(s))\urcorner)= \\
& =\ulcorner k(f(h(s)))\urcorner .
\end{aligned}
$$

Since the values coincide for an arbitrary $s$, the corresponding arrows also coincide. Thus, the naturalness of $\varphi$ is proven.

Now let us define $\psi: \operatorname{Set}(A, G B) \rightarrow \operatorname{Vect}_{K}(F A, B)$. We'll consider the arrow $g$ : $A \rightarrow G B$. The value of this function for any $a \in A$ can be represented as $\ulcorner b\urcorner$ for some $b \in B$. Since the mapping $\lambda x .\ulcorner x\urcorner$ is one-to-one, there is a single function that can be associated with the function $g$; this is the function $g^{*}: A \rightarrow B$, for which

$$
g(a)=\left\ulcorner g^{*}(a)\right\urcorner .
$$

The function $g^{*}$ in some specified sense "makes the analysis" of the element $a$, giving the permit to pass over from "structureless object" $\ulcorner b\urcorner$ (the element of the set $G B$ ) to the "structured object" $b$ (the element of the vector space $B$ ).

We need the behavior $g^{*}$ related to the composition. Let $h: A^{\prime} \rightarrow A$. Then according to the definition, $(g \circ h)(a)=\left\ulcorner(g \circ h)^{*}(a)\right\urcorner$. Furthermore, $(g \circ h)(a)=$ $g(h(a))=\left\ulcorner\left(g^{*}(h(a))\right\urcorner\right.$. Consequently,

$$
(g \circ h)^{*}=g^{*} \circ h .
$$

The situation is cleared somehow by the diagram

$$
\begin{array}{ccccc}
A^{\prime} & \stackrel{h}{\rightarrow} & A & \stackrel{g}{\rightarrow} & G B \\
\downarrow(g \circ h)^{*} & & \downarrow g^{*} & & \uparrow\ulcorner\urcorner \\
B & = & B & = & B,
\end{array}
$$

where \ulcorner\urcorner is a function $\lambda x .\ulcorner x\urcorner: B \rightarrow G B$. 
Now let $k: B \rightarrow B^{\prime}$, then $G k: G B \rightarrow G B^{\prime}$. According to the definition, $(G k \circ g)(a)=\left\ulcorner(G k \circ g)^{*}(a)\right\urcorner$. But $(G k \circ g)(a)=G k(g(a))=G k\left(\left\ulcorner g^{*}(a)\right\urcorner\right)=\left\ulcorner k\left(g^{*}(a)\right)\right\urcorner$

. Consequently,

$$
(G k \circ g)^{*}=k \circ g^{*},
$$

and this may be illustrated by the diagram

$$
\begin{array}{ccccc}
A & \stackrel{g}{\rightarrow} & G B & \stackrel{G k}{\rightarrow} & G B^{\prime} \\
\| & & \uparrow\ulcorner\urcorner & & \uparrow\ulcorner\urcorner \\
A & \stackrel{g^{*}}{\rightarrow} & B & \stackrel{k}{\rightarrow} & B^{\prime} .
\end{array}
$$

Now we are ready to define the arrow $\psi g: F A \rightarrow B$ with the values in the vector space $B$. It may be determined in such a way

$$
(\psi g)\left(\sum_{a_{i} \in A^{\prime}} k_{i} a_{i}\right)=\sum_{a_{i} \in A^{\prime}}\left(k_{i} g^{*}\left(a_{i}\right)\right) .
$$

Let us check the naturalness of the $\psi$. Once again we'll consider the arrows $h: A^{\prime} \rightarrow A$ and $k: B \rightarrow B^{\prime}$, where $A, A^{\prime} \in O b(\mathcal{S e t})$ and $B, B^{\prime} \in O b\left(\mathcal{V}_{\text {ect }}\right)$. We have $g^{\prime}=G k \circ g \circ h$ : $A^{\prime} \rightarrow G B^{\prime}$; this is why $\psi g^{\prime}: F A^{\prime} \rightarrow B^{\prime}$. Let us consider the element $t=\sum_{a_{i} \in A^{\prime}} k_{i} a_{i} \in F A^{\prime}$ and compute on it the value of the arrows that form the naturality diagram:

$$
\begin{aligned}
& \psi(G k \circ g \circ h)(t)= \\
& =\psi(G k \circ g \circ h)\left(\sum_{a_{i} \in A^{\prime}} k_{i} a_{i}\right)= \\
& =\sum_{a_{i} \in A^{\prime}} k_{i} \cdot(G k \circ g \circ h)^{*}\left(a_{i}\right)= \\
& =\sum_{a_{i} \in A^{\prime}} k_{i} \cdot k\left(g^{*}\left(h\left(a_{i}\right)\right)\right)
\end{aligned}
$$

and

$$
\begin{aligned}
& (k \circ \psi g \circ F h)(t)= \\
& =(k \circ \psi g \circ F h)\left(\sum_{a_{i} \in A^{\prime}} k_{i} a_{i}\right)= \\
& =k\left(\psi g\left(F h\left(\sum_{a_{i} \in A^{\prime}} k_{i} a_{i}\right)\right)\right)= \\
& =k\left(\psi g\left(\sum_{a_{i} \in A^{\prime}} k_{i} \cdot h\left(a_{i}\right)\right)\right)= \\
& =k\left(\sum_{a_{i} \in A^{\prime}} k_{i} \cdot g^{*}\left(h\left(a_{i}\right)\right)\right)= \\
& =\sum_{a_{i} \in A^{\prime}} k_{i} \cdot k\left(g^{*}\left(h\left(a_{i}\right)\right)\right) .
\end{aligned}
$$


The values coincide for arbitrary $t$, and this proves the naturality of $\psi$. This example is important because of three reasons:

1. The construction of the vector space is one of the oldest constructions for data representation and at the same time one of the simplest well-known algebraic constructions, and it is an example of a typical algebraic system (underlying set and a signature given by a set of axioms); therefore the construction of an adjoint functor demonstrates some typical common features of such functors.

2. The category of vector spaces, as distinguished, for example, from the category of monoids, hardly uses mechanisms specific to abstract data types (such as a queue or a stack), except for the proper neglecting functor inducing nesting of named objects of the corresponding categories; thanks to this the construction of the attachment is clearly seen in this example.

3. The vector spaces are well studied; this allows without a long introduction to use constructions of considerable generality, which must be specially constructed for other categories.

The above shown example, in particular, demonstrates that the adjunction does not formalize in any sense the idea of mutually inverse functors. We see that for a finite-dimensional space $B$ over an infinite field $K$, the set $G B$ is infinite, and, consequently, the space $F G B$ is infinite-dimensional, i. e., it is not isomorphic to the initial one. On the contrary, the adjunction acts as a mechanism for assigning a given structure with an additional structure (in our example-any set with a vector space structure) and operations on this additional structure, connecting it with the original one.

Taking into account the foregoing, the above given example demonstrates that conjunctions can be used to describe abstract data types (in our example, to describe an abstract vector). In the example, the mapping $\varphi$ demonstrates encapsulation, i.e., hiding the internal structure of the object, and $\psi$ provides the definition of operations on the encapsulated type of data.

In general case the functor specifies the correspondence of objects of one category with objects of another and does not suggest the presence of any arrows between these objects. However, in the given example, the fact that the vector space is defined as a set with an additional structure makes it possible to consider the function $g^{*}$ on the set with values in a vector space, as well as the inverse function $\lambda x .\ulcorner x\urcorner$. This construction is not valid in the general case.

\subsubsection{Monoids}

Let us consider another structure used to represent CMs-strings. The strings can be used to name CM's elements or bind additional textual information to CM. It appears that it is possible to formalize naming procedures for strings based on the category of monoids. Let us show this.

Let $M o n$ be the category of monoids. Mind that a monoid is a triple $M=$ $\langle M, \cdot, e\rangle$, where $M$ is the underlying set, the dot (.) is the binary operation on the set $M$, and $e \in M$ is the identity element of the monoid. Then the objects of category Mon are the monoids, and the arrows are the mappings keeping the monoid structure.

Let us consider the neglecting functor $G: \mathscr{M} o n \rightarrow \mathcal{S e t}$, which associates each underlying set with its monoid and to the mapping of the monoids to the corresponding mapping of the sets. Similar to the previous example, we'll mark $\ulcorner m\urcorner$ 
element $G M$, corresponding to the element $m$ of the initial monoid $M$. Like in the previous example, we have

$$
G g(\ulcorner m\urcorner)=\ulcorner g(m)\urcorner
$$

for the arrow $g$ between the monoids.

This functor has left adjoint $F: \operatorname{Set} \rightarrow$ Mon, which is defined as follows. For the set $A$, the underlying set of the monoid $F A$ is the set of finite sequences $\left\langle a_{1}, \ldots, a_{n}\right\rangle$ of the elements $a_{i} \in A$, including the empty sequence \langle\rangle . The monoid operation is defined by

$$
\left\langle a_{1}, \ldots, a_{n}\right\rangle \cdot\left\langle a_{n+1}, \ldots, a_{n+m}\right\rangle=\left\langle a_{1}, \ldots, a_{n}, a_{n+1}, \ldots, a_{n+m}\right\rangle,
$$

and the identity element of the monoid $F A$ is \langle\rangle . It is easily checked that the indicated construction correctly specifies the monoid.

For the function $f: A \rightarrow B$, the action of the functor $F$ is specified as follows:

$$
F f\left(\left\langle a_{1}, \ldots, a_{n}\right\rangle\right)=\left\langle f\left(a_{1}\right), \ldots, f\left(a_{n}\right)\right\rangle .
$$

It is easy to note that $F$ is really a functor.

For testing the adjunction, it needs to specify $\varphi$ and $\psi$ and verify that the conditions in the definition of conjoint functors are fulfilled. To set $\varphi$ : $\operatorname{Mon}(F A, M) \rightarrow \operatorname{Set}(A, G M)$, let us consider the arrow $f: F A \rightarrow M$ and put in correspondence with it the arrow $\varphi f: A \rightarrow G M$. Now we consider the values of the arrow $f$ on $F A$ elements of the form $\langle a\rangle$, i.e., single-element sequences. We put

$$
(\varphi f)(a)=\ulcorner f(\langle a\rangle)\urcorner .
$$

Let us check the naturality of the transformation defined by this way. We consider the arrows $h: A^{\prime} \rightarrow A$ and $k: M \rightarrow M^{\prime}$, where $A, A^{\prime} \in O b(\mathcal{S e t})$ and $M, M^{\prime} \in O b($ Mon $)$. We have $f^{\prime}=k \circ f \circ F h: F A^{\prime} \rightarrow M^{\prime}$; this is why $\varphi f^{\prime}: A^{\prime} \rightarrow G M^{\prime}$. Let us consider the element $s \in A^{\prime}$ and compute on it the values of the arrows that form the naturality diagram:

$$
\begin{aligned}
& \varphi(k \circ f \circ F h)(s)= \\
& =\ulcorner(k \circ f \circ F h)(\langle s\rangle)\urcorner= \\
& =\ulcorner k(f(F h(\langle s\rangle)))\urcorner= \\
& =\ulcorner k(f(\langle h(s)\rangle))\urcorner
\end{aligned}
$$

and

$$
\begin{aligned}
& (G k \circ \varphi f \circ h)(s)= \\
& =G k((\varphi f)(h(s)))= \\
& =G k(\ulcorner f(\langle h(s)\rangle)\urcorner)= \\
& =\ulcorner k(f(\langle h(s)\rangle))\urcorner .
\end{aligned}
$$

Now we'll specify $\psi: \operatorname{Set}(A, G M) \rightarrow \operatorname{Mon}(F A, M)$. Let us consider the arrow $g$ : $A \rightarrow G M$. Similar to the previous example with the function $g$, it is possible to associate the single function $g^{*}: A \rightarrow M$, for which

$$
g(a)=\left\ulcorner g^{*}(a)\right\urcorner .
$$


Likewise the previous example, it is possible to establish the properties $g^{*}$ related to the compositions

$$
(g \circ h)^{*}=g^{*} \circ h
$$

and

$$
(G k \circ g)^{*}=k \circ g^{*},
$$

where $h: A^{\prime} \rightarrow A$ and $k: M \rightarrow M^{\prime}$. Now

$$
(\psi g)\left\langle a_{1}, \ldots, a_{n}\right\rangle=g^{*}\left(a_{1}\right) \cdot \ldots \cdot g^{*}\left(a_{n}\right)=\prod_{i} g^{*}\left(a_{i}\right) .
$$

Let us check the naturality of $\psi$. Once again we consider the arrows $h: A^{\prime} \rightarrow A$ and $k: M \rightarrow M^{\prime}$, where $A, A^{\prime} \in O b(\mathcal{S e t})$ and $B, B^{\prime} \in O b(M o n)$. We have $g^{\prime}=$ $G k \circ g \circ h: A^{\prime} \rightarrow G M^{\prime}$; this is why $\psi g^{\prime}: F A^{\prime} \rightarrow M^{\prime}$. Let us consider the element $t=$ $\left\langle a_{1}, \ldots, a_{n}\right\rangle \in F A^{\prime}$ and compute on it the values of the arrows that form the naturality diagram:

$$
\begin{aligned}
& \psi(G k \circ g \circ h)(t)= \\
& =\psi(G k \circ g \circ h)\left(\left\langle a_{1}, \ldots, a_{n}\right\rangle\right)= \\
& =\prod_{i}(G k \circ g \circ h)^{*}\left(a_{i}\right)= \\
& =\prod_{i}\left(k \circ g^{*} \circ h\right)\left(a_{i}\right)= \\
& =\prod_{i} k\left(g^{*}\left(h\left(a_{i}\right)\right)\right)
\end{aligned}
$$

and

$$
\begin{aligned}
& (k \circ \psi g \circ F h)(t)= \\
& =(k \circ \psi g \circ F h)\left(\left\langle a_{1}, \ldots, a_{n}\right\rangle\right)= \\
& =k\left(\psi g\left(F h\left(\left\langle a_{1}, \ldots, a_{n}\right\rangle\right)\right)\right)= \\
& =k\left(\psi g\left(\left\langle h\left(a_{1}\right), \ldots, h\left(a_{n}\right)\right\rangle\right)\right)= \\
& =k\left(\prod_{i} g^{*}\left(h\left(a_{i}\right)\right)\right)= \\
& =\prod_{i} k\left(g^{*}\left(h\left(a_{i}\right)\right)\right) .
\end{aligned}
$$

The naturality of $\psi$ is proven by the results coincidence.

Comparing this example with the previous one, it is seen that the first example is indeed formally simpler, since it does not require the construction of sequences of elements. The sequences in this case can be considered as representing constructions that ensure the mapping of Mon to Set, meeting the requirements formulated at the beginning of the item. Indeed, (1) the formed constructions have a functorial nature, (2) the functions that provide naming and dereferencing are explicitly constructed, and (3) due to choosing the basic categories (Vect or Mon, respectively), the mapping of structures are ensured in the construction of the supporting programming environment. In this case the adjoint functors can be considered as a variant of the CM's representation technique by means of a practical programming system. 


\section{Conclusions}

The chapter considered a variant of solving the problem to store the data in a web environment and provide an access to the data based on their semantics. The semantics of data may be referred both to ensuring that the information complies with the put restrictions and to the traceability of nature of the problems that are solved by the users of different classes. The data is assumed to describe a certain subject area.

To represent the semantic nature of the data in the work, a representation in the form of a semantic network was used. The semantic network was considered as a set of marked nodes and marked links connecting them. The chapter considered the ways to access the nodes of the network, providing both the omission of irrelevant nodes and the decomposition of nodes.

The tools of describing users and their means of access to data that takes into account the specifics of the tasks to be solved must combine enough power to distinguish the relevant elements of the description and simplicity. It makes it possible to practically use the descriptions without excessive detailing, traditionally leading to an increase in the volume and complexity of the description. The work used cognitive maps to describe subjective views on the domain.

The chapter determines the CMs as hierarchically organized sets of nodes connected by unlabeled links. CMs can also contain links between nodes that are not in a hierarchical relationship. Due to:

1. The CM's syntax which differs from the semantic network syntax

2. The possibility of late fixation of typed restrictions

3. The possibility that links are fixed in the later stages of map development and are not placed or fixed by error

The cognitive maps cannot be considered as semantic networks. However, it is possible to propose matching procedures that will make it possible to consider CMs as a special type of semantic networks.

To determine the language of the description of the subjects and subjective points of view on the data, the work used a variant of intensional logic language. The essential feature of the language is the possibility to construct expressions that are indexable during interpretation, which makes it possible to study and use the dependence of expressions on a parameter. A number of methods for constructing CMs are distinguished, each of which is associated with a formula of intensional logic.

The semantics of intensional logic is constructed basing on recursively defined intensions. The inclusion of lambda expressions in the language and the definition of the corresponding semantic construction provide the computational nature of semantics. The interpretation of quantifiers and operators as special types of applications (applications of functions to the argument) makes it possible to determine all constructions of the model as applicative ones and attributes a computational nature to the models.

The constructed semantics makes it possible to express constructions in the form of CMs; these constructions describe the subject area from the point of view of experts. The chapter shows the possibility of such an expression with the example of the homotopy theory of types. Ever basic construction of the theory of types is accompanied by its presentation in the form of a cognitive map. The use of dependent type theory provides a subjective description of the subject area. 
Computational methods for representing CM's semantics can be promoted to the level of support for processing CMs by means of a programming system. The work develops a functor technique for this. The model constructions, naming semantic elements (CM's or their fragments), are mapped onto the constructions of the representing environment with the help of the technique of conjoint functors. In this way, the computational model can be extended to CM's support techniques. This approach ensures the correctness of the tool kits and reduces the time for their development.

In the whole the constructed computational model makes the basis for the description of subjective views on the subject area, their representation in the model, and placing in a supporting programming environment. Thus, the model can serve as the basis for the development technique and maintenance of tool kits to support the description of the domain based on CMs. The elements of the model were tested when developing the practical information systems in the field of legal regulation of the best available technology implementation.

\section{Acknowledgements}

The chapter is supported by the grants 19-07-00326-a, 19-07-00420-a, 18-0701082-a, and 17-07-00893-a of the Russian Foundation for Basic Research.

\section{Author details}

Larisa Yu. Ismailova ${ }^{1}$, Sergey V. Kosikov ${ }^{2 *}$ and Viacheslav E. Wolfengagen ${ }^{1}$

1 National Research Nuclear Institute “MEPhI”, Moscow, Russia

2 Institute for Contemporary Education “JurInfoR-MGU”, Moscow, Russia

*Address all correspondence to: kosikov.s.v@gmail.com

\section{IntechOpen}

(C) 2019 The Author(s). Licensee IntechOpen. This chapter is distributed under the terms of the Creative Commons Attribution License (http://creativecommons.org/licenses/ by/3.0), which permits unrestricted use, distribution, and reproduction in any medium, provided the original work is properly cited. (c) BY 


\section{References}

[1] Ismailova LY, Wolfengagen VE, Kosikov SV. A computational model for supporting access policies to semantic web. In: Proc. of the Ninth Annual Meeting of the BICA Society; 22-24 August 2018; Prague, Czech Republic. 2019. pp. $145-154$

[2] Kosikov SV, Ismailova LY, Wolfengagen VE. Network modeling environment for supporting families of displaced concepts. In: Proc. of the Ninth Annual Meeting of the BICA Society; 22-24 August 2018; Prague, Czech Republic. 2019. pp. 187-196

[3] Wolfengagen VE, Ismailova LY, Kosikov SV. A computational model for refining data domains in the property reconciliation. In: 2016 Third International Conference on Digital Information Processing, Data Mining, and Wireless Communications, Moscow, 6-8 July 2016; Moscow, Russia. 2016. pp. 58-63

[4] Kosikov SV, Ismailova LY, Wolfengagen VE. The presentation of evolutionary concepts. Advances in Intelligent Systems and Computing. 2018;636:113-125

[5] Ismailova LY, Kosikov SV, Wolfengagen VE. Data domains modeling situationally determined evaluation. In: Proc. of Intelligent Systems Conference (IntelliSys); 6-7 September 2018; London, UK. 2018. pp. 972-976

[6] Ismailova LY, Wolfengagen VE, Kosikov SV. Basic constructions of the computational model of support for access operations to the semantic network. In: Proc. of the 8th International Conference on Biologically Inspired Cognitive Architectures (BICA 2017); 1-6 August 2017; Moscow, Russia. 2018. pp. $83-188$
[7] FreeMind. Available from: http:// freemind.sourceforge.net/ [Accessed: 01 June 2019]

[8] MindMeister. Online Mind Mapping. Mind Mapping Software. Available from: https://www.mindmeister.com/ [Accessed: 01 June 2019]

[9] MindManager Mind Mapping Software. Available from: https://www. mindjet.com/mindmanager/ [Accessed: 01 June 2019]

[10] Cacoo. Mind Maps Guide. Available from: https://cacoo.com/resources/ mind-maps-guide/ [Accessed: 01 June 2019]

[11] Mindmup. Tutorials and Guides. Available from: https://www.mindmup. com/tutorials/index.html [Accessed: 01 June 2019]

[12] XMind-Mind Mapping Software. Available from: https://www.xmind. net/developer/ [Accessed: 01 June 2019]

[13] Laboratory of Cognitive Modelling and Management of Development of Situations. Institute of Control Sciences of Russian Academy of Sciences. Available from: https://www.ipu.ru/ node/11921 [Accessed: 17 May 2019]

[14] Bell DE, Raiffa H, Tversky A, editors. Decision Making: Descriptive, Normative and Prescriptive Interactions. Cambridge: Cambridge University Press; 1988. pp. 9-32

[15] Chrastil ER, Warren WH. From cognitive maps to cognitive graphs. PLoS One. 2014;9:e112544. DOI: 10.1371/journal.pone.0112544

[16] Ferreira Opaso EV, Terelanskiy PV. Representation of cognitive maps in 3-dimensional space. In: VSPU-2014, Moscow. 2014 
[17] Kotseruba I, Tsotsos JK. 40 years of cognitive architectures: Core cognitive abilities and practical applications. Artificial Intelligence Review. 2018. Available from: https://doi.org/10.1007/ s10462-018-9646 [Accessed: 01 June 2019]

[18] Jung JJ, Jung KY, Jo GS. Ontological cognitive map for sharing knowledge between heterogeneous businesses. In: Yazıcı A, Şener C, editors. Computer and Information Sciences. ISCIS. 2003. p. 2869

[19] Furnari S. A cognitive mapping approach to business models:

Representing causal structures and mechanisms. Advances in Strategic Management. 2015;33:207-239. DOI: 10.1108/S0742-332220150000033025

[20] Kluss T, Marsh WE, Zetzsche C, et al. Representation of impossible worlds in the cognitive map. Cognitive Processing. 2015;16:271. DOI: 10.1007/ s10339-015-0705-x

[21] Chaib-draa B. Cognitive maps: Theory, implementation, and practical applications in multiagent environments. IEEE Transactions on Knowledge and Data Engineering. 2002; 14(6):1201-1217

[22] Tarski A. On the calculus of relations. Journal of Symbolic Logic. 1941;6(3):73-89

[23] Miao YA. Cognitive map network model. In: Bai Q, Fukuta N, editors. Advances in Practical Multi-Agent Systems. Studies in Computational Intelligence. Vol. 325. Berlin, Heidelberg: Springer; 2002

[24] Concepción L, Nápoles G, Grau I, Vanhoof K, Bello R. Retracted chapter: Towards the convergence in fuzzy cognitive maps based decision-making models. In: Berger-Vachon C, Gil Lafuente A, Kacprzyk J, Kondratenko Y, Merigó J, Morabito C, editors. Complex
Systems: Solutions and Challenges in Economics, Management and Engineering. Studies in Systems, Decision and Control. Vol. 125. Cham: Springer; 2018

[25] Kireev VS. Development of fuzzy cognitive map for optimizing e-learning course. In: Kalinichenko L, Kuznetsov S, Manolopoulos Y, editors. Data Analytics and Management in Data Intensive Domains. DAMDID/RCDL 2016. Communications in Computer and Information Science. Vol. 706. Cham: Springer; 2017

[26] Słoń G, Yastrebov A. Optimization and adaptation of dynamic models of fuzzy relational cognitive maps. In: Kuznetsov SO, Ślezak D, Hepting DH, Mirkin BG, editors. Rough Sets, Fuzzy Sets, Data Mining and Granular Computing. RSFDGrC 2011. Lecture Notes in Computer Science. Vol. 6743. Berlin, Heidelberg: Springer; 2011

[27] Meilinger T. The network of reference frames theory: A synthesis of graphs and cognitive maps. In: Freksa C, Newcombe NS, Gärdenfors P, Wölfl S, editors. Spatial Cognition VI. Learning, Reasoning, and Talking about Space. Spatial Cognition. Lecture Notes in Computer Science. Vol. 5248. Berlin, Heidelberg: Springer; 2008

[28] Solodilova AV. Cognitive Maps: Form of Representation of Scientific Knowledge of Historic. Minsk: BGPU; 2012

[29] Shulman Y. Towards a broadening of privacy decision-making models: The use of cognitive architectures. In: Hansen M, Kosta E, Nai-Fovino I, Fischer-Hübner S, editors. Privacy and Identity Management. The Smart Revolution. Privacy and Identity 2017. IFIP Advances in Information and Communication Technology. Vol. 526. Cham: Springer; 2018 



\section{Edited by Marta Silvera-Roig and Asunción López-Varela Azcárate}

Cognitive and Intermedial Semiotics offers a window into applied cognitive semiotics with different examples of meaning production studies. Thus, in its chapters we will find examples of different approaches, methods, and theories that cognitive semiotics offers as an interdisciplinary field.

\section{IntechOpen}

